\title{
Normas e Julgados do Setor de Telecomunicações - 2008
}

\section{Statutes, Administrative Regulations and Judicial Decisions of the Telecommunication Sector}

\author{
Organizadores \\ Márcio lorio Aranha (Direito) \\ João Lima (Ciência da Informação) \\ Catalogação de Julgados \\ Patrick Faria \\ Rosa Amaral \\ Catalogação de Decisões da ANATEL \\ Artur Coimbra \\ Catalogação de Decisões do TCU \\ Rodrigo Fernandes \\ Coleta, Tratamento e Inserção de Dados \\ Laura Lira \\ Equipe: Elisa Leonel e Raphael Nunes
}




\section{Sumário}

Lista de Abreviaturas e Siglas ................................................ 321

Normas, Julgados e Atos de 2008 ............................................ 343

Infraestrutura e Recursos do Setor de Telecomunicações .............. 343

Infraestrutura de Telecomunicações ................................... 343

Compartilhamento de Infraestrutura .............................. 343

Bem Público (utilização e restrição) ................................ 343

Redes de Telecomunicações ......................................... 344

Equipamentos de Telecomunicações .................................. 344

Antenas ...................................................... 344

Estações de Telecomunicações ....................................... 345

Terminais ......................................................... 346

Certificação / Homologação ........................................... 348

Espectro de Radiofrequencia ..................................... 348

Destinação, Atribuição e Designação de Radiofrequência ............ 349

Condições de Uso de Radiofrequiência e Canalização (Distribuição de Canais) ........................................................ 350

Órbita e Satélite ........................................................ 350

Administração do Setor de Telecomunicações ........................... 350

Fiscalização das Telecomunicações .................................. 350

Tributação no Setor de Telecomunicações .............................. 353

Outorgas .............................................................. 355

Espécies de Outorga ........................................ 355

Concessão (regras aplicáveis) ............................... 355

Autorização (regras aplicáveis) .............................. 357

Preço Público e Preço Privado ........................................ 358

Políticas de Telecomunicações ........................................ 359

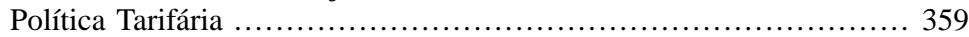

Política Industrial ............................................. 360

Concorrência no Setor de Telecomunicações ........................... 361

Universalização ...................................................... 362

Acesso às Telecomunicações ........................................ 362

Portador de Deficiência ....................................... 362

Zona Rural ................................................ 363

Educação ...................................................... 363

Telecentro Comunitário ........................................... 363

Metas de Universalização ........................................ 363

Fundos Setoriais de Telecomunicações ............................... 365

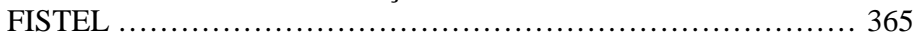

FUNTTEL ...................................................... 365

Pesquisa \& Desenvolvimento ..................................... 365

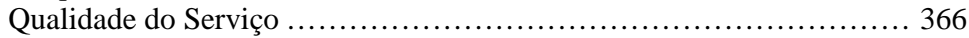

Controle de Conteúdo ............................................ 367

Controle Social, Hierárquico e Interorgânico (Accountability) .......... 367 
Sigilo em Telecomunicações ............................................ 367

Convergência .................................................. 368

Classificações de Serviços no Setor de Telecomunicações ............. 369

Quanto ao Regime Jurídico de Prestação ............................... 369

Quanto ao Gênero ........................................................ 369

Serviço Limitado ............................................................. 369

Serviço Limitado Privado ...................................... 369

Serviços no Setor de Telecomunicações ................................. 369

Serviço Telefônico Fixo Comutado (STFC) .......................... 369

Serviço Móvel Pessoal (SMP) ......................................... 374

Serviço de Comunicação Multimída (SCM) ............................ 377

Internet ............................................................ 379

TV a Cabo ...................................................... 379

TVA (Serviço Especial de TV por Assinatura) ........................ 380

DTH (Direct to Home - Serviço de Distribuição de Sinais de Televisão e de Áudio por Assinatura Via Satélite) ................................. 381

MMDS (Multichannel Multipoint Distribution Service - Serviço de

Distribuição de Sinais Multiponto Multicanal) ......................... 382

DISTV (Serviço de Distribuição de Sinais de TV por Meios Físicos) .... 383

Serviço Rádio do Cidadão ............................................... 384

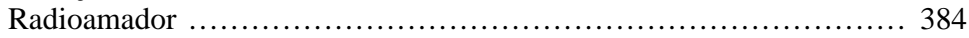

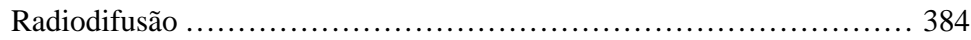

Radiodifusão Comunitária ..................................... 386

Serviço Auxiliar de Radiodifusão e Correlatos (SARC) .............. 386

Serviço Especial de Repetição de Televisão (RpTV) ................ 387

Rádio-taxi ...................................................... 387

Serviço de Rede de Transporte de Telecomunicações (SRTT) ............ 387

Serviço de Radiochamada ou Serviço Limitado Privado de Radiochamada

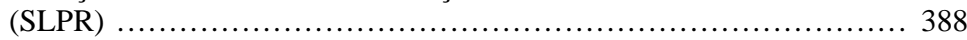

Serviço Especial de Radiochamada (SER) - ou Serviço Móvel Especial

de Radiochamada ................................................ 388

Serviço Móvel Especializado ou Trunking ou Trunk ou Sistema

Troncalizado ....................................................... 388

Serviço Móvel Global por Satélite (SMGS) .............................. 389

Serviço Móvel Marítimo ....................................................... 389

Serviço Especial de Sinais Horários .......................................... 389

Serviço Especial de Frequência Padrão ...................................... 389

Serviço Especial de Boletins Metereológicos ............................ 390

Serviço Especial de Fins Científicos ou Experimentais ................... 390

Serviço Especial de Música Funcional .................................... 390

Serviço Especial de Circuito Fechado de Televisão com utilização de Radioenlace ....................................................... 391

Serviço Especial de Radiorrecado ............................................. 391

Serviço Limitado de Radioestrada ........................................ 391

Serviço Avançado de Mensagens (SAM) ................................ 391

Serviço de Radiocomunicação Aeronáutico Público Restrito (SRA) ..... 392

Serviço Limitado Especializado (SLE) ............................. 392 
Serviços Científicos ..................................................... 392

Serviço de Pesquisa Espacial ..................................... 392

Serviço de Exploração da Terra por Satélite ........................ 393

Serviço Limitado Móvel Privado ............................................ 393

Serviço Limitado Privado ............................................ 393

Serviço de Telefonia Rural ............................................... 394

Ramos Jurídicos Afins ..................................................... 394

Direito do Consumidor ................................................. 394

Direito da Concorrência ................................................... 396

Servidor Público (Direito Administrativo) ............................. 396

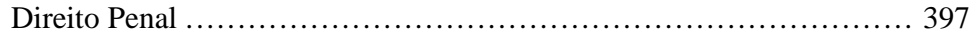

Direito Processual ..................................................... 397

Direito Tributário ............................................................. 398

Direito Administrativo ................................................... 398

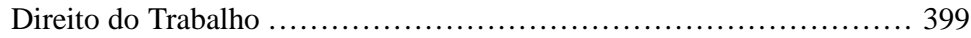

Aplicações de Telecomunicações ........................................ 399

Aplicações Médicas ...................................................... 399

Aplicações de Segurança .................................................... 399

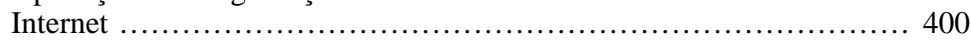

Telecomando ...................................................... 400

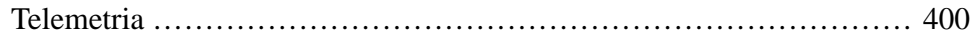

Acessibilidade ................................................ 400

Auxílio Auditivo .......................................... 401

Aeromodelismo ............................................... 401

Acesso a Serviços de Interesse Público e Uso de Radiofrequência por tais

Serviços ....................................................... 401

Segurança Pública ................................................ 401

Defesa Civil .......................................................... 402

Banda Larga ................................................. 402

Pesquisa Espacial .................................................. 402

Telecomunicações no Cenário Internacional .......................... 402

Comissões Brasileiras de Comunicações ................................ 402

Atores no Setor de Telecomunicações ....................................... 403

ANATEL .............................................................. 403

Poder Legislativo ....................................................... 404

Congresso Nacional ............................................. 404

Tribunal de Contas da União ........................................... 404

Poder Executivo ............................................................ 406

Presidência da República ......................................... 406

Ministério das Comunicações ........................................ 406

Poder Judiciário .................................................. 406

STF .............................................................. 406

STJ ............................................................ 407

TJs ............................................................ 409

TST ......................................................... 409

Prestadora / Operadora (direitos e deveres) ........................... 410 
Produtor Industrial ............................................ 413

Usuário / Consumidor (direitos e deveres) ......................... 413

Município .................................................. 417

Normas Referenciadas ............................................. 417

Lei Ordinária .................................................. 417

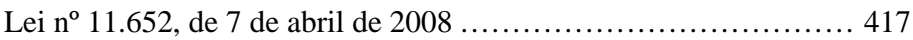

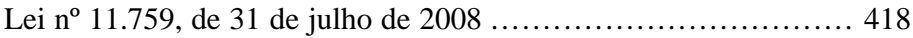

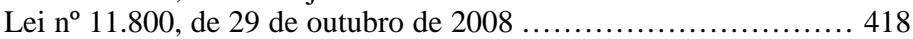

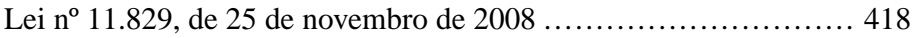

Decreto ..................................................... 418

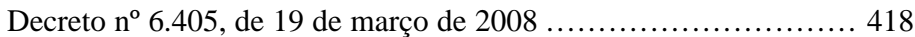

Decreto $n^{\circ} 6.424$, de 4 de abril de 2008 ........................ 419

Decreto de 14 de abril de 2008 - Renovação de Concessão da Globo em Belo Horizonte ........................................... 419

Decreto de 14 de abril de 2008 - Renovação de Concessão da Globo em Brasília .............................................. 419

Decreto de 14 de abril de 2008 - Renovação de Concessão da Globo em Recife .................................................. 420

Decreto de 14 de abril de 2008 - Renovação de Concessão da Globo em São Paulo ............................................... 420

Decreto de 14 de abril de 2008 - Renovação de Concessão da Globo no Rio de Janeiro .......................................... 420

Decreto $n^{\circ} 6.505$, de 4 de julho de 2008 ....................... 420

Decreto $n^{\circ} 6.523$, de 31 de julho de $2008 \ldots \ldots \ldots \ldots \ldots \ldots \ldots \ldots . \ldots 421$

Decreto $n^{\circ} 6.530$, de 4 de agosto de 2008 ....................... 421

Decreto de 17 de setembro de 2008 - Renovação de Concessão da

Record no Rio de Janeiro ...................................... 421

Decreto $n^{\circ} 6.602$, de 14 de outubro de $2008 \ldots \ldots \ldots \ldots \ldots \ldots \ldots \ldots . . \ldots 421$

Decreto $\mathrm{n}^{\mathrm{o}} 6.638$, de 7 de novembro de $2008 \ldots \ldots \ldots \ldots \ldots \ldots \ldots . . \ldots 22$

Decreto $n^{\circ} 6.654$, de 20 de novembro de $2008 \ldots \ldots \ldots \ldots \ldots \ldots \ldots . . \ldots 422$

Decreto $n^{\circ} 6.666$, de 27 de novembro de 2008 ................... 422

Decreto $n^{\circ} 6.689$, de 11 de dezembro de $2008 \ldots \ldots \ldots \ldots \ldots \ldots \ldots . . \ldots 23$

Portaria Ministerial .............................................. 423

Portaria MJ no 36, de 8 de janeiro de $2008 \ldots \ldots \ldots \ldots \ldots \ldots \ldots \ldots . . \ldots 23$

Portaria MC n $\mathrm{n}^{\mathrm{o}} 178$, de 22 de abril de $2008 \ldots \ldots \ldots \ldots \ldots \ldots \ldots \ldots . . \ldots 23$

Portaria MC $n^{\circ} 711$, de 9 de dezembro de $2008 \ldots \ldots \ldots \ldots \ldots \ldots . . . . . .423$

Portaria MC no 825, de 17 de dezembro de $2008 \ldots \ldots \ldots \ldots \ldots \ldots . . . . .424$

Portaria Interministerial ....................................... 424

Portaria Interministerial $n^{\circ} 23$, de 29 de janeiro de $2008 \ldots \ldots \ldots \ldots . .424$

Portaria Interministerial $n^{\circ} 29$, de 29 de janeiro de $2008 \ldots \ldots \ldots \ldots . . .424$

Portaria Interministerial $n^{\circ} 236$, de 29 de dezembro de 2008 ....... 425

Portaria Interministerial $n^{\circ} 237$, de 29 de dezembro de 2008 ....... 425

Resolução ...................................................... 426

Resolução da ANATEL n ${ }^{\circ} 490$, de 24 de janeiro de 2008 ........... 426

Resolução da ANATEL n ${ }^{\circ}$ 491, de 12 de fevereiro de 2008 ......... 426

Resolução da ANATEL n ${ }^{\circ}$ 492, de 19 de fevereiro de 2008 ......... 426

Resolução da ANATEL n ${ }^{\circ}$ 493, de 27 de fevereiro de 2008 ........ 427 
Resolução da ANATEL n ${ }^{\circ} 494$, de 24 de março de 2008 ........... 427

Resolução da ANATEL n ${ }^{\circ} 495$, de 24 de março de 2008 ........... 427

Resolução da ANATEL n ${ }^{\circ}$ 496, de 24 de março de 2008 ............ 427

Resolução da ANATEL n ${ }^{\circ} 497$, de 27 de março de 2008 ............ 428

Resolução da ANATEL n ${ }^{\circ} 498$, de 27 de março de 2008 ............ 428

Resolução da ANATEL n ${ }^{\circ} 499$, de 28 de março de 2008 ............ 428

Resolução da ANATEL n ${ }^{\circ} 501$, de 10 de abril de 2008 ............. 429

Resolução da ANATEL n ${ }^{\circ} 502$, de 18 de abril de 2008 ............. 429

Resolução da ANATEL n ${ }^{\circ} 503$, de 25 de abril de 2008 ............ 430

Resolução da ANATEL n ${ }^{\circ}$ 504, de 14 de maio de 2008 ............. 430

Resolução da ANATEL n ${ }^{\circ} 505$, de 5 de junho de 2008 .............. 431

Resolução da ANATEL $n^{\circ} 506$, de $1^{\circ}$ de julho de 2008 ............ 431

Resolução da ANATEL n ${ }^{\circ}$ 507, de 16 de julho de 2008 ............. 432

Resolução da ANATEL n ${ }^{\circ} 508$, de 31 de julho de 2008 ............. 432

Resolução da ANATEL $n^{\circ} 509$, de 14 de agosto de 2008 ........... 433

Resolução da ANATEL n ${ }^{\circ} 510$, de 28 de agosto de 2008 ........... 434

Resolução da ANATEL n ${ }^{\circ} 511$, de $1^{\circ}$ de setembro de 2008 ......... 434

Resolução da ANATEL n ${ }^{\circ}$ 512, de 23 de setembro de 2008 ......... 434

Resolução da ANATEL n ${ }^{\circ}$ 513, de 29 de setembro de 2008 ......... 435

Resolução da ANATEL n ${ }^{\circ}$ 514, de 7 de outubro de 2008 ............ 436

Resolução da ANATEL n ${ }^{\circ} 515$, de 10 de outubro de 2008 ........... 436

Resolução da ANATEL n ${ }^{\circ} 516$, de 30 de outubro de 2008 ........... 436

Resolução da ANATEL n ${ }^{\circ} 517$, de 31 de outubro de 2008 ............ 437

Resolução da ANATEL n ${ }^{\circ} 518$, de 21 de novembro de 2008 ........ 437

Resolução da ANATEL n ${ }^{\circ} 519$, de 21 de novembro de 2008 ........ 438

Resolução da ANATEL n ${ }^{\circ}$ 520, de 27 de novembro de 2008 ........ 438

Resolução da ANATEL n ${ }^{\circ}$ 522, de 3 de dezembro de 2008 .......... 439

Resolução da ANATEL n ${ }^{\circ} 523$, de 15 de dezembro de 2008 ........ 439

Resolução da ANATEL n ${ }^{\circ}$ 524, de 23 de dezembro de 2008 ........ 439

Resolução emitida por outros órgãos .............................. 439

Resolução da ANTT n ${ }^{\circ}$ 2.552, de 14 de fevereiro de 2008 .......... 439

Julgados Referenciados .................................................. 440

Súmulas ....................................................... 440

Superior Tribunal de Justiça (STJ) ............................ 440

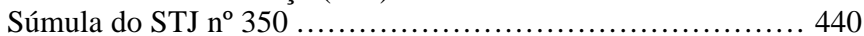

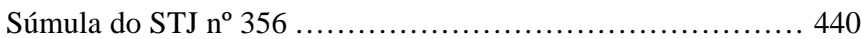

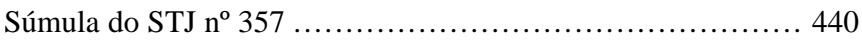

Acórdãos ..................................................... 441

Supremo Tribunal Federal (STF) .............................. 441

STF - RE 571572-8 / BA - Bahia .......................... 441

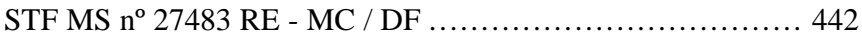

Superior Tribunal de Justiça (STJ) ............................ 443

STJ - HC 76686 / PR - Paraná ............................... 443

STJ - MC 13406 / SP - São Paulo ............................. 444

STJ - RESP 1053778 / RS ................................... 445

STJ - RESP 938827 / DF ................................. 447

STJ - RESP 754393 / DF ............................... 448 
Tribunal Superior do Trabalho (TST) ......................... 449

TST - RR 1542/2005-055-02-40 - AI ..................... 449

Tribunal de Contas da União (TCU) .......................... 450

TC-002.660/2007-8 ..................................... 450

TC-023.855/2007-0 ...................................... 458

TC-010.978/2008-1 ....................................... 458

TC-027.077/2006-4 ....................................... 460

TC-010.385/2006-7 ..................................... 463

TC-019.677/2006-2 ....................................... 465

TC-010.681/2008-0 ...................................... 468

Atos Referenciados ............................................... 470

Ato Administrativo ............................................. 470

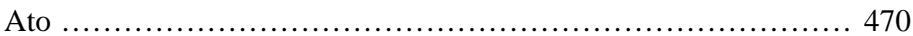

Ato do Conselho Diretor da ANATEL $\mathrm{n}^{\circ} 1.805$, de $1^{\circ}$ de abril de

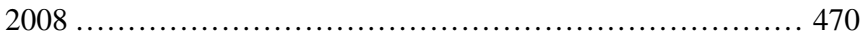

Ato do Conselho Diretor da ANATEL n ${ }^{\circ} 1.933$, de 7 de abril de

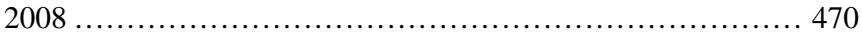

Ato do Conselho Diretor da ANATEL no 4.197, de 16 de julho

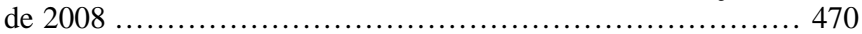

Ato do Conselho Diretor da ANATEL n ${ }^{\circ} 7.828$, de 19 de

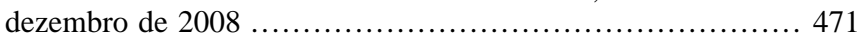

Análise da ANATEL ......................................... 471

Análise ANATEL/GCPJ no 368 , de 7 de outubro de 2008 ...... 471

Análise ANATEL/GCAB nº 455, de 9 de outubro de 2008 ..... 471

Termo de Autorização ...................................... 471

Termo Aditivo $n^{\circ}$ 001/2008/SPV - BRASIL TELECOM, de 8 de abril de 2008 ............................................. 471

Termo Aditivo ${ }^{\circ}$ 001/2008/SPV - SERCOMTEL, de 8 de abril

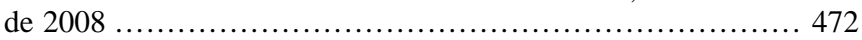

Termo Aditivo $\mathrm{n}^{\circ}$ 001/2008/SPV - CTBC, de 8 de abril de

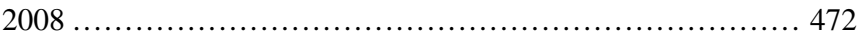

Termo Aditivo $n^{\circ}$ 001/2008/SPV - TELEMAR, de 8 de abril de

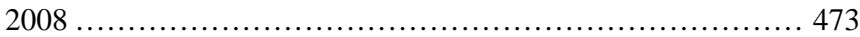

Índice Alfabético e Remissivo ........................................ 475 


\section{Lista de Abreviaturas e Siglas}

$1 \mathrm{G}$

$2.5 \mathrm{G}$

$2 \mathrm{G}$

$3 \mathrm{G}$

3G HS

AACD

ABA

ABAP

ABEMTIC

ABEPEC

ABEPREST

ABERT

ABETS

ABIFUMO

ABINEE

ABNT

ABPI-TV

ABPITV

ABPTA

ABRA

ABRACOM

ABRAFIC

ABRAFIX

ABRAPPIT

ABRATEL

ABRATER

ABRISAN

ABTA

ABTU

Acel

ACERP
Primeira Geração de Tecnologia de Telefonia Móvel (analógico).

Geração 2.5 de Tecnologia de Telefonia Móvel (GPRS).

Segunda Geração de Tecnologia de Telefonia Móvel (digital para dados, 9.6-14.4Kbps).

Terceira Geração de Tecnologia de Telefonia Móvel (digital para voz e dados, mínimo de 144Kbps).

3G High Speed (Rede celular de Terceira geração de Alto Desempenho).

Associação de Assistência à Criança Defeituosa.

Associação Brasileira de Anunciantes.

Associação Brasileira de Agências de Propaganda.

Associação Brasileira de Entidades Municipais de Tecnologia da Informação e Comunicação.

Associação Brasileira das Emissoras Públicas Educativas e Culturais.

Associação Brasileira de Empresas de Soluções de Telecomunicações e Informática.

Associação Brasileira de Emissoras de Rádio e Televisão.

Associação Brasileira das Empresas de Telecomunicações por Satélite.

Associação Brasileira da Indústria do Fumo.

Associação Brasileira da Indústria Elétrica e Eletrônica.

Associação Brasileira de Normas Técnicas.

Associação Brasileira de Produtores Independentes de Televisão.

Associação Brasileira das Empresas Produtoras Independentes de Televisão.

Associação Brasileira dos Programadores de TV por Assinatura.

Associação Brasileira de Radiodifusores.

Associação Brasileira de Antenas Comunitárias.

Associação Brasileira de Film Commissions (Brazilian Association of Film Commissions).

Associação Brasileira de Concessionárias de Serviço Telefônico Fixo Comutado.

Associação Brasileira de Pequenos Provedores de Internet e Telecomunicações.

Associação Brasileira de Radiodifusão, Tecnologia e Telecomunicações.

Associação Brasileira de Telecomunicações Rurais.

Associação Brasileira de Registro de Obras Audiovisuais.

Associação Brasileira de TV por Assinatura.

Associação Brasileira de Televisão Universitária.

Associação Nacional das Operadoras Celulares.

Associação de Comunicação Educativa Roquette Pinto. 
$\mathrm{AD}$

ADI

ADSL

AGVSEL

Ah

AI

AI

$\mathrm{AI} / \mathrm{E}$

AICE

AIE

AIRR

ALCA

AM

AM-DSB-SC

AME

AMMB

AMN

AMNT

AMPS

AN

ANACOM

ANATEL

ANCINE

ANEEL

ANER

ANJ

ANOp

ANP

ANSI

ANTT

APEX-Brasil

APS

Aptel

AR

AR

AR

ARIB
Adicional por Chamada (Serviço Móvel Pessoal).

Ação Direta de Inconstitucionalidade (Jurisdição).

Asymmetric Digital Subscriber Line.

Agravo em Suspensão de Execução de Liminar.

Ampère-hora.

Acesso Instalado.

Agravo de Instrumento (Jurisdição).

Acesso Instalado da Estação de Comutação.

Acesso Individual Classe Especial.

Acesso Instalado Equivalente.

Agravo de Instrumento em Recurso de Revista (Tribunal Superior do Trabalho).

Área de Livre Comércio das Américas.

Amplitude Modulation (Modulação em Amplitude).

Amplitude Modulation, Double-Sided Band, Suppressed Carrier (Modulação em Amplitude, em Faixa Lateral Dupla, com Portadora Suprimida).

Valor de Ativo Moderno Equivalente (Separação e Alocação de Contas).

Associação de Marketing Móvel do Brasil.

Artificial Mains Network (Rede Fictícia em V).

Assembléia Mundial de Normalização das Telecomunicações.

Advanced Mobile Phone System (Rede celular 1G).

Área de Numeração (Serviço Telefônico Fixo Comutado).

Autoridade Nacional de Comunicações (de Portugal).

Agência Nacional de Telecomunicações.

Agência Nacional do Cinema.

Agência Nacional de Energia Elétrica.

Associação Nacional das Empresas de Revistas.

Associação Nacional de Jornais.

Auditoria de Natureza Operacional (Tribunal de Contas da União).

Agência Nacional do Petróleo.

American National Standards Institute.

Agência Nacional de Transportes Terrestres.

Agência de Promoção de Exportações do Brasil.

Área de Prestação do Serviço (Serviços de Televisão por Assinatura).

Associação de Empresas Proprietárias de Infra-Estrutura e de Sistemas Privados de Telecomunicações.

Área de Registro (Serviço Móvel Especializado).

Área de Registro (Serviço Móvel Pessoal).

Área de Registro (Serviço Telefônico Fixo Comutado).

Association of Radio Industries and Businesses (Japão). 
ARM

ART

ASTM

AT

AT

ATA

ATB

ATB

ATC

ATS

ATSC

AVADAN

BACEN

BAL

$\mathrm{BB}$

$\mathrm{BBC}$

BCB

BDO

BDR

BDR

BDT

BDTA

BGAN

BIA

BID

BIRD

BIS

Bn

BNDES

BPL

BR

BRASSCOM

BS

BSR

BWA

C-INI

CA
Acordo de Reconhecimento Mútuo (Certificação e Homologação).

Anotação de Responsabilidade Técnica.

American Society for Testing and Materials.

Área de Tarifação (Serviço Móvel Especializado).

Área de Tarifação (Serviço Móvel Pessoal).

Analog Telephone Adaptor.

Área de Tarifa Básica.

Área de Tarifação Básica (Serviço Telefônico Fixo Comutado).

Ativos de Tecnologia Corrente (Separação e Alocação de Contas).

Ativos de Tecnologia Substituída (Separação e Alocação de Contas).

Advanced Television Systems Committee (Padrão de TV Digital Estados Unidos da América).

Avaliação de Danos - Formulário (Sistema Nacional de Defesa Civil).

Banco Central do Brasil.

Balanceamento Longitudinal.

Banda-Base.

British Broadcasting Corporation (Reino Unido).

Banco Central do Brasil.

Base de Dados Operacional (Portabilidade).

Base de Dados de Referência (Portabilidade).

Base de Dados Nacional de Referência da Portabilidade.

Bureau de Développement des Télécommunications (Escritório de Desenvolvimento das Telecomunicações da UIT).

Banco de Dados Técnicos e Administrativos (Radiofreqüência).

Broadband Global Area Network (INMARSAT).

Bens e Instalações em Andamento (Separação e Alocação de Contas).

Banco Interamericano de Desenvolvimento.

Banco Internacional para Reconstrução e Desenvolvimento (Banco Mundial).

Bens e Instalações em Serviço (Separação e Alocação de Contas).

Largura da Faixa Necessária (Certificação).

Banco Nacional de Desenvolvimento Econômico e Social.

Broadband over Powerlines.

Bureau des Radiocommunications (Escritório de Radiocomunicações da UIT).

Associação Brasileira de Empresas de Tecnologia da Informação e Comunicação.

Base Station (Estação Rádio Base).

Bloqueador de Sinais de Radiocomunicações.

Broadband Wireless Access.

Comitê sobre Infra-estrutura Nacional de Informações.

Corrente Alternada. 
CAACI

CADE

CADIN

CAPDA

CAPT

CARR

CBC

CBC 1

CBC 2

CBC 3

CBC 4

CBC 5

CBC 6

CBC 7

CBC 8

CBC 9

CBC 1

CBC 10

CBC 11

CBC 12

CBC 13

CBC 2

CBC 3

CBC 4

CBC Temp.

CBDT

CBLC

CBR
Conferência de Autoridades Audiovisuais e Cinematográficas IberoAmericana.

Conselho Administrativo de Defesa Econômica.

Cadastro Informativo de Créditos não Quitados do Setor Público Federal.

Comitê das Atividades de Pesquisa e Desenvolvimento na Amazônia. Controle Automático da Potência Transmitida.

Conferência Administrativa Regional de Radiocomunicações.

Comissão Brasileira de Comunicações.

Comissão Brasileira de Comunicações $\mathrm{n}^{\circ} 1$ - Redes de Dados e Características de Sistemas Telemáticos (extinta).

Comissão Brasileira de Comunicações n ${ }^{\circ} 2$ - Transmissão de Áudio e Vídeo e Sistemas Multimídia (extinta).

Comissão Brasileira de Comunicações $n^{\circ} 3$ - Tarifas e Princípios Contábeis (extinta).

Comissão Brasileira de Comunicações no 4 - Definição de Serviços, Planos Estruturais e Gerência de Redes (extinta).

Comissão Brasileira de Comunicações n ${ }^{\circ} 5$ - Sinalização, Comutação, Protocolos, Linguagens e Aspectos Gerais de Redes (extinta).

Comissão Brasileira de Comunicações n ${ }^{\circ} 6$ - Planta Externa e Compatibilidade Eletromagnética (extinta).

Comissão Brasileira de Comunicações $n^{\circ} 7$ - Desenvolvimento das Telecomunicações (extinta).

Comissão Brasileira de Comunicações $\mathrm{n}^{\circ} 8$ - Serviços Móveis, de Radiodeterminação e de Radioamador (extinta).

Comissão Brasileira de Comunicações $n^{\circ} 9$ - Serviços Fixos e Científicos (extinta).

Comissão Brasileira de Comunicações $n^{\circ} 1$ - Governança e Regimes Internacionais.

Comissão Brasileira de Comunicações $n^{\circ} 10$ - Administração do Espectro Radioelétrico e Propagação (extinta).

Comissão Brasileira de Comunicações $n^{\circ} 11$ - Radiodifusão (extinta).

Comissão Brasileira de Comunicações $\mathrm{n}^{\circ} 12$ - Negociações Internacionais em Telecomunicações (extinta).

Comissão Brasileira de Comunicações $n^{\circ} 13$ - Governança da Internet (extinta).

Comissão Brasileira de Comunicações n 2 - Radiocomunicações.

Comissão Brasileira de Comunicações $n^{\circ} 3$ - Normalização de Telecomunicações.

Comissão Brasileira de Comunicações n ${ }^{\circ} 4$ - Desenvolvimento das Telecomunicações.

Comissão Brasileira de Telecomunicações Temporária.

Coleção Brasileira de Direito Regulatório das Telecomunicações.

Comissão Brasileira de Liquidação e Custódia.

Comissão Brasileira de Radiocomunicações. 
CBT

CBTTs

$\mathrm{CC}$

$\mathrm{CCC}$

$\mathrm{CCC}$

CCC

CCIR

$\mathrm{CCOM}$

CCP.I

CCP.II

CCP.III

CCPs-CITEL

CCT

CCT

CCT

CCTCI

ccTLD

CDC

CDI

CDMA

CDMA 1xEV-DO

CDMA 1xEV-DV

CEDEC

CEFET

CEITEC

CENAD

CENELEC

CEPED

CERT.br

CETIC.br
Código Brasileiro de Telecomunicações (Lei nº 4.117/62).

Comissões Brasileiras de Telecomunicações.

Corrente Contínua.

Central de Comutação e Controle (Serviço Móvel Pessoal).

Central de Comutação e Controle (Sistemas de Acesso sem Fio do STFC).

Central de Controle e Comutação do SMC (Internacional).

Comitê Consultivo Internacional das Radiocomunicações.

Centro de Políticas, Direito, Economia e Tecnologias das Comunicações da UnB.

Comitê Consultivo Permanente $\mathrm{n}^{\circ} 1$ da Comissão Interamericana de Telecomunicações.

Comitê Consultivo Permanente $\mathrm{n}^{\circ} 2$ da Comissão Interamericana de Telecomunicações.

Comitê Consultivo Permanente $\mathrm{n}^{\circ} 3$ da Comissão Interamericana de Telecomunicações.

Comitês Consultivos Permanentes da CITEL.

Cargo Comissionado Técnico (Agências Reguladoras).

Comissão de Ciência, Tecnologia, Inovação, Comunicação e Informática (Senado Federal).

Conselho Nacional de Ciência e Tecnologia.

Comissão de Ciência e Tecnologia, Comunicação e Informática (Câmara dos Deputados).

country code Top Level Domain (Domínio de Primeiro Nível) (INTERNET).

Código de Defesa do Consumidor.

Comutação Digital Integrada.

Code Division Multiple Access (Múltiplo Acesso por Divisão de Código).

CDMA Evolution Data-Optimized (Rede celular 3G).

CDMA Evolution, Data and Voice (Rede celular 3G).

Coordenadoria Estadual de Defesa Civil (Sistema Nacional de Defesa Civil).

Centro Federal de Educação Tecnológica.

Centro Nacional de Tecnologia Eletrônica Avançada S.A.

Centro Nacional de Gerenciamento de Riscos e Desastres (Sistema Nacional de Defesa Civil).

European Commitee for Electrotechnical Standardization.

Centro Universitário de Ensino e Pesquisa sobre Desastres (Sistema Nacional de Defesa Civil).

Centro de Estudos, Resposta e Tratamento de Incidentes de Segurança no Brasil (Comitê Gestor da Internet no Brasil).

Centro de Estudos sobre as Tecnologias da Informação e da Comunicação (Comitê Gestor da Internet no Brasil). 
CFM

CFTV

CG-CBC

CGIbr

CGPD

CGRBT

CIC

CIDE

CIPA

CISCOMIS

CITEL

CMDT

CMGLO

CMI

CMR

$\mathrm{CN}$

CNAL

$\mathrm{CNC}$

CNDI

$\mathrm{CNI}$

$\mathrm{CNPq}$

CNPq-MCT

$\mathrm{COE}$

COE

COER

COFDM

COFINS

COG

COGEF

COMDEC

CONANDA

Conapsi

CONAR

CONARQ

CONCAR
Conselho Federal de Medicina.

Serviço Especial de Circuito Fechado de Televisão com Utilização de Radioenlace.

Grupo de Coordenação das Comissões Brasileiras de Comunicações.

Comitê Gestor da Internet no Brasil.

Comitê Gestor de Políticas de Inclusão das Pessoas com Deficiência (Presidência da República).

Comitê Gestor de Articulação Institucional da Rede Brasil de Tecnologia.

Central de Intermediação de Comunicação Telefônica.

Contribuição de Intervenção no Domínio Econômico.

Comissão Interna de Prevenção de Acidentes.

Comissão de Desenvolvimento do Projeto e da Implantação do Sistema de Comunicações Militares por Satélite.

Comissão Interamericana de Telecomunicações.

Conferência Mundial de Desenvolvimento das Telecomunicações.

Gerência de Engenharia, Planejamento e Controle de Licitações e Outorgas.

Cúpula Mundial da Informação.

Conferência Mundial de Radiocomunicações.

Código Nacional.

Cadastro Nacional de Áreas Locais.

Conselho Nacional de Comunicações.

Conselho Nacional de Desenvolvimento Industrial.

Confederação Nacional da Indústria.

Conselho Nacional de Desenvolvimento Científico e Tecnológico.

Centro Nacional de Pesquisa do Ministério da Ciência e Tecnologia.

Coeficiente de Onda Estacionária.

Coeficiente de Reflexão.

Certificado de Operador de Estação de Radioamador.

Coded Orthogonal Frequency Division Multiplexing.

Contribuição para Financiamento da Seguridade Social.

Cabo Óptico Geral.

Comissão de Gerência do Espectro de Radiofreqüência de Interesse do Ministério da Defesa.

Coordenadoria Municipal de Defesa Civil (Sistema Nacional de Defesa Civil).

Conselho Nacional dos Direitos da Criança e do Adolescente.

Conselho Nacional dos Provedores de Serviço de Internet.

Conselho Nacional de Auto-Regulamentação Publicitária.

Conselho Nacional de Arquivos.

Comissão Nacional de Cartografia. 
CONDEC

CONDECINE

CONFAZ

CONTCOP

CONTEL

COP

COR

CORDE

CORDEC

CP

CP

CPADS

CPC

CPCT

CPCT

CPI

CPLP

CPP

$\mathrm{CPqD}$

$\mathrm{CPqD}$

CRE

CREA

CSP

CTBC
Conselho Nacional de Defesa Civil (Sistema Nacional de Defesa Civil).

Contribuição para o Desenvolvimento da Indústria Cinematográfica Nacional.

Conselho Nacional de Política Fazendária.

Confederação Nacional dos Trabalhadores em Comunicações e Publicidade (Representação profissional).

Conselho Nacional de Telecomunicações (Extinto).

Cabo Óptico "Plenum".

Cabo Óptico "Riser".

Coordenadoria Nacional para Integração da Pessoa Portadora de Deficiência.

Coordenadoria Regional de Defesa Civil (Sistema Nacional de Defesa Civil).

Código Penal.

Consulta Pública.

Comissão Permanente de Avaliação de Documentos Sigilosos.

Código de Processo Civil.

Central Privada de Comutação Telefônica.

Central Privativa de Comutação Telefônica (Serviço Telefônico Fixo Comutado).

Comissão Parlamentar de Inquérito.

Comunidade de Países de Língua Portuguesa.

Código de Processo Penal.

Centro de Pesquisa e Desenvolvimento (Telebrás).

Fundação CPqD Centro de Pesquisa e Desenvolvimento em Telecomunicações.

Contrato de Receita Extraordinária (Concessionária de Rodovia).

Conselho Regional de Engenharia e Arquitetura.

Código de Seleção de Prestadora.

Companhia de Telecomunicações do Brasil Central.

CTs-SGT.1-MERCOSUL Comissões Temáticas do Subgrupo de Trabalho de Comunicações do MERCOSUL.

CVM Comissão de Valores Mobiliários.

CVR Relações Custo-Volume (Separação e Alocação de Contas).

D-AMPS Digital Advanced Mobile Phone System.

DAC Departamento de Aviação Civil.

DAS Direção e Assessoramento Superiores.

dB Decibel.

dB SPL Decibel relativo a $20 \mu \mathrm{Pa}$.

dB SPL(A) Decibel relativo a $20 \mu \mathrm{Pa}$ medido com ponderação A (IEC 60651).

dB V Decibel Relativo a $1 \mathrm{~V}$.

DBDG Diretório Brasileiro de Dados Geoespaciais (DBDG). 


\begin{tabular}{|c|c|}
\hline $\mathrm{dBk}$ & Potência, em dB, relativa a $1 \mathrm{~kW}$. \\
\hline $\mathrm{dBmp}$ & Decibel medido com ponderação psofométrica (Rec. O.41 da ITU-T). \\
\hline $\mathrm{dBPa}$ & Decibel Relativo a 1 Pascal. \\
\hline $\mathrm{dBPa}(\mathrm{A})$ & Decibel relativo a 1 Pa medido com ponderação A (IEC 60651). \\
\hline $\mathrm{dB} \mu$ & Decibel Relativo a $1 \mathrm{~mW}$. \\
\hline $\mathrm{dB} \mu$ & Intensidade de campo, em $\mathrm{dB}$, relativa a $1 \mu \mathrm{V} / \mathrm{m}$. \\
\hline DCOR & Diretoria de Concessões e Operações Rodoviárias. \\
\hline DDG & Discagem Direta Gratuita. \\
\hline DDI & Discagem Direta Internacional. \\
\hline DDR & Discagem Direta a Ramal. \\
\hline DEA & Data Envelopment Analysis. \\
\hline DECEA & Departamento de Controle do Espaço Aéreo. \\
\hline DECT & DECT. \\
\hline DEINT & $\begin{array}{l}\text { Departamento de Negociações Internacionais da Secretaria de } \\
\text { Comércio Exterior do Ministério da Indústria, do Comércio e do } \\
\text { Turismo. }\end{array}$ \\
\hline DENTEL & Departamento Nacional de Telecomunicações (Extinto). \\
\hline DEPEN & Departamento Penitenciário Nacional. \\
\hline DETRAF & Documento de Declaração de Tráfego e de Prestação de Serviços. \\
\hline DG & Distribuidor Geral (Serviço Telefônico Fixo Comutado). \\
\hline DIC & Discagem Interurbana a Cobrar. \\
\hline DISTV & Serviço de Distribuição de Sinais de TV por Meios Físicos. \\
\hline DJ & Diário da Justiça (Imprensa Nacional). \\
\hline DJe & Diário da Justiça eletrônico. \\
\hline DLC & Discagem Local a Cobrar. \\
\hline DNER & Departamento Nacional de Estradas de Rodagem. \\
\hline DNS & Domain Name System. \\
\hline DOP & Documento Operacional de Prazos da Portabilidade. \\
\hline DRM & Digital Radio Mondiale (padrão europeu de rádio digital). \\
\hline DS-CDMA & Múltiplo Acesso por Divisão em Código com Seqüência Direta. \\
\hline DSAC & Documento de Separação e Alocação de Contas. \\
\hline DSB & Double Side Band 'Modulation' (Modulação em Faixa Lateral Dupla). \\
\hline DSC & Documento Sigiloso Controlado. \\
\hline DSL & Digital Subscriber Line. \\
\hline DTH & $\begin{array}{l}\text { Direct-to-Home (Serviço de Distribuição de Sinais de Televisão e de } \\
\text { Áudio por Assinatura Via Satélite). }\end{array}$ \\
\hline DTMF & Dual Tone Multi-Frequency. \\
\hline DVB & Digital Video Broadcasting (Padrão de TV Digital - União Européia). \\
\hline DVB-H & Digital Video Broadcasting Handheld. \\
\hline e-DJF1 & $\begin{array}{l}\text { Diário da Justiça Federal da Primeira Região eletrônico (TRF } 1^{\text {a }} \\
\text { Região). }\end{array}$ \\
\hline e.i.r.p. & Potência Equivalente Isotropicamente Radiada. \\
\hline
\end{tabular}


e.r.p. Potência Efetiva Radiada (Campo Eletromagnético).

e.r.p. Potência Efetivamente Irradiada.

EB Estação Base.

EBC Empresa Brasil de Comunicação.

EBITDA Earning Before Interest, Tax, Depreciation and Amortization.

EC Estação de Controle.

Ec / ec Campo Característico, respectivamente em $\mathrm{dB} \mu \mathrm{e} \mathrm{mV/m}$.

ECA Estatuto da Criança e do Adolescente.

ECAD Escritório Central de Arrecadação e Distribuição.

ECD Equipamento de Comunicação de Dados.

ECT Empresa Brasileira de Correios e Telégrafos.

EDGE $\quad$ EDGE.

EEII Empresa Exploradora de Troncos Interestaduais e Internacionais.

EESPT Entidade Exploradora de Serviços Públicos de Telecomunicações.

EHF Extremely High Frequency.

EILD Exploração Industrial de Linha Dedicada.

ELI Estágio de Linha Integrado.

ELR Estágio de Linha Remoto.

EM Estação Móvel.

Enom / enom Intensidade de campo nominal utilizável, respectivamente em $\mathrm{dB} \mu \mathrm{e}$ $\mathrm{mV} / \mathrm{m}$.

ENUM

Telephony Numbering Mapping (Protocolo desenvolvido pela IETF).

EPMU Equal Proporcionate Mark Up (Alocação Proporcional e Eqüitativa

- Separação e Alocação de Contas).

EPON Ethernet Passive Optical Network.

ER Estação Repetidora.

ER Estágio Remoto (Serviço Telefônico Fixo Comutado).

ERB Estação Rádio Base.

ERB Estação Rádio Base (Serviço Móvel Pessoal).

ERC Estação Radioelétrica Central.

ERG European Regulators Group.

ERP Potência Efetivamente Radiada.

ESC Equipamento a Ser Certificado.

ET Estação Terminal.

ETA Estação Terminal de Acesso.

ETD Equipamento Terminal de Dados.

ETSI European Telecommunications Standards Institute.

Eu / eu Intensidade de campo utilizável, respectivamente em $\mathrm{dB} \mu \mathrm{e} \mathrm{mV} / \mathrm{m}$.

FAC Fully Allocated Costs (Custos Totalmente Alocados).

FCC Federal Communications Commission (United States of America).

FCPT Fórum de Certificação de Produtos para Telecomunicações. 
FCT

FCT

FDD

FDMA

FEBRAPEL

FGP

FGTS

FH-CDMA

FINEP

FISTEL

FITTEL

FM

FMCA

FNDCT

FNT

FTTB

FTTC

FTTH

FTTN

FUNCAP

Fundomic

FUNTTEL

FUST

FWA

GCOM

GESAC

GETEL

GGSN

GIP

GIP

GMC

GNR

GPON

GPRS

GPS
Função Comissionada Técnica.

Funções Comissionadas de Telecomunicações.

Frequency Division Duplexing (Duplexação por Divisão na Frequência).

Frequency Division Multiple Access (Múltiplo Acesso por Divisão de Frequência).

Federação Brasileira de Telecomunicações (Representação empresarial).

Fundo Garantidor de Parcerias Público-Privadas.

Fundo de Garantia por Tempo de Serviço.

Múltiplo Acesso por Divisão em Código com Saltos de Frequiência.

Financiadora de Estudos e Projetos.

Fundo de Fiscalização das Telecomunicações.

Federação Interestadual dos Trabalhadores em Telecomunicações.

Frequência Modulada.

Fixed-Mobile Convergence Alliance.

Fundo Nacional de Desenvolvimento Científico e Tecnológico.

Fundo Nacional de Telecomunicações.

Fiber to the Building.

Fiber to the Curb.

Fiber to the Home.

Fiber to the Node.

Fundo Especial para Calamidades Públicas (Sistema Nacional de Defesa Civil).

Fundo de Universalização do Acesso a Serviços de Telecomunicação (Minas Gerais).

Fundo para o Desenvolvimento Tecnológico das Telecomunicações.

Fundo de Universalização dos Serviços de Telecomunicações.

Fixed Wireless Access.

Grupo Interdisciplinar de Políticas, Direito, Economia e Tecnologias das Comunicações (UnB).

Governo Eletrônico - Serviço de Atendimento ao Cidadão.

Grupo de Estudos em Direito das Telecomunicações (UnB).

Gateway GPRS Support Node.

Grupo de Implantação da Portabilidade.

Grupo de Implementação da Portabilidade.

Grupo Mercado Comum.

Guia Nacional de Recolhimento de Tributos Estaduais.

Gigabit Passive Optical Network.

General Packet Radio Service (Rede celular 2.5G).

Global Positioning System (Sistema de Posicionamento Global). 


\section{GSM}

HCA

HCA

HF

HMM

HNMT

HSDPA

HSPA

HSUPA

IAF

IAP

IARP

IARU

IBGE

IBICT

IBOC

ICANN

ICC

ICCo

ICMS

ICNIRP

ICP-Brasil

ICR

ICT

IDDF

IDEC

IDH

IEC

IEEE

IETF

Ifd

IFS
Global System Mobile (Global System for Mobile Communications) (Rede celular 2G).

Base de Custos Históricos ( Separação e Alocação de Contas).

Historical Cost Accounting (Base de Custos Históricos na Separação e Alocação de Contas).

High Frequency (Alta Frequiência).

Hora de Maior Movimento.

Altura da Antena sobre o Nível Médio do Terreno.

High Speed Downlink Packet Access (Rede celular 3G).

High-Speed Packet Access (tipo de padrão de telefonia móvel por dados) (Rede celular 3G).

High Speed Uplink Packet Access (Rede celular 3G).

International Accreditation Forum (Certificação e Homologação).

Índice de Atendimento Pessoal.

International Amateur Radio Permission (Permissão Internacional de Radioamador).

União Internacional de Radioamadores.

Instituto Brasileiro de Geografia e Estatística.

Instituto Brasileiro de Informação em Ciência e Tecnologia.

In-Band On-Channel (padrão norte-americano de rádio digital).

Internet Corporation for Assigned Names and Numbers (Corporação da Imternet para a Atribuição de Nomes e Números).

Índice de Chamadas Completadas.

Índice de Cessação de Cobrança.

Imposto sobre Operações Relativas à Circulação de Mercadorias e Sobre Prestações de Serviços de Transporte Interestadual, Intermunicipal e de Comunicações.

International Commission on Non Ionizing Radiation Protection (Comissão Internacional de Proteção Contra Radiações Não Ionizantes).

Infra-Estrutura de Chaves Públicas Brasileira.

Índice de Correspondências Respondidas.

Instituição Científica e Tecnológica.

Informações de Demanda e Dados Físicos (Separação e Alocação de Contas).

Instituto de Defesa do Consumidor.

Índice de Desenvolvimento Humano.

International Electrotechnical Commission.

Institute of Electrical and Electronics Engineers.

Internet Engineering Task Force (Força Tarefa de Engenharia da Internet).

Fator de Degradação.

Serviço Franqueado Internacional. 
IGF

IGP-DI

IGP-M

II

IIS

IITS

ILA

ILAC

IMSI

IMT-2000

INDE

INFRAERO

INI

INMARSAT

INMETRO

INTELSAT

IP

IPAOG/FGV

IPCA/IBGE

IPI

IPTF

IPTF DEA

IPTF F

IPTF F

IPTV

IQF

IQP

IQP

IR

IREDC

IRS

ISAN

ISDB

ISDB-C

ISDB-S
Internet Governance Fórum (Fórum de Governança da Internet vinculado à $\mathrm{ONU}$ ).

Índice Geral de Preços - Disponibilidade Interna.

Índice Geral de Preços - Mercado.

Imposto de Importação.

Índice de Instalação do Serviço.

Índice de Interrupções Solucionadas.

Índice de Ligações Atendidas.

International Laboratories Accreditation Cooperation (Certificação e Homologação).

International Mobile Subscriber Identity (Identificação Internacional de Acesso Móvel).

International Mobile Telecommunications-2000.

Infra-Estrutura Nacional de Dados Espaciais (INDE).

Empresa Brasileira de Infra-estrutura Aeroportuária.

Infra-estrutura Nacional de Informações.

Organização Internacional de Telecomunicações Marítimas por Satélite.

Instituto Nacional de Metrologia, Normalização e Qualidade Industrial.

International Telecommunications Satellite Consortium (Organização Internacional de Telecomunicações por Satélite).

Internet Protocol (Protocolo de Internet).

Índice de Preços por Atacado - Oferta Global.

Índice de Preços ao Consumidor Amplo.

Imposto sobre Produtos Industrializados.

IPTF F.

Índice de Produtividade Total de Fatores DEA.

Índice de Produtividade Total de Fatores Fisher.

Índice de Produtividade Total de Fatores Fisher (Reajuste Tarifário do STFC).

Internet Protocol TV.

Índice de Quantidade dos Fatores de Produção (Reajuste Tarifário do STFC).

Índice de Fator de Produção.

Índice de Quantidade dos Produtos (Reajuste Tarifário do STFC).

Imposto de Renda.

Índice de Reclamação por Erro em Documento de Cobrança.

Índice de Reclamação do Serviço.

International Standard Audiovisual Number.

Integrated Services Digital Broadcasting.

Integrated Services Digital Broadcasting Cable.

Integrated Services Digital Broadcasting Satellite Television. 
ISDB-T

ISDTV

ISO

ISP

ISRA

ISS

IST

ISYDS

ITI

ITU

1

LAN

LaPCom

LBS

LDI

LDN

LED

LEP

LF

LGT

LIBRAS

LLU

LRGP

LRIC

LSI

LSZH

LTE

LTOG

MAN

MdE

MERCOSUL

MF

MICS

MIN

MMDS

MMS

MNO

MOS
Integrated Services Digital Broadcasting Terrestrial (Serviços Integrados de Radiodifusão Digital Terrestre).

International System for Digital TV (novo nome do SBTVD).

International Standards Organisation.

Internet Service Provider (vide PSCI).

Índice de Solicitações de Reparos Atendidas.

Imposto sobre Serviços de Qualquer Natureza.

Índice de Serviços de Telecomunicações.

Integrated System for Decision Support (vide SIAD).

Instituto Nacional de Tecnologia da Informação (Autarquia vinculada à Casa Civil da Presidência da República).

International Telecommunication Union (União Internacional de Telecomunicações).

Comprimento de Onda.

Local Area Network.

Laboratório de Políticas de Comunicação da UnB.

Location Based Services.

Longa Distância Internacional.

Longa Distância Nacional.

Light Emitting Diode (Diodo Emissor de Luz).

Lei de Execuções Penais.

Low Frequency.

Lei Geral de Telecomunicações.

Língua Brasileira de Sinais.

Local Loop Unbundling.

Loudness Rating Guard-Ring Position.

Long Run Incremental Costs (Custos Incrementais de Longo Prazo).

Laboratório de Sistemas Integráveis da USP.

"Low Smoke and Zero Halogen".

Long Term Evolution (Rede Celular 3G).

Lista Telefônica Obrigatória e Gratuita.

Metropolitan Area Network.

Memorando de Entendimento - MdE.

Mercado Comum do Sul.

Medium Frequency (Média Freqüiência).

Sistemas de Comunicações de Implantes Médicos.

Valor do Minuto de Tarifação (Serviço Telefônico Fixo Comutado).

Multichannel Multipoint Distribution Service (Serviço de Distribuição de Sinais Multiponto Multicanal).

Multimedia Message.

Mobile Network Operator (Operador de Rede Móvel).

Mean Opinion Score (Pontuação Média de Opinião). 
MSCID

MVNO

NBM

NC

$\mathrm{NCM}$

NFST

NGN

NGT

NOPRED

NRA

NSR

NUDEC

NWA

OCC

OCD

OCDE

OECD

OFDM

OFDMA

OIT

OL

OM

OMC

OPGW

OT

OTI

P\&D

PAC

PAC

PADIS

PADO

PASEP

PASI

PASOO

PAT
Mobile Switching Center Identification.

Mobile Virtual Network Operator (Operador de Rede Virtual Móvel). Nomenclatura Brasileira de Mercadorias.

Noise Criteria.

Nomenclatura Comum do Mercosul.

Nota Fiscal de Serviço de Telecomunicações.

Next Generation Network.

Norma Geral de Telecomunicações (Ministério das Comunicações).

Notificação Preliminar de Desastres - Formulário (Sistema Nacional de Defesa Civil).

National Regulatory Authorities (União Européia).

Nível do Sinal Recebido.

Núcleo Comunitário de Defesa Civil (Sistema Nacional de Defesa Civil).

Nomadic Wireless Access (Aplicação Nomádica).

Organismo de Certificação Credenciado.

Organismo de Certificação Designado.

Organização para Cooperação e Desenvolvimento Econômico.

Organisation for Economic Co-operation and Development (Organização para Cooperação e Desenvolvimento Econômico).

Orthogonal Frequency Division Multiplexing (Multiplexação Ortogonal por Divisão de Freqüência).

Orthogonal Frequency-Division Multiple Access.

Oxidative Induction Time (Tempo de Indução Oxidativa).

Oscilador Local.

Onda Média.

Organização Mundial do Comércio.

Optical Ground Wire (Cabos Pára-raios com Fibras Ópticas).

Onda Tropical.

Organización de Televisión Iberoamericana.

Pesquisa e Desenvolvimento.

Plano Anual de Capacitação (Capacitação Profissional nas Agências Reguladoras).

Programa de Aceleração do Crescimento (Programa de Governo de Janeiro de 2007).

Programa de Apoio ao Desenvolvimento Tecnológico da Indústria de Semicondutores.

Procedimento Administrativo para Apuração de Descumprimento de Obrigações (Agência Nacional de Telecomunicações).

Programa de Formação do Patrimônio do Servidor Público.

Provedor de Acesso a Serviços de Internet.

Plano Alternativo de Serviço de Oferta Obrigatória.

Parcela Adicional de Transição. 
PATVD

PATVD

PBFM

PBOC

PBOM

PBOT

PBRTV

PBTV

PBTVA

PBTVD

PBX

PCNR

PDE

PDP

PEP

PGA

PGA-SME

PGA-SMP

PGCN

PGMC

PGMQ

PGMQ-2006

PGMQ-SMP

PGMU

PGMU-2006

PGO

PGR

PICT

PIS

PLC

PMD
Programa de Apoio ao Desenvolvimento Tecnológico da Indústria de Equipamentos para a TV Digital.

Programa de Incentivos ao Setor da TV Digital (Integrante do PAC).

Plano Básico de Distribuição de Canais de Radiodifusão Sonora em Frequiência Modulada.

Plano Básico de Distribuição de Canais de Radiodifusão Sonora em Ondas Curtas.

Plano Básico de Distribuição de Canais de Radiodifusão Sonora em Onda Média.

Plano Básico de Distribuição de Canais de Radiodifusão Sonora em Onda Tropical.

Plano Básico de Distribuição de Canais de Retransmissão de Televisão em VHF e UHF.

Plano Básico de Distribuição de Canais de Televisão em VHF e UHF. Plano Básico de Distribuição de Canais de Televisão por Assinatura.

Plano Básico de Distribuição de Canais de Televisão Digital.

Private Branch Exchange.

Parcela de Custo Não Recuperável pela Exploração Eficiente do Serviço (Fundo de Universalização dos Serviços de Telecomunicações).

Plano de Desenvolvimento da Educação.

Plasma Display Pannel (Painel Mostrador de Plasma).

Peak Envelope Power (Potência de Pico da Envoltória).

Plano Geral de Autorizações.

Plano Geral de Autorizações do Serviço Móvel Especializado.

Plano Geral de Autorizações do Serviço Móvel Pessoal.

Plano Geral de Códigos Nacionais.

Plano Geral de Metas de Competição.

Plano Geral de Metas de Qualidade.

Plano Geral de Metas de Qualidade do STFC para a Renovação dos Contratos de Concessão.

Plano Geral de Metas de Qualidade para o Serviço Móvel Pessoal.

Plano Geral de Metas de Universalização.

Plano Geral de Metas para Universalização do STFC no Regime Público para a Renovação dos Contratos de Concessão.

Plano Geral de Outorgas.

Plano Geral de Atualização da Regulamentação das Telecomunicações no Brasil.

Projeto de Proteção da Infraestrutura Crítica de Telecomunicações (Anatel e CPqD).

Programa de Integração Social.

Power Line Communication.

Polarization Mode Dispersion (Modo de Polarização por Dispersão) (Cabo de Fibra Óptica). 
PMM

PMS

POI

POP

PP

PPA

PPB

PPDESS

PPDF

PPDUR

ppm

PPP

PR

PRB

PRO-REG

PROCON

PROINFO

PROM

PRRadCom

PSCI

PST

PTR

PTT

PUC

PVR

RadCom

RBR

RBT

RDSI

RDSI-FE

RDSI-FL

$\mathrm{RE}$

RECAP

REDEC

REGISTRO.br
Período de Maior Movimento (Televisão por Assinatura (Gênero)). Poder de Mercado Significativo.

Ponto de Interconexão.

Post Office Protocol (INTERNET).

Conferência de Plenipotenciários da UIT.

Plano Plurianual.

Processo Produtivo Básico.

Preço Público pelo Direito de Exploração do Serviço.

Previsão de Demanda e Dados Físicos (Separação e Alocação de Contas).

Preço Público pelo Direito de Uso de Radiofreqüencias.

partes por milhão.

Parceria Público-Privada.

Perda de Retorno.

Ponto de Referência da Boca.

Programa de Fortalecimento da Capacidade Institucional para Gestão em Regulação.

Promotoria de Defesa do Consumidor.

Programa Nacional de Informática na Educação.

Plano Regional de Distribuição de Canais de Radiodifusão Sonora em Onda Média ou Plano do Rio de Janeiro (Radiodifusão Sonora).

Plano de Referência para Distribuição de Canais do Serviço de Radiodifusão Comunitária.

Provedor de Serviço de Conexão à INTERNET.

Posto de Serviço de Telecomunicações.

Ponto de Terminação de Rede.

Ponto de Troca de Tráfego (Internet).

Prestação, Utilidade ou Comodidade (Serviço Telefônico Fixo Comutado).

Personal Video Recorder.

Serviço de Radiodifusão Comunitária.

Relação de Bens Reversíveis.

Rede Brasil de Tecnologia.

Rede Digital de Serviços Integrados.

Rede Digital de Serviços Integrados - Faixa Estreita.

Rede Digital de Serviços Integrados - Faixa Larga.

Recurso Extraordinário (Jurisdição).

Regime Especial de Aquisição de Bens de Capital para Empresas Exportadoras.

Regional Estadual de Defesa Civil (Sistema Nacional de Defesa Civil).

Registro de Domínios para a Internet no Brasil (Comitê Gestor da Internet no Brasil). 
REGULATEL

REPES

RF

RFID

RGP

RIQ

RITU

RLL

RNI

RNP

RNR

RPF

RpTV

RR

RRD

RSAC

RSQ

RTV

RVU-M

SA

SAC

SAC

SACP

SAM

SAMU

SAP

SAPN

SAR

SARC

SATVA

SBC

SBTVD

SBTVD-T

SCI

SCM

SCMa
Foro Latino-Americano de Autoridades Reguladoras das Telecomunicações.

Regime Especial de Tributação para a Plataforma de Exportação de Serviços de Tecnologia da Informação.

Radiofrequência.

Radio Frequency Identification Device (Sistema de Identificação por Radiofreqüência).

Regulamento Geral de Portabilidade.

Regulamento de Indicadores de Qualidade do Serviço Telefônico Fixo Comutado.

Rede de Intercâmbio de Televisão Universitária.

Radio in the Local Loop.

Radiação Não Ionizante (Campo Eletromagnético).

Rede Nacional de Pesquisa.

Rede Nacional de Radiovideometria.

Request for Proposal.

Serviço de Repetição de Televisão.

Regulamento de Radiocomunicações da UIT.

Restricted Radiation Device.

Regulamento de Separação e Alocação de Contas.

Raiz quadrada da soma dos quadrados.

Serviço de Retransmissão de Televisão.

Valor de Referência de VU-M.

Specific Absorption (Absorção Específica).

Serviço de Atendimento ao Consumidor.

Stand Alone Cost (Custo Total Individual - Separação e Alocação de Contas).

Sistema de Acompanhamento de Consulta Pública.

Serviço Avançado de Mensagens.

Serviço de Atendimento Móvel de Urgência.

Secondary Audio Programming (Programa Secundário de Áudio).

Sistema de Administração dos Recursos de Numeração.

Specific Absorption Rate (Taxa de Absorção Específica).

Serviço Auxiliar de Radiodifusão e Correlatos.

Sistema de Acompanhamento das Obrigações das Prestadoras de TV por Assinatura.

Sistema Brasileiro de Certificação.

Sistema Brasileiro de Televisão Digital.

Sistema Brasileiro de Televisão Digital Terrestre.

Serviço de Conexão à INTERNET.

Serviço de Comunicação Multimídia.

Serviço de Comunicação de Massa por assinatura. 
SCR

SDE

SEAE

SECEX

SEDH

SEFID

SELIC

SER

SETA

SGAL

SGB

SGIQ

SGME

SGT.1

SHF

SI

SIAD

SIAFI

SICOM

SIG

SINAMOB

SINAPI/IBGE

SINAR

SINCAB

SINDEC

SINDER

SINDESB

SINDISAT

SINDITELEBRASIL

SINSTAL
Serviço de Comunicações de Interesse Restrito.

Secretaria de Direito Econômico (Ministério da Justiça).

Secretaria de Acompanhamento Econômico (Ministério da Fazenda).

Secretaria de Controle Externo (Tribunal de Contas da União).

Secretaria Especial de Direitos Humanos da Presidência da República.

Secretaria de Fiscalização de Desestatização (Tribunal de Contas da União).

Sistema Especial de Liquidação e Custódia.

Serviço Especial de Radiochamada.

Sindicato Nacional das Empresas Operadoras de Sistemas de Televisão por Assinatura (Representação empresarial).

Sistema de Gerenciamento de Áreas Locais.

Sistema Geoestarcionário Brasileiro.

Sistema de Gerenciamento de Indicadores de Qualidade.

Sistema de Gestão e Monitoragem do Espectro.

Subgrupo de Trabalho $n^{\circ} 1$ - Comunicações do Mercosul.

Super High Frequency.

Sociedade da Informação.

Sistema Integrado de Apoio à Decisão (Programa para obtenção dos Valores de Eficiência DEA).

Sistema Integrado de Administração Financeira do Governo Federal.

Sistema de Comunicação de Governo do Poder Executivo (Publicidade da Administração Pública Federal).

Sistema de Informações Geográficas do Brasil.

Sistema Nacional de Mobilização.

Sistema Nacional de Pesquisa de Custos e Índices da Construção Civil.

Sistema Nacional de Arquivos.

Sindicato Nacional dos Trabalhadores em Sistemas de TV por Assinatura e Serviços Especiais de Telecomunicações (Representação profissional).

Sistema Nacional de Defesa Civil.

Sindicato Nacional das Empresas de Radiocomunicações (Representação empresarial).

Sistema de Informações sobre Desastres no Brasil (Sistema Nacional de Defesa Civil).

Sindicato Nacional das Empresas de Telecomunicações por Satélite (Representação empresarial).

Sindicato Nacional das Empresas Operadoras de Serviços de Telecomunicações (Representação empresarial).

Sindicato Nacional das Empresas Instaladoras de Sistemas e Redes de TV por Assinatura e Telecomunicações (Representação empresarial). 
SINTEIS

SITARWEB

SLD

SLDA

SLDD

SLDT

SLE

SLMP

SMC

SMD

SME

SMGS

SMP

SMS

SMT

SNDC

SPV

SRA

SRD

SRTT

SSB

STE

STEL

STF

STFC

STJ

STM

STP

STS

SUFRAMA

SVA

TAB

TAP

TAP

TAP

TBSMC

TCD

TCP
Sindicatos Estaduais dos Trabalhadores em Telecomunicações (Representação profissional).

Sistema de Informações Técnicas para Administração das Radiocomunicações WEB.

Serviço por Linha Dedicada.

Serviço por Linha Dedicada para Sinais Analógicos.

Serviço por Linha Dedicada para Sinais Digitais.

Serviço por Linha Dedicada para Sinais Telegráficos.

Serviço Limitado Especializado.

Serviço Limitado Móvel Privativo.

Serviço Móvel Celular.

Surface Mounted Device.

Serviço Móvel Especializado.

Serviço Móvel Global por Satélite.

Serviço Móvel Pessoal.

Short Message Service.

Surface Mounted Technology.

Sistema Nacional de Defesa do Consumidor.

Superintendência de Serviços Privados.

Serviço de Radiocomunicação Aeronáutica Público-Restrito.

Short Range Device.

Serviço de Rede de Transporte de Telecomunicações.

Single Side Band 'Modulation' (Modulação em Faixa Lateral Simples).

Secretaria de Telecomunicações (Ministério das Comunicações).

Sistema de Serviços de Telecomunicações.

Supremo Tribunal Federal.

Serviço Telefônico Fixo Comutado Destinado ao Uso do Público em Geral.

Superior Tribunal de Justiça.

Superior Tribunal Militar.

Serviço Telefônico Público (em desuso).

Serviço de Transporte de Sinais de Telecomunicações por Satélite.

Superintendência da Zona Franca de Manaus.

Serviço de Valor Adicionado.

Tarifa Aduaneira do Brasil.

Television Association of Programmers (Estados Unidos da América).

Terminal de Acesso Público.

Terminal de Acesso Público (Serviço Telefônico Fixo Comutado).

Tarifa Básica do Serviço Móvel Celular.

Termo de Compromisso de Desempenho.

Transport Control Protocol (INTERNET). 
TCU

TDD

TDMA

TEB

TEC

TelComp

TelComp

TELEBRÁS

TELEBRASIL

TELEX

TFEL

TFF

TFI

TICs

TIPI

TME

TOE

TR

TRD

TRF

TRF1

TRI

TRX

TSC

TSE

TST

TT

TU

TU-COM

TU-M

TU-RIU

TU-RIU1

TU-RIU2

TU-RL

TUP

TVA

UAC
Tribunal de Contas da União.

Time Division Duplexing (Duplexação por Divisão no Tempo).

Time Division Multiple Access (Múltiplo Acesso por Divisão de Tempo).

Taxa de Erro de Bits.

Tarifa Externa Comum.

Associação Brasileira das Prestadoras de Serviços de Telecomunicações Competitivas.

Associação das Prestadoras de Serviços de Telecomunicações Competitivas.

Telecomunicações Brasileiras S.A..

Associação Brasileira de Telecomunicações.

Comutação Telegráfica.

Thin-Film Electroluminescent (Displays Eletroluminescentes a Filme Fino).

Taxa de Fiscalização do Funcionamento.

Taxa de Fiscalização da Instalação.

Tecnologias de Informação e Comunicação.

Tabela de Incidência do Imposto sobre Produtos Industrializados.

Tarifa de Mudança de Endereço (Serviço Telefônico Fixo Comutado).

Taxa de Onda.

Taxa Referencial.

Taxa Referencial Diária.

Tribunal Regional Federal.

Tribunal Regional Federal da $1^{\mathrm{a}}$ Região.

Termo de Responsabilidade de Instalação.

Transceptor.

Terminal Móvel de Acesso a Ser Certificado.

Tribunal Superior Eleitoral.

Tribunal Superior do Trabalho.

Tronco/Canal Telefônico de Entrada.

Tarifa de Uso.

Tarifa de Uso de Comutação.

Tarifa de Uso Móvel.

Tarifa de Uso de Rede Interurbana.

Tarifa de Uso de Rede Interurbana Nível 1.

Tarifa de Uso de Rede Interurbana Nível 2.

Tarifa de Uso de Rede Local.

Telefone de Uso Público (Serviço Telefônico Fixo Comutado).

Serviço Especial de Televisão por Assinatura.

Unidade de Atendimento de Cooperativa. 
UCS

UHF

UIT

UIT-R

UMB

UMTS

UNE-P

UNICEF

UO

UPS

URA

URV

USG

UTP

UTRAN

UWB

$\mathrm{VC}$

VC-T

VC-VST-R

$\mathrm{VC} 1$

VCA

VELOX

VHF

VIGP

VLF

VSAT

VSWR

VTP

VU-M

VU-M

VU-T

WACC

WAN

WAP
Unidade de Controle do Sistema (Sistemas de Acesso sem Fio do STFC).

Ultra High Frequency (Frequiência Ultra Alta).

União Internacional de Telecomunicações (Union Internationale des Télécommunications / Unión Internacional de Telecommunicaciones).

Setor de Radiocomunicações da União Internacional de Telecomunicações.

Ultra Mobile Broadband.

Universal Mobile Telecommunications Service (Rede celular 3G).

Desagregação de Plataforma.

United Nations Children's Fund (Fundo das Nações Unidas para a Infância).

Unidade Operacional.

Uninterruptable Power Supply.

Unidade Remota de Assinante.

Unidade Real de Valor.

Unidade de Supervisão e Gerência (Sistemas de Acesso sem Fio do STFC).

Unidade de Tarifação para TUP e TAP (Serviço Telefônico Fixo Comutado).

Universal Terrestrial Radio Access Network.

Ultrawideband.

Valor de Comunicação (Serviço Telefônico Fixo Comutado).

Valor de Comunicação (Serviço Móvel Especializado).

Valor de Comunicação do Visitante em Roaming.

Valor de Comunicação 1 (Serviço Móvel Pessoal).

Valor de Chamada Atendida (Serviço Telefônico Fixo Comutado).

Serviço de acesso à internet de banda larga comercializado pela empresa Oi.

Very High Frequency (Frequiência Muito Alta).

Variação do Índice Geral de Preços - Disponibilidade Interna.

Very Low Frequency.

Very Small Aperture Terminal (Certificação).

Relação de Onda Estacionária.

Valor da Unidade de Tarifação para TUP e TAP (Serviço Telefônico Fixo Comutado).

Valor de Remuneração de Uso de Rede do SMP.

Valor de Uso de Rede Móvel.

Valor de Remuneração de Uso de Rede do SME.

Weighted Average Cost of Capital (Custo Médio Ponderado de Capital na Separação e Alocação de Contas).

Wide Area Network.

Wireless Application Protocol. 
WCDMA

WDM

WDMA

Wi-Fi

WIMAX

WiMesh

WISP

WLAN

WLL

WMAN

$\mathrm{xDSL}$
Wideband CDMA (CDMA de banda larga).

Wavelength Division Multiplexing (Multiplexação por Divisão de Comprimento de Onda).

Wavelegth Division Multiple Access (Acesso Múltiplo por Divisão de Comprimento de Onda).

Wireless Fidelity (padrão IEEE 802.11).

Worldwide Interoperability for Microwave Access.

WiMesh - Wireless Mesh.

Wireless Internet Service Provider.

Wireless Local Area Network.

Wireless Local Loop (Rede Local sem Fio).

Wireless Metropolitan Area Network.

x Digital Subscriber Line. 


\title{
Normas, Julgados e Atos de 2008
}

\section{Infraestrutura e Recursos do Setor de Telecomunicações}

\author{
Infraestrutura de Telecomunicações
}

\section{Compartilhamento de Infraestrutura}

Normatização

Decreto $\mathbf{n}^{\mathbf{0}}$ 6.654, de 20 de novembro de 2008 - Aprova o Plano Geral de Outorgas de Serviço de Telecomunicações prestado no regime público.

$\hookrightarrow$ Anexo 1 - Regiões do Plano Geral de Outorgas.

$\hookrightarrow$ Anexo 2 - Setores das Regiões do Plano Geral de Outorgas.

Portaria MC $\mathbf{n}^{0}$ 178, de 22 de abril de 2008 - Dispõe sobre diretrizes para implementação das políticas públicas em telecomunicações.

Resolução da ANTT no 2.552, de 14 de fevereiro de 2008 - Dispõe sobre a captação de receitas extraordinárias nas rodovias federais reguladas pela ANTT.

\section{Bem Público (utilização e restrição)}

Jurisprudência

Superior Tribunal de Justiça - Medida Cautelar no 13406 (STJ - MC 13406 / SP - São Paulo) - Relator: Min. Eliana Calmon - Segunda Turma do STJ Unânime - j. 16/10/2008 - Diário da Justiça, Seção 1, 07/11/2008. [Descrição do Caso] [Catalogação de Patrick Faria ]

Discussão sobre a legalidade de taxa instituída pelo município de São Paulo pela instalação de fios e cabos usados por empresas de telecomunicações no perímetro do sistema viário de sua área. Decisão unânime da $2^{\mathrm{a}}$ Turma do STJ no sentido de, primeiro, admitir a medida cautelar para conferir efeito suspensivo ao recurso especial pendente de admissibilidade na origem; posteriormente, julgar procedente o pedido cautelar, uma vez que configurado o fumus bonis iuris e o periculum in mora. $\mathrm{O}$ fumus bonis iuris, em razão do próprio dissídio jurisprudencial em que se assenta a admissibilidade do recurso, havendo precedentes no STJ no sentido da ilegalidade da cobrança por não deter esta natureza de preço público tampouco de taxa. O periculum in mora, tendo em vista que, caso a taxa seja considerada legal, acarretará o pagamento de vultosas quantias, fato que resultará em danos de difícil reparação. 


\title{
Redes de Telecomunicações
}

\author{
Normatização
}

Decreto $\mathbf{n}^{\circ}$ 6.654, de 20 de novembro de 2008 - Aprova o Plano Geral de Outorgas de Serviço de Telecomunicações prestado no regime público.

$\hookrightarrow$ Anexo 1 - Regiões do Plano Geral de Outorgas.

$\hookrightarrow$ Anexo 2 - Setores das Regiões do Plano Geral de Outorgas.

Resolução da ANATEL no 516, de 30 de outubro de 2008 - Aprova o Plano Geral de Atualização da Regulamentação das Telecomunicações no Brasil (PGR).

$\hookrightarrow$ Anexo - Plano Geral de Atualização da Regulamentação das Telecomunicações no Brasil (PGR).

$\checkmark$ Inscrição da ampliação do uso de serviços e redes de telecomunicações como princípio regulatório.

\section{Equipamentos de Telecomunicações}

\section{Normatização}

Decreto $\mathrm{n}^{\circ}$ 6.654, de 20 de novembro de 2008 - Aprova o Plano Geral de Outorgas de Serviço de Telecomunicações prestado no regime público.

$\hookrightarrow$ Anexo 1 - Regiões do Plano Geral de Outorgas.

$\hookrightarrow$ Anexo 2 - Setores das Regiões do Plano Geral de Outorgas.

Resolução da ANATEL $\mathbf{n}^{\circ}$ 506, de $1^{\circ}$ de julho de 2008 - Republica o Regulamento sobre Equipamentos de Radiocomunicação de Radiação Restrita.

$\hookrightarrow$ Anexo - Regulamento sobre Equipamentos de Radiocomunicação de Radiação Restrita.

$\checkmark$ Os equipamentos de radiocomunicação de radiação restrita, em regra, independem de autorização de uso de radiofreqüiência e de licenciamento para instalação e funcionamento de estação.

\section{Antenas}

\section{Normatização}

Resolução da ANATEL no 504, de 14 de maio de 2008 - Alteração do Regulamento Sobre Canalização e Condições de Uso da Faixa de Radiofreqüências de $6.430 \mathrm{MHz}$ a $7.110 \mathrm{MHz}$.

$\hookrightarrow$ Anexo - Regulamento Sobre Canalização e Condições de Uso da Subfaixa de Radiofreqüências de $6.430 \mathrm{MHz}$ a $7.110 \mathrm{MHz}$

Autorizada a utilização de antenas com polarização vertical, horizontal ou dupla na faixa de radiofrequiências de $6.430 \mathrm{MHz}$ a $7.110 \mathrm{MHz}$ por sistemas digitais de radiocomunicação do serviço fixo, desde que utilizem arranjos com 
diferentes polarizações, alternadamente, para canais de radiofreqüências adjacentes conforme especificação do Regulamento.

Resolução da ANATEL $n^{\circ}$ 506, de $1^{\circ}$ de julho de 2008 - Republica o Regulamento sobre Equipamentos de Radiocomunicação de Radiação Restrita. $\hookrightarrow$ Anexo - Regulamento sobre Equipamentos de Radiocomunicação de Radiação Restrita.

$\checkmark \mathrm{O}$ uso de antenas alternativas às fornecidas com o equipamento de radiação restrita é vedado pela regulamentação da ANATEL.

Resolução da ANATEL $\mathbf{n}^{\circ}$ 511, de $1^{\circ}$ de setembro de 2008 - Aprova o Regulamento de Controle das Zonas de Proteção das Áreas Adjacentes às Estações de Telecomunicações sob responsabilidade da ANATEL.

$\hookrightarrow$ Anexo - Regulamento de Controle das Zonas de Proteção das Áreas Adjacentes às Estações de Telecomunicações sob responsabilidade da Anatel.

$\hookrightarrow$ Anexo 1 - Solicitação de Assentimento: Autorização para Aproveitamento do Solo em Área do Plano de Zona de Proteção.

$\hookrightarrow$ Anexo 2 - Formulário de Requerimento de Certidão Prévia de Gabarito.

$\hookrightarrow$ Anexo 3 - Modelos de Carimbo de Assentimento.

$\hookrightarrow$ Anexo 4 - Carimbos de Assentimento com Restrições e Prazos de Validade.

$\hookrightarrow$ Anexo 5 - Carimbo de Não-Assentimento.

$\hookrightarrow$ Anexo 6 - Carimbos de Certidão de Gabarito.

$\hookrightarrow$ Anexo 7 - Ofício de encaminhamento da documentação, com a decisão da ANATEL, à Prefeitura Municipal.

$\hookrightarrow$ Anexo 8 - Regulamento de Proteção de Sítios de Radiomonitoragem: Fluxograma de Atividades.

$\hookrightarrow$ Anexo 9 - Relações das Estações do SGME.

Resolução da ANATEL no 514, de 7 de outubro de 2008 - Aprova a alteração do Regulamento Técnico para Prestação do Serviço de Radiodifusão Sonora em Onda Média e em Onda Tropical (faixa de $120 \mathrm{~m}$ ).

$\hookrightarrow$ Anexo - Alteração do Regulamento Técnico para Prestação do Serviço de Radiodifusão Sonora em Onda Média e em Onda Tropical (faixa de 120 m), aprovado pela Resolução no 116, de 25 de março de 1999.

\section{Estações de Telecomunicações}

\section{Normatização}

Resolução da ANATEL $\mathbf{n}^{\circ}$ 506, de $1^{\circ}$ de julho de 2008 - Republica o Regulamento sobre Equipamentos de Radiocomunicação de Radiação Restrita.

$\hookrightarrow$ Anexo - Regulamento sobre Equipamentos de Radiocomunicação de Radiação Restrita. 
$\checkmark$ Os equipamentos de radiocomunicação de radiação restrita, em regra, independem de autorização de uso de radiofrequiência e de licenciamento para instalação e funcionamento de estação.

Resolução da ANATEL $\mathbf{n}^{\circ}$ 511, de $1^{\circ}$ de setembro de 2008 - Aprova o Regulamento de Controle das Zonas de Proteção das Áreas Adjacentes às Estações de Telecomunicações sob responsabilidade da ANATEL.

$\hookrightarrow$ Anexo - Regulamento de Controle das Zonas de Proteção das Áreas Adjacentes às Estações de Telecomunicações sob responsabilidade da Anatel.

$\hookrightarrow$ Anexo 1 - Solicitação de Assentimento: Autorização para Aproveitamento do Solo em Área do Plano de Zona de Proteção.

$\hookrightarrow$ Anexo 2 - Formulário de Requerimento de Certidão Prévia de Gabarito.

$\hookrightarrow$ Anexo 3 - Modelos de Carimbo de Assentimento.

$\hookrightarrow$ Anexo 4 - Carimbos de Assentimento com Restrições e Prazos de Validade.

$\hookrightarrow$ Anexo 5 - Carimbo de Não-Assentimento.

$\hookrightarrow$ Anexo 6 - Carimbos de Certidão de Gabarito.

$\hookrightarrow$ Anexo 7 - Ofício de encaminhamento da documentação, com a decisão da ANATEL, à Prefeitura Municipal.

$\hookrightarrow$ Anexo 8 - Regulamento de Proteção de Sítios de Radiomonitoragem: Fluxograma de Atividades.

$\hookrightarrow$ Anexo 9 - Relações das Estações do SGME.

Resolução da ANATEL no 514, de 7 de outubro de 2008 - Aprova a alteração do Regulamento Técnico para Prestação do Serviço de Radiodifusão Sonora em Onda Média e em Onda Tropical (faixa de $120 \mathrm{~m}$ ).

$\hookrightarrow$ Anexo - Alteração do Regulamento Técnico para Prestação do Serviço de Radiodifusão Sonora em Onda Média e em Onda Tropical (faixa de 120 m), aprovado pela Resolução no 116, de 25 de março de 1999.

\section{Terminais}

\section{Normatização}

Portaria Interministerial $\mathbf{n}^{\circ}$ 23, de 29 de janeiro de 2008 [ Revogado por: Portaria Interministerial $n^{\circ} 236 / 2008$ ] - Altera a Portaria Interministerial n. 236, de 6 de dezembro de 2007, referente ao Processo Produtivo Básico de Terminal Portátil de Telefonia Celular industrializado na Zona Franca de Manaus.

Portaria Interministerial $\mathbf{n}^{\mathbf{0}}$ 29, de 29 de janeiro de 2008 - Altera a Portaria Interministerial n. 237, de 6 de dezembro de 2007, referente ao Processo Produtivo Básico de Terminal Portátil de Telefonia Celular.

Portaria Interministerial $n^{\circ}$ 236, de 29 de dezembro de 2008 - Estabelece o Processo Produtivo Básico de Terminal Portátil de Telefonia Celular 
industrializado na Zona Franca de Manaus, dispõe sobre metas de produção e dá outras providências.

$\hookrightarrow$ Anexo 1 - Fabricação do conversor de corrente contínua (CA-CC) ou carregador de bateria para telefone celular.

$\hookrightarrow$ Anexo 2 - Fabricação do transformador elétrico de potência não superior a 3KVA, com núcleo de pó ferromagnético.

$\hookrightarrow$ Anexo 3 - Fabricação dos fios e cabos com conectores destinados a conversor e carregador de bateria para celular.

Portaria Interministerial $n^{\circ}$ 237, de 29 de dezembro de 2008 - Estabelece o Processo Produtivo Básico de Terminal Portátil de Telefonia Celular, dispõe sobre metas de produção e dá outras providências.

$\hookrightarrow$ Anexo 1 - Fabricação do conversor de corrente contínua (CA-CC) ou carregador de bateria para telefone celular.

$\hookrightarrow$ Anexo 2 - Fabricação do transformador elétrico de potência não superior a 3KVA, com núcleo de pó ferromagnético.

$\hookrightarrow$ Anexo 3 - Fabricação dos fios e cabos com conectores destinados a conversor e carregador de bateria para celular.

Resolução da ANATEL $\mathbf{n}^{\circ}$ 506, de $1^{\circ}$ de julho de 2008 - Republica o Regulamento sobre Equipamentos de Radiocomunicação de Radiação Restrita.

$\hookrightarrow$ Anexo - Regulamento sobre Equipamentos de Radiocomunicação de Radiação Restrita.

$\checkmark$ O telefone sem fio conectado à rede telefônica pública comutada é considerado equipamento de radiocomunicação de radiação restrita e, portanto, independe de outorga de autorização de uso de radiofrequiência e de licenciamento para instalação e funcionamento, bem como opera em caráter secundário sem direito à proteção contra interferência prejudicial, inclusive de estações do mesmo tipo, e não podem causar interferências a sistemas operando em caráter primário.

Resolução da ANATEL $\mathbf{n}^{\circ}$ 509, de 14 de agosto de 2008 - Aprova o Regulamento da Central de Intermediação de Comunicação Telefônica a ser utilizada por pessoas com deficiência auditiva ou da fala - CIC.

$\hookrightarrow$ Anexo - Regulamento da Central de Intermediação de Comunicação Telefônica a ser Utilizada por Pessoas com Deficiência Auditiva ou da Fala - CIC.

Resolução da ANATEL n 512, de 23 de setembro de 2008 - Aprova a Norma para Certificação e Homologação da Interface Analógica de Adaptadores para Terminal de Assinante.

$\hookrightarrow$ Anexo - Norma para Certificação e Homologação da Interface Analógica de Adaptadores para Terminal de Assinante. 


\title{
Certificação / Homologação
}

\author{
Normatização
}

Resolução da ANATEL n 492, de 19 de fevereiro de 2008 - Aprova a Norma para Certificação e Homologação de Transmissores e Transceptores Digitais para o Serviço Fixo em Aplicações Ponto-Multiponto nas Faixas de Freqüências acima de $1 \mathrm{GHz}$.

$\hookrightarrow$ Anexo - Norma para Certificação e Homologação de Transmissores e Transceptores Digitais para o Serviço Fixo em Aplicações Ponto-Multiponto nas Faixas de Freqüências acima de $1 \mathrm{GHz}$.

Resolução da ANATEL n 498, de 27 de março de 2008 - Norma para Certificação e Homologação de Transmissores e Retransmissores para o Sistema Brasileiro de Televisão Digital Terrestre.

$\hookrightarrow$ Anexo - Norma para Certificação e Homologação de Transmissores e Retransmissores para o Sistema Brasileiro de Televisão Digital Terrestre.

Resolução da ANATEL $\mathbf{n}^{\circ}$ 506, de $1^{\circ}$ de julho de 2008 - Republica o Regulamento sobre Equipamentos de Radiocomunicação de Radiação Restrita. $\hookrightarrow$ Anexo - Regulamento sobre Equipamentos de Radiocomunicação de Radiação Restrita.

$\checkmark$ É exigido dos equipamentos de radiocomunicação de radiação restrita certificação emitida pela ANATEL de reconhecimento da condição de radiação restrita.

Resolução da ANATEL n 512, de 23 de setembro de 2008 - Aprova a Norma para Certificação e Homologação da Interface Analógica de Adaptadores para Terminal de Assinante.

$\hookrightarrow$ Anexo - Norma para Certificação e Homologação da Interface Analógica de Adaptadores para Terminal de Assinante.

\section{Espectro de Radiofrequencia}

\section{Normatização}

Resolução da ANATEL $\mathbf{n}^{\circ}$ 506, de $1^{\circ}$ de julho de 2008 - Republica o Regulamento sobre Equipamentos de Radiocomunicação de Radiação Restrita.

$\hookrightarrow$ Anexo - Regulamento sobre Equipamentos de Radiocomunicação de Radiação Restrita.

Os equipamentos de radiocomunicação de radiação restrita, em regra, independem de autorização de uso de radiofreqüência e de licenciamento para instalação e funcionamento de estação. 


\title{
Destinação, Atribuição e Designação de Radiofrequência
}

\author{
Normatização
}

Resolução da ANATEL $\mathbf{n}^{\circ}$ 495, de 24 de março de 2008 - Aprova o Regulamento sobre Canalização e Condições de Uso da Faixa de Radiofreqüências de $5 \mathrm{GHz}$.

$\hookrightarrow$ Anexo - Regulamento sobre Canalização e Condições de Uso da Faixa de Radiofreqüências de $5 \mathrm{GHz}$.

Resolução da ANATEL no 497, de 27 de março de 2008 - Destina a faixa de radiofreqüências de $2.400 \mathrm{MHz}$ a $2.483,5 \mathrm{MHz}$ para uso, em caráter secundário, por sistemas do Serviço Limitado Privado.

Resolução da ANATEL n ${ }^{0}$ 501, de 10 de abril de 2008 - Revoga a Resolução $\mathrm{n}^{\circ} 227$, de 21 de junho de 2000, que destina as faixas de freqüências de 1710 a $1755 \mathrm{MHz}, 1775$ a $1785 \mathrm{MHz}, 1805$ a $1850 \mathrm{MHz}$ e 1870 a $1880 \mathrm{MHz}$ para implantação de sistemas de telecomunicações móveis terrestres e as faixas de frequiências de 1885 a $1900 \mathrm{MHz}, 1950$ a $1980 \mathrm{MHz}$ e 2140 a $2170 \mathrm{MHz}$ para a implantação de sistemas de telecomunicações móveis que sigam as especificações IMT-2000 da UIT.

$\checkmark$ A Resolução 454/2006 regulou o uso de todas as faixas de frequiência do serviço móvel abstendo-se de disciplinar a tecnologia a ser utilizada. A revogação da Resolução 227/2000 uniformiza o tratamento regulatório sem restrição tecnológica nas faixas de frequiência de telefonia móvel.

Resolução da ANATEL n ${ }^{\circ}$ 510, de 28 de agosto de 2008 - Atribui a Faixa de Radiofrequiências de $216 \mathrm{MHz}$ a $220 \mathrm{MHz}$ adicionalmente ao Serviço Móvel, em caráter secundário, destina a Faixa de Radiofrequiências de $217 \mathrm{MHz}$ a 218 $\mathrm{MHz}$ ao Serviço Limitado Privado (SLP) e ao Serviço Limitado Especializado (SLE), em caráter secundário, e aprova o Regulamento sobre Canalização e Condições de Uso na faixa de Radiofrequiências de $217 \mathrm{MHz}$ a $218 \mathrm{MHz}$.

$\hookrightarrow$ Anexo - Regulamento sobre Canalização e Condições de Uso na Faixa de Radiofreqüências de $217 \mathrm{MHz}$ a $218 \mathrm{MHz}$.

Resolução da ANATEL $\mathbf{n}^{\circ}$ 515, de 10 de outubro de 2008 - Destina a faixa de radiofrequiências de 143,60 MHz a 143,65 MHz ao Serviço Limitado Privado, para uso em aplicações de Pesquisa Espacial, sentido espaço para Terra.

Resolução da ANATEL $n^{\circ}$ 522, de 3 de dezembro de 2008 - Destina faixas de radiofreqüências para fins exclusivamente militares.

Atos

Ato do Conselho Diretor da ANATEL $\mathbf{n}^{0} \mathbf{1 . 8 0 5}$, de $1^{\circ}$ de abril de 2008 Aprova a Edição 2008 do Plano de Atribuição, Destinação e Distribuição de Faixas de Freqüências no Brasil.

$\hookrightarrow$ Anexo - Plano de Atribuição, Destinação e Distribuição de Faixas de Frequiências no Brasil. 


\section{Condições de Uso de Radiofreqüência e Canalização (Distribuição de Canais)}

\section{Normatização}

Resolução da ANATEL $\mathbf{n}^{\circ}$ 494, de 24 de março de 2008 - Aprova o Regulamento sobre Canalização e Condições de Uso de Radiofreqüências na Faixa de 4,9 GHz.

$\hookrightarrow$ Anexo - Regulamento sobre Canalização e Condições de Uso de Radiofreqüências na Faixa de 4,9 GHz.

$\checkmark$ Destina a faixa de radiofrequiências de $4.940 \mathrm{MHz}$ a $4.990 \mathrm{MHz}$ para Proteção Pública e Situações de Calamidade.

Resolução da ANATEL $n^{0}$ 504, de 14 de maio de 2008 - Alteração do Regulamento Sobre Canalização e Condições de Uso da Faixa de Radiofrequiências de $6.430 \mathrm{MHz}$ a $7.110 \mathrm{MHz}$.

$\hookrightarrow$ Anexo - Regulamento Sobre Canalização e Condições de Uso da Subfaixa de Radiofrequiências de $6.430 \mathrm{MHz}$ a $7.110 \mathrm{MHz}$

Resolução da ANATEL no 510, de 28 de agosto de 2008 - Atribui a Faixa de Radiofrequiências de $216 \mathrm{MHz}$ a $220 \mathrm{MHz}$ adicionalmente ao Serviço Móvel, em caráter secundário, destina a Faixa de Radiofrequiências de $217 \mathrm{MHz}$ a 218 $\mathrm{MHz}$ ao Serviço Limitado Privado (SLP) e ao Serviço Limitado Especializado (SLE), em caráter secundário, e aprova o Regulamento sobre Canalização e Condições de Uso na faixa de Radiofreqüências de $217 \mathrm{MHz}$ a $218 \mathrm{MHz}$.

$\hookrightarrow$ Anexo - Regulamento sobre Canalização e Condições de Uso na Faixa de Radiofreqüências de $217 \mathrm{MHz}$ a $218 \mathrm{MHz}$.

\section{Órbita e Satélite}

\section{Normatização}

Resolução da ANATEL $n^{\circ}$ 515, de 10 de outubro de 2008 - Destina a faixa de radiofrequiências de 143,60 MHz a 143,65 MHz ao Serviço Limitado Privado, para uso em aplicações de Pesquisa Espacial, sentido espaço para Terra.

\section{Administração do Setor de Telecomunicações}

\section{Fiscalização das Telecomunicações}

\section{Jurisprudência}

- Tribunal de Contas da União - Processo Público no TC-002.660/2007-8 Auditoria de Natureza Operacional - Relator: Min. Raimundo Carreiro Plenário do TCU - Unânime - j. 02/04/2008 - Diário Oficial da União, Seção 1, 04/04/2008. [Descrição do Caso] [Catalogação de Rodrigo Fernandes ]

Decisão em que o TCU verificou a existência de baixo grau de consistência na elaboração de políticas públicas para o setor de telecomunicações; a 
ausência de metas para a utilização dos recursos do Fundo para o Desenvolvimento Tecnológico das Telecomunicações - Funttel; a carência de controles de arrecadação, bem como a ocorrência de irregularidades na elaboração e execução de convênios, contratos de repasses e outros instrumentos congêneres.

Tribunal de Contas da União - Processo Público no TC-010.385/2006-7 Denúncia - Relator: Min. Ubiratan Aguiar - Plenário do TCU - Unânime - j. 24/09/2008 - Diário Oficial da União, Seção 1, 26/09/2008. [Descrição do Caso] [Catalogação de Rodrigo Fernandes ]

Decisão em que o TCU verificou que o Ministério das Comunicações não observou o critério da representatividade, definido no art. $9^{\circ}, \S 5^{\circ}$, da Lei 9.612/98, na seleção de prestador do serviço de radiodifusão comunitária. Apurou-se ainda, a existência de fragilidade na instrução e análise dos processos naquele órgão.

Tribunal de Contas da União - Processo Público no TC-010.978/2008-1Monitoramento - Relator: Min. Augusto Sherman Cavalcanti - Plenário do TCU - Unânime - j. 23/07/2008 - Diário Oficial da União, Seção 1, 25/07/2008. [Descrição do Caso] [Catalogação de Rodrigo Fernandes ]

Decisão em que o TCU, ao monitorar o cumprimento do Acórdão 532/2005TCU-Plenário, atinente a irregularidades no recolhimento de taxas de fiscalização dos serviços de telecomunicações, entendeu indevido o procedimento adotado pela ANATEL de cancelar os créditos decorrentes do não pagamento da taxa de fiscalização dos serviços de telecomunicações - TFF.

Tribunal de Contas da União - Processo Público no TC-019.677/2006-2 Monitoramento - Relator: Min. Ubiratan Aguiar - Plenário do TCU - Unânime - j. 26/11/2008 - Diário Oficial da União, Seção 1, 01/12/2008. [Descrição do Caso] [Catalogação de Rodrigo Fernandes ]

Decisão em que o TCU verificou que o estudo realizado acerca da situação econômico-financeira dos contratos de concessão de telefonia fixa, apresentava inconsistências na segregação dos dados e padecia de circularidades nos procedimentos de cálculo, bem como fazia conclusões com base em metodologia não confiável, não permitindo, portanto, aferir se foi mantido o equilíbrio econômico-financeiro dos contratos de concessão, no período de 1999-2004.

Tribunal de Contas da União - Processo Público no TC-023.855/2007-0 Acompanhamento - Relator: Min. Raimundo Carreiro - Plenário do TCU Unânime - j. 23/04/2008 - Diário Oficial da União, Seção 1, 25/04/2008. [Descrição do Caso] [Catalogação de Rodrigo Fernandes ]

Decisão em que o TCU verificou o processo de outorga de autorização para exploração do Serviço Móvel Pessoal e de autorização de uso de radiofrequiências nas subfaixas do IMT-2000 (J, F, G e I). O TCU entendeu regulares os compromissos de abrangência estipulados que se destinavam a assegurar o acesso ao serviço móvel pessoal em municípios com população inferior a 30.000 mil habitantes. 
Tribunal de Contas da União - Processo Público no TC-027.077/2006-4Representação - Relator: Min. Ubiratan Aguiar - Plenário do TCU - Unânime - j. 03/09/2008 - Diário Oficial da União, Seção 1, 05/09/2008. [Descrição do Caso] [Catalogação de Rodrigo Fernandes ]

Decisão em que o TCU entendeu que o art. 223, $\S 4^{\circ}$, da Constituição Federal não se aplica nos casos em que se verifica ocorrência de nulidade. A consultoria jurídica do Ministério das Comunicações, apesar de reconhecer o vício existente no processo de concessão de radiodifusão, entendia que somente seria possível a anulação da concessão por meio de ação judicial.

Tribunal de Contas da União - Processo $n^{0}$ TC-010.681/2008-0Representação - Relator: Min. Marcos Vinicios Vilaça - Plenário do TCU Unânime - j. 03/12/2008 - Diário Oficial da União, Seção 1, 09/12/2008. [Descrição do Caso] [Catalogação de Rodrigo Fernandes ]

Decisão em que o TCU verificou ser improcedente representação efetuada contra a aquisição do controle acionário da Brasil Telecom, pela Oi/Telemar, com recursos do Banco Nacional de Desenvolvimento Econômico e Social.

\section{Normatização}

Lei $\mathbf{n}^{\circ}$ 11.829, de 25 de novembro de 2008 - Altera a Lei no 8.069, de 13 de julho de 1990 - Estatuto da Criança e do Adolescente, para aprimorar o combate à produção, venda e distribuição de pornografia infantil, bem como criminalizar a aquisição e a posse de tal material e outras condutas relacionadas à pedofilia na internet.

Resolução da ANATEL no 493, de 27 de fevereiro de 2008 - Aprova a alteração do art. $6^{\circ}$ do Plano Geral de Metas de Qualidade para os serviços de televisão por assinatura (PGMQ - televisão por assinatura).

Resolução da ANATEL n 496, de 24 de março de 2008 - Republicar, com alterações, o Regimento Interno do Comitê de Defesa dos Usuários de Serviços de Telecomunicações anexo à Resolução n 107 , de 26 de fevereiro de 1999, alterado pela Resolução no 223 , de 18 de maio de 2000.

$\hookrightarrow$ Anexo - Regimento Interno do Comitê de Defesa dos Usuários de Serviços de Telecomunicações.

Resolução da ANATEL no 503, de 25 de abril de 2008 - Prorroga o prazo para apresentação do Apêndice B do Anexo I do Documento de Separação e Alocação de Contas (DSAC) por Prestadoras do SMP que integrem Grupo detentor de Poder de Mercado Significativo na interconexão em rede móvel ou que façam parte de Grupo que contenha Concessionária do STFC.

Resolução da ANATEL $\mathbf{n}^{\circ}$ 506, de $1^{\circ}$ de julho de 2008 - Republica o Regulamento sobre Equipamentos de Radiocomunicação de Radiação Restrita.

$\hookrightarrow$ Anexo - Regulamento sobre Equipamentos de Radiocomunicação de Radiação Restrita. 
$\checkmark$ Os equipamentos de radiocomunicação de radiação restrita, em regra, independem de autorização de uso de radiofrequiência e de licenciamento para instalação e funcionamento de estação.

Resolução da ANATEL $\mathbf{n}^{\circ}$ 511, de $1^{\circ}$ de setembro de 2008 - Aprova o Regulamento de Controle das Zonas de Proteção das Áreas Adjacentes às Estações de Telecomunicações sob responsabilidade da ANATEL.

$\hookrightarrow$ Anexo - Regulamento de Controle das Zonas de Proteção das Áreas Adjacentes às Estações de Telecomunicações sob responsabilidade da Anatel.

$\hookrightarrow$ Anexo 1 - Solicitação de Assentimento: Autorização para Aproveitamento do Solo em Área do Plano de Zona de Proteção.

$\hookrightarrow$ Anexo 2 - Formulário de Requerimento de Certidão Prévia de Gabarito.

$\hookrightarrow$ Anexo 3 - Modelos de Carimbo de Assentimento.

$\hookrightarrow$ Anexo 4 - Carimbos de Assentimento com Restrições e Prazos de Validade.

$\hookrightarrow$ Anexo 5 - Carimbo de Não-Assentimento.

$\hookrightarrow$ Anexo 6 - Carimbos de Certidão de Gabarito.

$\hookrightarrow$ Anexo 7 - Ofício de encaminhamento da documentação, com a decisão da ANATEL, à Prefeitura Municipal.

$\hookrightarrow$ Anexo 8 - Regulamento de Proteção de Sítios de Radiomonitoragem: Fluxograma de Atividades.

$\hookrightarrow$ Anexo 9 - Relações das Estações do SGME.

\section{Tributação no Setor de Telecomunicações}

\section{Jurisprudência}

\footnotetext{
- Superior Tribunal de Justiça - Medida Cautelar no 13406 (STJ - MC 13406

/ SP - São Paulo) - Relator: Min. Eliana Calmon - Segunda Turma do STJ Unânime - j. 16/10/2008 - Diário da Justiça, Seção 1, 07/11/2008. [Descrição do Caso] [Catalogação de Patrick Faria ]

Discussão sobre a legalidade de taxa instituída pelo município de São Paulo pela instalação de fios e cabos usados por empresas de telecomunicações no perímetro do sistema viário de sua área. Decisão unânime da $2^{\mathrm{a}}$ Turma do STJ no sentido de, primeiro, admitir a medida cautelar para conferir efeito suspensivo ao recurso especial pendente de admissibilidade na origem; posteriormente, julgar procedente o pedido cautelar, uma vez que configurado o fumus bonis iuris e o periculum in mora. $\mathrm{O}$ fumus bonis iuris, em razão do próprio dissídio jurisprudencial em que se assenta a admissibilidade do recurso, havendo precedentes no STJ no sentido da ilegalidade da cobrança por não deter esta natureza de preço público tampouco de taxa. $O$ periculum in mora, tendo em vista que, caso a taxa seja considerada legal, acarretará o pagamento de vultosas quantias, fato que resultará em danos de difícil reparação.
} 
Tribunal de Contas da União - Processo Público no TC-002.660/2007-8 Auditoria de Natureza Operacional - Relator: Min. Raimundo Carreiro Plenário do TCU - Unânime - j. 02/04/2008 - Diário Oficial da União, Seção 1, 04/04/2008. [Descrição do Caso] [Catalogação de Rodrigo Fernandes ]

Decisão em que o TCU verificou a existência de baixo grau de consistência na elaboração de políticas públicas para o setor de telecomunicações; a ausência de metas para a utilização dos recursos do Fundo para o Desenvolvimento Tecnológico das Telecomunicações - Funttel; a carência de controles de arrecadação, bem como a ocorrência de irregularidades na elaboração e execução de convênios, contratos de repasses e outros instrumentos congêneres.

Superior Tribunal de Justiça - Recurso Especial no 1053778 (STJ - RESP 1053778 / RS - Rio Grande do Sul) - Relator: Min. Herman Benjamin Segunda Turma do STJ - Unânime - j. 09/09/2008 - Diário da Justiça, 10/10/2008. [Descrição do Caso] [Catalogação de Márcio Iório Aranha ]

É ilegal a prática de repercussão do PIS e da COFINS na tarifa cobrada do usuário de serviços de telefonia fixa prestado por concessionária, tanto de forma expressa, quanto de forma não destacada na conta telefônica. Consideração da composição de tarifa de telefonia como líquida de tributos não autoriza a empresa a acrescer à tarifa o PIS e a COFINS. Incidentalmente, reafirmou-se a competência da Justiça Estadual para julgar causas envolvendo composição da fatura de telefonia. A prática comercial de englobar no valor da tarifa o repasse do PIS e da COFINS viola o disposto no art. $3^{\circ}$, IV, da LGT, de direito à informação adequada, bem como se caracteriza como prática abusiva, conforme o art. 39, caput, do Código de Defesa do Consumidor.

Superior Tribunal de Justiça - Recurso Especial no 754393 (STJ - RESP 754393 / DF - Distrito Federal) - Relator: Min. Francisco Falcão - Primeira Turma do STJ - Maioria - j. 02/12/2008 - Diário da Justiça, 16/02/2009. [Descrição do Caso] [Catalogação de Márcio Iório Aranha ]

Não-incidência do ICMS sobre a assinatura mensal de telefonia, quando esta não comporta franquia de utilização.

Superior Tribunal de Justiça - Recurso Especial no 938827 (STJ - RESP 938827 / DF - Distrito Federal) - Relator: Min. Denise Arruda - Primeira Turma do STJ - Unânime - j. 18/09/2008 - Diário da Justiça, 29/09/2008. [Descrição do Caso] [Catalogação de Rosa Amaral ]

Discussão acerca da legitimidade passiva ad causam da concessionária do serviço público de telecomunicações para responder pela devolução de valores de ICMS. Pronunciamento pela ilegitimidade da prestadora para figurar no pólo passivo dessas demandas, por ser a Fazenda Pública o sujeito ativo da relação tributária, e não a concessionária de telefonia, simples responsável pelo repasse dos tributos ao ente federativo.

Superior Tribunal de Justiça - Súmula do STJ no 350 - Primeira Seção do STJ - j. 11/06/2008 - Diário Oficial da União, Seção 1, 19/06/2008, pág. 1. [Descrição do Caso] 
O ICMS não incide sobre o serviço de habilitação de telefone celular.

\section{Normatização}

Lei $\mathrm{n}^{\circ}$ 11.652, de 7 de abril de 2008 - Institui os princípios e objetivos dos serviços de radiodifusão pública explorados pelo Poder Executivo ou outorgados a entidades de sua administração indireta; autoriza o Poder Executivo a constituir a Empresa Brasil de Comunicação - EBC; altera a Lei no 5.070, de 7 de julho de 1966; e dá outras providências [Conversão da Medida Provisória nº 398, de 10 de outubro de 2007].

$\checkmark$ O art. 32, da Lei 11.652/2008, institui a Contribuição para o Fomento da Radiodifusão Pública.

\section{Outorgas}

\section{Espécies de Outorga}

\section{Concessão (regras aplicáveis)}

\section{Jurisprudência}

Tribunal de Contas da União - Processo Público no TC-019.677/2006-2 Monitoramento - Relator: Min. Ubiratan Aguiar - Plenário do TCU - Unânime - j. 26/11/2008 - Diário Oficial da União, Seção 1, 01/12/2008. [Descrição do Caso] [Catalogação de Rodrigo Fernandes ]

Decisão em que o TCU verificou que o estudo realizado acerca da situação econômico-financeira dos contratos de concessão de telefonia fixa, apresentava inconsistências na segregação dos dados e padecia de circularidades nos procedimentos de cálculo, bem como fazia conclusões com base em metodologia não confiável, não permitindo, portanto, aferir se foi mantido o equilíbrio econômico-financeiro dos contratos de concessão, no período de 1999-2004.

Tribunal de Contas da União - Processo $n^{0}$ TC-010.681/2008-0 Representação - Relator: Min. Marcos Vinicios Vilaça - Plenário do TCU Unânime - j. 03/12/2008 - Diário Oficial da União, Seção 1, 09/12/2008. [Descrição do Caso] [Catalogação de Rodrigo Fernandes ]

Decisão em que o TCU verificou ser improcedente representação efetuada contra a aquisição do controle acionário da Brasil Telecom, pela Oi/Telemar, com recursos do Banco Nacional de Desenvolvimento Econômico e Social.

\section{Normatização}

Lei $\mathbf{n}^{\circ} 11.800$, de 29 de outubro de 2008 - Acrescenta parágrafo único ao art. 33 da Lei no 8.078, de 11 de setembro de 1990 - Código de Defesa do Consumidor, para impedir que os fornecedores veiculem publicidade ao consumidor que aguarda, na linha telefônica, $o$ atendimento de suas solicitações. 
Decreto $\mathrm{n}^{\mathbf{0}}$ 6.424, de 4 de abril de $\mathbf{2 0 0 8}$ - Altera e acresce dispositivos ao Anexo do Decreto $n^{\circ} 4.769$, de 27 de junho de 2003, que aprova o Plano Geral de Metas para a Universalização do Serviço Telefônico Fixo Comutado prestado no Regime Público - PGMU.

Decreto $n^{\circ}$ 6.523, de 31 de julho de 2008 - Regulamenta a Lei no 8.078, de 11 de setembro de 1990, para fixar normas gerais sobre o Serviço de Atendimento ao Consumidor - SAC.

$\checkmark$ O Decreto 6.523/2008 tem o escopo específico de fixar normas gerais sobre o SAC por telefone, no âmbito dos fornecedores de serviços regulados pelo Poder Público federal.

Decreto $n^{\circ}$ 6.654, de 20 de novembro de 2008 - Aprova o Plano Geral de Outorgas de Serviço de Telecomunicações prestado no regime público.

$\hookrightarrow$ Anexo 1 - Regiões do Plano Geral de Outorgas.

$\hookrightarrow$ Anexo 2 - Setores das Regiões do Plano Geral de Outorgas.

Resolução da ANATEL $\mathbf{n}^{\circ}$ 490, de 24 de janeiro de 2008 - Aprova o Regulamento de Conselho de Usuários do Serviço Telefônico Fixo Comutado - STFC.

$\hookrightarrow$ Anexo - Regulamento de Conselho de Usuários do Serviço Telefônico Fixo Comutado - STFC.

Resolução da ANATEL n $^{\circ}$ 507, de 16 de julho de 2008 - Aprova a Norma da Metodologia para Cálculo do Fator de Transferência " $X$ ", aplicado nos Reajustes de Tarifas do Serviço Telefônico Fixo Comutado, destinado ao uso do público em geral - STFC.

$\hookrightarrow$ Anexo - Norma da Metodologia para Cálculo do Fator de Transferência "X”, aplicado nos Reajustes de Tarifas do Serviço Telefônico Fixo Comutado, destinado ao uso do público em geral - STFC.

\section{Atos}

Análise ANATEL/GCPJ no 368, de 7 de outubro de 2008 - Submete à aprovação a proposta de revisão do Plano Geral de Outorgas (PGO), aprovado pelo Decreto $\mathrm{n}^{\mathbf{0}} 2.534$, de 2 de abril de 1998.

Ato do Conselho Diretor da ANATEL no 1.933, de 7 de abril de 2008 Aprova a celebração dos Termos Aditivos aos Termos de Autorização do Serviço de Comunicação Multimídia e do Serviço de Rede de Transporte de Telecomunicações detidos pelas concessionárias do Serviço Telefônico Fixo.

$\checkmark$ O Ato $n^{\circ} 1.933 / 2008$ é a conseqüência operacional do Decreto $n^{\circ} 6.424 / 2008$, que alterou o Plano Geral de Metas para a Universalização do STFC prestado no regime público após a aceitação por parte das concessionárias de STFC de proposta governamental de substituição de metas de universalização de instalação de PSTs pelo compromisso de instalação e manutenção de provimento de serviço de acesso banda larga a escolas públicas.

Ato do Conselho Diretor da ANATEL n* 4.197, de 16 de julho de 2008 Fixa os valores dos fatores de transferência X e DEA. 


\section{Autorização (regras aplicáveis)}

\section{Normatização}

Lei $\mathbf{n}^{\mathbf{0}} \mathbf{1 1 . 8 0 0}$, de 29 de outubro de 2008 - Acrescenta parágrafo único ao art. 33 da Lei no 8.078, de 11 de setembro de 1990 - Código de Defesa do Consumidor, para impedir que os fornecedores veiculem publicidade ao consumidor que aguarda, na linha telefônica, o atendimento de suas solicitações. Decreto $\mathbf{n}^{\mathbf{0}}$ 6.523, de 31 de julho de 2008 - Regulamenta a Lei no 8.078, de 11 de setembro de 1990, para fixar normas gerais sobre o Serviço de Atendimento ao Consumidor - SAC.

$\checkmark$ O Decreto 6.523/2008 tem o escopo específico de fixar normas gerais sobre o SAC por telefone, no âmbito dos fornecedores de serviços regulados pelo Poder Público federal.

Resolução da ANATEL $\mathbf{n}^{0}$ 518, de 21 de novembro de 2008 - Aprova alteração no Regulamento do Serviço Móvel Especializado -SME.

$\hookrightarrow$ Anexo - Alteração do Regulamento do Serviço Móvel Especializado -SME.

Resolução da ANATEL $n^{0}$ 519, de 21 de novembro de 2008 - Aprova alteração no Plano Geral de Autorizações do Serviço Móvel Especializado SME.

$\hookrightarrow$ Anexo - Alteração do Plano Geral de Autorizações do Serviço Móvel Especializado - SME.

\section{Atos}

Ato do Conselho Diretor da ANATEL $\mathbf{n}^{0}$ 1.933, de 7 de abril de 2008 Aprova a celebração dos Termos Aditivos aos Termos de Autorização do Serviço de Comunicação Multimídia e do Serviço de Rede de Transporte de Telecomunicações detidos pelas concessionárias do Serviço Telefônico Fixo.

$\checkmark \mathrm{O}$ Ato $\mathrm{n}^{\mathrm{o}} 1.933 / 2008$ é a conseqüência operacional do Decreto ${ }^{\circ}$ 6.424/2008, que alterou o Plano Geral de Metas para a Universalização do STFC prestado no regime público após a aceitação por parte das concessionárias de STFC de proposta governamental de substituição de metas de universalização de instalação de PSTs pelo compromisso de instalação e manutenção de provimento de serviço de acesso banda larga a escolas públicas.

Termo Aditivo $\mathrm{n}^{\circ}$ 001/2008/SPV - BRASIL TELECOM, de 8 de abril de 2008 - Termo Aditivo ao Termo de Autorização para Exploração do SCM celebrado entre a ANATEL e a BRASIL TELECOM S.A. para implementação do compromisso de instalação e manutenção de provimento de serviço de acesso banda larga a escolas públicas até 31 de dezembro de 2025.

$\hookrightarrow$ Anexo - Prazos, condições e critérios de qualidade para prestação de serviço de acesso banda larga.

Termo Aditivo no 001/2008/SPV - CTBC, de 8 de abril de 2008 - Termo Aditivo ao Termo de Autorização para Exploração do SRTT celebrado entre a ANATEL e a COMPANHIA DE TELECOMUNICAÇÕES DO BRASIL CENTRAL para implementação do compromisso de instalação e manutenção 
de provimento de serviço de acesso banda larga a escolas públicas até 31 de dezembro de 2025.

$\hookrightarrow$ Anexo - Prazos, condições e critérios de qualidade para prestação de serviço de acesso banda larga.

Termo Aditivo no 001/2008/SPV - SERCOMTEL, de 8 de abril de 2008 Termo Aditivo ao Termo de Autorização para Exploração do SRTT celebrado entre a ANATEL e a SERCOMTEL S/A TELECOMUNICAÇÕES para implementação do compromisso de instalação e manutenção de provimento de serviço de acesso banda larga a escolas públicas até 31 de dezembro de 2025.

Termo Aditivo no 001/2008/SPV - TELEMAR, de 8 de abril de 2008 Termo Aditivo ao Termo de Autorização para Exploração do SCM celebrado entre a ANATEL e a TELEMAR NORTE LESTE S.A. para implementação do compromisso de instalação e manutenção de provimento de serviço de acesso banda larga a escolas públicas até 31 de dezembro de 2025.

$\hookrightarrow$ Anexo - Prazos, condições e critérios de qualidade para prestação de serviço de acesso banda larga.

\section{Preço Público e Preço Privado}

\section{Jurisprudência}

Superior Tribunal de Justiça - Recurso Especial no 1053778 (STJ - RESP 1053778 / RS - Rio Grande do Sul) - Relator: Min. Herman Benjamin Segunda Turma do STJ - Unânime - j. 09/09/2008 - Diário da Justiça, 10/10/2008. [Descrição do Caso] [Catalogação de Márcio Iório Aranha ]

É ilegal a prática de repercussão do PIS e da COFINS na tarifa cobrada do usuário de serviços de telefonia fixa prestado por concessionária, tanto de forma expressa, quanto de forma não destacada na conta telefônica. Consideração da composição de tarifa de telefonia como líquida de tributos não autoriza a empresa a acrescer à tarifa o PIS e a COFINS. Incidentalmente, reafirmou-se a competência da Justiça Estadual para julgar causas envolvendo composição da fatura de telefonia. A prática comercial de englobar no valor da tarifa o repasse do PIS e da COFINS viola o disposto no art. $3^{\circ}$, IV, da LGT, de direito à informação adequada, bem como se caracteriza como prática abusiva, conforme o art. 39, caput, do Código de Defesa do Consumidor.

Superior Tribunal de Justiça - Recurso Especial no 754393 (STJ - RESP 754393 / DF - Distrito Federal) - Relator: Min. Francisco Falcão - Primeira Turma do STJ - Maioria - j. 02/12/2008 - Diário da Justiça, 16/02/2009. [Descrição do Caso] [Catalogação de Márcio Iório Aranha ]

Não-incidência do ICMS sobre a assinatura mensal de telefonia, quando esta não comporta franquia de utilização.

Superior Tribunal de Justiça - Súmula do STJ no 356 - Primeira Seção do STJ - j. 25/06/2008 - Diário da Justiça, 08/09/2008. [Descrição do Caso] 
É legítima a cobrança da tarifa básica pelo uso dos serviços de telefonia fixa.

\section{Normatização}

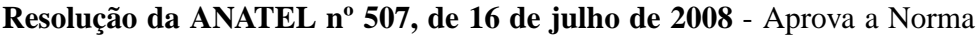
da Metodologia para Cálculo do Fator de Transferência "X", aplicado nos Reajustes de Tarifas do Serviço Telefônico Fixo Comutado, destinado ao uso do público em geral - STFC.

$\hookrightarrow$ Anexo - Norma da Metodologia para Cálculo do Fator de Transferência “ X", aplicado nos Reajustes de Tarifas do Serviço Telefônico Fixo Comutado, destinado ao uso do público em geral - STFC.

Atos

רT Ato do Conselho Diretor da ANATEL n* 4.197, de 16 de julho de 2008 Fixa os valores dos fatores de transferência X e DEA.

\section{Políticas de Telecomunicações}

Atos

Análise ANATEL/GCAB no 455, de 9 de outubro de 2008 - Submete à aprovação a proposta de Plano Geral para Atualização da Regulamentação das Telecomunicações no Brasil (PGR).

\section{Política Tarifária}

Jurisprudência

\footnotetext{
Superior Tribunal de Justiça - Recurso Especial no 1053778 (STJ - RESP 1053778 / RS - Rio Grande do Sul) - Relator: Min. Herman Benjamin Segunda Turma do STJ - Unânime - j. 09/09/2008 - Diário da Justiça, 10/10/2008. [Descrição do Caso] [Catalogação de Márcio Iório Aranha ]

É ilegal a prática de repercussão do PIS e da COFINS na tarifa cobrada do usuário de serviços de telefonia fixa prestado por concessionária, tanto de forma expressa, quanto de forma não destacada na conta telefônica. Consideração da composição de tarifa de telefonia como líquida de tributos não autoriza a empresa a acrescer à tarifa o PIS e a COFINS. Incidentalmente, reafirmou-se a competência da Justiça Estadual para julgar causas envolvendo composição da fatura de telefonia. A prática comercial de englobar no valor da tarifa o repasse do PIS e da COFINS viola o disposto no art. $3^{\circ}$, IV, da LGT, de direito à informação adequada, bem como se caracteriza como prática abusiva, conforme o art. 39, caput, do Código de Defesa do Consumidor.
} 


\section{Normatização}

Resolução da ANATEL no 507, de 16 de julho de 2008 - Aprova a Norma da Metodologia para Cálculo do Fator de Transferência "X", aplicado nos Reajustes de Tarifas do Serviço Telefônico Fixo Comutado, destinado ao uso do público em geral - STFC.

$\hookrightarrow$ Anexo - Norma da Metodologia para Cálculo do Fator de Transferência "X", aplicado nos Reajustes de Tarifas do Serviço Telefônico Fixo Comutado, destinado ao uso do público em geral - STFC.

Atos

Ato do Conselho Diretor da ANATEL no 4.197, de 16 de julho de 2008 Fixa os valores dos fatores de transferência X e DEA.

\section{Política Industrial}

\section{Normatização}

Lei no 11.759, de 31 de julho de 2008 - Autoriza a criação da empresa pública Centro Nacional de Tecnologia Eletrônica Avançada S.A. - CEITEC e dá outras providências.

Decreto n$^{\circ}$ 6.405, de 19 de março de 2008 - Dá nova redação e acresce dispositivos ao Decreto no 5.906, de 26 de setembro de 2006, para adequação dos produtos que especifica com os respectivos códigos de classificação na Nomenclatura Comum do Mercosul - NCM, alterada a partir de 10 de janeiro de 2007.

$\hookrightarrow$ Anexo 1 - Relação de Bens de Informática e Automação.

$\hookrightarrow$ Anexo 2 - Relação de Produtos Excluídos da Isenção ou Redução do IPI.

Decreto $n^{\circ}$ 6.638, de 7 de novembro de 2008 - Cria a empresa pública Centro Nacional de Tecnologia Eletrônica Avançada S.A. - CEITEC, aprova seu Estatuto e dá outras providências.

Portaria MC n⿳ 178, de 22 de abril de 2008 - Dispõe sobre diretrizes para implementação das políticas públicas em telecomunicações.

Portaria Interministerial $\mathbf{n}^{\circ}$ 23, de 29 de janeiro de 2008 [ Revogado por: Portaria Interministerial $n^{\circ} 236 / 2008$ ] - Altera a Portaria Interministerial n. 236, de 6 de dezembro de 2007, referente ao Processo Produtivo Básico de Terminal Portátil de Telefonia Celular industrializado na Zona Franca de Manaus.

Portaria Interministerial $\mathbf{n}^{\mathbf{0}}$ 29, de 29 de janeiro de 2008 - Altera a Portaria Interministerial n. 237, de 6 de dezembro de 2007, referente ao Processo Produtivo Básico de Terminal Portátil de Telefonia Celular.

Portaria Interministerial $n^{\circ}$ 236, de 29 de dezembro de 2008 - Estabelece o Processo Produtivo Básico de Terminal Portátil de Telefonia Celular industrializado na Zona Franca de Manaus, dispõe sobre metas de produção e dá outras providências. 
$\hookrightarrow$ Anexo 1 - Fabricação do conversor de corrente contínua (CA-CC) ou carregador de bateria para telefone celular.

$\hookrightarrow$ Anexo 2 - Fabricação do transformador elétrico de potência não superior a 3KVA, com núcleo de pó ferromagnético.

$\hookrightarrow$ Anexo 3 - Fabricação dos fios e cabos com conectores destinados a conversor e carregador de bateria para celular.

Portaria Interministerial $n^{\circ}$ 237, de 29 de dezembro de 2008 - Estabelece o Processo Produtivo Básico de Terminal Portátil de Telefonia Celular, dispõe sobre metas de produção e dá outras providências.

$\hookrightarrow$ Anexo 1 - Fabricação do conversor de corrente contínua (CA-CC) ou carregador de bateria para telefone celular.

$\hookrightarrow$ Anexo 2 - Fabricação do transformador elétrico de potência não superior a 3KVA, com núcleo de pó ferromagnético.

$\hookrightarrow$ Anexo 3 - Fabricação dos fios e cabos com conectores destinados a conversor e carregador de bateria para celular.

Resolução da ANATEL no 514, de 7 de outubro de 2008 - Aprova a alteração do Regulamento Técnico para Prestação do Serviço de Radiodifusão Sonora em Onda Média e em Onda Tropical (faixa de $120 \mathrm{~m}$ ).

$\hookrightarrow$ Anexo - Alteração do Regulamento Técnico para Prestação do Serviço de Radiodifusão Sonora em Onda Média e em Onda Tropical (faixa de $120 \mathrm{~m}$ ), aprovado pela Resolução no 116, de 25 de março de 1999.

Resolução da ANATEL no 516, de 30 de outubro de 2008 - Aprova o Plano Geral de Atualização da Regulamentação das Telecomunicações no Brasil (PGR).

$\hookrightarrow$ Anexo - Plano Geral de Atualização da Regulamentação das Telecomunicações no Brasil (PGR).

$\checkmark$ Inscrição do desenvolvimento industrial e tecnológico como princípio regulatório, bem como do desenvolvimento da indústria nacional como objetivo da atualização da regulamentação a partir de 2008.

\section{Concorrência no Setor de Telecomunicações}

Normatização

Resolução da ANATEL $n^{\circ}$ 492, de 19 de fevereiro de 2008 - Aprova a Norma para Certificação e Homologação de Transmissores e Transceptores Digitais para o Serviço Fixo em Aplicações Ponto-Multiponto nas Faixas de Frequiências acima de $1 \mathrm{GHz}$.

$\hookrightarrow$ Anexo - Norma para Certificação e Homologação de Transmissores e Transceptores Digitais para o Serviço Fixo em Aplicações Ponto-Multiponto nas Faixas de Frequiências acima de $1 \mathrm{GHz}$. 
Resolução da ANATEL $\mathbf{n}^{\circ}$ 516, de 30 de outubro de 2008 - Aprova o Plano Geral de Atualização da Regulamentação das Telecomunicações no Brasil (PGR).

$\hookrightarrow$ Anexo - Plano Geral de Atualização da Regulamentação das Telecomunicações no Brasil (PGR).

$\checkmark$ Inscrição da propiciação de competição como princípio regulatório e do asseguramento de níveis adequados de competição e concorrência na exploração de serviços de telecomunicações como objetivo da atualização da regulamentação a partir de 2008 .

Resolução da ANATEL no 518, de 21 de novembro de 2008 - Aprova alteração no Regulamento do Serviço Móvel Especializado -SME.

$\hookrightarrow$ Anexo - Alteração do Regulamento do Serviço Móvel Especializado -SME.

Resolução da ANATEL $n^{\circ}$ 519, de 21 de novembro de 2008 - Aprova alteração no Plano Geral de Autorizações do Serviço Móvel Especializado SME.

$\hookrightarrow$ Anexo - Alteração do Plano Geral de Autorizações do Serviço Móvel Especializado - SME.

\section{Atos}

Ato do Conselho Diretor da ANATEL no 7.828, de 19 de dezembro de 2008 - Anuência prévia à aquisição por parte da TELEMAR NORTE LESTE S.A. de ações representativas do controle societário da Invitel S.A., controladora direta da Solpart Participações S.A. e controladora indireta da Brasil Telecom Participações S.A., da Brasil Telecom S.A., da Brasil Telecom Celular S.A., da Brasil Telecom Comunicação Multimídia S.A., da Brasil Telecom Cabos Submarinos LTDA., e da Vant Telecomunicações S.A.

$\hookrightarrow$ Anexo - Condicionamentos para o Ato de Anuência.

\section{Universalização}

\section{Acesso às Telecomunicações}

\section{Portador de Deficiência}

\section{Normatização}

Resolução da ANATEL no 491, de 12 de fevereiro de 2008 - Aprova a alteração do art. 118 do Anexo à Resolução no 477, de 7 de agosto de 2007, que trata do Regulamento do Serviço Móvel Pessoal - SMP, e acrescenta ao Anexo o art. 119.

Resolução da ANATEL $\mathbf{n}^{\circ}$ 506, de $1^{\circ}$ de julho de 2008 - Republica o Regulamento sobre Equipamentos de Radiocomunicação de Radiação Restrita. $\hookrightarrow$ Anexo - Regulamento sobre Equipamentos de Radiocomunicação de Radiação Restrita. 
$\checkmark$ O dispositivo de auxílio auditivo é qualificado como equipamento de radiocomunicação de radiação restrita e, portanto, independe de outorga de autorização de uso de radiofreqüência e de licenciamento para instalação e funcionamento.

Resolução da ANATEL $\mathbf{n}^{\circ}$ 509, de 14 de agosto de 2008 - Aprova o Regulamento da Central de Intermediação de Comunicação Telefônica a ser utilizada por pessoas com deficiência auditiva ou da fala - CIC.

$\hookrightarrow$ Anexo - Regulamento da Central de Intermediação de Comunicação Telefônica a ser Utilizada por Pessoas com Deficiência Auditiva ou da Fala - CIC.

\section{Zona Rural}

\section{Normatização}

Resolução da ANATEL no 516, de 30 de outubro de 2008 - Aprova o Plano Geral de Atualização da Regulamentação das Telecomunicações no Brasil (PGR).

$\hookrightarrow$ Anexo - Plano Geral de Atualização da Regulamentação das Telecomunicações no Brasil (PGR).

$\checkmark$ Inscrição da criação e oferta de serviços a preços módicos em áreas rurais como objetivo da atualização da regulamentação a partir de 2008.

\section{Educação}

Normatização

Portaria MC $\mathbf{n}^{0}$ 178, de 22 de abril de 2008 - Dispõe sobre diretrizes para implementação das políticas públicas em telecomunicações.

\section{Telecentro Comunitário}

\section{Normatização}

Portaria MC no 711, de 9 de dezembro de 2008 - Capacitação de representantes municipais para uso de Telecentros Comunitários.

Portaria $M C \mathbf{n}^{\circ} \mathbf{8 2 5}$, de 17 de dezembro de 2008 - Apoio à participação do Programa GESAC e do Programa Inclusão Digital - Telecentros Comunitários na convergência de ações e produção colaborativa de conteúdo às iniciativas de inclusão digital.

\section{Metas de Universalização}

\section{Normatização}

Decreto $\mathrm{n}^{\mathbf{0}} \mathbf{6 . 4 2 4}$, de 4 de abril de 2008 - Altera e acresce dispositivos ao Anexo do Decreto $\mathrm{n}^{\circ} 4.769$, de 27 de junho de 2003, que aprova o Plano Geral 
de Metas para a Universalização do Serviço Telefônico Fixo Comutado prestado no Regime Público - PGMU.

\section{Atos}

Ato do Conselho Diretor da ANATEL no 1.933, de 7 de abril de 2008 Aprova a celebração dos Termos Aditivos aos Termos de Autorização do Serviço de Comunicação Multimídia e do Serviço de Rede de Transporte de Telecomunicações detidos pelas concessionárias do Serviço Telefônico Fixo.

$\checkmark$ O Ato $\mathrm{n}^{\circ} 1.933 / 2008$ é a conseqüência operacional do Decreto $\mathrm{n}^{\circ} 6.424 / 2008$, que alterou o Plano Geral de Metas para a Universalização do STFC prestado no regime público após a aceitação por parte das concessionárias de STFC de proposta governamental de substituição de metas de universalização de instalação de PSTs pelo compromisso de instalação e manutenção de provimento de serviço de acesso banda larga a escolas públicas.

Termo Aditivo no 001/2008/SPV - BRASIL TELECOM, de 8 de abril de 2008 - Termo Aditivo ao Termo de Autorização para Exploração do SCM celebrado entre a ANATEL e a BRASIL TELECOM S.A. para implementação do compromisso de instalação e manutenção de provimento de serviço de acesso banda larga a escolas públicas até 31 de dezembro de 2025 .

$\hookrightarrow$ Anexo - Prazos, condições e critérios de qualidade para prestação de serviço de acesso banda larga.

Termo Aditivo n $^{0}$ 001/2008/SPV - CTBC, de 8 de abril de 2008 - Termo Aditivo ao Termo de Autorização para Exploração do SRTT celebrado entre a ANATEL e a COMPANHIA DE TELECOMUNICAÇÕES DO BRASIL CENTRAL para implementação do compromisso de instalação e manutenção de provimento de serviço de acesso banda larga a escolas públicas até 31 de dezembro de 2025.

$\hookrightarrow$ Anexo - Prazos, condições e critérios de qualidade para prestação de serviço de acesso banda larga.

Termo Aditivo no 001/2008/SPV - SERCOMTEL, de 8 de abril de 2008 Termo Aditivo ao Termo de Autorização para Exploração do SRTT celebrado entre a ANATEL e a SERCOMTEL S/A TELECỎMUNICAÇÕES para implementação do compromisso de instalação e manutenção de provimento de serviço de acesso banda larga a escolas públicas até 31 de dezembro de 2025.

Termo Aditivo no 001/2008/SPV - TELEMAR, de 8 de abril de 2008 Termo Aditivo ao Termo de Autorização para Exploração do SCM celebrado entre a ANATEL e a TELEMAR NORTE LESTE S.A. para implementação do compromisso de instalação e manutenção de provimento de serviço de acesso banda larga a escolas públicas até 31 de dezembro de 2025 .

$\hookrightarrow$ Anexo - Prazos, condições e critérios de qualidade para prestação de serviço de acesso banda larga. 


\section{Fundos Setoriais de Telecomunicações}

\section{FISTEL}

\section{Normatização}

Lei $\mathbf{n}^{\circ}$ 11.652, de 7 de abril de 2008 - Institui os princípios e objetivos dos serviços de radiodifusão pública explorados pelo Poder Executivo ou outorgados a entidades de sua administração indireta; autoriza o Poder Executivo a constituir a Empresa Brasil de Comunicação - EBC; altera a Lei no 5.070, de 7 de julho de 1966; e dá outras providências [Conversão da Medida Provisória no 398, de 10 de outubro de 2007].

$\checkmark$ O art. 33, da Lei 11.652/2008, altera o percentual de cobrança da Taxa de Fiscalização de Funcionamento prevista na Lei 5.070/1966.

\section{FUNTTEL}

\section{Jurisprudência}

- 1 Tribunal de Contas da União - Processo Público no TC-002.660/2007-8 Auditoria de Natureza Operacional - Relator: Min. Raimundo Carreiro Plenário do TCU - Unânime - j. 02/04/2008 - Diário Oficial da União, Seção 1, 04/04/2008. [Descrição do Caso] [Catalogação de Rodrigo Fernandes ]

Decisão em que o TCU verificou a existência de baixo grau de consistência na elaboração de políticas públicas para o setor de telecomunicações; a ausência de metas para a utilização dos recursos do Fundo para o Desenvolvimento Tecnológico das Telecomunicações - Funttel; a carência de controles de arrecadação, bem como a ocorrência de irregularidades na elaboração e execução de convênios, contratos de repasses e outros instrumentos congêneres.

\section{Pesquisa \& Desenvolvimento}

\section{Jurisprudência}

Tribunal de Contas da União - Processo Público no TC-002.660/2007-8 Auditoria de Natureza Operacional - Relator: Min. Raimundo Carreiro Plenário do TCU - Unânime - j. 02/04/2008 - Diário Oficial da União, Seção 1, 04/04/2008. [Descrição do Caso] [Catalogação de Rodrigo Fernandes ]

Decisão em que o TCU verificou a existência de baixo grau de consistência na elaboração de políticas públicas para o setor de telecomunicações; a ausência de metas para a utilização dos recursos do Fundo para o Desenvolvimento Tecnológico das Telecomunicações - Funttel; a carência de controles de arrecadação, bem como a ocorrência de irregularidades na elaboração e execução de convênios, contratos de repasses e outros instrumentos congêneres. 


\section{Normatização}

Lei $n^{0}$ 11.759, de 31 de julho de 2008 - Autoriza a criação da empresa pública Centro Nacional de Tecnologia Eletrônica Avançada S.A. - CEITEC e dá outras providências.

Decreto $\mathbf{n}^{\circ}$ 6.405, de 19 de março de 2008 - Dá nova redação e acresce dispositivos ao Decreto no 5.906, de 26 de setembro de 2006, para adequação dos produtos que especifica com os respectivos códigos de classificação na Nomenclatura Comum do Mercosul - NCM, alterada a partir de 1o de janeiro de 2007.

$\hookrightarrow$ Anexo 1 - Relação de Bens de Informática e Automação.

$\hookrightarrow$ Anexo 2 - Relação de Produtos Excluídos da Isenção ou Redução do IPI.

Decreto $n^{\circ}$ 6.638, de 7 de novembro de 2008 - Cria a empresa pública Centro Nacional de Tecnologia Eletrônica Avançada S.A. - CEITEC, aprova seu Estatuto e dá outras providências.

Resolução da ANATEL no 516, de 30 de outubro de 2008 - Aprova o Plano Geral de Atualização da Regulamentação das Telecomunicações no Brasil (PGR).

$\hookrightarrow$ Anexo - Plano Geral de Atualização da Regulamentação das Telecomunicações no Brasil (PGR).

$\checkmark$ Inscrição do desenvolvimento industrial e tecnológico como princípio regulatório.

\section{Qualidade do Serviço}

\section{Normatização}

Resolução da ANATEL no 493, de 27 de fevereiro de 2008 - Aprova a alteração do art. $6^{\circ}$ do Plano Geral de Metas de Qualidade para os serviços de televisão por assinatura (PGMQ - televisão por assinatura).

Resolução da ANATEL no 514, de 7 de outubro de 2008 - Aprova a alteração do Regulamento Técnico para Prestação do Serviço de Radiodifusão Sonora em Onda Média e em Onda Tropical (faixa de $120 \mathrm{~m}$ ).

$\hookrightarrow$ Anexo - Alteração do Regulamento Técnico para Prestação do Serviço de Radiodifusão Sonora em Onda Média e em Onda Tropical (faixa de $120 \mathrm{~m}$ ), aprovado pela Resolução no 116, de 25 de março de 1999.

Resolução da ANATEL n $^{\circ}$ 516, de 30 de outubro de 2008 - Aprova o Plano Geral de Atualização da Regulamentação das Telecomunicações no Brasil (PGR).

$\hookrightarrow$ Anexo - Plano Geral de Atualização da Regulamentação das Telecomunicações no Brasil (PGR).

$\checkmark$ Inscrição da melhoria dos níveis de qualidade percebida pelos usuários como objetivo da atualização da regulamentação a partir de 2008. 


\title{
Controle de Conteúdo
}

\author{
Normatização
}

Portaria $\mathrm{MJ} \mathrm{n}^{0}$ 36, de 8 de janeiro de 2008 - Altera o parágrafo único do art. 24 da Portaria $n^{\circ} 1.220$, de 11 de julho de 2007, que regulamenta o processo de classificação indicativa de obras audiovisuais destinadas à televisão e congêneres.

\section{Controle Social, Hierárquico e Interorgânico (Accountability)}

Jurisprudência

Tribunal de Contas da União - Processo Público nº TC-002.660/2007-8 Auditoria de Natureza Operacional - Relator: Min. Raimundo Carreiro Plenário do TCU - Unânime - j. 02/04/2008 - Diário Oficial da União, Seção 1, 04/04/2008. [Descrição do Caso] [Catalogação de Rodrigo Fernandes ] Decisão em que o TCU verificou a existência de baixo grau de consistência na elaboração de políticas públicas para o setor de telecomunicações; a ausência de metas para a utilização dos recursos do Fundo para o Desenvolvimento Tecnológico das Telecomunicações - Funttel; a carência de controles de arrecadação, bem como a ocorrência de irregularidades na elaboração e execução de convênios, contratos de repasses e outros instrumentos congêneres.

\section{Sigilo em Telecomunicações}

\section{Jurisprudência}

Tribunal Superior do Trabalho - Agravo de Instrumento no Recurso de Revista $n^{\circ}$ 1542/2005-055-02-40 (TST - RR 1542/2005-055-02-40 - AI) Relator: Min. Ives Gandra Martins Filho - Sétima Turma do TST - Unânime j. 04/06/2008 - Diário da Justiça, 06/06/2008. [Descrição do Caso] [Catalogação de Márcio Iório Aranha ]

É lícito o acesso, por empregador, à caixa de e-mail corporativo de seu empregado, não configurando violação de sigilo de comunicações de dados.

Superior Tribunal de Justiça - Habeas Corpus no 76686 (STJ - HC 76686 / PR - Paraná) - Relator: Min. Nilson Naves - Sexta Turma do STJ - Unânime - j. 09/09/2008 - Diário da Justiça, Seção 1, 10/11/2008. [Descrição do Caso] [Catalogação de Patrick Faria ]

Discussão sobre a legalidade da renovação sucessiva de autorização judicial de interceptação telefônica. Decisão unânime da $6^{a}$ Turma do STJ no sentido de que inexiste, na Lei $n^{\circ}$ 9.296/96, previsão de renovação sucessiva de interceptação e de que, havendo conflito entre normas, decide-se a favor da liberdade, sendo que a prorrogação de quebra de sigilo por prazo distinto ao da Lei de Interceptação deve ser exaustivamente fundamentada. 
Supremo Tribunal Federal - Referendo de Medida Cautelar no Mandado de Segurança no 27483 (STF MS no 27483 REF-MC / DF - Distrito Federal) - Relator: Min. Cezar Peluso - Tribunal Pleno do STF - Maioria - j. 14/08/2008 - Diário da Justiça, 10/10/2008. [Descrição do Caso] [Catalogação de Márcio Iório Aranha ]

Reconhecimento, por parte do Plenário do Supremo Tribunal Federal, da constitucionalidade de poderes de Comissão Parlamentar de Inquérito (CPI) em requisitar de operadoras de telecomunicações dados consolidados de juízos, mandados, órgãos policiais, localização e duração de interceptações telefônicas em determinado período para fins investigativos, vedada a entrega de quaisquer outras informações, em especial, números de processos, nomes das partes, titulares dos terminais interceptados, números telefônicos interceptados e cópias dos mandados ou de decisões que os ensejaram. Mantida a posição jurisprudencial do tribunal em vedar a decretação, por CPI, de interceptação telefônica, por tratar-se de matéria de reserva de jurisdição. Declarada a aplicação do princípio da separação dos poderes como limite a pretensões de CPI em obter informações sigilosas de processos em segredo de justiça.

\section{Convergência}

\section{Normatização}

Portaria MC no 178, de 22 de abril de 2008 - Dispõe sobre diretrizes para implementação das políticas públicas em telecomunicações.

Resolução da ANATEL no 492, de 19 de fevereiro de 2008 - Aprova a Norma para Certificação e Homologação de Transmissores e Transceptores Digitais para o Serviço Fixo em Aplicações Ponto-Multiponto nas Faixas de Freqüências acima de $1 \mathrm{GHz}$.

$\hookrightarrow$ Anexo - Norma para Certificação e Homologação de Transmissores e Transceptores Digitais para o Serviço Fixo em Aplicações Ponto-Multiponto nas Faixas de Freqüências acima de $1 \mathrm{GHz}$.

Resolução da ANATEL no 516, de 30 de outubro de 2008 - Aprova o Plano Geral de Atualização da Regulamentação das Telecomunicações no Brasil (PGR).

$\hookrightarrow$ Anexo - Plano Geral de Atualização da Regulamentação das Telecomunicações no Brasil (PGR).

$\checkmark$ Inscrição da ampliação da oferta convergente de serviços como objetivo da atualização da regulamentação a partir de 2008 . 


\section{Classificações de Serviços no Setor de Telecomunicações}

\section{Quanto ao Regime Jurídico de Prestação}

Normatização

Decreto $\mathbf{n}^{\mathbf{0}}$ 6.654, de 20 de novembro de 2008 - Aprova o Plano Geral de Outorgas de Serviço de Telecomunicações prestado no regime público.

$\hookrightarrow$ Anexo 1 - Regiões do Plano Geral de Outorgas.

$\hookrightarrow$ Anexo 2 - Setores das Regiões do Plano Geral de Outorgas.

\section{Quanto ao Gênero}

\section{Serviço Limitado}

\section{Serviço Limitado Privado}

\section{Normatização}

Resolução da ANATEL no 494, de 24 de março de 2008 - Aprova o Regulamento sobre Canalização e Condições de Uso de Radiofreqüências na Faixa de 4,9 GHz.

$\hookrightarrow$ Anexo - Regulamento sobre Canalização e Condições de Uso de Radiofrequiências na Faixa de 4,9 GHz.

$\checkmark$ Destina a faixa de radiofrequiências de $4.940 \mathrm{MHz}$ a $4.990 \mathrm{MHz}$ para Proteção Pública e Situações de Calamidade.

Resolução da ANATEL $n^{0}$ 497, de 27 de março de 2008 - Destina a faixa de radiofrequiências de $2.400 \mathrm{MHz}$ a $2.483,5 \mathrm{MHz}$ para uso, em caráter secundário, por sistemas do Serviço Limitado Privado.

\section{Serviços no Setor de Telecomunicações}

\section{Serviço Telefônico Fixo Comutado (STFC)}

Jurisprudência

Tribunal de Contas da União - Processo Público no TC-019.677/2006-2 Monitoramento - Relator: Min. Ubiratan Aguiar - Plenário do TCU - Unânime - j. 26/11/2008 - Diário Oficial da União, Seção 1, 01/12/2008. [Descrição do Caso] [Catalogação de Rodrigo Fernandes ]

Decisão em que o TCU verificou que o estudo realizado acerca da situação econômico-financeira dos contratos de concessão de telefonia fixa, apresentava inconsistências na segregação dos dados e padecia de circularidades nos procedimentos de cálculo, bem como fazia conclusões com base em metodologia não confiável, não permitindo, portanto, aferir 
se foi mantido o equilíbrio econômico-financeiro dos contratos de concessão, no período de 1999-2004.

Tribunal de Contas da União - Processo $n^{0}$ TC-010.681/2008-0Representação - Relator: Min. Marcos Vinicios Vilaça - Plenário do TCU Unânime - j. 03/12/2008 - Diário Oficial da União, Seção 1, 09/12/2008. [Descrição do Caso] [Catalogação de Rodrigo Fernandes ]

Decisão em que o TCU verificou ser improcedente representação efetuada contra a aquisição do controle acionário da Brasil Telecom, pela Oi/Telemar, com recursos do Banco Nacional de Desenvolvimento Econômico e Social.

Superior Tribunal de Justiça - Recurso Especial no 1053778 (STJ - RESP 1053778 / RS - Rio Grande do Sul) - Relator: Min. Herman Benjamin Segunda Turma do STJ - Unânime - j. 09/09/2008 - Diário da Justiça, 10/10/2008. [Descrição do Caso] [Catalogação de Márcio Iório Aranha ]

É ilegal a prática de repercussão do PIS e da COFINS na tarifa cobrada do usuário de serviços de telefonia fixa prestado por concessionária, tanto de forma expressa, quanto de forma não destacada na conta telefônica. Consideração da composição de tarifa de telefonia como líquida de tributos não autoriza a empresa a acrescer à tarifa o PIS e a COFINS. Incidentalmente, reafirmou-se a competência da Justiça Estadual para julgar causas envolvendo composição da fatura de telefonia. A prática comercial de englobar no valor da tarifa o repasse do PIS e da COFINS viola o disposto no art. $3^{\circ}$, IV, da LGT, de direito à informação adequada, bem como se caracteriza como prática abusiva, conforme o art. 39, caput, do Código de Defesa do Consumidor.

Superior Tribunal de Justiça - Recurso Especial no 754393 (STJ - RESP 754393 / DF - Distrito Federal) - Relator: Min. Francisco Falcão - Primeira Turma do STJ - Maioria - j. 02/12/2008 - Diário da Justiça, 16/02/2009. [Descrição do Caso] [Catalogação de Márcio Iório Aranha ]

Não-incidência do ICMS sobre a assinatura mensal de telefonia, quando esta não comporta franquia de utilização.

Supremo Tribunal Federal - Recurso Extraordinário no 571572-8 (STF RE 571572-8 / BA - Bahia) - Relator: Min. Gilmar Mendes - Tribunal Pleno do STF - Unânime - j. 08/10/2008 - Diário da Justiça, Seção 1, 21/10/2008. [Descrição do Caso] [Catalogação de Patrick Faria ]

Discussão acerca da competência judicial - estadual ou federal - para julgamento de controvérsia entre consumidor e concessionária de STFC sobre cobrança de pulsos telefônicos além da franquia mensal. Decisão unânime do Pleno do STF no sentido de que é competente o juizado especial da justiça estadual, uma vez que não houve manifestação da Anatel no sentido de ter interesse na lide. Além do mais, a demanda não se caracteriza por complexa, bastando a análise de documentos e sua confrontação com as normas jurídicas aplicáveis. Quanto ao mérito do recurso em si, considerou-se que a matéria é eminentemente infraconstitucional, vez que as normas legais de direito do consumidor é que orientam o resultado da 
demanda e estas não tiveram sua constitucionalidade impugnada no curso da controvérsia.

Supremo Tribunal Federal - Referendo de Medida Cautelar no Mandado de Segurança no 27483 (STF MS no 27483 REF-MC / DF - Distrito Federal)

- Relator: Min. Cezar Peluso - Tribunal Pleno do STF - Maioria - j. 14/08/2008

- Diário da Justiça, 10/10/2008. [Descrição do Caso] [Catalogação de Márcio Iório Aranha ]

Reconhecimento, por parte do Plenário do Supremo Tribunal Federal, da constitucionalidade de poderes de Comissão Parlamentar de Inquérito (CPI) em requisitar de operadoras de telecomunicações dados consolidados de juízos, mandados, órgãos policiais, localização e duração de interceptações telefônicas em determinado período para fins investigativos, vedada a entrega de quaisquer outras informações, em especial, números de processos, nomes das partes, titulares dos terminais interceptados, números telefônicos interceptados e cópias dos mandados ou de decisões que os ensejaram. Mantida a posição jurisprudencial do tribunal em vedar a decretação, por CPI, de interceptação telefônica, por tratar-se de matéria de reserva de jurisdição. Declarada a aplicação do princípio da separação dos poderes como limite a pretensões de CPI em obter informações sigilosas de processos em segredo de justiça.

Superior Tribunal de Justiça - Súmula do STJ no 356 - Primeira Seção do STJ - j. 25/06/2008 - Diário da Justiça, 08/09/2008. [Descrição do Caso]

É legítima a cobrança da tarifa básica pelo uso dos serviços de telefonia fixa.

Superior Tribunal de Justiça - Súmula do STJ no 357 - Primeira Seção do STJ - j. 25/06/2008 - Diário da Justiça, 08/09/2008. [Descrição do Caso]

A pedido do assinante, que responderá pelos custos, é obrigatória, a partir de $1^{\circ}$ de janeiro de 2006, a discriminação de pulsos excedentes e ligações de telefone fixo para celular.

\section{Normatização}

Lei $\mathbf{n}^{\mathbf{0}}$ 11.652, de 7 de abril de 2008 - Institui os princípios e objetivos dos serviços de radiodifusão pública explorados pelo Poder Executivo ou outorgados a entidades de sua administração indireta; autoriza o Poder Executivo a constituir a Empresa Brasil de Comunicação - EBC; altera a Lei no 5.070, de 7 de julho de 1966; e dá outras providências [Conversão da Medida Provisória no 398, de 10 de outubro de 2007].

$\checkmark$ Previsão de incidência da Contribuição para o Fomento da Radiodifusão Pública.

Decreto $n^{0}$ 6.424, de 4 de abril de 2008 - Altera e acresce dispositivos ao Anexo do Decreto $n^{\circ} 4.769$, de 27 de junho de 2003, que aprova o Plano Geral de Metas para a Universalização do Serviço Telefônico Fixo Comutado prestado no Regime Público - PGMU.

Decreto $\mathbf{n}^{0}$ 6.654, de 20 de novembro de 2008 - Aprova o Plano Geral de Outorgas de Serviço de Telecomunicações prestado no regime público. 
$\hookrightarrow$ Anexo 1 - Regiões do Plano Geral de Outorgas.

$\hookrightarrow$ Anexo 2 - Setores das Regiões do Plano Geral de Outorgas.

Resolução da ANATEL $n^{\circ}$ 490, de 24 de janeiro de 2008 - Aprova o Regulamento de Conselho de Usuários do Serviço Telefônico Fixo Comutado - STFC.

$\hookrightarrow$ Anexo - Regulamento de Conselho de Usuários do Serviço Telefônico Fixo Comutado - STFC.

Resolução da ANATEL no 492, de 19 de fevereiro de 2008 - Aprova a Norma para Certificação e Homologação de Transmissores e Transceptores Digitais para o Serviço Fixo em Aplicações Ponto-Multiponto nas Faixas de Freqüências acima de $1 \mathrm{GHz}$.

$\hookrightarrow$ Anexo - Norma para Certificação e Homologação de Transmissores e Transceptores Digitais para o Serviço Fixo em Aplicações Ponto-Multiponto nas Faixas de Freqüências acima de $1 \mathrm{GHz}$.

Resolução da ANATEL no 499, de 28 de março de 2008 - Altera os Anexos I e II do Regulamento sobre Áreas Locais para o Serviço Telefônico Fixo Comutado Destinado ao Uso do Público em Geral - STFC.

$\hookrightarrow$ Anexo 1 - Altera o Anexo I do Regulamento sobre Áreas Locais.

$\hookrightarrow$ Anexo 2 - Altera o Anexo II do Regulamento sobre Áreas Locais.

Resolução da ANATEL $\mathbf{n}^{\circ}$ 506, de $1^{\circ}$ de julho de 2008 - Republica o Regulamento sobre Equipamentos de Radiocomunicação de Radiação Restrita. $\hookrightarrow$ Anexo - Regulamento sobre Equipamentos de Radiocomunicação de Radiação Restrita.

$\checkmark$ Regras aplicáveis ao bloqueio de sinais de radiocomunicações e aplicáveis ao acesso fixo sem fio para prestação do STFC.

Resolução da ANATEL $\mathbf{n}^{\circ}$ 507, de 16 de julho de 2008 - Aprova a Norma da Metodologia para Cálculo do Fator de Transferência "X", aplicado nos Reajustes de Tarifas do Serviço Telefônico Fixo Comutado, destinado ao uso do público em geral - STFC.

$\hookrightarrow$ Anexo - Norma da Metodologia para Cálculo do Fator de Transferência “X”, aplicado nos Reajustes de Tarifas do Serviço Telefônico Fixo Comutado, destinado ao uso do público em geral - STFC.

Resolução da ANATEL no 509, de 14 de agosto de 2008 - Aprova o Regulamento da Central de Intermediação de Comunicação Telefônica a ser utilizada por pessoas com deficiência auditiva ou da fala - CIC.

$\hookrightarrow$ Anexo - Regulamento da Central de Intermediação de Comunicação Telefônica a ser Utilizada por Pessoas com Deficiência Auditiva ou da Fala - CIC.

Resolução da ANATEL n 512, de 23 de setembro de 2008 - Aprova a Norma para Certificação e Homologação da Interface Analógica de Adaptadores para Terminal de Assinante.

$\hookrightarrow$ Anexo - Norma para Certificação e Homologação da Interface Analógica de Adaptadores para Terminal de Assinante. 
$\checkmark$ A Norma aprovada pela Res.512/2008 não se aplica à interface entre o STFC e o terminal do assinante definida pela Res.473/2007, nem às Centrais Privadas de Comutação Telefônica definidas pela Res.390/2004.

Resolução da ANATEL n $^{\circ}$ 516, de 30 de outubro de 2008 - Aprova o Plano Geral de Atualização da Regulamentação das Telecomunicações no Brasil (PGR).

$\hookrightarrow$ Anexo - Plano Geral de Atualização da Regulamentação das Telecomunicações no Brasil (PGR).

$\checkmark$ Projeção de demanda de 2008 a 2018.

Resolução da ANATEL $\mathbf{n}^{\circ}$ 523, de 15 de dezembro de 2008 - Aprova o Regulamento sobre Canalização e Condições de Uso de Radiofreqüências na Faixa de $148 \mathrm{MHz}$ a $174 \mathrm{MHz}$.

$\hookrightarrow$ Anexo

Manutenção da destinação das subfaixas de radiofrequência de $164,60 \mathrm{MHz}$ a $165,60 \mathrm{MHz}$ e de $169,20 \mathrm{MHz}$ a $170,20 \mathrm{MHz}$ para o STFC.

Resolução da ANATEL no 524, de 23 de dezembro de 2008 - Aprova a alteração dos Contratos de Concessão para a prestação do Serviço Telefônico Fixo Comutado - STFC, nas modalidades de serviço Local, Longa Distância Nacional - LDN e Longa Distância Internacional - LDI.

$\checkmark$ Prorrogação da consulta pública pertinente às propostas de alteração qüinquienal para 31 de março de 2009.

Atos

Análise ANATEL/GCPJ n$^{\circ}$ 368, de 7 de outubro de 2008 - Submete à aprovação a proposta de revisão do Plano Geral de Outorgas (PGO), aprovado pelo Decreto n ${ }^{\circ} 2.534$, de 2 de abril de 1998.

Ato do Conselho Diretor da ANATEL no 1.933, de 7 de abril de 2008 Aprova a celebração dos Termos Aditivos aos Termos de Autorização do Serviço de Comunicação Multimídia e do Serviço de Rede de Transporte de Telecomunicações detidos pelas concessionárias do Serviço Telefônico Fixo.

$\checkmark$ O Ato $n^{\circ} 1.933 / 2008$ é a conseqüência operacional do Decreto $n^{\circ} 6.424 / 2008$, que alterou o Plano Geral de Metas para a Universalização do STFC prestado no regime público após a aceitação por parte das concessionárias de STFC de proposta governamental de substituição de metas de universalização de instalação de PSTs pelo compromisso de instalação e manutenção de provimento de serviço de acesso banda larga a escolas públicas.

Ato do Conselho Diretor da ANATEL n* 4.197, de 16 de julho de 2008 Fixa os valores dos fatores de transferência X e DEA.

Ato do Conselho Diretor da ANATEL no 7.828, de 19 de dezembro de 2008 - Anuência prévia à aquisição por parte da TELEMAR NORTE LESTE S.A. de ações representativas do controle societário da Invitel S.A., controladora direta da Solpart Participações S.A. e controladora indireta da Brasil Telecom Participações S.A., da Brasil Telecom S.A., da Brasil Telecom Celular S.A., 
da Brasil Telecom Comunicação Multimídia S.A., da Brasil Telecom Cabos Submarinos LTDA., e da Vant Telecomunicações S.A.

$\hookrightarrow$ Anexo - Condicionamentos para o Ato de Anuência.

Termo Aditivo no 001/2008/SPV - BRASIL TELECOM, de 8 de abril de 2008 - Termo Aditivo ao Termo de Autorização para Exploração do SCM celebrado entre a ANATEL e a BRASIL TELECOM S.A. para implementação do compromisso de instalação e manutenção de provimento de serviço de acesso banda larga a escolas públicas até 31 de dezembro de 2025 .

$\hookrightarrow$ Anexo - Prazos, condições e critérios de qualidade para prestação de serviço de acesso banda larga.

Termo Aditivo n $^{0}$ 001/2008/SPV - CTBC, de 8 de abril de 2008 - Termo Aditivo ao Termo de Autorização para Exploração do SRTT celebrado entre a ANATEL e a COMPANHIA DE TELECOMUNICAÇÕES DO BRASIL CENTRAL para implementação do compromisso de instalação e manutenção de provimento de serviço de acesso banda larga a escolas públicas até 31 de dezembro de 2025.

$\hookrightarrow$ Anexo - Prazos, condições e critérios de qualidade para prestação de serviço de acesso banda larga.

Termo Aditivo no 001/2008/SPV - SERCOMTEL, de 8 de abril de 2008 Termo Aditivo ao Termo de Autorização para Exploração do SRTT celebrado entre a ANATEL e a SERCOMTEL S/A TELECOMUNICAÇÕES para implementação do compromisso de instalação e manutenção de provimento de serviço de acesso banda larga a escolas públicas até 31 de dezembro de 2025.

Termo Aditivo no 001/2008/SPV - TELEMAR, de 8 de abril de 2008 Termo Aditivo ao Termo de Autorização para Exploração do SCM celebrado entre a ANATEL e a TELEMAR NORTE LESTE S.A. para implementação do compromisso de instalação e manutenção de provimento de serviço de acesso banda larga a escolas públicas até 31 de dezembro de 2025 .

$\hookrightarrow$ Anexo - Prazos, condições e critérios de qualidade para prestação de serviço de acesso banda larga.

\section{Serviço Móvel Pessoal (SMP)}

Jurisprudência

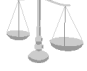

Tribunal de Contas da União - Processo Público no TC-023.855/2007-0 Acompanhamento - Relator: Min. Raimundo Carreiro - Plenário do TCU Unânime - j. 23/04/2008 - Diário Oficial da União, Seção 1, 25/04/2008. [Descrição do Caso] [Catalogação de Rodrigo Fernandes ]

Decisão em que o TCU verificou o processo de outorga de autorização para exploração do Serviço Móvel Pessoal e de autorização de uso de radiofreqüências nas subfaixas do IMT-2000 (J, F, G e I). O TCU entendeu regulares os compromissos de abrangência estipulados que se destinavam a assegurar o acesso ao serviço móvel pessoal em municípios com população inferior a 30.000 mil habitantes. 
Supremo Tribunal Federal - Referendo de Medida Cautelar no Mandado de Segurança no 27483 (STF MS no 27483 REF-MC / DF - Distrito Federal)

- Relator: Min. Cezar Peluso - Tribunal Pleno do STF - Maioria - j. 14/08/2008

- Diário da Justiça, 10/10/2008. [Descrição do Caso] [Catalogação de Márcio Iório Aranha ]

Reconhecimento, por parte do Plenário do Supremo Tribunal Federal, da constitucionalidade de poderes de Comissão Parlamentar de Inquérito (CPI) em requisitar de operadoras de telecomunicações dados consolidados de juízos, mandados, órgãos policiais, localização e duração de interceptações telefônicas em determinado período para fins investigativos, vedada a entrega de quaisquer outras informações, em especial, números de processos, nomes das partes, titulares dos terminais interceptados, números telefônicos interceptados e cópias dos mandados ou de decisões que os ensejaram. Mantida a posição jurisprudencial do tribunal em vedar a decretação, por CPI, de interceptação telefônica, por tratar-se de matéria de reserva de jurisdição. Declarada a aplicação do princípio da separação dos poderes como limite a pretensões de CPI em obter informações sigilosas de processos em segredo de justiça.

Superior Tribunal de Justiça - Súmula do STJ no 350 - Primeira Seção do STJ - j. 11/06/2008 - Diário Oficial da União, Seção 1, 19/06/2008, pág. 1. [Descrição do Caso]

O ICMS não incide sobre o serviço de habilitação de telefone celular.

\section{Normatização}

Lei $\mathbf{n}^{\circ}$ 11.652, de 7 de abril de 2008 - Institui os princípios e objetivos dos serviços de radiodifusão pública explorados pelo Poder Executivo ou outorgados a entidades de sua administração indireta; autoriza o Poder Executivo a constituir a Empresa Brasil de Comunicação - EBC; altera a Lei no 5.070, de 7 de julho de 1966; e dá outras providências [Conversão da Medida Provisória no 398, de 10 de outubro de 2007].

$\checkmark$ Previsão de incidência da Contribuição para o Fomento da Radiodifusão Pública.

Lei $\mathbf{n}^{\mathbf{0}}$ 11.829, de 25 de novembro de 2008 - Altera a Lei no 8.069, de 13 de julho de 1990 - Estatuto da Criança e do Adolescente, para aprimorar o combate à produção, venda e distribuição de pornografia infantil, bem como criminalizar a aquisição e a posse de tal material e outras condutas relacionadas à pedofilia na internet.

Portaria Interministerial $\mathbf{n}^{\mathbf{0}} \mathbf{2 3}$, de 29 de janeiro de 2008 [ Revogado por: Portaria Interministerial $n^{\circ} 236 / 2008$ ] - Altera a Portaria Interministerial n. 236, de 6 de dezembro de 2007, referente ao Processo Produtivo Básico de Terminal Portátil de Telefonia Celular industrializado na Zona Franca de Manaus.

Portaria Interministerial $\mathbf{n}^{\mathbf{0}}$ 29, de 29 de janeiro de 2008 - Altera a Portaria Interministerial n. 237, de 6 de dezembro de 2007, referente ao Processo Produtivo Básico de Terminal Portátil de Telefonia Celular. 
Portaria Interministerial $n^{\circ}$ 236, de 29 de dezembro de 2008 - Estabelece o Processo Produtivo Básico de Terminal Portátil de Telefonia Celular industrializado na Zona Franca de Manaus, dispõe sobre metas de produção e dá outras providências.

$\hookrightarrow$ Anexo 1 - Fabricação do conversor de corrente contínua (CA-CC) ou carregador de bateria para telefone celular.

$\hookrightarrow$ Anexo 2 - Fabricação do transformador elétrico de potência não superior a 3KVA, com núcleo de pó ferromagnético.

$\hookrightarrow$ Anexo 3 - Fabricação dos fios e cabos com conectores destinados a conversor e carregador de bateria para celular.

Portaria Interministerial $n^{\circ}$ 237, de 29 de dezembro de 2008 - Estabelece o Processo Produtivo Básico de Terminal Portátil de Telefonia Celular, dispõe sobre metas de produção e dá outras providências.

$\hookrightarrow$ Anexo 1 - Fabricação do conversor de corrente contínua (CA-CC) ou carregador de bateria para telefone celular.

$\hookrightarrow$ Anexo 2 - Fabricação do transformador elétrico de potência não superior a 3KVA, com núcleo de pó ferromagnético.

$\hookrightarrow$ Anexo 3 - Fabricação dos fios e cabos com conectores destinados a conversor e carregador de bateria para celular.

Resolução da ANATEL no 491, de 12 de fevereiro de 2008 - Aprova a alteração do art. 118 do Anexo à Resolução no 477, de 7 de agosto de 2007, que trata do Regulamento do Serviço Móvel Pessoal - SMP, e acrescenta ao Anexo o art. 119.

Resolução da ANATEL no 501, de 10 de abril de 2008 - Revoga a Resolução $\mathrm{n}^{\mathbf{o}}$ 227, de 21 de junho de 2000, que destina as faixas de freqüências de 1710 a $1755 \mathrm{MHz}, 1775$ a $1785 \mathrm{MHz}, 1805$ a $1850 \mathrm{MHz}$ e 1870 a $1880 \mathrm{MHz}$ para implantação de sistemas de telecomunicações móveis terrestres e as faixas de freqüências de 1885 a $1900 \mathrm{MHz}, 1950$ a $1980 \mathrm{MHz}$ e 2140 a $2170 \mathrm{MHz}$ para a implantação de sistemas de telecomunicações móveis que sigam as especificações IMT-2000 da UIT.

$\checkmark$ A Resolução 454/2006 regulou o uso de todas as faixas de frequiência do serviço móvel abstendo-se de disciplinar a tecnologia a ser utilizada. A revogação da Resolução 227/2000 uniformiza o tratamento regulatório sem restrição tecnológica nas faixas de freqüência de telefonia móvel.

Resolução da ANATEL no 503, de 25 de abril de 2008 - Prorroga o prazo para apresentação do Apêndice B do Anexo I do Documento de Separação e Alocação de Contas (DSAC) por Prestadoras do SMP que integrem Grupo detentor de Poder de Mercado Significativo na interconexão em rede móvel ou que façam parte de Grupo que contenha Concessionária do STFC.

Resolução da ANATEL $\mathbf{n}^{\circ}$ 506, de $1^{\circ}$ de julho de 2008 - Republica o Regulamento sobre Equipamentos de Radiocomunicação de Radiação Restrita. $\hookrightarrow$ Anexo - Regulamento sobre Equipamentos de Radiocomunicação de Radiação Restrita. 
$\checkmark$ Regras aplicáveis ao bloqueio de sinais de radiocomunicações.

Resolução da ANATEL $n^{\circ}$ 509, de 14 de agosto de 2008 - Aprova o Regulamento da Central de Intermediação de Comunicação Telefônica a ser utilizada por pessoas com deficiência auditiva ou da fala - CIC.

$\hookrightarrow$ Anexo - Regulamento da Central de Intermediação de Comunicação Telefônica a ser Utilizada por Pessoas com Deficiência Auditiva ou da Fala - CIC.

Resolução da ANATEL no 516, de 30 de outubro de 2008 - Aprova o Plano Geral de Atualização da Regulamentação das Telecomunicações no Brasil (PGR).

$\hookrightarrow$ Anexo - Plano Geral de Atualização da Regulamentação das Telecomunicações no Brasil (PGR).

$\checkmark$ Projeção de demanda de 2008 a 2018.

\section{Serviço de Comunicação Multimída (SCM)}

\section{Normatização}

Lei $\mathbf{n}^{\circ}$ 11.652, de 7 de abril de 2008 - Institui os princípios e objetivos dos serviços de radiodifusão pública explorados pelo Poder Executivo ou outorgados a entidades de sua administração indireta; autoriza o Poder Executivo a constituir a Empresa Brasil de Comunicação - EBC; altera a Lei no 5.070, de 7 de julho de 1966; e dá outras providências [Conversão da Medida Provisória no 398, de 10 de outubro de 2007].

$\checkmark$ Previsão de incidência da Contribuição para o Fomento da Radiodifusão Pública.

Lei $\mathbf{n}^{\circ}$ 11.829, de 25 de novembro de 2008 - Altera a Lei no 8.069, de 13 de julho de 1990 - Estatuto da Criança e do Adolescente, para aprimorar o combate à produção, venda e distribuição de pornografia infantil, bem como criminalizar a aquisição e a posse de tal material e outras condutas relacionadas à pedofilia na internet.

Portaria MC n $\mathbf{n}^{0}$ 178, de 22 de abril de 2008 - Dispõe sobre diretrizes para implementação das políticas públicas em telecomunicações.

Resolução da ANATEL n 492, de 19 de fevereiro de 2008 - Aprova a Norma para Certificação e Homologação de Transmissores e Transceptores Digitais para o Serviço Fixo em Aplicações Ponto-Multiponto nas Faixas de Frequiências acima de $1 \mathrm{GHz}$.

$\hookrightarrow$ Anexo - Norma para Certificação e Homologação de Transmissores e Transceptores Digitais para o Serviço Fixo em Aplicações Ponto-Multiponto nas Faixas de Freqüências acima de $1 \mathrm{GHz}$.

Resolução da ANATEL n $^{\circ}$ 497, de 27 de março de 2008 - Destina a faixa de radiofreqüências de $2.400 \mathrm{MHz}$ a $2.483,5 \mathrm{MHz}$ para uso, em caráter secundário, por sistemas do Serviço Limitado Privado.

Resolução da ANATEL $n^{\circ} 506$, de $1^{\circ}$ de julho de 2008 - Republica o Regulamento sobre Equipamentos de Radiocomunicação de Radiação Restrita. 
$\hookrightarrow$ Anexo - Regulamento sobre Equipamentos de Radiocomunicação de Radiação Restrita.

$\checkmark$ Regras aplicáveis ao bloqueio de sinais de radiocomunicações.

Resolução da ANATEL no 516, de 30 de outubro de 2008 - Aprova o Plano Geral de Atualização da Regulamentação das Telecomunicações no Brasil (PGR).

$\hookrightarrow$ Anexo - Plano Geral de Atualização da Regulamentação das Telecomunicações no Brasil (PGR).

$\checkmark$ Projeção de demanda de 2008 a 2018.

Atos

Ato do Conselho Diretor da ANATEL $n^{\circ}$ 1.933, de 7 de abril de 2008 Aprova a celebração dos Termos Aditivos aos Termos de Autorização do Serviço de Comunicação Multimídia e do Serviço de Rede de Transporte de Telecomunicações detidos pelas concessionárias do Serviço Telefônico Fixo.

$\checkmark$ O Ato $n^{\circ} 1.933 / 2008$ é a conseqüência operacional do Decreto $n^{\circ} 6.424 / 2008$, que alterou o Plano Geral de Metas para a Universalização do STFC prestado no regime público após a aceitação por parte das concessionárias de STFC de proposta governamental de substituição de metas de universalização de instalação de PSTs pelo compromisso de instalação e manutenção de provimento de serviço de acesso banda larga a escolas públicas.

Termo Aditivo $\mathrm{n}^{\circ}$ 001/2008/SPV - BRASIL TELECOM, de 8 de abril de 2008 - Termo Aditivo ao Termo de Autorização para Exploração do SCM celebrado entre a ANATEL e a BRASIL TELECOM S.A. para implementação do compromisso de instalação e manutenção de provimento de serviço de acesso banda larga a escolas públicas até 31 de dezembro de 2025 .

$\hookrightarrow$ Anexo - Prazos, condições e critérios de qualidade para prestação de serviço de acesso banda larga.

Termo Aditivo n* 001/2008/SPV - CTBC, de 8 de abril de 2008 - Termo Aditivo ao Termo de Autorização para Exploração do SRTT celebrado entre a ANATEL e a COMPANHIA DE TELECOMUNICAÇÕES DO BRASIL CENTRAL para implementação do compromisso de instalação e manutenção de provimento de serviço de acesso banda larga a escolas públicas até 31 de dezembro de 2025.

$\hookrightarrow$ Anexo - Prazos, condições e critérios de qualidade para prestação de serviço de acesso banda larga.

Termo Aditivo no 001/2008/SPV - TELEMAR, de 8 de abril de 2008 Termo Aditivo ao Termo de Autorização para Exploração do SCM celebrado entre a ANATEL e a TELEMAR NORTE LESTE S.A. para implementação do compromisso de instalação e manutenção de provimento de serviço de acesso banda larga a escolas públicas até 31 de dezembro de 2025 .

$\hookrightarrow$ Anexo - Prazos, condições e critérios de qualidade para prestação de serviço de acesso banda larga. 


\section{Internet}

\section{Jurisprudência}

Tribunal Superior do Trabalho - Agravo de Instrumento no Recurso de Revista no 1542/2005-055-02-40 (TST - RR 1542/2005-055-02-40 - AI) Relator: Min. Ives Gandra Martins Filho - Sétima Turma do TST - Unânime j. 04/06/2008 - Diário da Justiça, 06/06/2008. [Descrição do Caso] [Catalogação de Márcio Iório Aranha ]

É lícito o acesso, por empregador, à caixa de e-mail corporativo de seu empregado, não configurando violação de sigilo de comunicações de dados.

\section{Normatização}

Lei no 11.829, de 25 de novembro de 2008 - Altera a Lei no 8.069, de 13 de julho de 1990 - Estatuto da Criança e do Adolescente, para aprimorar o combate à produção, venda e distribuição de pornografia infantil, bem como criminalizar a aquisição e a posse de tal material e outras condutas relacionadas à pedofilia na internet.

Portaria MC no 178, de 22 de abril de 2008 - Dispõe sobre diretrizes para implementação das políticas públicas em telecomunicações.

\section{TV a Cabo}

\section{Normatização}

Lei $\mathbf{n}^{\mathbf{0}}$ 11.652, de 7 de abril de 2008 - Institui os princípios e objetivos dos serviços de radiodifusão pública explorados pelo Poder Executivo ou outorgados a entidades de sua administração indireta; autoriza o Poder Executivo a constituir a Empresa Brasil de Comunicação - EBC; altera a Lei no 5.070, de 7 de julho de 1966; e dá outras providências [Conversão da Medida Provisória n ${ }^{\circ}$ 398, de 10 de outubro de 2007].

$\checkmark$ Previsão de incidência da Contribuição para o Fomento da Radiodifusão Pública.

Lei $\mathbf{n}^{\mathbf{0}} \mathbf{1 1 . 8 2 9}$, de 25 de novembro de 2008 - Altera a Lei no 8.069, de 13 de julho de 1990 - Estatuto da Criança e do Adolescente, para aprimorar o combate à produção, venda e distribuição de pornografia infantil, bem como criminalizar a aquisição e a posse de tal material e outras condutas relacionadas à pedofilia na internet.

Portaria $\mathrm{MJ} \mathbf{n}^{\mathbf{0}}$ 36, de 8 de janeiro de 2008 - Altera o parágrafo único do art. 24 da Portaria $\mathrm{n}^{\circ} 1.220$, de 11 de julho de 2007 , que regulamenta o processo de classificação indicativa de obras audiovisuais destinadas à televisão e congêneres.

Resolução da ANATEL $\mathbf{n}^{\mathbf{0}}$ 493, de 27 de fevereiro de 2008 - Aprova a alteração do art. $6^{\circ}$ do Plano Geral de Metas de Qualidade para os serviços de televisão por assinatura (PGMQ - televisão por assinatura). 


\title{
TVA (Serviço Especial de TV por Assinatura)
}

\author{
Normatização
}

Lei $\mathrm{n}^{\mathbf{0}}$ 11.652, de 7 de abril de 2008 - Institui os princípios e objetivos dos serviços de radiodifusão pública explorados pelo Poder Executivo ou outorgados a entidades de sua administração indireta; autoriza o Poder Executivo a constituir a Empresa Brasil de Comunicação - EBC; altera a Lei no 5.070, de 7 de julho de 1966; e dá outras providências [Conversão da Medida Provisória no 398, de 10 de outubro de 2007].

$\checkmark$ Previsão de incidência da Contribuição para o Fomento da Radiodifusão Pública.

Lei $n^{\mathbf{0}}$ 11.829, de 25 de novembro de 2008 - Altera a Lei no 8.069, de 13 de julho de 1990 - Estatuto da Criança e do Adolescente, para aprimorar o combate à produção, venda e distribuição de pornografia infantil, bem como criminalizar a aquisição e a posse de tal material e outras condutas relacionadas à pedofilia na internet.

Portaria MJ n 36, de 8 de janeiro de 2008 - Altera o parágrafo único do art. 24 da Portaria $n^{\circ} 1.220$, de 11 de julho de 2007, que regulamenta o processo de classificação indicativa de obras audiovisuais destinadas à televisão e congêneres.

Resolução da ANATEL $\mathbf{n}^{\circ}$ 493, de 27 de fevereiro de 2008 - Aprova a alteração do art. $6^{\circ}$ do Plano Geral de Metas de Qualidade para os serviços de televisão por assinatura (PGMQ - televisão por assinatura).

Resolução da ANATEL n 505, de 5 de junho de 2008 - Suspende a eficácia, pelo prazo de 60 (sessenta) dias, dos arts. 30, 31 e 32 do Regulamento de Proteção e Defesa dos Direitos dos Assinantes dos Serviços de Televisão por Assinatura, aprovado pela Resolução no 488, de 3 de dezembro de 2007.

Resolução da ANATEL no 508, de 31 de julho de 2008 - Prorroga o prazo de suspensão da eficácia dos arts. 30 e 32 e suspende a eficácia do art. 29 do Regulamento de Proteção e Defesa dos Direitos dos Assinantes dos Serviços de Televisão por Assinatura, aprovado pela Resolução $n^{\circ} 488$, de 3 de dezembro de 2007.

Resolução da ANATEL no 513, de 29 de setembro de 2008 - Prorroga o prazo de suspensão da eficácia dos arts. 29, 30 e 32 do Regulamento de Proteção e Defesa dos Direitos dos Assinantes dos Serviços de Televisão por Assinatura, aprovado pela Resolução no 488, de 3 de dezembro de 2007.

Resolução da ANATEL no 517, de 31 de outubro de 2008 - Prorroga o prazo de suspensão da eficácia dos arts. 29, 30 e 32 do Regulamento de Proteção e Defesa dos Direitos dos Assinantes dos Serviços de Televisão por Assinatura, aprovado pela Resolução $n^{\circ} 488$, de 3 de dezembro de 2007.

Resolução da ANATEL n $^{\circ}$ 520, de 27 de novembro de 2008 - Prorroga o prazo de suspensão da eficácia dos arts. 29, 30 e 32 do Regulamento de Proteção e Defesa dos Direitos dos Assinantes dos Serviços de Televisão por Assinatura, aprovado pela Resolução n $^{\circ}$ 488, de 3 de dezembro de 2007. 


\section{DTH (Direct to Home - Serviço de Distribuição de Sinais de Televisão e de Áudio por Assinatura Via Satélite)}

\section{Normatização}

Lei $\mathbf{n}^{\mathbf{0}}$ 11.652, de 7 de abril de 2008 - Institui os princípios e objetivos dos serviços de radiodifusão pública explorados pelo Poder Executivo ou outorgados a entidades de sua administração indireta; autoriza o Poder Executivo a constituir a Empresa Brasil de Comunicação - EBC; altera a Lei no 5.070, de 7 de julho de 1966; e dá outras providências [Conversão da Medida Provisória no 398, de 10 de outubro de 2007].

$\checkmark$ Previsão de incidência da Contribuição para o Fomento da Radiodifusão Pública.

Lei $n^{\circ}$ 11.829, de 25 de novembro de 2008 - Altera a Lei no 8.069, de 13 de julho de 1990 - Estatuto da Criança e do Adolescente, para aprimorar o combate à produção, venda e distribuição de pornografia infantil, bem como criminalizar a aquisição e a posse de tal material e outras condutas relacionadas à pedofilia na internet.

Portaria MJ no 36, de 8 de janeiro de 2008 - Altera o parágrafo único do art. 24 da Portaria $n^{\circ} 1.220$, de 11 de julho de 2007, que regulamenta o processo de classificação indicativa de obras audiovisuais destinadas à televisão e congêneres.

Resolução da ANATEL $n^{\circ}$ 493, de 27 de fevereiro de 2008 - Aprova a alteração do art. $6^{\circ}$ do Plano Geral de Metas de Qualidade para os serviços de televisão por assinatura (PGMQ - televisão por assinatura).

Resolução da ANATEL n 505, de 5 de junho de 2008 - Suspende a eficácia, pelo prazo de 60 (sessenta) dias, dos arts. 30, 31 e 32 do Regulamento de Proteção e Defesa dos Direitos dos Assinantes dos Serviços de Televisão por Assinatura, aprovado pela Resolução no 488, de 3 de dezembro de 2007.

Resolução da ANATEL no 508, de 31 de julho de 2008 - Prorroga o prazo de suspensão da eficácia dos arts. 30 e 32 e suspende a eficácia do art. 29 do Regulamento de Proteção e Defesa dos Direitos dos Assinantes dos Serviços de Televisão por Assinatura, aprovado pela Resolução $n^{\circ} 488$, de 3 de dezembro de 2007.

Resolução da ANATEL no 513, de 29 de setembro de 2008 - Prorroga o prazo de suspensão da eficácia dos arts. 29, 30 e 32 do Regulamento de Proteção e Defesa dos Direitos dos Assinantes dos Serviços de Televisão por Assinatura, aprovado pela Resolução no 488, de 3 de dezembro de 2007.

Resolução da ANATEL no 517, de 31 de outubro de 2008 - Prorroga o prazo de suspensão da eficácia dos arts. 29, 30 e 32 do Regulamento de Proteção e Defesa dos Direitos dos Assinantes dos Serviços de Televisão por Assinatura, aprovado pela Resolução $n^{\circ} 488$, de 3 de dezembro de 2007.

Resolução da ANATEL no 520, de 27 de novembro de 2008 - Prorroga o prazo de suspensão da eficácia dos arts. 29, 30 e 32 do Regulamento de Proteção e Defesa dos Direitos dos Assinantes dos Serviços de Televisão por Assinatura, aprovado pela Resolução n 488, de 3 de dezembro de 2007. 


\section{MMDS (Multichannel Multipoint Distribution Service - Serviço de Distribuição de Sinais Multiponto Multicanal)}

\section{Normatização}

Lei $\mathbf{n}^{\circ}$ 11.652, de 7 de abril de 2008 - Institui os princípios e objetivos dos serviços de radiodifusão pública explorados pelo Poder Executivo ou outorgados a entidades de sua administração indireta; autoriza o Poder Executivo a constituir a Empresa Brasil de Comunicação - EBC; altera a Lei no 5.070, de 7 de julho de 1966; e dá outras providências [Conversão da Medida Provisória no 398, de 10 de outubro de 2007].

$\checkmark$ Previsão de incidência da Contribuição para o Fomento da Radiodifusão Pública.

Lei $\mathbf{n}^{\circ}$ 11.829, de 25 de novembro de 2008 - Altera a Lei no 8.069, de 13 de julho de 1990 - Estatuto da Criança e do Adolescente, para aprimorar o combate à produção, venda e distribuição de pornografia infantil, bem como criminalizar a aquisição e a posse de tal material e outras condutas relacionadas à pedofilia na internet.

Portaria MJ no 36, de 8 de janeiro de 2008 - Altera o parágrafo único do art. 24 da Portaria $n^{\circ} 1.220$, de 11 de julho de 2007, que regulamenta o processo de classificação indicativa de obras audiovisuais destinadas à televisão e congêneres.

Resolução da ANATEL $n^{\circ}$ 493, de 27 de fevereiro de 2008 - Aprova a alteração do art. $6^{\circ}$ do Plano Geral de Metas de Qualidade para os serviços de televisão por assinatura (PGMQ - televisão por assinatura).

Resolução da ANATEL no 505, de 5 de junho de 2008 - Suspende a eficácia, pelo prazo de 60 (sessenta) dias, dos arts. 30, 31 e 32 do Regulamento de Proteção e Defesa dos Direitos dos Assinantes dos Serviços de Televisão por Assinatura, aprovado pela Resolução no 488, de 3 de dezembro de 2007.

Resolução da ANATEL no 508, de 31 de julho de 2008 - Prorroga o prazo de suspensão da eficácia dos arts. 30 e 32 e suspende a eficácia do art. 29 do Regulamento de Proteção e Defesa dos Direitos dos Assinantes dos Serviços de Televisão por Assinatura, aprovado pela Resolução $n^{\circ} 488$, de 3 de dezembro de 2007.

Resolução da ANATEL no 513, de 29 de setembro de 2008 - Prorroga o prazo de suspensão da eficácia dos arts. 29, 30 e 32 do Regulamento de Proteção e Defesa dos Direitos dos Assinantes dos Serviços de Televisão por Assinatura, aprovado pela Resolução no 488, de 3 de dezembro de 2007.

Resolução da ANATEL no 517, de 31 de outubro de 2008 - Prorroga o prazo de suspensão da eficácia dos arts. 29, 30 e 32 do Regulamento de Proteção e Defesa dos Direitos dos Assinantes dos Serviços de Televisão por Assinatura, aprovado pela Resolução $n^{\circ} 488$, de 3 de dezembro de 2007.

Resolução da ANATEL no 520, de 27 de novembro de 2008 - Prorroga o prazo de suspensão da eficácia dos arts. 29, 30 e 32 do Regulamento de Proteção e Defesa dos Direitos dos Assinantes dos Serviços de Televisão por Assinatura, aprovado pela Resolução n 488, de 3 de dezembro de 2007. 


\title{
DISTV (Serviço de Distribuição de Sinais de TV por Meios Físicos)
}

\author{
Normatização
}

Lei $\mathbf{n}^{\mathbf{0}}$ 11.652, de 7 de abril de 2008 - Institui os princípios e objetivos dos serviços de radiodifusão pública explorados pelo Poder Executivo ou outorgados a entidades de sua administração indireta; autoriza o Poder Executivo a constituir a Empresa Brasil de Comunicação - EBC; altera a Lei no 5.070, de 7 de julho de 1966; e dá outras providências [Conversão da Medida Provisória n ${ }^{\circ}$ 398, de 10 de outubro de 2007].

$\checkmark$ Previsão de incidência da Contribuição para o Fomento da Radiodifusão Pública.

Lei $\mathbf{n}^{\mathbf{0}}$ 11.829, de 25 de novembro de 2008 - Altera a Lei no 8.069, de 13 de julho de 1990 - Estatuto da Criança e do Adolescente, para aprimorar o combate à produção, venda e distribuição de pornografia infantil, bem como criminalizar a aquisição e a posse de tal material e outras condutas relacionadas à pedofilia na internet.

Portaria $\mathrm{MJ} \mathrm{n}^{\circ}$ 36, de 8 de janeiro de 2008 - Altera o parágrafo único do art. 24 da Portaria $\mathrm{n}^{\circ} 1.220$, de 11 de julho de 2007, que regulamenta o processo de classificação indicativa de obras audiovisuais destinadas à televisão e congêneres.

Resolução da ANATEL no 505, de 5 de junho de 2008 - Suspende a eficácia, pelo prazo de 60 (sessenta) dias, dos arts. 30, 31 e 32 do Regulamento de Proteção e Defesa dos Direitos dos Assinantes dos Serviços de Televisão por Assinatura, aprovado pela Resolução no 488, de 3 de dezembro de 2007.

Resolução da ANATEL no 508, de 31 de julho de 2008 - Prorroga o prazo de suspensão da eficácia dos arts. 30 e 32 e suspende a eficácia do art. 29 do Regulamento de Proteção e Defesa dos Direitos dos Assinantes dos Serviços de Televisão por Assinatura, aprovado pela Resolução n ${ }^{\circ} 488$, de 3 de dezembro de 2007.

Resolução da ANATEL no 513, de 29 de setembro de 2008 - Prorroga o prazo de suspensão da eficácia dos arts. 29, 30 e 32 do Regulamento de Proteção e Defesa dos Direitos dos Assinantes dos Serviços de Televisão por Assinatura, aprovado pela Resolução no 488, de 3 de dezembro de 2007.

Resolução da ANATEL no 517, de 31 de outubro de 2008 - Prorroga o prazo de suspensão da eficácia dos arts. 29, 30 e 32 do Regulamento de Proteção e Defesa dos Direitos dos Assinantes dos Serviços de Televisão por Assinatura, aprovado pela Resolução $n^{\circ} 488$, de 3 de dezembro de 2007.

Resolução da ANATEL $\mathbf{n}^{\circ}$ 520, de 27 de novembro de 2008 - Prorroga o prazo de suspensão da eficácia dos arts. 29, 30 e 32 do Regulamento de Proteção e Defesa dos Direitos dos Assinantes dos Serviços de Televisão por Assinatura, aprovado pela Resolução n 488, de 3 de dezembro de 2007. 


\title{
Serviço Rádio do Cidadão
}

\author{
Normatização
}

Lei $\mathbf{n}^{0}$ 11.652, de 7 de abril de 2008 - Institui os princípios e objetivos dos serviços de radiodifusão pública explorados pelo Poder Executivo ou outorgados a entidades de sua administração indireta; autoriza o Poder Executivo a constituir a Empresa Brasil de Comunicação - EBC; altera a Lei no 5.070, de 7 de julho de 1966; e dá outras providências [Conversão da Medida Provisória no 398, de 10 de outubro de 2007].

$\checkmark$ Previsão de incidência da Contribuição para o Fomento da Radiodifusão Pública.

\section{Radioamador}

\section{Normatização}

Lei $\mathbf{n}^{\circ}$ 11.652, de 7 de abril de 2008 - Institui os princípios e objetivos dos serviços de radiodifusão pública explorados pelo Poder Executivo ou outorgados a entidades de sua administração indireta; autoriza o Poder Executivo a constituir a Empresa Brasil de Comunicação - EBC; altera a Lei no 5.070, de 7 de julho de 1966; e dá outras providências [Conversão da Medida Provisória nº 398, de 10 de outubro de 2007].

$\checkmark$ Previsão de incidência da Contribuição para o Fomento da Radiodifusão Pública.

Resolução da ANATEL $\mathbf{n}^{\circ}$ 506, de $1^{\circ}$ de julho de 2008 - Republica o Regulamento sobre Equipamentos de Radiocomunicação de Radiação Restrita.

$\hookrightarrow$ Anexo - Regulamento sobre Equipamentos de Radiocomunicação de Radiação Restrita.

$\checkmark$ O Regulamento de Equipamentos de Radiocomunicação de Radiação Restrita destina subfaixas de freqüência ao uso de sistemas de telecomando pelos portadores de Certificado de Operador de Estações de Radioamador - COER.

\section{Radiodifusão}

\section{Normatização}

Lei $\mathbf{n}^{\circ}$ 11.652, de 7 de abril de 2008 - Institui os princípios e objetivos dos serviços de radiodifusão pública explorados pelo Poder Executivo ou outorgados a entidades de sua administração indireta; autoriza o Poder Executivo a constituir a Empresa Brasil de Comunicação - EBC; altera a Lei no 5.070, de 7 de julho de 1966; e dá outras providências [Conversão da Medida Provisória no 398, de 10 de outubro de 2007].

Lei $n^{0}$ 11.829, de 25 de novembro de 2008 - Altera a Lei no 8.069, de 13 de julho de 1990 - Estatuto da Criança e do Adolescente, para aprimorar o combate à produção, venda e distribuição de pornografia infantil, bem como criminalizar a aquisição e a posse de tal material e outras condutas relacionadas à pedofilia na internet. 
Decreto de 14 de abril de 2008 - Renovação de Concessão da Globo em Belo Horizonte - Renova a concessão outorgada à Globo Comunicação e Participações S.A. para explorar serviço de radiodifusão de sons e imagens, sem direito de exclusividade, no Município de Belo Horizonte, Estado de Minas Gerais.

Decreto de 14 de abril de 2008 - Renovação de Concessão da Globo em Brasília - Renova a concessão outorgada à Globo Comunicação e Participações S.A. para explorar serviço de radiodifusão de sons e imagens, sem direito de exclusividade, na cidade de Brasília, Distrito Federal.

Decreto de 14 de abril de 2008 - Renovação de Concessão da Globo em Recife - Renova a concessão outorgada à Globo Comunicação e Participações S.A. para explorar serviço de radiodifusão de sons e imagens, sem direito de exclusividade, no Município de Recife, Estado de Pernambuco.

Decreto de 14 de abril de 2008 - Renovação de Concessão da Globo em São Paulo - Renova a concessão outorgada à Globo Comunicação e Participações S.A. para explorar serviço de radiodifusão de sons e imagens, sem direito de exclusividade, no Município de São Paulo, Estado de São Paulo.

Decreto de 14 de abril de 2008 - Renovação de Concessão da Globo no Rio de Janeiro - Renova a concessão outorgada à Globo Comunicação e Participações S.A. para explorar serviço de radiodifusão de sons e imagens, sem direito de exclusividade, no Município do Rio de Janeiro, Estado do Rio de Janeiro.

Decreto n⿳ 6.505, de 4 de julho de 2008 - Aprova o Regulamento Simplificado para contratação de serviços e aquisição de bens pela Empresa Brasil de Comunicação S.A. - EBC.

$\hookrightarrow$ Anexo - Regulamento Simplificado para contratação de serviços e aquisição de bens.

Decreto de 17 de setembro de 2008 - Renovação de Concessão da Record no Rio de Janeiro - Renova a concessão outorgada à Televisão Record do Rio de Janeiro Ltda., para explorar serviço de radiodifusão de sons e imagem (televisão), sem direito de exclusividade, no Município do Rio de Janeiro, Estado do Rio de Janeiro.

Decreto $n^{\circ}$ 6.689, de 11 de dezembro de 2008 - Aprova o Estatuto Social da Empresa Brasil de Comunicação S.A. - EBC e revoga o art. 4o do Decreto no 6.246, 24 de outubro de 2007.

$\hookrightarrow$ Anexo - Estatuto Social da EBC

Portaria MJ no 36, de 8 de janeiro de 2008 - Altera o parágrafo único do art. 24 da Portaria $n^{\circ} 1.220$, de 11 de julho de 2007, que regulamenta o processo de classificação indicativa de obras audiovisuais destinadas à televisão e congêneres.

Resolução da ANATEL no 498, de 27 de março de 2008 - Norma para Certificação e Homologação de Transmissores e Retransmissores para o Sistema Brasileiro de Televisão Digital Terrestre. 
$\hookrightarrow$ Anexo - Norma para Certificação e Homologação de Transmissores e Retransmissores para o Sistema Brasileiro de Televisão Digital Terrestre.

Resolução da ANATEL no 504, de 14 de maio de 2008 - Alteração do Regulamento Sobre Canalização e Condições de Uso da Faixa de Radiofreqüências de $6.430 \mathrm{MHz}$ a $7.110 \mathrm{MHz}$.

$\hookrightarrow$ Anexo - Regulamento Sobre Canalização e Condições de Uso da Subfaixa de Radiofrequiências de $6.430 \mathrm{MHz}$ a $7.110 \mathrm{MHz}$

$\checkmark$ A Resolução ${ }^{\circ} 504$ não se aplica às condições de uso das faixas de $6.650 \mathrm{MHz}$ a $6.770 \mathrm{MHz}$ e de $6.990 \mathrm{MHz}$ a $7.110 \mathrm{MHz}$, quando utilizadas pelo Serviço Auxiliar de Radiodifusão e Correlatos (SARC) e pelo Serviço de Repetição de Televisão (RpTV), que continuam submetidos à Resolução $n^{\circ} 82$, de 30 de dezembro de 1998.

Resolução da ANATEL n 514, de 7 de outubro de 2008 - Aprova a alteração do Regulamento Técnico para Prestação do Serviço de Radiodifusão Sonora em Onda Média e em Onda Tropical (faixa de $120 \mathrm{~m}$ ).

$\hookrightarrow$ Anexo - Alteração do Regulamento Técnico para Prestação do Serviço de Radiodifusão Sonora em Onda Média e em Onda Tropical (faixa de $120 \mathrm{~m}$ ), aprovado pela Resolução no 116, de 25 de março de 1999.

\section{Radiodifusão Comunitária}

\section{Jurisprudência}

Tribunal de Contas da União - Processo Público no TC-010.385/2006-7 Denúncia - Relator: Min. Ubiratan Aguiar - Plenário do TCU - Unânime - j. 24/09/2008 - Diário Oficial da União, Seção 1, 26/09/2008. [Descrição do Caso] [Catalogação de Rodrigo Fernandes ]

Decisão em que o TCU verificou que o Ministério das Comunicações não observou o critério da representatividade, definido no art. $9^{\circ}, \S 5^{\circ}$, da Lei 9.612/98, na seleção de prestador do serviço de radiodifusão comunitária. Apurou-se ainda, a existência de fragilidade na instrução e análise dos processos naquele órgão.

\section{Serviço Auxiliar de Radiodifusão e Correlatos (SARC)}

\section{Normatização}

Lei $\mathbf{n}^{\circ}$ 11.652, de 7 de abril de 2008 - Institui os princípios e objetivos dos serviços de radiodifusão pública explorados pelo Poder Executivo ou outorgados a entidades de sua administração indireta; autoriza o Poder Executivo a constituir a Empresa Brasil de Comunicação - EBC; altera a Lei no 5.070, de 7 de julho de 1966; e dá outras providências [Conversão da Medida Provisória no 398, de 10 de outubro de 2007].

$\checkmark$ Previsão de incidência da Contribuição para o Fomento da Radiodifusão Pública. 


\section{Serviço Especial de Repetição de Televisão (RpTV)}

\section{Normatização}

Lei $\mathbf{n}^{\mathbf{0}}$ 11.652, de 7 de abril de 2008 - Institui os princípios e objetivos dos serviços de radiodifusão pública explorados pelo Poder Executivo ou outorgados a entidades de sua administração indireta; autoriza o Poder Executivo a constituir a Empresa Brasil de Comunicação - EBC; altera a Lei no 5.070, de 7 de julho de 1966; e dá outras providências [Conversão da Medida Provisória n ${ }^{\circ} 398$, de 10 de outubro de 2007].

$\checkmark$ Previsão de incidência da Contribuição para o Fomento da Radiodifusão Pública.

\section{Rádio-taxi}

\section{Normatização}

Resolução da ANATEL $n^{\circ}$ 523, de 15 de dezembro de 2008 - Aprova o Regulamento sobre Canalização e Condições de Uso de Radiofrequiências na Faixa de $148 \mathrm{MHz}$ a $174 \mathrm{MHz}$.

\section{$\hookrightarrow$ Anexo}

$\checkmark$ Revogação da destinação das radiofrequiências de $158,71 \mathrm{MHz}, 163,31 \mathrm{MHz}$, $163,95 \mathrm{MHz}$ e $163,97 \mathrm{MHz}$ ao Serviço de Radiotáxi.

\section{Serviço de Rede de Transporte de Telecomunicações (SRTT)}

\section{Normatização}

Portaria MC no 178, de 22 de abril de 2008 - Dispõe sobre diretrizes para implementação das políticas públicas em telecomunicações.

\section{Atos}

Ato do Conselho Diretor da ANATEL no 1.933, de 7 de abril de 2008 Aprova a celebração dos Termos Aditivos aos Termos de Autorização do Serviço de Comunicação Multimídia e do Serviço de Rede de Transporte de Telecomunicações detidos pelas concessionárias do Serviço Telefônico Fixo.

$\checkmark$ O Ato $\mathrm{n}^{\circ} 1.933 / 2008$ é a conseqüência operacional do Decreto ${ }^{\circ} 6.424 / 2008$, que alterou o Plano Geral de Metas para a Universalização do STFC prestado no regime público após a aceitação por parte das concessionárias de STFC de proposta governamental de substituição de metas de universalização de instalação de PSTs pelo compromisso de instalação e manutenção de provimento de serviço de acesso banda larga a escolas públicas.

Termo Aditivo no 001/2008/SPV - SERCOMTEL, de 8 de abril de 2008 Termo Aditivo ao Termo de Autorização para Exploração do SRTT celebrado entre a ANATEL e a SERCOMTEL S/A TELECOMUNICAÇÕES para implementação do compromisso de instalação e manutenção de provimento de serviço de acesso banda larga a escolas públicas até 31 de dezembro de 2025. 
Serviço de Radiochamada ou Serviço Limitado Privado de Radiochamada (SLPR)

\section{Normatização}

Resolução da ANATEL $n^{\circ}$ 506, de $1^{\circ}$ de julho de 2008 - Republica o Regulamento sobre Equipamentos de Radiocomunicação de Radiação Restrita. $\hookrightarrow$ Anexo - Regulamento sobre Equipamentos de Radiocomunicação de Radiação Restrita.

$\checkmark$ Regras aplicáveis ao bloqueio de sinais de radiocomunicações.

\section{Serviço Especial de Radiochamada (SER) - ou Serviço Móvel Especial de Radiochamada}

\section{Normatização}

Lei $\mathrm{n}^{\mathbf{0}}$ 11.652, de 7 de abril de 2008 - Institui os princípios e objetivos dos serviços de radiodifusão pública explorados pelo Poder Executivo ou outorgados a entidades de sua administração indireta; autoriza o Poder Executivo a constituir a Empresa Brasil de Comunicação - EBC; altera a Lei no 5.070, de 7 de julho de 1966; e dá outras providências [Conversão da Medida Provisória no 398, de 10 de outubro de 2007].

$\checkmark$ Previsão de incidência da Contribuição para o Fomento da Radiodifusão Pública.

\section{Serviço Móvel Especializado ou Trunking ou Trunk ou Sistema Troncalizado}

Normatização

Resolução da ANATEL $\mathbf{n}^{\circ}$ 506, de $1^{\circ}$ de julho de 2008 - Republica o Regulamento sobre Equipamentos de Radiocomunicação de Radiação Restrita. $\hookrightarrow$ Anexo - Regulamento sobre Equipamentos de Radiocomunicação de Radiação Restrita.

$\checkmark$ Regras aplicáveis ao bloqueio de sinais de radiocomunicações.

Resolução da ANATEL $\mathbf{n}^{0}$ 518, de 21 de novembro de 2008 - Aprova alteração no Regulamento do Serviço Móvel Especializado -SME.

$\hookrightarrow$ Anexo - Alteração do Regulamento do Serviço Móvel Especializado -SME.

Resolução da ANATEL no 519, de 21 de novembro de 2008 - Aprova alteração no Plano Geral de Autorizações do Serviço Móvel Especializado SME.

$\hookrightarrow$ Anexo - Alteração do Plano Geral de Autorizações do Serviço Móvel Especializado - SME. 


\title{
Serviço Móvel Global por Satélite (SMGS)
}

\author{
Normatização
}

Resolução da ANATEL $\mathbf{n}^{0}$ 506, de $1^{\circ}$ de julho de 2008 - Republica o Regulamento sobre Equipamentos de Radiocomunicação de Radiação Restrita. $\hookrightarrow$ Anexo - Regulamento sobre Equipamentos de Radiocomunicação de Radiação Restrita.

$\checkmark$ Regras aplicáveis ao bloqueio de sinais de radiocomunicações.

\section{Serviço Móvel Marítimo}

\section{Normatização}

Lei $\mathbf{n}^{0}$ 11.652, de 7 de abril de 2008 - Institui os princípios e objetivos dos serviços de radiodifusão pública explorados pelo Poder Executivo ou outorgados a entidades de sua administração indireta; autoriza o Poder Executivo a constituir a Empresa Brasil de Comunicação - EBC; altera a Lei no 5.070, de 7 de julho de 1966; e dá outras providências [Conversão da Medida Provisória n ${ }^{\circ} 398$, de 10 de outubro de 2007].

$\checkmark$ Previsão de incidência da Contribuição para o Fomento da Radiodifusão Pública.

Resolução da ANATEL $n^{\circ}$ 523, de 15 de dezembro de 2008 - Aprova o Regulamento sobre Canalização e Condições de Uso de Radiofrequiências na Faixa de $148 \mathrm{MHz}$ a $174 \mathrm{MHz}$.

\section{$\hookrightarrow$ Anexo}

$\checkmark$ Manutenção da destinação das subfaixas de radiofrequência de $156,025 \mathrm{MHz}$ a $157,425 \mathrm{MHz}$, de $160,625 \mathrm{MHz}$ a $160,875 \mathrm{MHz}$, de $160,925 \mathrm{MHz}$ a 160,975 MHz e de 161,475 MHz a 162,025 MHz para o Serviço Móvel Marítimo.

\section{Serviço Especial de Sinais Horários}

\section{Normatização}

Lei $\mathbf{n}^{\mathbf{0}}$ 11.652, de 7 de abril de 2008 - Institui os princípios e objetivos dos serviços de radiodifusão pública explorados pelo Poder Executivo ou outorgados a entidades de sua administração indireta; autoriza o Poder Executivo a constituir a Empresa Brasil de Comunicação - EBC; altera a Lei no 5.070, de 7 de julho de 1966; e dá outras providências [Conversão da Medida Provisória n ${ }^{\circ}$ 398, de 10 de outubro de 2007].

$\checkmark$ Isenção de pagamento da Contribuição para o Fomento da Radiodifusão Pública.

\section{Serviço Especial de Frequência Padrão}

\section{Normatização}

Lei $\mathbf{n}^{0}$ 11.652, de 7 de abril de 2008 - Institui os princípios e objetivos dos serviços de radiodifusão pública explorados pelo Poder Executivo ou outorgados 
a entidades de sua administração indireta; autoriza o Poder Executivo a constituir a Empresa Brasil de Comunicação - EBC; altera a Lei no 5.070, de 7 de julho de 1966; e dá outras providências [Conversão da Medida Provisória no 398, de 10 de outubro de 2007].

$\checkmark$ Isenção de pagamento da Contribuição para o Fomento da Radiodifusão Pública.

\section{Serviço Especial de Boletins Metereológicos}

\section{Normatização}

Lei $\mathbf{n}^{\circ}$ 11.652, de 7 de abril de 2008 - Institui os princípios e objetivos dos serviços de radiodifusão pública explorados pelo Poder Executivo ou outorgados a entidades de sua administração indireta; autoriza o Poder Executivo a constituir a Empresa Brasil de Comunicação - EBC; altera a Lei no 5.070, de 7 de julho de 1966; e dá outras providências [Conversão da Medida Provisória nº 398, de 10 de outubro de 2007].

$\checkmark$ Isenção de pagamento da Contribuição para o Fomento da Radiodifusão Pública.

\section{Serviço Especial de Fins Científicos ou Experimentais}

\section{Normatização}

Lei $\mathbf{n}^{\circ}$ 11.652, de 7 de abril de 2008 - Institui os princípios e objetivos dos serviços de radiodifusão pública explorados pelo Poder Executivo ou outorgados a entidades de sua administração indireta; autoriza o Poder Executivo a constituir a Empresa Brasil de Comunicação - EBC; altera a Lei no 5.070, de 7 de julho de 1966; e dá outras providências [Conversão da Medida Provisória $n^{\circ} 398$, de 10 de outubro de 2007].

$\checkmark$ Previsão de incidência da Contribuição para o Fomento da Radiodifusão Pública.

\section{Serviço Especial de Música Funcional}

\section{Normatização}

Lei $\mathbf{n}^{0}$ 11.652, de 7 de abril de 2008 - Institui os princípios e objetivos dos serviços de radiodifusão pública explorados pelo Poder Executivo ou outorgados a entidades de sua administração indireta; autoriza o Poder Executivo a constituir a Empresa Brasil de Comunicação - EBC; altera a Lei no 5.070, de 7 de julho de 1966; e dá outras providências [Conversão da Medida Provisória nº 398, de 10 de outubro de 2007].

$\checkmark$ Previsão de incidência da Contribuição para o Fomento da Radiodifusão Pública. 


\section{Serviço Especial de Circuito Fechado de Televisão com utilização de Radioenlace}

\section{Normatização}

Lei $\mathrm{n}^{\mathbf{0}}$ 11.652, de 7 de abril de 2008 - Institui os princípios e objetivos dos serviços de radiodifusão pública explorados pelo Poder Executivo ou outorgados a entidades de sua administração indireta; autoriza o Poder Executivo a constituir a Empresa Brasil de Comunicação - EBC; altera a Lei no 5.070, de 7 de julho de 1966; e dá outras providências [Conversão da Medida Provisória nº 398, de 10 de outubro de 2007].

$\checkmark$ Previsão de incidência da Contribuição para o Fomento da Radiodifusão Pública.

\section{Serviço Especial de Radiorrecado}

\section{Normatização}

Lei $\mathbf{n}^{\mathbf{0}}$ 11.652, de 7 de abril de 2008 - Institui os princípios e objetivos dos serviços de radiodifusão pública explorados pelo Poder Executivo ou outorgados a entidades de sua administração indireta; autoriza o Poder Executivo a constituir a Empresa Brasil de Comunicação - EBC; altera a Lei no 5.070, de 7 de julho de 1966; e dá outras providências [Conversão da Medida Provisória nº 398, de 10 de outubro de 2007].

$\checkmark$ Previsão de incidência da Contribuição para o Fomento da Radiodifusão Pública.

\section{Serviço Limitado de Radioestrada}

\section{Normatização}

Lei $\mathrm{n}^{\mathbf{0}}$ 11.652, de 7 de abril de 2008 - Institui os princípios e objetivos dos serviços de radiodifusão pública explorados pelo Poder Executivo ou outorgados a entidades de sua administração indireta; autoriza o Poder Executivo a constituir a Empresa Brasil de Comunicação - EBC; altera a Lei no 5.070, de 7 de julho de 1966; e dá outras providências [Conversão da Medida Provisória nº 398, de 10 de outubro de 2007].

$\checkmark$ Previsão de incidência da Contribuição para o Fomento da Radiodifusão Pública.

\section{Serviço Avançado de Mensagens (SAM)}

\section{Normatização}

Resolução da ANATEL $\mathbf{n}^{\circ}$ 506, de $1^{\circ}$ de julho de 2008 - Republica o Regulamento sobre Equipamentos de Radiocomunicação de Radiação Restrita.

$\hookrightarrow$ Anexo - Regulamento sobre Equipamentos de Radiocomunicação de Radiação Restrita.

$\checkmark$ Regras aplicáveis ao bloqueio de sinais de radiocomunicações. 


\title{
Serviço de Radiocomunicação Aeronáutico Público Restrito (SRA)
}

\author{
Normatização
}

Lei $\mathbf{n}^{\circ}$ 11.652, de 7 de abril de 2008 - Institui os princípios e objetivos dos serviços de radiodifusão pública explorados pelo Poder Executivo ou outorgados a entidades de sua administração indireta; autoriza o Poder Executivo a constituir a Empresa Brasil de Comunicação - EBC; altera a Lei no 5.070, de 7 de julho de 1966; e dá outras providências [Conversão da Medida Provisória no 398, de 10 de outubro de 2007].

$\checkmark$ Previsão de incidência da Contribuição para o Fomento da Radiodifusão Pública.

\section{Serviço Limitado Especializado (SLE)}

\section{Normatização}

Resolução da ANATEL n $^{\circ}$ 510, de 28 de agosto de 2008 - Atribui a Faixa de Radiofrequiências de $216 \mathrm{MHz}$ a $220 \mathrm{MHz}$ adicionalmente ao Serviço Móvel, em caráter secundário, destina a Faixa de Radiofrequiências de $217 \mathrm{MHz}$ a 218 $\mathrm{MHz}$ ao Serviço Limitado Privado (SLP) e ao Serviço Limitado Especializado (SLE), em caráter secundário, e aprova o Regulamento sobre Canalização e Condições de Uso na faixa de Radiofreqüências de 217 MHz a $218 \mathrm{MHz}$.

$\hookrightarrow$ Anexo - Regulamento sobre Canalização e Condições de Uso na Faixa de Radiofreqüências de $217 \mathrm{MHz}$ a $218 \mathrm{MHz}$.

Resolução da ANATEL no 523, de 15 de dezembro de 2008 - Aprova o Regulamento sobre Canalização e Condições de Uso de Radiofrequiências na Faixa de $148 \mathrm{MHz}$ a $174 \mathrm{MHz}$.

\section{$\hookrightarrow$ Anexo}

Destinação de subfaixas de radiofrequência entre $148 \mathrm{MHz}$ e $174 \mathrm{MHz}$ para o Serviço Limitado Especializado.

\section{Serviços Científicos}

\section{Serviço de Pesquisa Espacial}

\section{Normatização}

Resolução da ANATEL n$^{\circ}$ 515, de 10 de outubro de 2008 - Destina a faixa de radiofreqüências de 143,60 MHz a 143,65 MHz ao Serviço Limitado Privado, para uso em aplicações de Pesquisa Espacial, sentido espaço para Terra. 


\title{
Serviço de Exploração da Terra por Satélite
}

\author{
Normatização
}

Decreto $n^{\circ}$ 6.666, de 27 de novembro de 2008 - Institui, no âmbito do Poder Executivo federal, a Infra-Estrutura Nacional de Dados Espaciais - INDE, e dá outras providências.

\section{Serviço Limitado Móvel Privado}

\section{Normatização}

Resolução da ANATEL $\mathbf{n}^{\circ}$ 494, de 24 de março de 2008 - Aprova o Regulamento sobre Canalização e Condições de Uso de Radiofreqüências na Faixa de 4,9 GHz.

$\hookrightarrow$ Anexo - Regulamento sobre Canalização e Condições de Uso de Radiofreqüências na Faixa de 4,9 GHz.

Destina a faixa de radiofreqüências de $4.940 \mathrm{MHz}$ a 4.990 MHz para Proteção Pública e Situações de Calamidade.

\section{Serviço Limitado Privado}

\section{Normatização}

Lei $\mathbf{n}^{\circ}$ 11.652, de 7 de abril de 2008 - Institui os princípios e objetivos dos serviços de radiodifusão pública explorados pelo Poder Executivo ou outorgados a entidades de sua administração indireta; autoriza o Poder Executivo a constituir a Empresa Brasil de Comunicação - EBC; altera a Lei no 5.070, de 7 de julho de 1966; e dá outras providências [Conversão da Medida Provisória no 398, de 10 de outubro de 2007].

$\checkmark$ Previsão de incidência da Contribuição para o Fomento da Radiodifusão Pública.

Resolução da ANATEL $n^{\circ}$ 506, de $1^{\circ}$ de julho de 2008 - Republica o Regulamento sobre Equipamentos de Radiocomunicação de Radiação Restrita.

$\hookrightarrow$ Anexo - Regulamento sobre Equipamentos de Radiocomunicação de Radiação Restrita.

Dispensa de autorização do serviço e de licença e cadastramento de equipamentos de radiação restrita para Sistema de Acesso sem Fio em Banda Larga para Redes Locais.

Resolução da ANATEL $\mathbf{n}^{\circ}$ 510, de 28 de agosto de 2008 - Atribui a Faixa de Radiofreqüências de $216 \mathrm{MHz}$ a $220 \mathrm{MHz}$ adicionalmente ao Serviço Móvel, em caráter secundário, destina a Faixa de Radiofreqüências de $217 \mathrm{MHz}$ a 218 $\mathrm{MHz}$ ao Serviço Limitado Privado (SLP) e ao Serviço Limitado Especializado (SLE), em caráter secundário, e aprova o Regulamento sobre Canalização e Condições de Uso na faixa de Radiofreqüências de $217 \mathrm{MHz}$ a $218 \mathrm{MHz}$.

$\hookrightarrow$ Anexo - Regulamento sobre Canalização e Condições de Uso na Faixa de Radiofreqüências de $217 \mathrm{MHz}$ a $218 \mathrm{MHz}$. 
Resolução da ANATEL n$^{\circ}$ 515, de 10 de outubro de 2008 - Destina a faixa de radiofrequiências de 143,60 MHz a 143,65 MHz ao Serviço Limitado Privado, para uso em aplicações de Pesquisa Espacial, sentido espaço para Terra.

Resolução da ANATEL no 523, de 15 de dezembro de 2008 - Aprova o Regulamento sobre Canalização e Condições de Uso de Radiofreqüências na Faixa de $148 \mathrm{MHz}$ a $174 \mathrm{MHz}$.

$\hookrightarrow$ Anexo

$\checkmark$ Manutenção da destinação de subfaixas de radiofrequência entre $148 \mathrm{MHz}$ e $174 \mathrm{MHz}$ para o Serviço Limitado Privado.

\section{Serviço de Telefonia Rural}

\section{Normatização}

Resolução da ANATEL n$^{\circ}$ 523, de 15 de dezembro de 2008 - Aprova o Regulamento sobre Canalização e Condições de Uso de Radiofreqüências na Faixa de $148 \mathrm{MHz}$ a $174 \mathrm{MHz}$.

$\hookrightarrow$ Anexo

Uso das subfaixas de radiofrequências de $164,60 \mathrm{MHz}$ a $165,60 \mathrm{MHz}$ e de $169,20 \mathrm{MHz}$ a 170,20 MHz pelo Serviço de Telefonia Rural.

\section{Ramos Jurídicos Afins}

\section{Direito do Consumidor}

Jurisprudência

Superior Tribunal de Justiça - Recurso Especial no 1053778 (STJ - RESP 1053778 / RS - Rio Grande do Sul) - Relator: Min. Herman Benjamin Segunda Turma do STJ - Unânime - j. 09/09/2008 - Diário da Justiça, 10/10/2008. [Descrição do Caso] [Catalogação de Márcio Iório Aranha ]

É ilegal a prática de repercussão do PIS e da COFINS na tarifa cobrada do usuário de serviços de telefonia fixa prestado por concessionária, tanto de forma expressa, quanto de forma não destacada na conta telefônica. Consideração da composição de tarifa de telefonia como líquida de tributos não autoriza a empresa a acrescer à tarifa o PIS e a COFINS. Incidentalmente, reafirmou-se a competência da Justiça Estadual para julgar causas envolvendo composição da fatura de telefonia. A prática comercial de englobar no valor da tarifa o repasse do PIS e da COFINS viola o disposto no art. $3^{\circ}$, IV, da LGT, de direito à informação adequada, bem como se caracteriza como prática abusiva, conforme o art. 39, caput, do Código de Defesa do Consumidor.

Superior Tribunal de Justiça - Recurso Especial no 938827 (STJ - RESP 938827 / DF - Distrito Federal) - Relator: Min. Denise Arruda - Primeira 
Turma do STJ - Unânime - j. 18/09/2008 - Diário da Justiça, 29/09/2008. [Descrição do Caso] [Catalogação de Rosa Amaral ]

Discussão acerca da legitimidade passiva ad causam da concessionária do serviço público de telecomunicações para responder pela devolução de valores de ICMS. Pronunciamento pela ilegitimidade da prestadora para figurar no pólo passivo dessas demandas, por ser a Fazenda Pública o sujeito ativo da relação tributária, e não a concessionária de telefonia, simples responsável pelo repasse dos tributos ao ente federativo.

Supremo Tribunal Federal - Recurso Extraordinário no 571572-8 (STF RE 571572-8 / BA - Bahia) - Relator: Min. Gilmar Mendes - Tribunal Pleno do STF - Unânime - j. 08/10/2008 - Diário da Justiça, Seção 1, 21/10/2008. [Descrição do Caso] [Catalogação de Patrick Faria ]

Discussão acerca da competência judicial - estadual ou federal - para julgamento de controvérsia entre consumidor e concessionária de STFC sobre cobrança de pulsos telefônicos além da franquia mensal. Decisão unânime do Pleno do STF no sentido de que é competente o juizado especial da justiça estadual, uma vez que não houve manifestação da Anatel no sentido de ter interesse na lide. Além do mais, a demanda não se caracteriza por complexa, bastando a análise de documentos e sua confrontação com as normas jurídicas aplicáveis. Quanto ao mérito do recurso em si, considerou-se que a matéria é eminentemente infraconstitucional, vez que as normas legais de direito do consumidor é que orientam o resultado da demanda e estas não tiveram sua constitucionalidade impugnada no curso da controvérsia.

Superior Tribunal de Justiça - Súmula do STJ no 356 - Primeira Seção do STJ - j. 25/06/2008 - Diário da Justiça, 08/09/2008. [Descrição do Caso]

É legítima a cobrança da tarifa básica pelo uso dos serviços de telefonia fixa.

Superior Tribunal de Justiça - Súmula do STJ no 357 - Primeira Seção do STJ - j. 25/06/2008 - Diário da Justiça, 08/09/2008. [Descrição do Caso]

A pedido do assinante, que responderá pelos custos, é obrigatória, a partir de $1^{\circ}$ de janeiro de 2006, a discriminação de pulsos excedentes e ligações de telefone fixo para celular.

\section{Normatização}

Lei $\mathrm{n}^{\mathbf{0}} \mathbf{1 1 . 8 0 0}$, de 29 de outubro de 2008 - Acrescenta parágrafo único ao art. 33 da Lei no 8.078, de 11 de setembro de 1990 - Código de Defesa do Consumidor, para impedir que os fornecedores veiculem publicidade ao consumidor que aguarda, na linha telefônica, o atendimento de suas solicitações.

Decreto no 6.523, de 31 de julho de 2008 - Regulamenta a Lei no 8.078, de 11 de setembro de 1990, para fixar normas gerais sobre o Serviço de Atendimento ao Consumidor - SAC.

$\checkmark$ O Decreto 6.523/2008 tem o escopo específico de fixar normas gerais sobre o SAC por telefone, no âmbito dos fornecedores de serviços regulados pelo Poder Público federal. 
Resolução da ANATEL $\mathbf{n}^{\circ}$ 490, de 24 de janeiro de 2008 - Aprova o Regulamento de Conselho de Usuários do Serviço Telefônico Fixo Comutado - STFC.

$\hookrightarrow$ Anexo - Regulamento de Conselho de Usuários do Serviço Telefônico Fixo Comutado - STFC.

Resolução da ANATEL n 493, de 27 de fevereiro de 2008 - Aprova a alteração do art. $6^{\circ}$ do Plano Geral de Metas de Qualidade para os serviços de televisão por assinatura (PGMQ - televisão por assinatura).

Resolução da ANATEL $\mathbf{n}^{\circ}$ 506, de $1^{\circ}$ de julho de 2008 - Republica o Regulamento sobre Equipamentos de Radiocomunicação de Radiação Restrita. $\hookrightarrow$ Anexo - Regulamento sobre Equipamentos de Radiocomunicação de Radiação Restrita.

$\checkmark$ Os equipamentos de radiocomunicação de radiação restrita devem conter, em lugar facilmente visível, em etiqueta de difícil remoção, a informação de que operam em caráter secundário e, portanto, não têm direito à proteção contra interferência prejudicial, mesmo de estações do mesmo tipo, bem como não podem causar interferências a sistemas operando em caráter primário.

\section{Direito da Concorrência}

Atos

Ato do Conselho Diretor da ANATEL no 7.828, de 19 de dezembro de 2008 - Anuência prévia à aquisição por parte da TELEMAR NORTE LESTE S.A. de ações representativas do controle societário da Invitel S.A., controladora direta da Solpart Participações S.A. e controladora indireta da Brasil Telecom Participações S.A., da Brasil Telecom S.A., da Brasil Telecom Celular S.A., da Brasil Telecom Comunicação Multimídia S.A., da Brasil Telecom Cabos Submarinos LTDA., e da Vant Telecomunicações S.A.

$\hookrightarrow$ Anexo - Condicionamentos para o Ato de Anuência.

\section{Servidor Público (Direito Administrativo)}

\section{Normatização}

Decreto $\mathrm{n}^{\circ} \mathbf{6 . 5 3 0}$, de 4 de agosto de 2008 - Regulamenta a progressão e a promoção para os servidores do quadro efetivo das Agências Reguladoras de que tratam as Leis nos 10.768, de 19 de novembro de 2003, e 10.871, de 20 de maio de 2004, e dá outras providências.

$\hookrightarrow$ Anexo 1 - Requisitos Mínimos de Capacitação no Campo Específico de Atuação da Respectiva Carreira para Fins de Progressão.

$\hookrightarrow$ Anexo 2 - Requisitos Mínimos de Experiência e Capacitação no Campo Específico de Atuação da Respectiva Carreira para Fins de Promoção dos Ocupantes dos Cargos de Nível Superior. 
$\hookrightarrow$ Anexo 3 - Requisitos Mínimos de Experiência e Capacitação no Campo Específico de Atuação da Respectiva Carreira para Fins de Promoção dos Ocupantes dos Cargos de Nível Intermediário.

Decreto $n^{\circ}$ 6.602, de 14 de outubro de 2008 - Dispõe sobre o remanejamento de Funções Comissionadas Técnicas - FCT, da Agência Nacional de Telecomunicações - ANATEL para o Ministério do Planejamento, Orçamento e Gestão.

$\hookrightarrow$ Anexo - Tabela de Níveis das Funções Comissionadas Técnicas - FCT.

\section{Direito Penal}

\section{Jurisprudência}

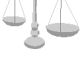

Superior Tribunal de Justiça - Habeas Corpus no 76686 (STJ - HC 76686

/ PR - Paraná) - Relator: Min. Nilson Naves - Sexta Turma do STJ - Unânime - j. 09/09/2008 - Diário da Justiça, Seção 1, 10/11/2008. [Descrição do Caso] [Catalogação de Patrick Faria ]

Discussão sobre a legalidade da renovação sucessiva de autorização judicial

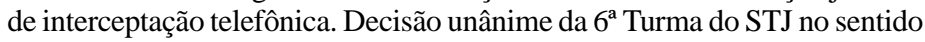
de que inexiste, na Lei $n^{\circ} 9.296 / 96$, previsão de renovação sucessiva de interceptação e de que, havendo conflito entre normas, decide-se a favor da liberdade, sendo que a prorrogação de quebra de sigilo por prazo distinto ao da Lei de Interceptação deve ser exaustivamente fundamentada.

\section{Normatização}

Lei $\mathbf{n}^{\circ}$ 11.829, de 25 de novembro de 2008 - Altera a Lei no 8.069, de 13 de julho de 1990 - Estatuto da Criança e do Adolescente, para aprimorar o combate à produção, venda e distribuição de pornografia infantil, bem como criminalizar a aquisição e a posse de tal material e outras condutas relacionadas à pedofilia na internet.

\section{Direito Processual}

\section{Jurisprudência}

Superior Tribunal de Justiça - Habeas Corpus no 76686 (STJ - HC 76686 / PR - Paraná) - Relator: Min. Nilson Naves - Sexta Turma do STJ - Unânime - j. 09/09/2008 - Diário da Justiça, Seção 1, 10/11/2008. [Descrição do Caso] [Catalogação de Patrick Faria ]

Discussão sobre a legalidade da renovação sucessiva de autorização judicial

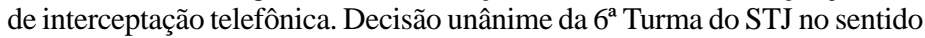
de que inexiste, na Lei n $^{\circ} 9.296 / 96$, previsão de renovação sucessiva de interceptação e de que, havendo conflito entre normas, decide-se a favor da liberdade, sendo que a prorrogação de quebra de sigilo por prazo distinto ao da Lei de Interceptação deve ser exaustivamente fundamentada. 


\section{Direito Tributário}

Jurisprudência

Superior Tribunal de Justiça - Recurso Especial no 1053778 (STJ - RESP
1053778 / RS - Rio Grande do Sul) - Relator: Min. Herman Benjamin -
Segunda Turma do STJ - Unânime - j. 09/09/2008 - Diário da Justiça,
10/10/2008. [Descrição do Caso] [Catalogação de Márcio Iório Aranha ]
É ilegal a prática de repercussão do PIS e da COFINS na tarifa cobrada do
usuário de serviços de telefonia fixa prestado por concessionária, tanto de
forma expressa, quanto de forma não destacada na conta telefônica.
Consideração da composição de tarifa de telefonia como líquida de tributos
não autoriza a empresa a acrescer à tarifa o PIS e a COFINS.
Incidentalmente, reafirmou-se a competência da Justiça Estadual para
julgar causas envolvendo composição da fatura de telefonia. A prática
comercial de englobar no valor da tarifa o repasse do PIS e da COFINS
viola o disposto no art. $3^{\circ}$, IV, da LGT, de direito à informação adequada,
bem como se caracteriza como prática abusiva, conforme o art. 39, caput,
do Código de Defesa do Consumidor.

Superior Tribunal de Justiça - Recurso Especial no 754393 (STJ - RESP 754393 / DF - Distrito Federal) - Relator: Min. Francisco Falcão - Primeira Turma do STJ - Maioria - j. 02/12/2008 - Diário da Justiça, 16/02/2009. [Descrição do Caso] [Catalogação de Márcio Iório Aranha ]

Não-incidência do ICMS sobre a assinatura mensal de telefonia, quando esta não comporta franquia de utilização.

\section{Direito Administrativo}

Jurisprudência

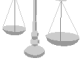

Superior Tribunal de Justiça - Recurso Especial no 1053778 (STJ - RESP 1053778 / RS - Rio Grande do Sul) - Relator: Min. Herman Benjamin Segunda Turma do STJ - Unânime - j. 09/09/2008 - Diário da Justiça, 10/10/2008. [Descrição do Caso] [Catalogação de Márcio Iório Aranha ]

É ilegal a prática de repercussão do PIS e da COFINS na tarifa cobrada do usuário de serviços de telefonia fixa prestado por concessionária, tanto de forma expressa, quanto de forma não destacada na conta telefônica. Consideração da composição de tarifa de telefonia como líquida de tributos não autoriza a empresa a acrescer à tarifa o PIS e a COFINS. Incidentalmente, reafirmou-se a competência da Justiça Estadual para julgar causas envolvendo composição da fatura de telefonia. A prática comercial de englobar no valor da tarifa o repasse do PIS e da COFINS viola o disposto no art. $3^{\circ}, \mathrm{IV}$, da LGT, de direito à informação adequada, bem como se caracteriza como prática abusiva, conforme o art. 39, caput, do Código de Defesa do Consumidor.

Superior Tribunal de Justiça - Recurso Especial no 754393 (STJ - RESP 754393 / DF - Distrito Federal) - Relator: Min. Francisco Falcão - Primeira 
Turma do STJ - Maioria - j. 02/12/2008 - Diário da Justiça, 16/02/2009. [Descrição do Caso] [Catalogação de Márcio Iório Aranha ]

Não-incidência do ICMS sobre a assinatura mensal de telefonia, quando esta não comporta franquia de utilização.

\section{Direito do Trabalho}

\section{Jurisprudência}

Tribunal Superior do Trabalho - Agravo de Instrumento no Recurso de Revista no 1542/2005-055-02-40 (TST - RR 1542/2005-055-02-40 - AI) Relator: Min. Ives Gandra Martins Filho - Sétima Turma do TST - Unânime j. 04/06/2008 - Diário da Justiça, 06/06/2008. [Descrição do Caso] [Catalogação de Márcio Iório Aranha ]

É lícito o acesso, por empregador, à caixa de e-mail corporativo de seu empregado, não configurando violação de sigilo de comunicações de dados.

\section{Aplicações de Telecomunicações}

\section{Aplicações Médicas}

\section{Normatização}

Resolução da ANATEL $\mathbf{n}^{\circ}$ 506, de $1^{\circ}$ de julho de 2008 - Republica o Regulamento sobre Equipamentos de Radiocomunicação de Radiação Restrita.

$\hookrightarrow$ Anexo - Regulamento sobre Equipamentos de Radiocomunicação de Radiação Restrita.

$\checkmark$ O dispositivo de telemedição biomédica é qualificado como equipamento de radiocomunicação de radiação restrita e, portanto, independe de outorga de autorização de uso de radiofreqüência e de licenciamento para instalação e funcionamento.

\section{Aplicações de Segurança}

\section{Normatização}

Resolução da ANATEL $\mathbf{n}^{\circ}$ 506, de $1^{\circ}$ de julho de 2008 - Republica o Regulamento sobre Equipamentos de Radiocomunicação de Radiação Restrita.

$\hookrightarrow$ Anexo - Regulamento sobre Equipamentos de Radiocomunicação de Radiação Restrita.

$\checkmark$ O emissor-sensor de variação de campo eletromagnético e o equipamento bloqueador de sinais de radiocomunicações - BSR são qualificados como equipamentos de radiocomunicação de radiação restrita e, portanto, independem de outorga de autorização de uso de radiofreqüência e de licenciamento para instalação e funcionamento. 


\section{Internet}

Turisprudência

- Tribunal Superior do Trabalho - Agravo de Instrumento no Recurso de Revista no 1542/2005-055-02-40 (TST - RR 1542/2005-055-02-40 - AI) Relator: Min. Ives Gandra Martins Filho - Sétima Turma do TST - Unânime j. 04/06/2008 - Diário da Justiça, 06/06/2008. [Descrição do Caso] [Catalogação de Márcio Iório Aranha ]

É lícito o acesso, por empregador, à caixa de e-mail corporativo de seu empregado, não configurando violação de sigilo de comunicações de dados.

\section{Normatização}

Lei $\mathbf{n}^{\circ}$ 11.829, de 25 de novembro de 2008 - Altera a Lei no 8.069, de 13 de julho de 1990 - Estatuto da Criança e do Adolescente, para aprimorar o combate à produção, venda e distribuição de pornografia infantil, bem como criminalizar a aquisição e a posse de tal material e outras condutas relacionadas à pedofilia na internet.

\section{Telecomando}

\section{Normatização}

Resolução da ANATEL $\mathbf{n}^{\circ}$ 506, de $1^{\circ}$ de julho de 2008 - Republica o Regulamento sobre Equipamentos de Radiocomunicação de Radiação Restrita.

$\hookrightarrow$ Anexo - Regulamento sobre Equipamentos de Radiocomunicação de Radiação Restrita.

$\checkmark$ O Regulamento de Equipamentos de Radiocomunicação de Radiação Restrita estipula requisitos e faixas de freqüência para enquadramento dos sistemas de telecomando que menciona.

\section{Telemetria}

Normatização

Resolução da ANATEL $\mathbf{n}^{\circ}$ 506, de $1^{\circ}$ de julho de 2008 - Republica o Regulamento sobre Equipamentos de Radiocomunicação de Radiação Restrita.

$\hookrightarrow$ Anexo - Regulamento sobre Equipamentos de Radiocomunicação de Radiação Restrita.

\section{Acessibilidade}

\section{Normatização}

Resolução da ANATEL $n^{0}$ 491, de 12 de fevereiro de 2008 - Aprova a alteração do art. 118 do Anexo à Resolução n 477, de 7 de agosto de 2007, 
que trata do Regulamento do Serviço Móvel Pessoal - SMP, e acrescenta ao Anexo o art. 119.

Resolução da ANATEL $\mathbf{n}^{\circ}$ 509, de 14 de agosto de 2008 - Aprova o Regulamento da Central de Intermediação de Comunicação Telefônica a ser utilizada por pessoas com deficiência auditiva ou da fala - CIC.

$\hookrightarrow$ Anexo - Regulamento da Central de Intermediação de Comunicação Telefônica a ser Utilizada por Pessoas com Deficiência Auditiva ou da Fala - CIC.

\section{Auxílio Auditivo}

\section{Normatização}

Resolução da ANATEL $\mathbf{n}^{\circ}$ 506, de $1^{\circ}$ de julho de 2008 - Republica o Regulamento sobre Equipamentos de Radiocomunicação de Radiação Restrita.

$\hookrightarrow$ Anexo - Regulamento sobre Equipamentos de Radiocomunicação de Radiação Restrita.

$\checkmark$ O dispositivo de auxílio auditivo é qualificado como equipamento de radiocomunicação de radiação restrita e, portanto, independe de outorga de autorização de uso de radiofreqüência e de licenciamento para instalação e funcionamento.

\section{Aeromodelismo}

\section{Normatização}

Resolução da ANATEL $\mathbf{n}^{\circ}$ 506, de $1^{\circ}$ de julho de 2008 - Republica o Regulamento sobre Equipamentos de Radiocomunicação de Radiação Restrita.

$\hookrightarrow$ Anexo - Regulamento sobre Equipamentos de Radiocomunicação de Radiação Restrita.

$\checkmark$ O Regulamento de Equipamentos de Radiocomunicação de Radiação Restrita estabelece as freqüências para uso de sistemas de telecomando para operação de aeromodelos.

\section{Acesso a Serviços de Interesse Público e Uso de Radiofrequência por tais Serviços}

\section{Segurança Pública}

\section{Normatização}

Resolução da ANATEL $\mathbf{n}^{\circ}$ 494, de 24 de março de 2008 - Aprova o Regulamento sobre Canalização e Condições de Uso de Radiofrequiências na Faixa de 4,9 GHz.

$\hookrightarrow$ Anexo - Regulamento sobre Canalização e Condições de Uso de Radiofreqüências na Faixa de 4,9 GHz. 
Destina a faixa de radiofreqüências de 4.940 MHz a 4.990 MHz para Proteção Pública e Situações de Calamidade.

\section{Defesa Civil}

Normatização

Resolução da ANATEL no 494, de 24 de março de 2008 - Aprova o Regulamento sobre Canalização e Condições de Uso de Radiofrequiências na Faixa de 4,9 GHz.

$\hookrightarrow$ Anexo - Regulamento sobre Canalização e Condições de Uso de Radiofrequiências na Faixa de 4,9 GHz.

$\checkmark$ Destina a faixa de radiofrequiências de $4.940 \mathrm{MHz}$ a $4.990 \mathrm{MHz}$ para Proteção Pública e Situações de Calamidade.

\section{Banda Larga}

Normatização

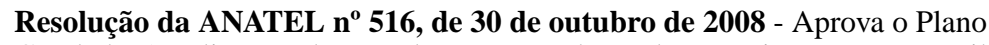
Geral de Atualização da Regulamentação das Telecomunicações no Brasil (PGR).

$\hookrightarrow$ Anexo - Plano Geral de Atualização da Regulamentação das Telecomunicações no Brasil (PGR).

$\checkmark$ Projeção de demanda de 2008 a 2018.

\section{Pesquisa Espacial}

Normatização

Resolução da ANATEL $\mathbf{n}^{0}$ 515, de 10 de outubro de 2008 - Destina a faixa de radiofrequiências de 143,60 MHz a 143,65 MHz ao Serviço Limitado Privado, para uso em aplicações de Pesquisa Espacial, sentido espaço para Terra.

\section{Telecomunicações no Cenário Internacional}

\section{Comissões Brasileiras de Comunicações}

Normatização

Resolução da ANATEL no ${ }^{\circ 02}$, de 18 de abril de 2008 - Altera a Estrutura Organizacional das Comissões Brasileiras de Comunicações.

$\hookrightarrow$ Anexo - Comissões Brasileiras de Comunicações. 


\section{Atores no Setor de Telecomunicações}

\section{ANATEL}

\section{Normatização}

Decreto $\mathrm{n}^{\mathbf{0}}$ 6.530, de 4 de agosto de 2008 - Regulamenta a progressão e a promoção para os servidores do quadro efetivo das Agências Reguladoras de que tratam as Leis nos 10.768, de 19 de novembro de 2003, e 10.871, de 20 de maio de 2004, e dá outras providências.

$\hookrightarrow$ Anexo 1 - Requisitos Mínimos de Capacitação no Campo Específico de Atuação da Respectiva Carreira para Fins de Progressão.

$\hookrightarrow$ Anexo 2 - Requisitos Mínimos de Experiência e Capacitação no Campo Específico de Atuação da Respectiva Carreira para Fins de Promoção dos Ocupantes dos Cargos de Nível Superior.

$\hookrightarrow$ Anexo 3 - Requisitos Mínimos de Experiência e Capacitação no Campo Específico de Atuação da Respectiva Carreira para Fins de Promoção dos Ocupantes dos Cargos de Nível Intermediário.

Decreto $n^{\circ}$ 6.602, de 14 de outubro de 2008 - Dispõe sobre o remanejamento de Funções Comissionadas Técnicas - FCT, da Agência Nacional de Telecomunicações - ANATEL para o Ministério do Planejamento, Orçamento e Gestão.

$\hookrightarrow$ Anexo - Tabela de Níveis das Funções Comissionadas Técnicas - FCT.

Resolução da ANATEL no 516, de 30 de outubro de 2008 - Aprova o Plano Geral de Atualização da Regulamentação das Telecomunicações no Brasil (PGR).

$\hookrightarrow$ Anexo - Plano Geral de Atualização da Regulamentação das Telecomunicações no Brasil (PGR).

$\checkmark$ Princípios, objetivos, propósitos e ações de curto, médio e longo prazos contados a partir de 2008 .

Atos

Análise ANATEL/GCAB n 455, de 9 de outubro de 2008 - Submete à aprovação a proposta de Plano Geral para Atualização da Regulamentação das Telecomunicações no Brasil (PGR).

Análise ANATEL/GCPJ n $^{\circ}$ 368, de 7 de outubro de 2008 - Submete à aprovação a proposta de revisão do Plano Geral de Outorgas (PGO), aprovado pelo Decreto $\mathrm{n}^{\circ} 2.534$, de 2 de abril de 1998. 


\section{Poder Legislativo}

\section{Congresso Nacional}

Jurisprudência

- Supremo Tribunal Federal - Referendo de Medida Cautelar no Mandado de Segurança no 27483 (STF MS no 27483 REF-MC / DF - Distrito Federal)

- Relator: Min. Cezar Peluso - Tribunal Pleno do STF - Maioria - j. 14/08/2008

- Diário da Justiça, 10/10/2008. [Descrição do Caso] [Catalogação de Márcio Iório Aranha ]

Reconhecimento, por parte do Plenário do Supremo Tribunal Federal, da constitucionalidade de poderes de Comissão Parlamentar de Inquérito (CPI) em requisitar de operadoras de telecomunicações dados consolidados de juízos, mandados, órgãos policiais, localização e duração de interceptações telefônicas em determinado período para fins investigativos, vedada a entrega de quaisquer outras informações, em especial, números de processos, nomes das partes, titulares dos terminais interceptados, números telefônicos interceptados e cópias dos mandados ou de decisões que os ensejaram. Mantida a posição jurisprudencial do tribunal em vedar a decretação, por CPI, de interceptação telefônica, por tratar-se de matéria de reserva de jurisdição. Declarada a aplicação do princípio da separação dos poderes como limite a pretensões de CPI em obter informações sigilosas de processos em segredo de justiça.

\section{Tribunal de Contas da União}

\section{Jurisprudência}

Tribunal de Contas da União - Processo Público no TC-002.660/2007-8 Auditoria de Natureza Operacional - Relator: Min. Raimundo Carreiro Plenário do TCU - Unânime - j. 02/04/2008 - Diário Oficial da União, Seção 1, 04/04/2008. [Descrição do Caso] [Catalogação de Rodrigo Fernandes ]

Decisão em que o TCU verificou a existência de baixo grau de consistência na elaboração de políticas públicas para o setor de telecomunicações; a ausência de metas para a utilização dos recursos do Fundo para o Desenvolvimento Tecnológico das Telecomunicações - Funttel; a carência de controles de arrecadação, bem como a ocorrência de irregularidades na elaboração e execução de convênios, contratos de repasses e outros instrumentos congêneres.

Tribunal de Contas da União - Processo Público no TC-010.385/2006-7 Denúncia - Relator: Min. Ubiratan Aguiar - Plenário do TCU - Unânime - j. 24/09/2008 - Diário Oficial da União, Seção 1, 26/09/2008. [Descrição do Caso] [Catalogação de Rodrigo Fernandes ]

Decisão em que o TCU verificou que o Ministério das Comunicações não observou o critério da representatividade, definido no art. $9^{\circ}$, § $5^{\circ}$, da Lei 9.612/98, na seleção de prestador do serviço de radiodifusão comunitária. 
Apurou-se ainda, a existência de fragilidade na instrução e análise dos processos naquele órgão.

Tribunal de Contas da União - Processo Público no TC-010.978/2008-1Monitoramento - Relator: Min. Augusto Sherman Cavalcanti - Plenário do TCU - Unânime - j. 23/07/2008 - Diário Oficial da União, Seção 1, 25/07/2008. [Descrição do Caso] [Catalogação de Rodrigo Fernandes ]

Decisão em que o TCU, ao monitorar o cumprimento do Acórdão 532/2005TCU-Plenário, atinente a irregularidades no recolhimento de taxas de fiscalização dos serviços de telecomunicações, entendeu indevido o procedimento adotado pela ANATEL de cancelar os créditos decorrentes do não pagamento da taxa de fiscalização dos serviços de telecomunicações - TFF.

Tribunal de Contas da União - Processo Público no TC-019.677/2006-2 Monitoramento - Relator: Min. Ubiratan Aguiar - Plenário do TCU - Unânime - j. 26/11/2008 - Diário Oficial da União, Seção 1, 01/12/2008. [Descrição do Caso] [Catalogação de Rodrigo Fernandes ]

Decisão em que o TCU verificou que o estudo realizado acerca da situação econômico-financeira dos contratos de concessão de telefonia fixa, apresentava inconsistências na segregação dos dados e padecia de circularidades nos procedimentos de cálculo, bem como fazia conclusões com base em metodologia não confiável, não permitindo, portanto, aferir se foi mantido o equilíbrio econômico-financeiro dos contratos de concessão, no período de 1999-2004.

Tribunal de Contas da União - Processo Público no TC-023.855/2007-0 Acompanhamento - Relator: Min. Raimundo Carreiro - Plenário do TCU Unânime - j. 23/04/2008 - Diário Oficial da União, Seção 1, 25/04/2008. [Descrição do Caso] [Catalogação de Rodrigo Fernandes ]

Decisão em que o TCU verificou o processo de outorga de autorização para exploração do Serviço Móvel Pessoal e de autorização de uso de radiofreqüências nas subfaixas do IMT-2000 (J, F, G e I). O TCU entendeu regulares os compromissos de abrangência estipulados que se destinavam a assegurar o acesso ao serviço móvel pessoal em municípios com população inferior a 30.000 mil habitantes.

Tribunal de Contas da União - Processo Público no TC-027.077/2006-4Representação - Relator: Min. Ubiratan Aguiar - Plenário do TCU - Unânime - j. 03/09/2008 - Diário Oficial da União, Seção 1, 05/09/2008. [Descrição do Caso] [Catalogação de Rodrigo Fernandes ]

Decisão em que o TCU entendeu que o art. 223, $\S 4^{\circ}$, da Constituição Federal não se aplica nos casos em que se verifica ocorrência de nulidade. A consultoria jurídica do Ministério das Comunicações, apesar de reconhecer o vício existente no processo de concessão de radiodifusão, entendia que somente seria possível a anulação da concessão por meio de ação judicial.

Tribunal de Contas da União - Processo no TC-010.681/2008-0Representação - Relator: Min. Marcos Vinicios Vilaça - Plenário do TCU - 
Unânime - j. 03/12/2008 - Diário Oficial da União, Seção 1, 09/12/2008. [Descrição do Caso] [Catalogação de Rodrigo Fernandes ]

Decisão em que o TCU verificou ser improcedente representação efetuada contra a aquisição do controle acionário da Brasil Telecom, pela Oi/Telemar, com recursos do Banco Nacional de Desenvolvimento Econômico e Social.

\section{Poder Executivo}

\section{Presidência da República}

\section{Normatização}

Decreto $\mathrm{n}^{\mathbf{0}}$ 6.424, de 4 de abril de 2008 - Altera e acresce dispositivos ao Anexo do Decreto $n^{\circ} 4.769$, de 27 de junho de 2003, que aprova o Plano Geral de Metas para a Universalização do Serviço Telefônico Fixo Comutado prestado no Regime Público - PGMU.

Decreto $n^{\circ}$ 6.654, de 20 de novembro de 2008 - Aprova o Plano Geral de Outorgas de Serviço de Telecomunicações prestado no regime público.

$\hookrightarrow$ Anexo 1 - Regiões do Plano Geral de Outorgas.

$\hookrightarrow$ Anexo 2 - Setores das Regiões do Plano Geral de Outorgas.

\section{Ministério das Comunicações}

\section{Jurisprudência}

Tribunal de Contas da União - Processo Público no TC-010.385/2006-7 Denúncia - Relator: Min. Ubiratan Aguiar - Plenário do TCU - Unânime - j. 24/09/2008 - Diário Oficial da União, Seção 1, 26/09/2008. [Descrição do Caso] [Catalogação de Rodrigo Fernandes ]

Decisão em que o TCU verificou que o Ministério das Comunicações não observou o critério da representatividade, definido no art. $9^{\circ}, \S 5^{\circ}$, da Lei 9.612/98, na seleção de prestador do serviço de radiodifusão comunitária. Apurou-se ainda, a existência de fragilidade na instrução e análise dos processos naquele órgão.

\section{Poder Judiciário}

\section{STF}

\section{Jurisprudência}

Supremo Tribunal Federal - Recurso Extraordinário no 571572-8 (STF RE 571572-8 / BA - Bahia) - Relator: Min. Gilmar Mendes - Tribunal Pleno do STF - Unânime - j. 08/10/2008 - Diário da Justiça, Seção 1, 21/10/2008. [Descrição do Caso] [Catalogação de Patrick Faria ] 
Discussão acerca da competência judicial - estadual ou federal - para julgamento de controvérsia entre consumidor e concessionária de STFC sobre cobrança de pulsos telefônicos além da franquia mensal. Decisão unânime do Pleno do STF no sentido de que é competente o juizado especial da justiça estadual, uma vez que não houve manifestação da Anatel no sentido de ter interesse na lide. Além do mais, a demanda não se caracteriza por complexa, bastando a análise de documentos e sua confrontação com as normas jurídicas aplicáveis. Quanto ao mérito do recurso em si, considerou-se que a matéria é eminentemente infraconstitucional, vez que as normas legais de direito do consumidor é que orientam o resultado da demanda e estas não tiveram sua constitucionalidade impugnada no curso da controvérsia.

Supremo Tribunal Federal - Referendo de Medida Cautelar no Mandado de Segurança no 27483 (STF MS n 27483 REF-MC / DF - Distrito Federal) - Relator: Min. Cezar Peluso - Tribunal Pleno do STF - Maioria - j. 14/08/2008 - Diário da Justiça, 10/10/2008. [Descrição do Caso] [Catalogação de Márcio Iório Aranha ]

Reconhecimento, por parte do Plenário do Supremo Tribunal Federal, da constitucionalidade de poderes de Comissão Parlamentar de Inquérito (CPI) em requisitar de operadoras de telecomunicações dados consolidados de juízos, mandados, órgãos policiais, localização e duração de interceptações telefônicas em determinado período para fins investigativos, vedada a entrega de quaisquer outras informações, em especial, números de processos, nomes das partes, titulares dos terminais interceptados, números telefônicos interceptados e cópias dos mandados ou de decisões que os ensejaram. Mantida a posição jurisprudencial do tribunal em vedar a decretação, por CPI, de interceptação telefônica, por tratar-se de matéria de reserva de jurisdição. Declarada a aplicação do princípio da separação dos poderes como limite a pretensões de CPI em obter informações sigilosas de processos em segredo de justiça.

\section{STJ}

\section{Jurisprudência}

Superior Tribunal de Justiça - Habeas Corpus no 76686 (STJ - HC 76686 / PR - Paraná) - Relator: Min. Nilson Naves - Sexta Turma do STJ - Unânime - j. 09/09/2008 - Diário da Justiça, Seção 1, 10/11/2008. [Descrição do Caso] [Catalogação de Patrick Faria ]

Discussão sobre a legalidade da renovação sucessiva de autorização judicial

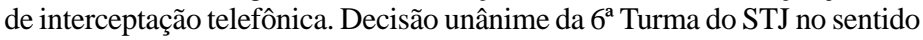
de que inexiste, na Lei $n^{\circ}$ 9.296/96, previsão de renovação sucessiva de interceptação e de que, havendo conflito entre normas, decide-se a favor da liberdade, sendo que a prorrogação de quebra de sigilo por prazo distinto ao da Lei de Interceptação deve ser exaustivamente fundamentada. 
Superior Tribunal de Justiça - Medida Cautelar n 13406 (STJ - MC 13406 / SP - São Paulo) - Relator: Min. Eliana Calmon - Segunda Turma do STJ Unânime - j. 16/10/2008 - Diário da Justiça, Seção 1, 07/11/2008. [Descrição do Caso] [Catalogação de Patrick Faria ]

Discussão sobre a legalidade de taxa instituída pelo município de São Paulo pela instalação de fios e cabos usados por empresas de telecomunicações no perímetro do sistema viário de sua área. Decisão unânime da $2^{\mathrm{a}}$ Turma do STJ no sentido de, primeiro, admitir a medida cautelar para conferir efeito suspensivo ao recurso especial pendente de admissibilidade na origem; posteriormente, julgar procedente o pedido cautelar, uma vez que configurado o fumus bonis iuris e o periculum in mora. $\mathrm{O}$ fumus bonis iuris, em razão do próprio dissídio jurisprudencial em que se assenta a admissibilidade do recurso, havendo precedentes no STJ no sentido da ilegalidade da cobrança por não deter esta natureza de preço público tampouco de taxa. $\mathrm{O}$ periculum in mora, tendo em vista que, caso a taxa seja considerada legal, acarretará o pagamento de vultosas quantias, fato que resultará em danos de difícil reparação.

Superior Tribunal de Justiça - Recurso Especial no 1053778 (STJ - RESP 1053778 / RS - Rio Grande do Sul) - Relator: Min. Herman Benjamin Segunda Turma do STJ - Unânime - j. 09/09/2008 - Diário da Justiça, 10/10/2008. [Descrição do Caso] [Catalogação de Márcio Iório Aranha ]

É ilegal a prática de repercussão do PIS e da COFINS na tarifa cobrada do usuário de serviços de telefonia fixa prestado por concessionária, tanto de forma expressa, quanto de forma não destacada na conta telefônica. Consideração da composição de tarifa de telefonia como líquida de tributos não autoriza a empresa a acrescer à tarifa o PIS e a COFINS. Incidentalmente, reafirmou-se a competência da Justiça Estadual para julgar causas envolvendo composição da fatura de telefonia. A prática comercial de englobar no valor da tarifa o repasse do PIS e da COFINS viola o disposto no art. $3^{\circ}$, IV, da LGT, de direito à informação adequada, bem como se caracteriza como prática abusiva, conforme o art. 39, caput, do Código de Defesa do Consumidor.

Superior Tribunal de Justiça - Recurso Especial no 754393 (STJ - RESP 754393 / DF - Distrito Federal) - Relator: Min. Francisco Falcão - Primeira Turma do STJ - Maioria - j. 02/12/2008 - Diário da Justiça, 16/02/2009. [Descrição do Caso] [Catalogação de Márcio Iório Aranha ]

Não-incidência do ICMS sobre a assinatura mensal de telefonia, quando esta não comporta franquia de utilização.

Superior Tribunal de Justiça - Recurso Especial no 938827 (STJ - RESP 938827 / DF - Distrito Federal) - Relator: Min. Denise Arruda - Primeira Turma do STJ - Unânime - j. 18/09/2008 - Diário da Justiça, 29/09/2008. [Descrição do Caso] [Catalogação de Rosa Amaral ]

Discussão acerca da legitimidade passiva ad causam da concessionária do serviço público de telecomunicações para responder pela devolução de valores de ICMS. Pronunciamento pela ilegitimidade da prestadora para figurar no pólo passivo dessas demandas, por ser a Fazenda Pública o 
sujeito ativo da relação tributária, e não a concessionária de telefonia, simples responsável pelo repasse dos tributos ao ente federativo.

Superior Tribunal de Justiça - Súmula do STJ no 350 - Primeira Seção do STJ - j. 11/06/2008 - Diário Oficial da União, Seção 1, 19/06/2008, pág. 1. [Descrição do Caso]

O ICMS não incide sobre o serviço de habilitação de telefone celular.

Superior Tribunal de Justiça - Súmula do STJ no 356 - Primeira Seção do STJ - j. 25/06/2008 - Diário da Justiça, 08/09/2008. [Descrição do Caso] É legítima a cobrança da tarifa básica pelo uso dos serviços de telefonia fixa.

Superior Tribunal de Justiça - Súmula do STJ no 357 - Primeira Seção do STJ - j. 25/06/2008 - Diário da Justiça, 08/09/2008. [Descrição do Caso] A pedido do assinante, que responderá pelos custos, é obrigatória, a partir de $1^{\circ}$ de janeiro de 2006, a discriminação de pulsos excedentes e ligações de telefone fixo para celular.

TJs

\section{Jurisprudência}

Supremo Tribunal Federal - Recurso Extraordinário no 571572-8 (STF RE 571572-8 / BA - Bahia) - Relator: Min. Gilmar Mendes - Tribunal Pleno do STF - Unânime - j. 08/10/2008 - Diário da Justiça, Seção 1, 21/10/2008. [Descrição do Caso] [Catalogação de Patrick Faria ]

Discussão acerca da competência judicial - estadual ou federal - para julgamento de controvérsia entre consumidor e concessionária de STFC sobre cobrança de pulsos telefônicos além da franquia mensal. Decisão unânime do Pleno do STF no sentido de que é competente o juizado especial da justiça estadual, uma vez que não houve manifestação da Anatel no sentido de ter interesse na lide. Além do mais, a demanda não se caracteriza por complexa, bastando a análise de documentos e sua confrontação com as normas jurídicas aplicáveis. Quanto ao mérito do recurso em si, considerou-se que a matéria é eminentemente infraconstitucional, vez que as normas legais de direito do consumidor é que orientam o resultado da demanda e estas não tiveram sua constitucionalidade impugnada no curso da controvérsia.

\section{TST}

Jurisprudência

Tribunal Superior do Trabalho - Agravo de Instrumento no Recurso de Revista no 1542/2005-055-02-40 (TST - RR 1542/2005-055-02-40 - AI) Relator: Min. Ives Gandra Martins Filho - Sétima Turma do TST - Unânime j. 04/06/2008 - Diário da Justiça, 06/06/2008. [Descrição do Caso] [Catalogação de Márcio Iório Aranha ] 
É lícito o acesso, por empregador, à caixa de e-mail corporativo de seu empregado, não configurando violação de sigilo de comunicações de dados.

\section{Prestadora / Operadora (direitos e deveres)}

Jurisprudência

Superior Tribunal de Justiça - Medida Cautelar no 13406 (STJ - MC 13406 / SP - São Paulo) - Relator: Min. Eliana Calmon - Segunda Turma do STJ Unânime - j. 16/10/2008 - Diário da Justiça, Seção 1, 07/11/2008. [Descrição do Caso] [Catalogação de Patrick Faria ]

Discussão sobre a legalidade de taxa instituída pelo município de São Paulo pela instalação de fios e cabos usados por empresas de telecomunicações no perímetro do sistema viário de sua área. Decisão unânime da $2^{\mathrm{a}}$ Turma do STJ no sentido de, primeiro, admitir a medida cautelar para conferir efeito suspensivo ao recurso especial pendente de admissibilidade na origem; posteriormente, julgar procedente o pedido cautelar, uma vez que configurado o fumus bonis iuris e o periculum in mora. $\mathrm{O}$ fumus bonis iuris, em razão do próprio dissídio jurisprudencial em que se assenta a admissibilidade do recurso, havendo precedentes no STJ no sentido da ilegalidade da cobrança por não deter esta natureza de preço público tampouco de taxa. O periculum in mora, tendo em vista que, caso a taxa seja considerada legal, acarretará o pagamento de vultosas quantias, fato que resultará em danos de difícil reparação.

Superior Tribunal de Justiça - Recurso Especial no 1053778 (STJ - RESP 1053778 / RS - Rio Grande do Sul) - Relator: Min. Herman Benjamin Segunda Turma do STJ - Unânime - j. 09/09/2008 - Diário da Justiça, 10/10/2008. [Descrição do Caso] [Catalogação de Márcio Iório Aranha ]

É ilegal a prática de repercussão do PIS e da COFINS na tarifa cobrada do usuário de serviços de telefonia fixa prestado por concessionária, tanto de forma expressa, quanto de forma não destacada na conta telefônica. Consideração da composição de tarifa de telefonia como líquida de tributos não autoriza a empresa a acrescer à tarifa o PIS e a COFINS. Incidentalmente, reafirmou-se a competência da Justiça Estadual para julgar causas envolvendo composição da fatura de telefonia. A prática comercial de englobar no valor da tarifa o repasse do PIS e da COFINS viola o disposto no art. $3^{\circ}$, IV, da LGT, de direito à informação adequada, bem como se caracteriza como prática abusiva, conforme o art. 39, caput, do Código de Defesa do Consumidor.

Superior Tribunal de Justiça - Recurso Especial no 754393 (STJ - RESP 754393 / DF - Distrito Federal) - Relator: Min. Francisco Falcão - Primeira Turma do STJ - Maioria - j. 02/12/2008 - Diário da Justiça, 16/02/2009. [Descrição do Caso] [Catalogação de Márcio Iório Aranha ]

Não-incidência do ICMS sobre a assinatura mensal de telefonia, quando esta não comporta franquia de utilização. 
Superior Tribunal de Justiça - Recurso Especial no 938827 (STJ - RESP 938827 / DF - Distrito Federal) - Relator: Min. Denise Arruda - Primeira Turma do STJ - Unânime - j. 18/09/2008 - Diário da Justiça, 29/09/2008. [Descrição do Caso] [Catalogação de Rosa Amaral ]

Discussão acerca da legitimidade passiva ad causam da concessionária do serviço público de telecomunicações para responder pela devolução de valores de ICMS. Pronunciamento pela ilegitimidade da prestadora para figurar no pólo passivo dessas demandas, por ser a Fazenda Pública o sujeito ativo da relação tributária, e não a concessionária de telefonia, simples responsável pelo repasse dos tributos ao ente federativo.

Supremo Tribunal Federal - Recurso Extraordinário no 571572-8 (STF RE 571572-8 / BA - Bahia) - Relator: Min. Gilmar Mendes - Tribunal Pleno do STF - Unânime - j. 08/10/2008 - Diário da Justiça, Seção 1, 21/10/2008. [Descrição do Caso] [Catalogação de Patrick Faria ]

Discussão acerca da competência judicial - estadual ou federal - para julgamento de controvérsia entre consumidor e concessionária de STFC sobre cobrança de pulsos telefônicos além da franquia mensal. Decisão unânime do Pleno do STF no sentido de que é competente o juizado especial da justiça estadual, uma vez que não houve manifestação da Anatel no sentido de ter interesse na lide. Além do mais, a demanda não se caracteriza por complexa, bastando a análise de documentos e sua confrontação com as normas jurídicas aplicáveis. Quanto ao mérito do recurso em si, considerou-se que a matéria é eminentemente infraconstitucional, vez que as normas legais de direito do consumidor é que orientam o resultado da demanda e estas não tiveram sua constitucionalidade impugnada no curso da controvérsia.

Supremo Tribunal Federal - Referendo de Medida Cautelar no Mandado de Segurança no 27483 (STF MS no 27483 REF-MC / DF - Distrito Federal) - Relator: Min. Cezar Peluso - Tribunal Pleno do STF - Maioria - j. 14/08/2008 - Diário da Justiça, 10/10/2008. [Descrição do Caso] [Catalogação de Márcio Iório Aranha ]

Reconhecimento, por parte do Plenário do Supremo Tribunal Federal, da constitucionalidade de poderes de Comissão Parlamentar de Inquérito (CPI) em requisitar de operadoras de telecomunicações dados consolidados de juízos, mandados, órgãos policiais, localização e duração de interceptações telefônicas em determinado período para fins investigativos, vedada a entrega de quaisquer outras informações, em especial, números de processos, nomes das partes, titulares dos terminais interceptados, números telefônicos interceptados e cópias dos mandados ou de decisões que os ensejaram. Mantida a posição jurisprudencial do tribunal em vedar a decretação, por CPI, de interceptação telefônica, por tratar-se de matéria de reserva de jurisdição. Declarada a aplicação do princípio da separação dos poderes como limite a pretensões de CPI em obter informações sigilosas de processos em segredo de justiça. 
Superior Tribunal de Justiça - Súmula do STJ no 350 - Primeira Seção do STJ - j. 11/06/2008 - Diário Oficial da União, Seção 1, 19/06/2008, pág. 1. [Descrição do Caso]

O ICMS não incide sobre o serviço de habilitação de telefone celular.

Superior Tribunal de Justiça - Súmula do STJ no 356 - Primeira Seção do STJ - j. 25/06/2008 - Diário da Justiça, 08/09/2008. [Descrição do Caso]

É legítima a cobrança da tarifa básica pelo uso dos serviços de telefonia fixa.

Superior Tribunal de Justiça - Súmula do STJ no 357 - Primeira Seção do STJ - j. 25/06/2008 - Diário da Justiça, 08/09/2008. [Descrição do Caso]

A pedido do assinante, que responderá pelos custos, é obrigatória, a partir de $1^{\circ}$ de janeiro de 2006, a discriminação de pulsos excedentes e ligações de telefone fixo para celular.

\section{Normatização}

Lei $\mathrm{n}^{\circ} \mathbf{1 1 . 8 0 0}$, de 29 de outubro de 2008 - Acrescenta parágrafo único ao art. 33 da Lei no 8.078, de 11 de setembro de 1990 - Código de Defesa do Consumidor, para impedir que os fornecedores veiculem publicidade ao consumidor que aguarda, na linha telefônica, o atendimento de suas solicitações.

Decreto $n^{\circ}$ 6.523, de 31 de julho de 2008 - Regulamenta a Lei no 8.078, de 11 de setembro de 1990, para fixar normas gerais sobre o Serviço de Atendimento ao Consumidor - SAC.

$\checkmark$ O Decreto 6.523/2008 tem o escopo específico de fixar normas gerais sobre o SAC por telefone, no âmbito dos fornecedores de serviços regulados pelo Poder Público federal.

Resolução da ANATEL $\mathbf{n}^{\circ}$ 493, de 27 de fevereiro de 2008 - Aprova a alteração do art. $6^{\circ}$ do Plano Geral de Metas de Qualidade para os serviços de televisão por assinatura (PGMQ - televisão por assinatura).

Resolução da ANATEL no 505, de 5 de junho de 2008 - Suspende a eficácia, pelo prazo de 60 (sessenta) dias, dos arts. 30, 31 e 32 do Regulamento de Proteção e Defesa dos Direitos dos Assinantes dos Serviços de Televisão por Assinatura, aprovado pela Resolução no 488, de 3 de dezembro de 2007.

Resolução da ANATEL no 508, de 31 de julho de 2008 - Prorroga o prazo de suspensão da eficácia dos arts. 30 e 32 e suspende a eficácia do art. 29 do Regulamento de Proteção e Defesa dos Direitos dos Assinantes dos Serviços de Televisão por Assinatura, aprovado pela Resolução n 488 , de 3 de dezembro de 2007.

Resolução da ANATEL $\mathbf{n}^{\circ}$ 509, de 14 de agosto de 2008 - Aprova o Regulamento da Central de Intermediação de Comunicação Telefônica a ser utilizada por pessoas com deficiência auditiva ou da fala - CIC.

$\hookrightarrow$ Anexo - Regulamento da Central de Intermediação de Comunicação Telefônica a ser Utilizada por Pessoas com Deficiência Auditiva ou da Fala - CIC. 
Resolução da ANATEL n 513, de 29 de setembro de 2008 - Prorroga o prazo de suspensão da eficácia dos arts. 29, 30 e 32 do Regulamento de Proteção e Defesa dos Direitos dos Assinantes dos Serviços de Televisão por Assinatura, aprovado pela Resolução no 488, de 3 de dezembro de 2007.

Resolução da ANATEL no 517, de 31 de outubro de 2008 - Prorroga o prazo de suspensão da eficácia dos arts. 29, 30 e 32 do Regulamento de Proteção e Defesa dos Direitos dos Assinantes dos Serviços de Televisão por Assinatura, aprovado pela Resolução $n^{\circ} 488$, de 3 de dezembro de 2007.

Resolução da ANATEL $\mathbf{n}^{\circ}$ 520, de 27 de novembro de 2008 - Prorroga o prazo de suspensão da eficácia dos arts. 29, 30 e 32 do Regulamento de Proteção e Defesa dos Direitos dos Assinantes dos Serviços de Televisão por Assinatura, aprovado pela Resolução n 488, de 3 de dezembro de 2007.

\section{Atos}

Ato do Conselho Diretor da ANATEL n 7.828, de 19 de dezembro de 2008 - Anuência prévia à aquisição por parte da TELEMAR NORTE LESTE S.A. de ações representativas do controle societário da Invitel S.A., controladora direta da Solpart Participações S.A. e controladora indireta da Brasil Telecom Participações S.A., da Brasil Telecom S.A., da Brasil Telecom Celular S.A., da Brasil Telecom Comunicação Multimídia S.A., da Brasil Telecom Cabos Submarinos LTDA., e da Vant Telecomunicações S.A.

$\hookrightarrow$ Anexo - Condicionamentos para o Ato de Anuência.

\section{Produtor Industrial}

\section{Normatização}

Resolução da ANATEL no 509, de 14 de agosto de 2008 - Aprova o Regulamento da Central de Intermediação de Comunicação Telefônica a ser utilizada por pessoas com deficiência auditiva ou da fala - CIC.

$\hookrightarrow$ Anexo - Regulamento da Central de Intermediação de Comunicação Telefônica a ser Utilizada por Pessoas com Deficiência Auditiva ou da Fala - CIC.

$\checkmark$ Os equipamentos empregados para intermediação de comunicação telefônica por pessoas com deficiência auditiva ou da fala devem garantir fidelidade, sigilo, confidencialidade e integralidade das mensagens e devem se comunicar com qualquer terminal ou estação móvel, inclusive com terminal adaptado para pessoas com deficiência auditiva ou da fala.

\section{Usuário / Consumidor (direitos e deveres)}

Jurisprudência

Superior Tribunal de Justiça - Habeas Corpus no 76686 (STJ - HC 76686
/ PR - Paraná) - Relator: Min. Nilson Naves - Sexta Turma do STJ - Unânime 
- j. 09/09/2008 - Diário da Justiça, Seção 1, 10/11/2008. [Descrição do Caso] [Catalogação de Patrick Faria ]

Discussão sobre a legalidade da renovação sucessiva de autorização judicial de interceptação telefônica. Decisão unânime da $6^{\text {a }}$ Turma do STJ no sentido de que inexiste, na Lei $n^{\circ} 9.296 / 96$, previsão de renovação sucessiva de interceptação e de que, havendo conflito entre normas, decide-se a favor da liberdade, sendo que a prorrogação de quebra de sigilo por prazo distinto ao da Lei de Interceptação deve ser exaustivamente fundamentada.

Superior Tribunal de Justiça - Recurso Especial no 1053778 (STJ - RESP 1053778 / RS - Rio Grande do Sul) - Relator: Min. Herman Benjamin Segunda Turma do STJ - Unânime - j. 09/09/2008 - Diário da Justiça, 10/10/2008. [Descrição do Caso] [Catalogação de Márcio Iório Aranha ]

É ilegal a prática de repercussão do PIS e da COFINS na tarifa cobrada do usuário de serviços de telefonia fixa prestado por concessionária, tanto de forma expressa, quanto de forma não destacada na conta telefônica. Consideração da composição de tarifa de telefonia como líquida de tributos não autoriza a empresa a acrescer à tarifa o PIS e a COFINS. Incidentalmente, reafirmou-se a competência da Justiça Estadual para julgar causas envolvendo composição da fatura de telefonia. A prática comercial de englobar no valor da tarifa o repasse do PIS e da COFINS viola o disposto no art. $3^{\circ}, \mathrm{IV}$, da LGT, de direito à informação adequada, bem como se caracteriza como prática abusiva, conforme o art. 39, caput, do Código de Defesa do Consumidor.

Superior Tribunal de Justiça - Recurso Especial no 754393 (STJ - RESP 754393 / DF - Distrito Federal) - Relator: Min. Francisco Falcão - Primeira Turma do STJ - Maioria - j. 02/12/2008 - Diário da Justiça, 16/02/2009. [Descrição do Caso] [Catalogação de Márcio Iório Aranha ]

Não-incidência do ICMS sobre a assinatura mensal de telefonia, quando esta não comporta franquia de utilização.

Superior Tribunal de Justiça - Recurso Especial no 938827 (STJ - RESP 938827 / DF - Distrito Federal) - Relator: Min. Denise Arruda - Primeira Turma do STJ - Unânime - j. 18/09/2008 - Diário da Justiça, 29/09/2008. [Descrição do Caso] [Catalogação de Rosa Amaral ]

Discussão acerca da legitimidade passiva ad causam da concessionária do serviço público de telecomunicações para responder pela devolução de valores de ICMS. Pronunciamento pela ilegitimidade da prestadora para figurar no pólo passivo dessas demandas, por ser a Fazenda Pública o sujeito ativo da relação tributária, e não a concessionária de telefonia, simples responsável pelo repasse dos tributos ao ente federativo.

Supremo Tribunal Federal - Recurso Extraordinário no 571572-8 (STF RE 571572-8 / BA - Bahia) - Relator: Min. Gilmar Mendes - Tribunal Pleno do STF - Unânime - j. 08/10/2008 - Diário da Justiça, Seção 1, 21/10/2008. [Descrição do Caso] [Catalogação de Patrick Faria ]

Discussão acerca da competência judicial - estadual ou federal - para julgamento de controvérsia entre consumidor e concessionária de STFC 
sobre cobrança de pulsos telefônicos além da franquia mensal. Decisão unânime do Pleno do STF no sentido de que é competente o juizado especial da justiça estadual, uma vez que não houve manifestação da Anatel no sentido de ter interesse na lide. Além do mais, a demanda não se caracteriza por complexa, bastando a análise de documentos e sua confrontação com as normas jurídicas aplicáveis. Quanto ao mérito do recurso em si, considerou-se que a matéria é eminentemente infraconstitucional, vez que as normas legais de direito do consumidor é que orientam o resultado da demanda e estas não tiveram sua constitucionalidade impugnada no curso da controvérsia.

Supremo Tribunal Federal - Referendo de Medida Cautelar no Mandado de Segurança no 27483 (STF MS no 27483 REF-MC / DF - Distrito Federal)

- Relator: Min. Cezar Peluso - Tribunal Pleno do STF - Maioria - j. 14/08/2008

- Diário da Justiça, 10/10/2008. [Descrição do Caso] [Catalogação de Márcio Iório Aranha ]

Reconhecimento, por parte do Plenário do Supremo Tribunal Federal, da constitucionalidade de poderes de Comissão Parlamentar de Inquérito (CPI) em requisitar de operadoras de telecomunicações dados consolidados de juízos, mandados, órgãos policiais, localização e duração de interceptações telefônicas em determinado período para fins investigativos, vedada a entrega de quaisquer outras informações, em especial, números de processos, nomes das partes, titulares dos terminais interceptados, números telefônicos interceptados e cópias dos mandados ou de decisões que os ensejaram. Mantida a posição jurisprudencial do tribunal em vedar a decretação, por CPI, de interceptação telefônica, por tratar-se de matéria de reserva de jurisdição. Declarada a aplicação do princípio da separação dos poderes como limite a pretensões de CPI em obter informações sigilosas de processos em segredo de justiça.

Superior Tribunal de Justiça - Súmula do STJ no 356 - Primeira Seção do STJ - j. 25/06/2008 - Diário da Justiça, 08/09/2008. [Descrição do Caso]

É legítima a cobrança da tarifa básica pelo uso dos serviços de telefonia fixa.

Superior Tribunal de Justiça - Súmula do STJ no 357 - Primeira Seção do STJ - j. 25/06/2008 - Diário da Justiça, 08/09/2008. [Descrição do Caso]

A pedido do assinante, que responderá pelos custos, é obrigatória, a partir de $1^{\circ}$ de janeiro de 2006, a discriminação de pulsos excedentes e ligações de telefone fixo para celular.

\section{Normatização}

Lei $\mathrm{n}^{\mathbf{0}} \mathbf{1 1 . 8 0 0}$, de 29 de outubro de 2008 - Acrescenta parágrafo único ao art. 33 da Lei no 8.078, de 11 de setembro de 1990 - Código de Defesa do Consumidor, para impedir que os fornecedores veiculem publicidade ao consumidor que aguarda, na linha telefônica, o atendimento de suas solicitações. 
Decreto $n^{0}$ 6.523, de 31 de julho de 2008 - Regulamenta a Lei no 8.078, de 11 de setembro de 1990, para fixar normas gerais sobre o Serviço de Atendimento ao Consumidor - SAC.

$\checkmark$ O Decreto 6.523/2008 tem o escopo específico de fixar normas gerais sobre o SAC por telefone, no âmbito dos fornecedores de serviços regulados pelo Poder Público federal.

Portaria MC n⿳ 178, de 22 de abril de 2008 - Dispõe sobre diretrizes para implementação das políticas públicas em telecomunicações.

Resolução da ANATEL $n^{\circ}$ 490, de 24 de janeiro de 2008 - Aprova o Regulamento de Conselho de Usuários do Serviço Telefônico Fixo Comutado - STFC.

$\hookrightarrow$ Anexo - Regulamento de Conselho de Usuários do Serviço Telefônico Fixo Comutado - STFC.

Resolução da ANATEL no 493, de 27 de fevereiro de 2008 - Aprova a alteração do art. $6^{\circ}$ do Plano Geral de Metas de Qualidade para os serviços de televisão por assinatura (PGMQ - televisão por assinatura).

Resolução da ANATEL n 496, de 24 de março de 2008 - Republicar, com alterações, o Regimento Interno do Comitê de Defesa dos Usuários de Serviços de Telecomunicações anexo à Resolução n 107 , de 26 de fevereiro de 1999, alterado pela Resolução $n^{\circ} 223$, de 18 de maio de 2000.

$\hookrightarrow$ Anexo - Regimento Interno do Comitê de Defesa dos Usuários de Serviços de Telecomunicações.

Resolução da ANATEL no 505, de 5 de junho de 2008 - Suspende a eficácia, pelo prazo de 60 (sessenta) dias, dos arts. 30, 31 e 32 do Regulamento de Proteção e Defesa dos Direitos dos Assinantes dos Serviços de Televisão por Assinatura, aprovado pela Resolução no 488, de 3 de dezembro de 2007.

Resolução da ANATEL $\mathbf{n}^{\circ}$ 506, de $1^{\circ}$ de julho de 2008 - Republica o Regulamento sobre Equipamentos de Radiocomunicação de Radiação Restrita.

$\hookrightarrow$ Anexo - Regulamento sobre Equipamentos de Radiocomunicação de Radiação Restrita.

$\checkmark$ Os equipamentos de radiocomunicação de radiação restrita devem conter, em lugar facilmente visível, em etiqueta de difícil remoção, a informação de que operam em caráter secundário e, portanto, não têm direito à proteção contra interferência prejudicial, mesmo de estações do mesmo tipo, bem como não podem causar interferências a sistemas operando em caráter primário.

Resolução da ANATEL $\mathbf{n}^{\circ}$ 508, de 31 de julho de 2008 - Prorroga o prazo de suspensão da eficácia dos arts. 30 e 32 e suspende a eficácia do art. 29 do Regulamento de Proteção e Defesa dos Direitos dos Assinantes dos Serviços de Televisão por Assinatura, aprovado pela Resolução $n^{\circ} 488$, de 3 de dezembro de 2007.

Resolução da ANATEL no 509, de 14 de agosto de 2008 - Aprova o Regulamento da Central de Intermediação de Comunicação Telefônica a ser utilizada por pessoas com deficiência auditiva ou da fala - CIC. 
$\hookrightarrow$ Anexo - Regulamento da Central de Intermediação de Comunicação Telefônica a ser Utilizada por Pessoas com Deficiência Auditiva ou da Fala - CIC.

Resolução da ANATEL n ${ }^{0}$ 513, de 29 de setembro de 2008 - Prorroga o prazo de suspensão da eficácia dos arts. 29, 30 e 32 do Regulamento de Proteção e Defesa dos Direitos dos Assinantes dos Serviços de Televisão por Assinatura, aprovado pela Resolução no 488, de 3 de dezembro de 2007.

Resolução da ANATEL no 517, de 31 de outubro de 2008 - Prorroga o prazo de suspensão da eficácia dos arts. 29, 30 e 32 do Regulamento de Proteção e Defesa dos Direitos dos Assinantes dos Serviços de Televisão por Assinatura, aprovado pela Resolução n 488, de 3 de dezembro de 2007.

Resolução da ANATEL no 520, de 27 de novembro de 2008 - Prorroga o prazo de suspensão da eficácia dos arts. 29, 30 e 32 do Regulamento de Proteção e Defesa dos Direitos dos Assinantes dos Serviços de Televisão por Assinatura, aprovado pela Resolução n 488, de 3 de dezembro de 2007.

\section{Município}

\section{Jurisprudência}

Superior Tribunal de Justiça - Medida Cautelar no 13406 (STJ - MC 13406 / SP - São Paulo) - Relator: Min. Eliana Calmon - Segunda Turma do STJ Unânime - j. 16/10/2008 - Diário da Justiça, Seção 1, 07/11/2008. [Descrição do Caso] [Catalogação de Patrick Faria ]

Discussão sobre a legalidade de taxa instituída pelo município de São Paulo pela instalação de fios e cabos usados por empresas de telecomunicações no perímetro do sistema viário de sua área. Decisão unânime da $2^{\mathrm{a}}$ Turma do STJ no sentido de, primeiro, admitir a medida cautelar para conferir efeito suspensivo ao recurso especial pendente de admissibilidade na origem; posteriormente, julgar procedente o pedido cautelar, uma vez que configurado o fumus bonis iuris e o periculum in mora. $\mathrm{O}$ fumus bonis iuris, em razão do próprio dissídio jurisprudencial em que se assenta a admissibilidade do recurso, havendo precedentes no STJ no sentido da ilegalidade da cobrança por não deter esta natureza de preço público tampouco de taxa. $O$ periculum in mora, tendo em vista que, caso a taxa seja considerada legal, acarretará o pagamento de vultosas quantias, fato que resultará em danos de difícil reparação.

\section{Normas Referenciadas}

\section{Lei Ordinária}

Lei n⿳ 11.652, de 7 de abril de 2008 - Institui os princípios e objetivos dos serviços de radiodifusão pública explorados pelo Poder Executivo ou outorgados a entidades de sua administração indireta; autoriza o Poder Executivo a constituir a Empresa Brasil de Comunicação - EBC; altera a Lei no 


\begin{tabular}{|c|c|}
\hline Dispositivos & LGT, Art. $2^{\circ}$, inciso IV; LGT, Art. 211, caput; LGT, Art. 212, caput. \\
\hline Altera & $\begin{array}{l}\text { Lei no 5.070/1966 - Cria o Fundo de Fiscalização das Telecomunicações e dá outras } \\
\text { providências. }\end{array}$ \\
\hline Correlata & Lei ${ }^{\circ} 6.301 / 1975$ \\
\hline Regulamenta & Constituição da República Federativa do Brasil de 1988 \\
\hline $\begin{array}{l}\text { Regulamentada } \\
\text { por }\end{array}$ & $\begin{array}{l}\text { Decreto } \mathrm{n}^{\circ} \text { 6.505/2008 - Aprova o Regulamento Simplificado para contratação de } \\
\text { serviços e aquisição de bens pela Empresa Brasil de Comunicação S.A. - EBC. } \\
\text { Decreto }{ }^{\circ} \text { 6.689/2008 - Aprova o Estatuto Social da Empresa Brasil de Comunicação } \\
\text { S.A. - EBC e revoga o art. 4o do Decreto no 6.246, } 24 \text { de outubro de } 2007 .\end{array}$ \\
\hline ublicação & Diário Oficial da União, Seção 1, null \\
\hline
\end{tabular}

Lei $\mathbf{n}^{0} 11.759$, de 31 de julho de 2008 - Autoriza a criação da empresa pública Centro Nacional de Tecnologia Eletrônica Avançada S.A. - CEITEC e dá outras providências.

\begin{tabular}{|l|l|}
\hline Dispositivos & LGT, Art. $2^{\circ}$, inciso V; LGT, Art. 78, caput. \\
\hline Correlata & $\begin{array}{l}\text { Lei } \mathrm{n}^{\circ} 6.404 / 1976 \\
\text { Decreto } \mathrm{n}^{\circ} 6.638 / 2008 \text { - Cria a empresa pública Centro Nacional de Tecnologia } \\
\text { Eletrônica Avançada S.A. - CEITEC, aprova seu Estatuto e dá outras providências. }\end{array}$ \\
\hline
\end{tabular}

Lei $\mathbf{n}^{0}$ 11.800, de 29 de outubro de 2008 - Acrescenta parágrafo único ao art. 33 da Lei no 8.078, de 11 de setembro de 1990 - Código de Defesa do Consumidor, para impedir que os fornecedores veiculem publicidade ao consumidor que aguarda, na linha telefônica, o atendimento de suas solicitações.

\begin{tabular}{|l|l|}
\hline Dispositivos & LGT, Art. $3^{\circ}$, caput. \\
\hline Altera & Lei $\mathrm{n}^{\circ} 8.078 / 1990$ - Código de Defesa do Consumidor. \\
\hline
\end{tabular}

Lei no 11.829, de 25 de novembro de 2008 - Altera a Lei no 8.069, de 13 de julho de 1990 - Estatuto da Criança e do Adolescente, para aprimorar o combate à produção, venda e distribuição de pornografia infantil, bem como criminalizar a aquisição e a posse de tal material e outras condutas relacionadas à pedofilia na internet.

\begin{tabular}{|l|l|}
\hline Dispositivos & LGT, Livro III, Título VI, CAPÍTULO II - Das Sanções Penais. \\
\hline Altera & Lei n ${ }^{\circ} 8.069 / 1990$ \\
\hline
\end{tabular}

\section{Decreto}

Decreto $\mathrm{n}^{\mathbf{0}}$ 6.405, de 19 de março de 2008 - Dá nova redação e acresce dispositivos ao Decreto no 5.906, de 26 de setembro de 2006, para adequação dos produtos que especifica com os respectivos códigos de classificação na Nomenclatura Comum do Mercosul - NCM, alterada a partir de 1o de janeiro de 2007.

\begin{tabular}{|l|l|}
\hline Anexos & $\begin{array}{l}\text { Anexo 1 - Relação de Bens de Informática e Automação. } \\
\text { Anexo 2 - Relação de Produtos Excluídos da Isenção ou Redução do IPI. }\end{array}$ \\
\hline Dispositivos & LGT, Art. 76, caput. \\
\hline Altera & ${\text { Decreto }{ }^{\circ} \text { 5.906/2006 }}$ \\
\hline
\end{tabular}




\begin{tabular}{|l|l|}
\hline Regulamenta & $\begin{array}{l}\text { Lei } n^{\circ} 8.248 / 1991 \text { - Dispõe sobre a capacitação e competitividade do setor de } \\
\text { informática e automação, e dá outras providências. } \\
\text { Lei } n^{\circ} 11.077 / 2004 \text { - Altera a Lei } n^{\circ} 8.248, \text { de } 23 \text { de outubro de 1991, a Lei } \text { n }^{\circ} 8.387, \\
\text { de } 30 \text { de dezembro de } 1991 \text {, e a Lei }{ }^{\circ} 10.176 \text {, de } 11 \text { de janeiro de 2001, dispondo } \\
\text { sobre a capacitação e competitividade do setor de informática e automação e dá outras } \\
\text { providências. }\end{array}$ \\
\hline
\end{tabular}

Decreto $\mathrm{n}^{\mathbf{0}}$ 6.424, de 4 de abril de 2008 - Altera e acresce dispositivos ao Anexo do Decreto $\mathrm{n}^{\circ} 4.769$, de 27 de junho de 2003, que aprova o Plano Geral de Metas para a Universalização do Serviço Telefônico Fixo Comutado prestado no Regime Público - PGMU.

\begin{tabular}{|c|c|}
\hline Dispositivos & $\begin{array}{l}\text { LGT, Art. 64, Parágrafo Único; LGT, Art. 79, } \S 1^{\circ} \text {; LGT, Art. 80, caput; LGT, Art. } \\
\text { 207, § } 1^{\circ} \text {. }\end{array}$ \\
\hline Altera & $\begin{array}{l}\text { Anexo ao Decreto } \mathrm{n}^{\circ} 4.769 \text {, de } 27 \text { de junho de } 2003 \text { - Plano Geral de Metas para a } \\
\text { Universalização do Serviço Telefônico Fixo Comutado Prestado no Regime Público } \\
\text { - PGMU. }\end{array}$ \\
\hline Correlata & $\begin{array}{l}\text { Portaria } \mathrm{MC} \mathrm{n}^{\circ} 178 / 2008 \text { - Dispõe sobre diretrizes para implementação das políticas } \\
\text { públicas em telecomunicações. }\end{array}$ \\
\hline Regulamenta & $\begin{array}{l}\text { Lei } \mathrm{n}^{\circ} 9.472 / 1997 \text { - Dispõe sobre a organização dos serviços de telecomunicações, a } \\
\text { criação e funcionamento de um órgão regulador e outros aspectos institucionais, nos } \\
\text { termos da Emenda Constitucional n }{ }^{\circ} 8 \text {, de } 1995 \text {. }\end{array}$ \\
\hline Publicação & ris $\mathrm{ffoi}$ \\
\hline
\end{tabular}

Decreto de 14 de abril de 2008 - Renovação de Concessão da Globo em Belo Horizonte - Renova a concessão outorgada à Globo Comunicação e Participações S.A. para explorar serviço de radiodifusão de sons e imagens, sem direito de exclusividade, no Município de Belo Horizonte, Estado de Minas Gerais.

\begin{tabular}{|c|c|}
\hline Dispositivos & LGT, Art. 211, caput. \\
\hline Correlata & $\begin{array}{l}\text { Decreto Legislativo } n^{\circ} 80 / 1996 \\
\text { Decreto }^{\circ} 35 / 1961 \\
\text { Decreto } n^{\circ} 62.194 / 1968 \\
\text { Decreto n }{ }^{\circ} 80.972 / 1977 \\
\text { Decreto/1994 } \\
\text { Decreto/2005 }\end{array}$ \\
\hline Regulamenta & Lei nº 4.117/1962 - Institui o Código Brasileiro de Telecomunicações. \\
\hline Publicação & Diário Oficial da União, Seção 1, 15/04/2008 \\
\hline
\end{tabular}

Decreto de 14 de abril de 2008 - Renovação de Concessão da Globo em Brasília - Renova a concessão outorgada à Globo Comunicação e Participações S.A. para explorar serviço de radiodifusão de sons e imagens, sem direito de exclusividade, na cidade de Brasília, Distrito Federal.

\begin{tabular}{|l|l|}
\hline Dispositivos & LGT, Art. 211, caput. \\
\hline Correlata & $\begin{array}{l}\text { Decreto Legislativo n }{ }^{\circ} \text { 84/ 1996 } \\
\text { Decreto n }\end{array}$ \\
& $\begin{array}{l}\text { Decreto/1994 } \\
\text { Decreto/2005 }\end{array}$ \\
\hline Regulamenta & Lei n ${ }^{\circ} 4.117 / 1962$ - Institui o Código Brasileiro de Telecomunicações. \\
\hline
\end{tabular}


\begin{tabular}{|l|l}
\hline Publicação & Diário Oficial da União, Seção 1, 15/04/2008 \\
\hline
\end{tabular}

Decreto de 14 de abril de 2008 - Renovação de Concessão da Globo em Recife - Renova a concessão outorgada à Globo Comunicação e Participações S.A. para explorar serviço de radiodifusão de sons e imagens, sem direito de exclusividade, no Município de Recife, Estado de Pernambuco.

\begin{tabular}{|l|l|}
\hline Dispositivos & LGT, Art. 211, caput. \\
\hline Correlata & $\begin{array}{l}\text { Decreto Legislativo } \mathrm{n}^{\circ} \text { 59/1996 } \\
\text { Decreto } \mathrm{n}^{\circ} \text { 81.215/1978 } \\
\end{array}$ \\
& $\begin{array}{l}\text { Decreto/1994 } \\
\text { Decreto/2005 }\end{array}$ \\
\hline Regulamenta & Lei ${ }^{\circ}$ 4.117/1962 - Institui o Código Brasileiro de Telecomunicações. \\
\hline Publicação & Diário Oficial da União, Seção 1, 15/04/2008 \\
\hline
\end{tabular}

Decreto de 14 de abril de 2008 - Renovação de Concessão da Globo em São Paulo - Renova a concessão outorgada à Globo Comunicação e Participações S.A. para explorar serviço de radiodifusão de sons e imagens, sem direito de exclusividade, no Município de São Paulo, Estado de São Paulo.

\begin{tabular}{|c|c|}
\hline Dispositivos & LGT, Art. 211, caput. \\
\hline Correlata & $\begin{array}{l}\text { Decreto Legislativo }{ }^{\circ} \text { 72/1996 } \\
\text { Decreto }^{\circ} 30.590 / 1952 \\
\text { Decreto/1994 } \\
\text { Decreto/2005 }\end{array}$ \\
\hline Regulamenta & Lei n ${ }^{\circ} 4.117 / 1962$ - Institui o Código Brasileiro de Telecomunicações. \\
\hline Publicação & Diário Oficial da União, Seção 1, 15/04/2008 \\
\hline
\end{tabular}

Decreto de 14 de abril de 2008 - Renovação de Concessão da Globo no Rio de Janeiro - Renova a concessão outorgada à Globo Comunicação e Participações S.A. para explorar serviço de radiodifusão de sons e imagens, sem direito de exclusividade, no Município do Rio de Janeiro, Estado do Rio de Janeiro.

\begin{tabular}{|c|c|}
\hline Dispositivos & LGT, Art. 211, caput. \\
\hline Correlata & $\begin{array}{l}\text { Decreto Legislativo }{ }^{\circ} \text { 73/1996 } \\
{\text { Decreto } n^{\circ} 55.782 / 1965} \\
\text { Decreto } n^{\circ} 55.879 / 1965 \\
\text { Decreto/1994 } \\
\text { Decreto/2005 }\end{array}$ \\
\hline Regulamenta & Lei n ${ }^{\circ} 4.117 / 1962$ - Institui o Código Brasileiro de Telecomunicações. \\
\hline Publicação & Diário Oficial da União, Seção 1, 15/04/2008 \\
\hline
\end{tabular}

Decreto $\mathrm{n}^{0}$ 6.505, de 4 de julho de 2008 - Aprova o Regulamento Simplificado para contratação de serviços e aquisição de bens pela Empresa Brasil de Comunicação S.A. - EBC.

\begin{tabular}{|l|l|}
\hline Anexos & Anexo - Regulamento Simplificado para contratação de serviços e aquisição de bens. \\
\hline Dispositivos & LGT, Art. $2^{\circ}$, inciso IV; LGT, Art. 211, caput. \\
\hline Regulamenta & $\begin{array}{l}\text { Lei } \mathrm{n}^{\circ} 11.652 / 2008 \text { - Institui os princípios e objetivos dos serviços de radiodifusão } \\
\text { pública explorados pelo Poder Executivo ou outorgados a entidades de sua }\end{array}$
\end{tabular}




\begin{tabular}{|l|l|}
\hline & $\begin{array}{l}\text { administração indireta; autoriza o Poder Executivo a constituir a Empresa Brasil de } \\
\text { Comunicação - EBC; altera a Lei no 5.070, de } 7 \text { de julho de 1966; e dá outras } \\
\text { providências [Conversão da Medida Provisória n }{ }^{\circ} \text { 398, de } 10 \text { de outubro de 2007]. }\end{array}$ \\
\hline
\end{tabular}

Decreto n 6.523, de 31 de julho de 2008 - Regulamenta a Lei no 8.078, de 11 de setembro de 1990, para fixar normas gerais sobre o Serviço de Atendimento ao Consumidor - SAC.

\begin{tabular}{|c|c|}
\hline Dispositivos & LGT, Art. $3^{\circ}$, caput. \\
\hline Regulamenta & Lei $\mathrm{n}^{\circ} 8.078 / 1990$ - Código de Defesa do Consumidor. \\
\hline
\end{tabular}

Decreto n $^{\circ}$ 6.530, de 4 de agosto de 2008 - Regulamenta a progressão e a promoção para os servidores do quadro efetivo das Agências Reguladoras de que tratam as Leis nos 10.768, de 19 de novembro de 2003, e 10.871, de 20 de maio de 2004, e dá outras providências.

\begin{tabular}{|c|c|}
\hline Anexos & $\begin{array}{l}\text { Anexo } 1 \text { - Requisitos Mínimos de Capacitação no Campo Específico de Atuação da } \\
\text { Respectiva Carreira para Fins de Progressão. } \\
\text { Anexo } 2 \text { - Requisitos Mínimos de Experiência e Capacitação no Campo Específico } \\
\text { de Atuação da Respectiva Carreira para Fins de Promoção dos Ocupantes dos Cargos } \\
\text { de Nível Superior. } \\
\text { Anexo } 3 \text { - Requisitos Mínimos de Experiência e Capacitação no Campo Específico } \\
\text { de Atuação da Respectiva Carreira para Fins de Promoção dos Ocupantes dos Cargos } \\
\text { de Nível Intermediário. }\end{array}$ \\
\hline Dispositivos & LGT, Art. 12, caput; LGT, Art. 13, caput. \\
\hline Regulamenta & $\begin{array}{l}\text { Lei } n^{\circ} 10.768 / 2003 \\
\text { Lei } n^{\circ} 10.871 / 2004 \text { - Dispõe sobre a criação de carreiras e organização de cargos } \\
\text { efetivos das autarquias especiais denominadas Agências Reguladoras, e dá outras } \\
\text { providências. }\end{array}$ \\
\hline
\end{tabular}

Decreto de 17 de setembro de 2008 - Renovação de Concessão da Record no Rio de Janeiro Renova a concessão outorgada à Televisão Record do Rio de Janeiro Ltda., para explorar serviço de radiodifusão de sons e imagem (televisão), sem direito de exclusividade, no Município do Rio de Janeiro, Estado do Rio de Janeiro.

\begin{tabular}{|l|l|}
\hline Dispositivos & LGT, Art. 211, caput. \\
\hline Correlata & $\begin{array}{l}\text { Decreto } n^{\circ} 88.066 / 1983 \text { - Dá nova regulamentação à Lei no } 5.785, \text { de } 23 \text { de junho de } \\
\text { 1972, e à renovação das concessões outorgadas para exploração de serviços de } \\
\text { radiodifusão de sons e imagens (televisão). } \\
\text { Decreto no }\end{array}$ \\
\hline Regulamenta & Lei no $^{\circ} 4.117 / 1962$ - Institui o Código Brasileiro de Telecomunicações. \\
\hline
\end{tabular}

Decreto $\mathbf{n}^{\circ}$ 6.602, de 14 de outubro de 2008 - Dispõe sobre o remanejamento de Funções Comissionadas Técnicas - FCT, da Agência Nacional de Telecomunicações - ANATEL para o Ministério do Planejamento, Orçamento e Gestão.

\begin{tabular}{|l|l|}
\hline Anexos & Anexo - Tabela de Níveis das Funções Comissionadas Técnicas - FCT. \\
\hline Dispositivos & LGT, Art. 13, caput. \\
\hline Correlata & Decreto $n^{\circ} 4.941 / 2003$ \\
\hline
\end{tabular}


\begin{tabular}{|l|l|}
\hline Regulamenta & Medida Provisória n ${ }^{\circ}$ 2.229-43/2001 \\
\hline
\end{tabular}

Decreto $^{\circ}$ 6.638, de 7 de novembro de 2008 - Cria a empresa pública Centro Nacional de Tecnologia Eletrônica Avançada S.A. - CEITEC, aprova seu Estatuto e dá outras providências.

\begin{tabular}{|l|l|}
\hline Dispositivos & LGT, Art. $2^{\circ}$, inciso V; LGT, Art. 78, caput. \\
\hline Correlata & $\begin{array}{l}\text { Lei }{ }^{\circ} 6.404 / 1976 \\
\text { Lei } \mathrm{n}^{\circ} 11.759 / 2008 \text { - Autoriza a criação da empresa pública Centro Nacional de } \\
\text { Tecnologia Eletrônica Avançada S.A. - CEITEC e dá outras providências. }\end{array}$ \\
\hline
\end{tabular}

Decreto ${ }^{0}$ 6.654, de 20 de novembro de 2008 - Aprova o Plano Geral de Outorgas de Serviço de Telecomunicações prestado no regime público.

\begin{tabular}{|c|c|}
\hline Anexos & $\begin{array}{l}\text { nexo } 1 \text { - Regiões do Plano Geral de Outorgas. } \\
\text { nexo } 2 \text { - Setores das Regiões do Plano Geral de Outorgas. }\end{array}$ \\
\hline Dispositivos & $\begin{array}{l}\text { LGT, Art. 18, inciso I; LGT, Art. 18, inciso II; LGT, Art. 64, Parágrafo Único; LGT, } \\
\text { Art. 188, caput; LGT, Art. 207, } \S 1^{\circ} \text {. }\end{array}$ \\
\hline Revoga & $\begin{array}{l}\text { Decreto } \mathrm{n}^{\circ} \text { 2.534/1998 - Aprova o Plano Geral de Outorgas de Serviço de } \\
\text { Telecomunicações prestado no regime público. }\end{array}$ \\
\hline Cor & $\begin{array}{l}\text { Decreto no 2.592/1998 - Aprova o Plano Geral de Metas para a Universalização do } \\
\text { Serviço Telefônico Fixo Comutado Prestado no Regime Público. } \\
\text { Resolução da ANATEL n 46/1998 - Diretrizes para Uso de Radiofrequiências pelas } \\
\text { Concessionárias e Autorizadas de Serviço Telefônico Fixo Comutado para Sistemas } \\
\text { de Acesso Fixo sem Fio. } \\
\text { Resolução da ANATEL no } 316 / 2002 \text { - Aprova o Regulamento do Serviço Móvel } \\
\text { Pessoal - SMP. } \\
\text { Resolução da ANATEL no 321/2002 - Aprova o Plano Geral de Autorizações do } \\
\text { Serviço Móvel Pessoal - PGA-SMP } \\
\text { Resolução da ANATEL no 418/2005 - Aprova a Norma para Estabelecimento da } \\
\text { Metodologia Simplificada para Cálculo do Fator de Transferência "X" Previsto nas } \\
\text { Regras de Reajuste de Tarifas do Serviço Telefônico Fixo Comutado Destinado ao } \\
\text { Uso do Público em Geral - STFC. } \\
\text { Resolução da ANATEL no 420/2005 - Aprova a Norma para Cálculo do Índice de } \\
\text { Serviços de Telecomunicações - IST - Aplicado no Reajuste e Atualização de Valores } \\
\text { Associados à Prestação dos Serviços de Telecomunicações. } \\
\text { Resolução da ANATEL no 423/2005 - Aprova a Norma para Alteração da Tarifação } \\
\text { do Plano Básico do Serviço Telefônico Fixo Comutado na Modalidade Local Prestado } \\
\text { em Regime Público. }\end{array}$ \\
\hline Julgados & Processo n ${ }^{\circ}$ TC-010.681/2008-0- Representação \\
\hline Regulamenta & $\begin{array}{l}\text { Lei no } 9.472 / 1997 \text { - Dispõe sobre a organização dos serviços de telecomunicações, a } \\
\text { criação e funcionamento de um órgão regulador e outros aspectos institucionais, nos } \\
\text { termos da Emenda Constitucional no } 8 \text {, de } 1995 \text {. }\end{array}$ \\
\hline
\end{tabular}

Decreto $n^{0}$ 6.666, de 27 de novembro de 2008 - Institui, no âmbito do Poder Executivo federal, a Infra-Estrutura Nacional de Dados Espaciais - INDE, e dá outras providências.

\begin{tabular}{|l|l|}
\hline Dispositivos & LGT, Livro III, Título V, CAPÍTULO III - Da Órbita e dos Satélites. \\
\hline Correlata & Decreto n $^{\circ} 89.817 / 1984$
\end{tabular}


Decreto/ 2008

Decreto $\mathrm{n}^{\mathbf{0}}$ 6.689, de 11 de dezembro de 2008 - Aprova o Estatuto Social da Empresa Brasil de Comunicação S.A. - EBC e revoga o art. 4o do Decreto no 6.246, 24 de outubro de 2007.

\begin{tabular}{|l|l|}
\hline Anexos & Anexo - Estatuto Social da EBC \\
\hline Dispositivos & LGT, Art. $2^{\circ}$, inciso IV; LGT, Art. 211, caput. \\
\hline Altera & $\begin{array}{l}\text { Decreto }{ }^{\circ} 6.246 / 2007 \text { - Cria a Empresa Brasil de Comunicação - EBC, aprova seu } \\
\text { Estatuto e dá outras providências. }\end{array}$ \\
\hline Revoga & Anexo ao Decreto ${ }^{\circ} 6.246$, de 24 de outubro de 2007 - Estatuto Social da EBC. \\
\hline Regulamenta & $\begin{array}{l}\text { Lei } \text { n }^{\circ} 11.652 / 2008 \text { - Institui os princípios e objetivos dos serviços de radiodifusão } \\
\text { pública explorados pelo Poder Executivo ou outorgados a entidades de sua } \\
\text { administração indireta; autoriza o Poder Executivo a constituir a Empresa Brasil de } \\
\text { Comunicação - EBC; altera a Lei no 5.070, de 7 de julho de 1966; e dá outras } \\
\text { providências [Conversão da Medida Provisória no } 398 \text {, de } 10 \text { de outubro de 2007]. }\end{array}$ \\
\hline
\end{tabular}

\section{Portaria Ministerial}

Portaria $\mathrm{MJ} \mathrm{n}^{\circ}$ 36, de 8 de janeiro de 2008 - Altera o parágrafo único do art. 24 da Portaria ${ }^{\circ} 1.220$, de 11 de julho de 2007, que regulamenta o processo de classificação indicativa de obras audiovisuais destinadas à televisão e congêneres.

Órgão Emissor Ministério da Justiça - Gabinete do Ministro.

\begin{tabular}{|l|l|}
\hline Dispositivos & LGT, Art. 211, caput. \\
\hline Regulamenta & $\begin{array}{l}\text { Lei n }{ }^{\circ} 8.069 / 1990 \\
\text { Lei } n^{\circ} 10.359 / 2001 \text { - Dispõe sobre a obrigatoriedade de os novos aparelhos de televisão } \\
\text { conterem dispositivo que possibilite o bloqueio temporário da recepção de programação } \\
\text { inadequada. } \\
\text { Decreto }{ }^{\circ} \text { 6.061/2007 }\end{array}$
\end{tabular}

Portaria MC nº 178, de 22 de abril de 2008 - Dispõe sobre diretrizes para implementação das políticas públicas em telecomunicações.

\begin{tabular}{|c|c|}
\hline Órgão Emissor & Ministério das Comunicações - Gabinete do Ministro. \\
\hline Dispositivos & LGT, Art. $1^{\circ}$, caput. \\
\hline Cor & $\begin{array}{l}\text { Decreto } \mathrm{n}^{\circ} 4.769 / 2003 \text { - Aprova o Plano Geral de Metas para a Universalização do } \\
\text { Serviço Telefônico Fixo Comutado Prestado no Regime Público - PGMU, e dá outras } \\
\text { providências. } \\
\text { Decreto } \mathrm{n}^{\circ} 6.424 / 2008 \text { - Altera e acresce dispositivos ao Anexo do Decreto } \text { n }^{\circ} 4.769 \text {, } \\
\text { de } 27 \text { de junho de } 2003 \text {, que aprova o Plano Geral de Metas para a Universalização } \\
\text { do Serviço Telefônico Fixo Comutado prestado no Regime Público - PGMU. }\end{array}$ \\
\hline eg & $\begin{array}{l}\text { Decreto } \mathrm{n}^{\circ} 4.733 / 2003 \text { - Dispõe sobre políticas públicas de telecomunicações, e dá } \\
\text { outras providências. }\end{array}$ \\
\hline
\end{tabular}

Portaria $\mathrm{MC} \mathrm{n}^{0}$ 711, de 9 de dezembro de 2008 - Capacitação de representantes municipais para uso de Telecentros Comunitários.

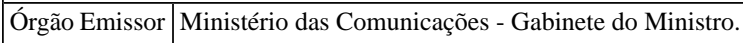

\begin{tabular}{l|l}
\hline Dispositivos & LGT, Art. $2^{\circ}$, inciso I.
\end{tabular} 
\begin{tabular}{|l|l|}
\hline Correlata & Portaria $\mathrm{MC} \mathrm{n}^{\circ}$ 825/2008 - Apoio à participação do Programa GESAC e do Programa
\end{tabular} Inclusão Digital - Telecentros Comunitários na convergência de ações e produção colaborativa de conteúdo às iniciativas de inclusão digital.

Portaria Interministerial no $127 / 2008$

Portaria MC n⿳ 825, de 17 de dezembro de 2008 - Apoio à participação do Programa GESAC e do Programa Inclusão Digital - Telecentros Comunitários na convergência de ações e produção colaborativa de conteúdo às iniciativas de inclusão digital.

\begin{tabular}{|l|l|}
\hline Órgão Emissor & Ministério das Comunicações - Gabinete do Ministro. \\
\hline Dispositivos & LGT, Art. $2^{\circ}$, inciso I. \\
\hline Correlata & $\begin{array}{l}\text { Portaria MC } \mathrm{n}^{\circ} 711 / 2008 \text { - Capacitação de representantes municipais para uso de } \\
\text { Telecentros Comunitários. }\end{array}$ \\
\hline
\end{tabular}

\section{Portaria Interministerial}

Portaria Interministerial $\mathbf{n}^{\mathbf{0}}$ 23, de 29 de janeiro de 2008 - Altera a Portaria Interministerial n. 236, de 6 de dezembro de 2007, referente ao Processo Produtivo Básico de Terminal Portátil de Telefonia Celular industrializado na Zona Franca de Manaus.

\begin{tabular}{|l|l|}
\hline Órgão Emissor & $\begin{array}{l}\text { Ministério do Desenvolvimento, Indústria e Comércio Exterior; Ministério da Ciência } \\
\text { e Tecnologia. }\end{array}$ \\
\hline Situação & Revogado Expressamente \\
\hline Dispositivos & LGT, Art. 78, caput. \\
\hline Altera & $\begin{array}{l}\text { Portaria Interministerial } n^{\circ} \text { 236/2007 - Estabelece o Processo Produtivo Básico de } \\
\text { Terminal Portátil de Telefonia Celular industrializado na Zona Franca de Manaus, } \\
\text { dispõe sobre metas de produção e dá outras providências. }\end{array}$ \\
\hline Revogada por & $\begin{array}{l}\text { Portaria Interministerial no 236/2008 - Estabelece o Processo Produtivo Básico de } \\
\text { Terminal Portátil de Telefonia Celular industrializado na Zona Franca de Manaus, } \\
\text { dispõe sobre metas de produção e dá outras providências. }\end{array}$ \\
\hline Regulamenta & $\begin{array}{l}\text { Decreto-Lei no 288/1967 - Altera as disposições da Lei número 3.173 de 6 de junho } \\
\text { de 1957 e regula a Zona Franca de Manaus. }\end{array}$ \\
\hline Publicação & Diário Oficial da União, Seção 1, 30/12/2008, págs. 142-143 \\
\hline
\end{tabular}

Portaria Interministerial $\mathbf{n}^{\mathbf{0}}$ 29, de 29 de janeiro de 2008 - Altera a Portaria Interministerial n. 237, de 6 de dezembro de 2007, referente ao Processo Produtivo Básico de Terminal Portátil de Telefonia Celular.

\begin{tabular}{|l|l|}
\hline Órgão Emissor & $\begin{array}{l}\text { Ministério do Desenvolvimento, Indústria e Comércio Exterior; Ministério da Ciência } \\
\text { e Tecnologia. }\end{array}$ \\
\hline Situação & Revogado Expressamente \\
\hline Dispositivos & LGT, Art. 78, caput. \\
\hline Altera & Portaria Interministerial n ${ }^{\circ} 237 / 2007$ \\
\hline Regulamenta & $\begin{array}{l}\text { Lei } n^{\circ} 8.248 / 1991 \text { - Dispõe sobre a capacitação e competitividade do setor de } \\
\text { informática e automação, e dá outras providências. } \\
\text { Decreto } n^{\circ} 5.906 / 2006\end{array}$ \\
\hline
\end{tabular}


\begin{tabular}{|l|l}
\hline Publicação & Diário Oficial da União, Seção 1, 30/01/2008, pág. 142
\end{tabular}

Portaria Interministerial $\mathbf{n}^{\circ}$ 236, de 29 de dezembro de 2008 - Estabelece o Processo Produtivo Básico de Terminal Portátil de Telefonia Celular industrializado na Zona Franca de Manaus, dispõe sobre metas de produção e dá outras providências.

Órgão Emissor Ministério do Desenvolvimento, Indústria e Comércio Exterior; Ministério da Ciência e Tecnologia.

\begin{tabular}{l|l} 
Anexos & Anexo 1 - Fabricação do conversor de corrente contínua (CA-CC) ou carregador de
\end{tabular} bateria para telefone celular.

Anexo 2 - Fabricação do transformador elétrico de potência não superior a 3KVA, com núcleo de pó ferromagnético.

Anexo 3 - Fabricação dos fios e cabos com conectores destinados a conversor e carregador de bateria para celular.

\begin{tabular}{l|l} 
Dispositivos & LGT, Art. 78, caput.
\end{tabular}

\begin{tabular}{l|l} 
Revoga & Portaria Interministerial no 236/2007 - Estabelece o Processo Produtivo Básico de
\end{tabular} Terminal Portátil de Telefonia Celular industrializado na Zona Franca de Manaus, dispõe sobre metas de produção e dá outras providências.

Portaria Interministerial no 23/2008 - Altera a Portaria Interministerial n. 236, de 6 de dezembro de 2007, referente ao Processo Produtivo Básico de Terminal Portátil de Telefonia Celular industrializado na Zona Franca de Manaus.

Regulamenta $\quad$ Decreto-Lei no 288/1967 - Altera as disposições da Lei número 3.173 de 6 de junho de 1957 e regula a Zona Franca de Manaus.

Decreto $n^{\circ} 6.008 / 2006$ - Regulamenta o $\$ 6^{\circ}$ do art. $7^{\circ}$ do Decreto-Lei ${ }^{\circ} 288$, de 28 de fevereiro de 1967 , o art. $2^{\circ}$ da Lei ${ }^{\circ} 8.387$, de 30 de dezembro de 1991 , e o art. $4^{\circ}$ da Lei $n^{\circ} 11.077$, de 30 de dezembro de 2004, que tratam do benefício fiscal concedido às empresas que produzam bens de informática na Zona Franca de Manaus que investirem em atividades de pesquisa e desenvolvimento na Amazônia, e dá outras providências.

\begin{tabular}{|l|l}
\hline Publicação & Diário Oficial da União, Seção 1, 30/12/2008, págs. 92-93
\end{tabular}

Portaria Interministerial $\mathbf{n}^{0}$ 237, de 29 de dezembro de 2008 - Estabelece o Processo Produtivo Básico de Terminal Portátil de Telefonia Celular, dispõe sobre metas de produção e dá outras providências.

Órgão Emissor Ministério do Desenvolvimento, Indústria e Comércio Exterior; Ministério da Ciência e Tecnologia.

\begin{tabular}{l|l}
\hline Anexos & Anexo 1 - Fabricação do conversor de corrente contínua (CA-CC) ou carregador de
\end{tabular} bateria para telefone celular.

Anexo 2 - Fabricação do transformador elétrico de potência não superior a 3KVA, com núcleo de pó ferromagnético.

Anexo 3 - Fabricação dos fios e cabos com conectores destinados a conversor e carregador de bateria para celular.

\begin{tabular}{l|l}
\hline Dispositivos & LGT, Art. 78, caput.
\end{tabular}

\begin{tabular}{l|l} 
Revoga & Portaria Interministerial no $237 / 2007$
\end{tabular}

Portaria Interministerial $n^{\circ} 22 / 2008$

Regulamenta $\quad$ Lei $\mathrm{n}^{\circ} 8.248 / 1991$ - Dispõe sobre a capacitação e competitividade do setor de informática e automação, e dá outras providências.

Decreto n ${ }^{\circ} 5.906 / 2006$ 
\begin{tabular}{|l|l|}
\hline Publicação & Diário Oficial da União, Seção 1, 30/12/2008, págs. 93-94 \\
\hline
\end{tabular}

\section{Resolução}

Resolução da ANATEL no ${ }^{\circ}$ 490, de 24 de janeiro de 2008 - Aprova o Regulamento de Conselho de Usuários do Serviço Telefônico Fixo Comutado - STFC.

\begin{tabular}{|l|l|}
\hline Órgão Emissor & ANATEL - Conselho Diretor. \\
\hline Anexos & $\begin{array}{l}\text { Anexo - Regulamento de Conselho de Usuários do Serviço Telefônico Fixo Comutado } \\
\text { - STFC. }\end{array}$ \\
\hline Dispositivos & LGT, Art. 3º, caput; LGT, Art. 64, Parágrafo Único. \\
\hline Regulamenta & $\begin{array}{l}\text { Lei } \text { n }^{\circ} \text { 9.472/1997 - Dispõe sobre a organização dos serviços de telecomunicações, a } \\
\text { criação e funcionamento de um órgão regulador e outros aspectos institucionais, nos } \\
\text { termos da Emenda Constitucional no 8, de 1995. }\end{array}$ \\
\hline
\end{tabular}

Resolução da ANATEL $n^{\circ}$ 491, de 12 de fevereiro de 2008 - Aprova a alteração do art. 118 do Anexo à Resolução n ${ }^{\circ} 477$, de 7 de agosto de 2007, que trata do Regulamento do Serviço Móvel Pessoal - SMP, e acrescenta ao Anexo o art. 119.

\begin{tabular}{|l|l|}
\hline Órgão Emissor & ANATEL - Conselho Diretor. \\
\hline Dispositivos & LGT, Art. 127, inciso VIII; LGT, Art. 128, inciso III. \\
\hline Altera & $\begin{array}{l}\text { Anexo à Resolução da ANATEL n }{ }^{\circ} \text { 477, de } 7 \text { de agosto de } 2007 \text { - Regulamento do } \\
\text { Serviço Móvel Pessoal - SMP. }\end{array}$ \\
\hline Correlata & $\begin{array}{l}\text { Resolução da ANATEL no 509/2008 - Aprova o Regulamento da Central de } \\
\text { Intermediação de Comunicação Telefônica a ser utilizada por pessoas com deficiência } \\
\text { auditiva ou da fala - CIC. }\end{array}$ \\
\hline Regulamenta & $\begin{array}{l}\text { Lei no 9.472/1997 - Dispõe sobre a organização dos serviços de telecomunicações, a } \\
\text { criação e funcionamento de um órgão regulador e outros aspectos institucionais, nos } \\
\text { termos da Emenda Constitucional no 8, de 1995. }\end{array}$ \\
\hline
\end{tabular}

Resolução da ANATEL $n^{\circ}$ 492, de 19 de fevereiro de 2008 - Aprova a Norma para Certificação e Homologação de Transmissores e Transceptores Digitais para o Serviço Fixo em Aplicações PontoMultiponto nas Faixas de Freqüências acima de $1 \mathrm{GHz}$.

\begin{tabular}{|l|l|}
\hline Órgão Emissor & ANATEL - Conselho Diretor. \\
\hline Anexos & $\begin{array}{l}\text { Anexo - Norma para Certificação e Homologação de Transmissores e Transceptores } \\
\text { Digitais para o Serviço Fixo em Aplicações Ponto-Multiponto nas Faixas de } \\
\text { Frequiências acima de 1 GHz. }\end{array}$ \\
\hline Dispositivos & LGT, Art. 19, inciso XIII; LGT, Art. 156, caput; LGT, Art. 214, inciso I. \\
\hline Revoga & $\begin{array}{l}\text { Resolução da ANATEL }{ }^{\circ} \text { 368/2004 - Aprova Norma para Certificação e Homologação } \\
\text { de Transmissores e Transceptores Digitais para o Serviço Fixo em Aplicações Ponto- } \\
\text { Multiponto nas Faixas de Freqüências acima de 1 GHz. }\end{array}$ \\
\hline Correlata & $\begin{array}{l}\text { Resolução da ANATEL } n^{\circ} \text { 242/2000 - Aprova o Regulamento para Certificação e } \\
\text { Homologação de Produtos para Telecomunicações. }\end{array}$ \\
\hline
\end{tabular}




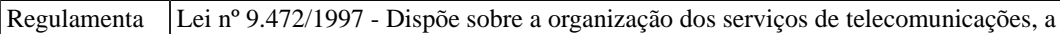
criação e funcionamento de um órgão regulador e outros aspectos institucionais, nos termos da Emenda Constitucional nº 8, de 1995.

Resolução da ANATEL no 493, de 27 de fevereiro de 2008 - Aprova a alteração do art. $6^{\circ}$ do Plano Geral de Metas de Qualidade para os serviços de televisão por assinatura (PGMQ - televisão por assinatura).

\begin{tabular}{|l|l|}
\hline Órgão Emissor & ANATEL - Conselho Diretor. \\
\hline Dispositivos & LGT, Art. 30, inciso I; LGT, Art. 19, inciso X. \\
\hline Altera & $\begin{array}{l}\text { Anexo à Resolução da ANATEL n }{ }^{\circ} 411 \text {, de 14 de julho de 2005 - Plano Geral de } \\
\text { Metas de Qualidade para os serviços de televisão por assinatura (PGMQ - televisão } \\
\text { por assinatura). }\end{array}$ \\
\hline Regulamenta & $\begin{array}{l}\text { Lei no 9.472/1997 - Dispõe sobre a organização dos serviços de telecomunicações, a } \\
\text { criação e funcionamento de um órgão regulador e outros aspectos institucionais, nos } \\
\text { termos da Emenda Constitucional no 8, de 1995. }\end{array}$ \\
\hline
\end{tabular}

Resolução da ANATEL no 494, de 24 de março de 2008 - Aprova o Regulamento sobre Canalização e Condições de Uso de Radiofreqüências na Faixa de 4,9 GHz.

\begin{tabular}{|l|l|}
\hline Órgão Emissor & ANATEL - Conselho Diretor. \\
\hline Anexos & $\begin{array}{l}\text { Anexo - Regulamento sobre Canalização e Condições de Uso de Radiofreqüências } \\
\text { na Faixa de 4,9 GHz. }\end{array}$ \\
\hline Dispositivos & LGT, Art. 19, inciso VIII; LGT, Art. 161, caput. \\
\hline Regulamenta & $\begin{array}{l}\text { Lei n }{ }^{\circ} \text { 9.472/1997 - Dispõe sobre a organização dos serviços de telecomunicações, a } \\
\text { criação e funcionamento de um órgão regulador e outros aspectos institucionais, nos } \\
\text { termos da Emenda Constitucional no } 8 \text {, de } 1995 .\end{array}$ \\
\hline
\end{tabular}

Resolução da ANATEL n⿳ 495, de 24 de março de 2008 - Aprova o Regulamento sobre Canalização e Condições de Uso da Faixa de Radiofreqüências de $5 \mathrm{GHz}$.

\begin{tabular}{|l|l|}
\hline Órgão Emissor & ANATEL - Conselho Diretor. \\
\hline Anexos & $\begin{array}{l}\text { Anexo - Regulamento sobre Canalização e Condições de Uso da Faixa de } \\
\text { Radiofrequeências de 5 GHz. }\end{array}$ \\
\hline Dispositivos & LGT, Art. 19, inciso VIII; LGT, Art. 159, caput; LGT, Art. 160, caput. \\
\hline Revoga & $\begin{array}{l}\text { Resolução da ANATEL no 104/1999 - Aprova o Regulamento sobre Canalização e } \\
\text { Condições de Uso da Faixa de 5 GHz. }\end{array}$ \\
\hline Regulamenta & $\begin{array}{l}\text { Lei no 9.472/1997 - Dispõe sobre a organização dos serviços de telecomunicações, a } \\
\text { criação e funcionamento de um órgão regulador e outros aspectos institucionais, nos } \\
\text { termos da Emenda Constitucional n }{ }^{\circ} \text { 8, de 1995. }\end{array}$ \\
\hline
\end{tabular}

Resolução da ANATEL no 496, de 24 de março de 2008 - Republicar, com alterações, o Regimento Interno do Comitê de Defesa dos Usuários de Serviços de Telecomunicações anexo à Resolução $n^{\circ}$ 107, de 26 de fevereiro de 1999, alterado pela Resolução no 223, de 18 de maio de 2000.

\begin{tabular}{|l|l|}
\hline Órgão Emissor & ANATEL - Conselho Diretor. \\
\hline Anexos & $\begin{array}{l}\text { Anexo - Regimento Interno do Comitê de Defesa dos Usuários de Serviços de } \\
\text { Telecomunicações. }\end{array}$ \\
\hline Dispositivos & LGT, Art. $3^{\circ}$, caput; LGT, Art. 19, inciso XVIII; LGT, Art. 22, inciso X. \\
\hline
\end{tabular}




\begin{tabular}{|l|l|}
\hline Revoga & $\begin{array}{l}\text { Anexo à Resolução da ANATEL no 107, de } 26 \text { de fevereiro de 1999 - Regimento } \\
\text { Interno do Comitê de Defesa dos Usuários de Serviços de Telecomunicações. }\end{array}$ \\
\hline Regulamenta & $\begin{array}{l}\text { Lei no 9.472/1997 - Dispõe sobre a organização dos serviços de telecomunicações, a } \\
\text { criação e funcionamento de um órgão regulador e outros aspectos institucionais, nos } \\
\text { termos da Emenda Constitucional no 8, de 1995. }\end{array}$ \\
\hline
\end{tabular}

\begin{tabular}{|c|c|}
\hline \multicolumn{2}{|c|}{$\begin{array}{l}\text { Resolução da ANATEL no 497, de } 27 \text { de março de } \mathbf{2 0 0 8} \text { - Destina a faixa de radiofrequiências de } \\
2.400 \mathrm{MHz} \text { a } 2.483,5 \mathrm{MHz} \text { para uso, em caráter secundário, por sistemas do Serviço Limitado Privado. }\end{array}$} \\
\hline Órgão Emissor & ANATEL - Conselho Diretor. \\
\hline Dispositivos & LGT, Art. 19, inciso VIII; LGT, Art. 159, caput; LGT, Art. 161, caput. \\
\hline Altera & $\begin{array}{l}\text { Resolução da ANATEL no } 397 / 2005 \text { - Aprova o Regulamento sobre Condições de } \\
\text { Uso de Radiofreqüências na Faixa de } 2.400 \mathrm{MHz} \text { a } 2.483,5 \mathrm{MHz} \text { por Equipamentos } \\
\text { Utilizando Tecnologia de Espalhamento Espectral ou Tecnologia de Multiplexação } \\
\text { Ortogonal por Divisão de Freqüência. }\end{array}$ \\
\hline Regulamenta & $\begin{array}{l}\text { Lei no 9.472/1997 - Dispõe sobre a organização dos serviços de telecomunicações, a } \\
\text { criação e funcionamento de um órgão regulador e outros aspectos institucionais, nos } \\
\text { termos da Emenda Constitucional n }{ }^{\circ} 8 \text {, de } 1995 \text {. }\end{array}$ \\
\hline ublicação & União, Seção 1, 01/04/2008 \\
\hline
\end{tabular}

Resolução da ANATEL n 498, de 27 de março de 2008 - Norma para Certificação e Homologação de Transmissores e Retransmissores para o Sistema Brasileiro de Televisão Digital Terrestre.

\begin{tabular}{|c|c|}
\hline Órgão Emissor & ANATEL - Conselho Diretor. \\
\hline Anexos & $\begin{array}{l}\text { Anexo - Norma para Certificação e Homologação de Transmissores e Retransmissores } \\
\text { para o Sistema Brasileiro de Televisão Digital Terrestre. }\end{array}$ \\
\hline Dispositivos & LGT, Art. 19, inciso XIII; LGT, Art. 211, caput; LGT, Art. 214, inciso I. \\
\hline \multirow[t]{5}{*}{ Correlata } & $\begin{array}{l}\text { Resolução da ANATEL no 238/2000 - Aprova o Regulamento para a Certificação de } \\
\text { Equipamentos de Telecomunicações quanto aos Aspectos de Segurança Elétrica. }\end{array}$ \\
\hline & $\begin{array}{l}\text { Resolução da ANATEL n }{ }^{\circ} 242 / 2000 \text { - Aprova o Regulamento para Certificação e } \\
\text { Homologação de Produtos para Telecomunicações. }\end{array}$ \\
\hline & $\begin{array}{l}\text { Resolução da ANATEL n }{ }^{\circ} 359 / 2004 \text { - Aprova Norma para Certificação e Homologação } \\
\text { de Transmissores e Transceptores Digitais para o Serviço Fixo em Aplicações Ponto- } \\
\text { Multiponto nas Faixas de Freqüências abaixo de } 1 \mathrm{GHz} \text {. }\end{array}$ \\
\hline & $\begin{array}{l}\text { Resolução da ANATEL no 407/2005 - Aprova o Plano Básico de Distribuição de } \\
\text { Canais de Televisão Digital - PBTVD. }\end{array}$ \\
\hline & $\begin{array}{l}\text { Resolução da ANATEL n }{ }^{\circ} 442 / 2006 \text { - Aprova Regulamento para a Certificação de } \\
\text { Equipamentos de Telecomunicações quanto aos Aspectos de Compatibilidade } \\
\text { Eletromagnética. }\end{array}$ \\
\hline Regulamenta & $\begin{array}{l}\text { Lei } n^{\circ} 9.472 / 1997 \text { - Dispõe sobre a organização dos serviços de telecomunicações, a } \\
\text { criação e funcionamento de um órgão regulador e outros aspectos institucionais, nos } \\
\text { termos da Emenda Constitucional nº } 8 \text {, de } 1995 \text {. }\end{array}$ \\
\hline
\end{tabular}

Resolução da ANATEL no 499, de 28 de março de 2008 - Altera os Anexos I e II do Regulamento sobre Áreas Locais para o Serviço Telefônico Fixo Comutado Destinado ao Uso do Público em Geral $-\mathrm{STFC}$.

\begin{tabular}{|l|l|}
\hline Órgão Emissor & ANATEL - Conselho Diretor. \\
\hline Anexos & Anexo 1 - Altera o Anexo I do Regulamento sobre Áreas Locais.
\end{tabular}




\begin{tabular}{|c|c|}
\hline & Anexo 2 - Altera o Anexo II do Regulamento sobre Áreas Locais. \\
\hline Dispositivos & LGT, Art. 64, Parágrafo Único. \\
\hline Altera & $\begin{array}{l}\text { Resolução da ANATEL no } 373 / 2004 \text { - Aprova o Regulamento sobre Áreas Locais } \\
\text { para o Serviço Telefônico Fixo Comutado Destinado ao Uso do Público em Geral - } \\
\text { STFC, dá nova redação ao inciso I do art. } 3^{\circ} \text { e ao art. } 43 \text { do Regulamento do Serviço } \\
\text { Telefônico Fixo Comutado e dá outras providências. }\end{array}$ \\
\hline \multirow[t]{5}{*}{ Correlata } & $\begin{array}{l}\text { Resolução da ANATEL no 377/2004 - Aprova a adaptação do Regulamento sobre } \\
\text { Áreas Locais para o Serviço Telefônico Fixo Comutado Destinado ao Uso do Público } \\
\text { em Geral - STFC, para concessão de prazos para efeito de ajustes de caráter técnico- } \\
\text { operaçionais. }\end{array}$ \\
\hline & $\begin{array}{l}\text { Resolução da ANATEL no } 389 / 2004 \text { - Altera o Anexo II do Regulamento sobre Áreas } \\
\text { Locais para o Serviço Telefônico Fixo Comutado Destinado ao Uso do Público em } \\
\text { Geral - STFC. }\end{array}$ \\
\hline & $\begin{array}{l}\text { Resolução da ANATEL n } \text { }^{403 / 2005} \text { - Altera o Anexo II do Regulamento sobre Áreas } \\
\text { Locais para o Serviço Telefônico Fixo Comutado Destinado ao Uso do Público em } \\
\text { Geral - STFC para correção de erros materiais. }\end{array}$ \\
\hline & $\begin{array}{l}\text { Resolução ANATEL nº63/2007 - Altera o Anexo II do Regulamento sobre Áreas } \\
\text { Locais para o Serviço Telefônico Fixo Comutado Destinado ao Uso do Público em } \\
\text { Geral - STFC. }\end{array}$ \\
\hline & $\begin{array}{l}\text { Resolução da ANATEL n } \text { n }^{475 / 2007} \text { - Alterações das Tabelas anexas ao Regulamento } \\
\text { sobre Areas Locais para o Serviço Telefônico Fixo Comutado Destinado ao Uso do } \\
\text { Público em Geral aprovado pela Resolução no } 373 \text {, de } 3 \text { de junho de } 2004 \text {. }\end{array}$ \\
\hline Regulamenta & $\begin{array}{l}\text { Lei } n^{\circ} 9.472 / 1997 \text { - Dispõe sobre a organização dos serviços de telecomunicações, a } \\
\text { criação e funcionamento de um órgão regulador e outros aspectos institucionais, nos } \\
\text { termos da Emenda Constitucional } n^{\circ} 8 \text {, de } 1995 \text {. }\end{array}$ \\
\hline
\end{tabular}

Resolução da ANATEL n $^{\circ}$ 501, de 10 de abril de 2008 - Revoga a Resolução n 227 , de 21 de junho de 2000, que destina as faixas de frequiências de 1710 a $1755 \mathrm{MHz}, 1775$ a $1785 \mathrm{MHz}, 1805$ a 1850 MHz e 1870 a $1880 \mathrm{MHz}$ para implantação de sistemas de telecomunicações móveis terrestres e as faixas de freqüências de 1885 a 1900 MHz, 1950 a 1980 MHz e 2140 a 2170 MHz para a implantação de sistemas de telecomunicações móveis que sigam as especificações IMT-2000 da UIT.

\begin{tabular}{|c|c|}
\hline Órgão Emissor & ANATEL - Conselho Diretor. \\
\hline Dispositivos & LGT, Art. 19, inciso VIII. \\
\hline Revoga & $\begin{array}{l}\text { Resolução da ANATEL n }{ }^{\circ} 227 / 2000 \text { - Destina as faixas de frequiências de } 1710 \text { a } 1755 \\
\text { MHz, 1775 a } 1785 \mathrm{MHz}, 1805 \text { a } 1850 \mathrm{MHz} \text { e } 1870 \text { a } 1880 \mathrm{MHz} \text { para a implantação } \\
\text { de sistemas de telecomunicações móveis terrestres e as faixas de freqüências de } 1885 \\
\text { a } 1900 \mathrm{MHz}, 1950 \text { a } 1980 \mathrm{MHz} \text { e } 2140 \text { a } 2170 \mathrm{MHz} \text { para a implantação de sistemas } \\
\text { de telecomunicações móveis que sigam as especificações IMT-2000 da UIT. }\end{array}$ \\
\hline Correlata & $\begin{array}{l}\text { Resolução da ANATEL no 454/2006 - Aprova o Regulamento sobre Condições de } \\
\text { Uso de Radiofreqüências nas Faixas de } 800 \mathrm{MHz}, 900 \mathrm{MHz}, 1.800 \mathrm{MHz}, 1.900 \mathrm{MHz} \\
\text { e } 2.100 \mathrm{MHz} \text {. }\end{array}$ \\
\hline Regulamenta & $\begin{array}{l}\text { Lei no } 9.472 / 1997 \text { - Dispõe sobre a organização dos serviços de telecomunicações, a } \\
\text { criação e funcionamento de um órgão regulador e outros aspectos institucionais, nos } \\
\text { termos da Emenda Constitucional } n^{\circ} 8 \text {, de } 1995 \text {. }\end{array}$ \\
\hline
\end{tabular}

Resolução da ANATEL $n^{0}$ 502, de 18 de abril de 2008 - Altera a Estrutura Organizacional das Comissões Brasileiras de Comunicações.

\begin{tabular}{l|l} 
Órgão Emissor & ANATEL - Conselho Diretor.
\end{tabular} 


\begin{tabular}{|c|c|}
\hline Anexos & Anexo - Comissões Brasileiras de Comunicações. \\
\hline Dispositivos & LGT, Art. 19, inciso II. \\
\hline \multirow[t]{4}{*}{ Revoga } & $\begin{array}{l}\text { Resolução da ANATEL no }{ }^{\circ} \text { 110/1999 - Criação das Comissões Brasileiras de } \\
\text { Comunicações - CBCs. }\end{array}$ \\
\hline & $\begin{array}{l}\text { Resolução da ANATEL no 265/2001 - Criação da CBC nº } 12 \text { - Negociações } \\
\text { Internacionais em Telecomunicações. }\end{array}$ \\
\hline & $\begin{array}{l}\text { Resolução da ANATEL n }{ }^{\circ} 462 / 2007 \text { - Cria a Comissão Brasileira de Comunicações } \\
\text { Temporária AMNT } 2008 \text { - Preparação para a Assembléia Mundial de Normalização } \\
\text { das Telecomunicações da UIT. }\end{array}$ \\
\hline & $\begin{array}{l}\text { Resolução da ANATEL no 474/2007 - Criação da Comissão Brasileira de } \\
\text { Comunicações } \mathrm{n}^{\circ} 13 \text { - Governança da Internet. }\end{array}$ \\
\hline Correlata & $\begin{array}{l}\text { Resolução da ANATEL } \mathrm{n}^{\circ} \text { 347/2003 - Republica o Regimento Interno de } \\
\text { Funcionamento das Comissões Brasileiras de Comunicações - CBCs. }\end{array}$ \\
\hline Regulamenta & $\begin{array}{l}\text { Lei no } 9.472 / 1997 \text { - Dispõe sobre a organização dos serviços de telecomunicações, a } \\
\text { criação e funcionamento de um órgão regulador e outros aspectos institucionais, nos } \\
\text { termos da Emenda Constitucional no } 8 \text {, de } 1995 \text {. }\end{array}$ \\
\hline
\end{tabular}

Resolução da ANATEL $\mathbf{n}^{\circ}$ 503, de 25 de abril de 2008 - Prorroga o prazo para apresentação do Apêndice B do Anexo I do Documento de Separação e Alocação de Contas (DSAC) por Prestadoras do SMP que integrem Grupo detentor de Poder de Mercado Significativo na interconexão em rede móvel ou que façam parte de Grupo que contenha Concessionária do STFC.

\begin{tabular}{|l|l|}
\hline Órgão Emissor & ANATEL - Conselho Diretor. \\
\hline Dispositivos & LGT, Art. 127, inciso X. \\
\hline Correlata & $\begin{array}{l}\text { Resolução da ANATEL n }{ }^{\circ} \text { 396/2005 - Aprova o Regulamento de Separação e Alocação } \\
\text { de Contas. } \\
\text { Resolução da ANATEL no 480/2007 - Aprova o prazo para apresentação, pelas } \\
\text { detentoras de PMS na oferta de interconexão em rede móvel, do Documento de } \\
\text { Separação e Alocação de Contas (DSAC). } \\
\text { Resolução da ANATEL no 483/2007 - Estende o prazo para apresentação do primeiro } \\
\text { Documento de Separação e Alocação de Contas (DSAC) pelas detentoras de Poder } \\
\text { de Mercado Significativo (PMS) na oferta de interconexão em rede móvel. }\end{array}$ \\
\hline Regulamenta & $\begin{array}{l}\text { Lei no 9.472/1997 - Dispõe sobre a organização dos serviços de telecomunicações, a } \\
\text { criação e funcionamento de um órgão regulador e outros aspectos institucionais, nos } \\
\text { termos da Emenda Constitucional no } \text { n, de 1995. }^{\circ}\end{array}$ \\
\hline
\end{tabular}

Resolução da ANATEL n 504, de 14 de maio de 2008 - Alteração do Regulamento Sobre Canalização e Condições de Uso da Faixa de Radiofreqüências de $6.430 \mathrm{MHz}$ a 7.110 MHz.

\begin{tabular}{|l|l|}
\hline Órgão Emissor & ANATEL - Conselho Diretor. \\
\hline Anexos & $\begin{array}{l}\text { Anexo - Regulamento Sobre Canalização e Condições de Uso da Subfaixa de } \\
\text { Radiofrequeências de 6.430 MHz a 7.110 MHz }\end{array}$ \\
\hline Dispositivos & LGT, Art. 19, inciso VIII; LGT, Art. 161, caput. \\
\hline Revoga & $\begin{array}{l}\text { Resolução da ANATEL no } 346 / 2003 \text { - Aprova o Regulamento sobre Canalização e } \\
\text { Condições de Uso da Faixa de Radiofreqüências de 6.430 MHz a 7.110 MHz. }\end{array}$ \\
\hline
\end{tabular}




\begin{tabular}{|l|l|}
\hline Regulamenta & $\begin{array}{l}\text { Lei } \mathrm{n}^{\circ} \text { 9.472/1997 - Dispõe sobre a organização dos serviços de telecomunicações, a } \\
\text { criação e funcionamento de um órgão regulador e outros aspectos institucionais, nos } \\
\text { termos da Emenda Constitucional } \mathrm{n}^{\circ} 8, \text { de } 1995 .\end{array}$ \\
\hline
\end{tabular}

Resolução da ANATEL $\mathbf{n}^{\circ}$ 505, de 5 de junho de 2008 - Suspende a eficácia, pelo prazo de 60 (sessenta) dias, dos arts. 30, 31 e 32 do Regulamento de Proteção e Defesa dos Direitos dos Assinantes dos Serviços de Televisão por Assinatura, aprovado pela Resolução no 488, de 3 de dezembro de 2007.

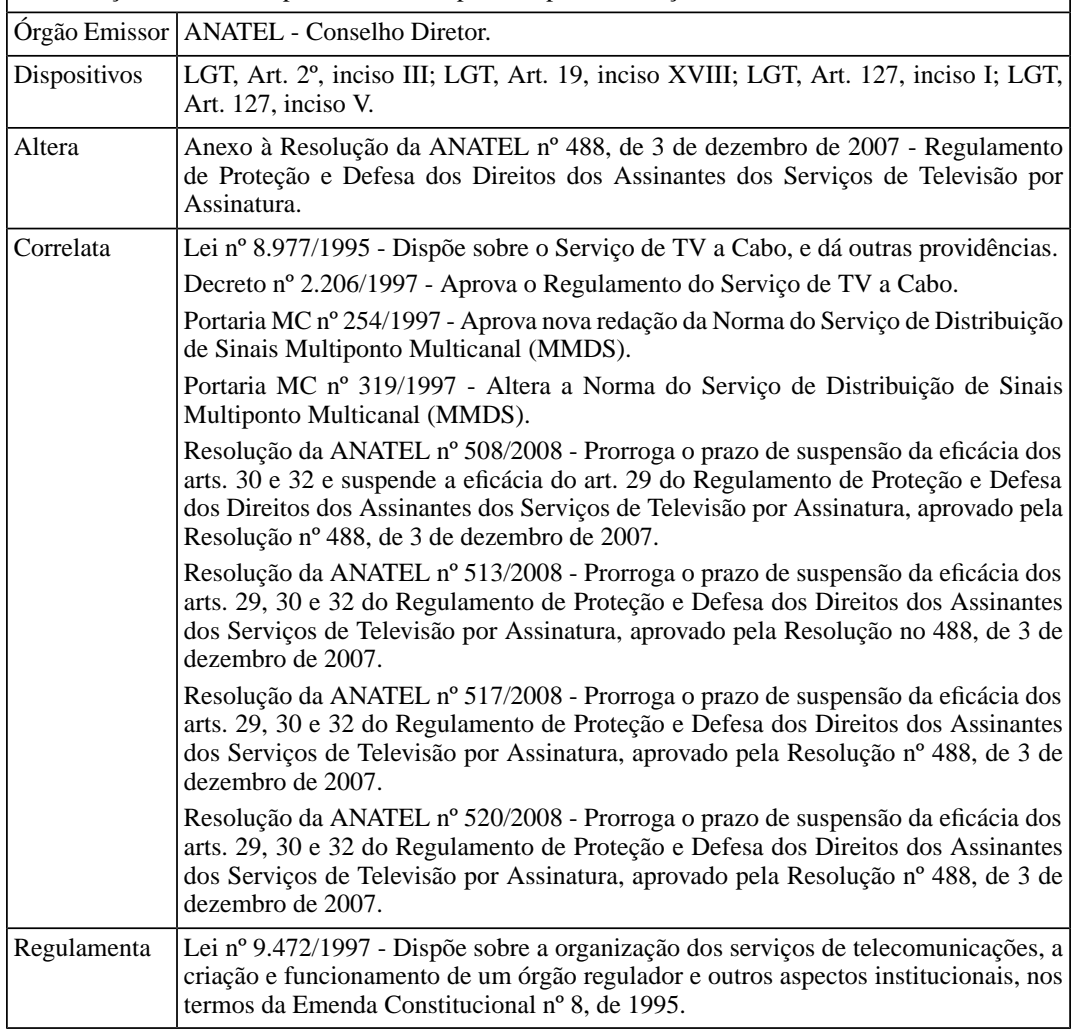

Resolução da ANATEL $\mathbf{n}^{\circ} \mathbf{5 0 6}$, de $1^{\circ}$ de julho de 2008 - Republica o Regulamento sobre Equipamentos de Radiocomunicação de Radiação Restrita.

\begin{tabular}{|l|l|}
\hline Órgão Emissor & ANATEL - Conselho Diretor. \\
\hline Anexos & Anexo - Regulamento sobre Equipamentos de Radiocomunicação de Radiação Restrita. \\
\hline Dispositivos & $\begin{array}{l}\text { LGT, Art. 19, inciso XII; LGT, Art. 19, inciso XVIII; LGT, Art. 156, caput; LGT, } \\
\text { Art. 161, caput; LGT, Art. 163, § 2, inciso I. }\end{array}$ \\
\hline Revoga & $\begin{array}{l}\text { Resolução da ANATEL n } 365 / 2004 \text { - Republica o Regulamento sobre Equipamentos } \\
\text { de Radiocomunicação de Radiação Restrita. }\end{array}$ \\
\hline
\end{tabular}


\begin{tabular}{|l|l|}
\hline Regulamenta & $\begin{array}{l}\text { Lei no 9.472/1997 - Dispõe sobre a organização dos serviços de telecomunicações, a } \\
\text { criação e funcionamento de um órgão regulador e outros aspectos institucionais, nos } \\
\text { termos da Emenda Constitucional no } 8 \text {, de 1995. }\end{array}$ \\
\hline
\end{tabular}

Resolução da ANATEL $\mathbf{n}^{0}$ 507, de 16 de julho de 2008 - Aprova a Norma da Metodologia para Cálculo do Fator de Transferência "X", aplicado nos Reajustes de Tarifas do Serviço Telefônico Fixo Comutado, destinado ao uso do público em geral - STFC.

\begin{tabular}{|c|c|}
\hline Órgão Emissor & ANATEL - Conselho Diretor. \\
\hline Anexos & $\begin{array}{l}\text { Anexo - Norma da Metodologia para Cálculo do Fator de Transferência "X", aplicado } \\
\text { nos Reajustes de Tarifas do Serviço Telefônico Fixo Comutado, destinado ao uso do } \\
\text { público em geral - STFC. }\end{array}$ \\
\hline Dispositivos & $\begin{array}{l}\text { LGT, Art. 64, Parágrafo Único; LGT, Art. 93, inciso VII; LGT, Art. 103, § 1º LGT, } \\
\text { Art. 108, caput. }\end{array}$ \\
\hline Revoga & $\begin{array}{l}\text { Resolução da ANATEL no 418/2005 - Aprova a Norma para Estabelecimento da } \\
\text { Metodologia Simplificada para Cálculo do Fator de Transferência "X" Previsto nas } \\
\text { Regras de Reajuste de Tarifas do Serviço Telefônico Fixo Comutado Destinado ao } \\
\text { Uso do Público em Geral - STFC. }\end{array}$ \\
\hline Correlata & $\begin{array}{l}\text { Decreto } \mathrm{n}^{\circ} 4.733 / 2003 \text { - Dispõe sobre políticas públicas de telecomunicações, e dá } \\
\text { outras providências. } \\
\text { Ato do Conselho Diretor da ANATEL } n^{\circ} 4.197 \text {, de } 16 \text { de julho de } 2008 \text { - Fixa os } \\
\text { valores dos fatores de transferência X e DEA. }\end{array}$ \\
\hline Regulamenta & $\begin{array}{l}\text { Lei n }{ }^{\circ} 9.472 / 1997 \text { - Dispõe sobre a organização dos serviços de telecomunicações, a } \\
\text { criação e funcionamento de um órgão regulador e outros aspectos institucionais, nos } \\
\text { termos da Emenda Constitucional no } 8 \text {, de } 1995 \text {. }\end{array}$ \\
\hline Publicação & Diário Oficial da União, Seção 1, 18/07/2008, págs. 54-57 \\
\hline
\end{tabular}

Resolução da ANATEL $n^{0}$ 508, de 31 de julho de 2008 - Prorroga o prazo de suspensão da eficácia dos arts. 30 e 32 e suspende a eficácia do art. 29 do Regulamento de Proteção e Defesa dos Direitos dos Assinantes dos Serviços de Televisão por Assinatura, aprovado pela Resolução $n^{\circ} 488$, de 3 de dezembro de 2007.

\begin{tabular}{|c|c|}
\hline Órgão Emissor & ANATEL - Conselho Diretor. \\
\hline Dispositivos & $\begin{array}{l}\text { LGT, Art. } 2^{\circ} \text {, inciso III; LGT, Art. 19, inciso XVIII; LGT, Art. 127, inciso I; LGT, } \\
\text { Art. 127, inciso V. }\end{array}$ \\
\hline Altera & $\begin{array}{l}\text { Resolução da ANATEL no 488/2007 - Aprova o Regulamento de Proteção e Defesa } \\
\text { dos Direitos dos Assinantes dos Serviços de Televisão por Assinatura. }\end{array}$ \\
\hline Correlata & $\begin{array}{l}\text { Lei no } 8.977 / 1995 \text { - Dispõe sobre o Serviço de TV a Cabo, e dá outras providências. } \\
\text { Decreto no 2.206/1997 - Aprova o Regulamento do Serviço de TV a Cabo. } \\
\text { Portaria MC nº 254/1997 - Aprova nova redação da Norma do Serviço de Distribuição } \\
\text { de Sinais Multiponto Multicanal (MMDS). } \\
\text { Portaria MC no } 319 / 1997 \text { - Altera a Norma do Serviço de Distribuição de Sinais } \\
\text { Multiponto Multicanal (MMDS). } \\
\text { Resolução da ANATEL n }{ }^{\circ} \text { 505/2008 - Suspende a eficácia, pelo prazo de } 60 \text { (sessenta) } \\
\text { dias, dos arts. 30, } 31 \text { e } 32 \text { do Regulamento de Proteção e Defesa dos Direitos dos } \\
\text { Assinantes dos Serviços de Televisão por Assinatura, aprovado pela Resolução no } \\
\text { 488, de } 3 \text { de dezembro de 2007. } \\
\text { Resolução da ANATEL no } 513 / 2008 \text { - Prorroga o prazo de suspensão da eficácia dos } \\
\text { arts. } 29,30 \text { e } 32 \text { do Regulamento de Proteção e Defesa dos Direitos dos Assinantes }\end{array}$ \\
\hline
\end{tabular}




\begin{tabular}{|c|c|}
\hline & $\begin{array}{l}\text { dos Serviços de Televisão por Assinatura, aprovado pela Resolução no 488, de } 3 \text { de } \\
\text { dezembro de } 2007 .\end{array}$ \\
\hline & $\begin{array}{l}\text { Resolução da ANATEL n }{ }^{\circ} \text { 517/2008 - Prorroga o prazo de suspensão da eficácia dos } \\
\text { arts. } 29,30 \text { e } 32 \text { do Regulamento de Proteção e Defesa dos Direitos dos Assinantes } \\
\text { dos Serviços de Televisão por Assinatura, aprovado pela Resolução no } 488 \text {, de } 3 \text { de } \\
\text { dezembro de } 2007 \text {. }\end{array}$ \\
\hline & $\begin{array}{l}\text { Resolução da ANATEL n }{ }^{\circ} 520 / 2008 \text { - Prorroga o prazo de suspensão da eficácia dos } \\
\text { arts. } 29,30 \text { e } 32 \text { do Regulamento de Proteção e Defesa dos Direitos dos Assinantes } \\
\text { dos Serviços de Televisão por Assinatura, aprovado pela Resolução no } 488 \text {, de } 3 \text { de } \\
\text { dezembro de } 2007 \text {. }\end{array}$ \\
\hline Regulamenta & $\begin{array}{l}\text { Lei no } 9.472 / 1997 \text { - Dispõe sobre a organização dos serviços de telecomunicações, a } \\
\text { criação e funcionamento de um órgão regulador e outros aspectos institucionais, nos } \\
\text { termos da Emenda Constitucional no } 8 \text {, de } 1995 \text {. }\end{array}$ \\
\hline
\end{tabular}

Resolução da ANATEL no 509, de 14 de agosto de 2008 - Aprova o Regulamento da Central de Intermediação de Comunicação Telefônica a ser utilizada por pessoas com deficiência auditiva ou da fala - CIC.

\begin{tabular}{|c|c|}
\hline Órgão Emissor & ANATEL - Conselho Diretor. \\
\hline Anexos & $\begin{array}{l}\text { Anexo - Regulamento da Central de Intermediação de Comunicação Telefônica a ser } \\
\text { Utilizada por Pessoas com Deficiência Auditiva ou da Fala - CIC. }\end{array}$ \\
\hline Dispositivos & $\begin{array}{l}\text { LGT, Art. } 3^{\circ} \text {, inciso I; LGT, Art. } 3^{\circ} \text {, inciso III; LGT, Art. } 3^{\circ} \text {, inciso V; LGT, Art. 19, } \\
\text { inciso I; LGT, Art. 64, Parágrafo Unico; LGT, Art. 127, caput. }\end{array}$ \\
\hline Altera & $\begin{array}{l}\text { Anexo à Resolução da ANATEL n }{ }^{\circ} 477 \text {, de } 7 \text { de agosto de } 2007 \text { - Regulamento do } \\
\text { Serviço Móvel Pessoal - SMP. }\end{array}$ \\
\hline Correlata & $\begin{array}{l}\text { Resolução da ANATEL n }{ }^{\circ} \text { 357/2004 - Aprova o Regulamento sobre as Condições de } \\
\text { Acesso e Fruição dos Serviços de Utilidade Pública e de Apoio ao STFC. } \\
\text { Resolução da ANATEL no 426/2005 - Aprova o Regulamento do Serviço Telefônico } \\
\text { Fixo Comutado - STFC. } \\
\text { Resolução da ANATEL no } 477 / 2007 \text { - Aprova o Regulamento do Serviço Móvel } \\
\text { Pessoal - SMP. } \\
\text { Resolução da ANATEL no 491/ } 2008 \text { - Aprova a alteração do art. } 118 \text { do Anexo à } \\
\text { Resolução no } 477 \text {, de } 7 \text { de agosto de } 2007 \text {, que trata do Regulamento do Serviço Móvel } \\
\text { Pessoal - SMP, e acrescenta ao Anexo o art. } 119 \text {. } \\
\text { Ato do Conselho Diretor da ANATEL n }{ }^{\circ} 43.151 \text {, de } 15 \text { de março de } 2004 \text { - Designa } \\
\text { os Códigos de Acesso aos Serviços de Utilidade Pública e aos Serviços de Apoio ao } \\
\text { Serviço Telefônico Fixo Comutado. }\end{array}$ \\
\hline Regulamenta & 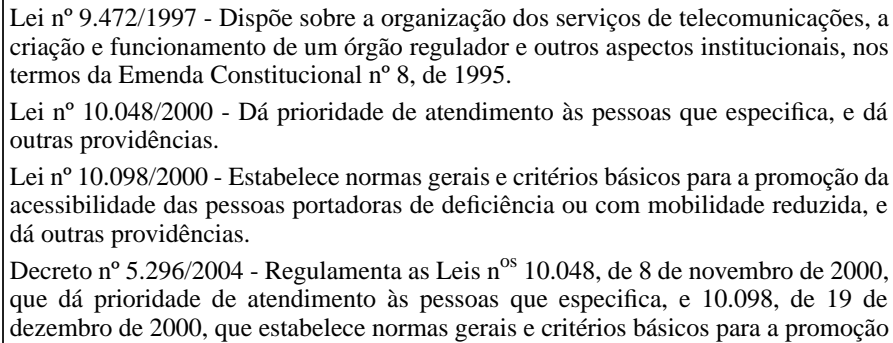 \\
\hline
\end{tabular}


da acessibilidade das pessoas portadoras de deficiência ou com mobilidade reduzida, e dá outras providências.

Resolução da ANATEL $\mathbf{n}^{0}$ 510, de 28 de agosto de 2008 - Atribui a Faixa de Radiofrequiências de $216 \mathrm{MHz}$ a $220 \mathrm{MHz}$ adicionalmente ao Serviço Móvel, em caráter secundário, destina a Faixa de Radiofrequiências de $217 \mathrm{MHz}$ a $218 \mathrm{MHz}$ ao Serviço Limitado Privado (SLP) e ao Serviço Limitado Especializado (SLE), em caráter secundário, e aprova o Regulamento sobre Canalização e Condições de Uso na faixa de Radiofreqüências de $217 \mathrm{MHz}$ a $218 \mathrm{MHz}$.

\begin{tabular}{|l|l|}
\hline Órgão Emissor & ANATEL - Conselho Diretor. \\
\hline Anexos & $\begin{array}{l}\text { Anexo - Regulamento sobre Canalização e Condições de Uso na Faixa de } \\
\text { Radiofreqüências de 217 MHz a 218 MHz. }\end{array}$ \\
\hline Dispositivos & LGT, Art. 19, inciso VIII; LGT, Art. 159, caput; LGT, Art. 161, caput. \\
\hline Correlata & Processo da Anatel nº 53500.018886/2007 \\
\hline Regulamenta & $\begin{array}{l}\text { Lei no } 9.472 / 1997 \text { - Dispõe sobre a organização dos serviços de telecomunicações, a } \\
\text { criação e funcionamento de um órgão regulor e outros aspectos institucionais, nos } \\
\text { termos da Emenda Constitucional no 8, de 1995. }\end{array}$ \\
\hline Publicação & Diário Oficial da União, Seção 1, 01/09/2008, págs. 93-94 \\
\hline
\end{tabular}

Resolução da ANATEL $\mathbf{n}^{\circ}$ 511, de $1^{\circ}$ de setembro de 2008 - Aprova o Regulamento de Controle das Zonas de Proteção das Áreas Adjacentes às Estações de Telecomunicações sob responsabilidade da ANATEL.

\begin{tabular}{|c|c|}
\hline Órgão Emissor & ANATEL - C \\
\hline Ane & $\begin{array}{l}\text { Anexo - Regulamento de Controle das Zonas de Proteção das Áreas Adjacentes às } \\
\text { Estações de Telecomunicações sob responsabilidade da Anatel. } \\
\text { Anexo } 1 \text { - Solicitação de Assentimento: Autorização para Aproveitamento do Solo } \\
\text { em Área do Plano de Zona de Proteção. } \\
\text { Anexo } 2 \text { - Formulário de Requerimento de Certidão Prévia de Gabarito. } \\
\text { Anexo } 3 \text { - Modelos de Carimbo de Assentimento. } \\
\text { Anexo } 4 \text { - Carimbos de Assentimento com Restrições e Prazos de Validade. } \\
\text { Anexo } 5 \text { - Carimbo de Não-Assentimento. } \\
\text { Anexo } 6 \text { - Carimbos de Certidão de Gabarito. } \\
\text { Anexo } 7 \text { - Ofício de encaminhamento da documentação, com a decisão da ANATEL, } \\
\text { à Prefeitura Municipal. } \\
\text { Anexo } 8 \text { - Regulamento de Proteção de Sítios de Radiomonitoragem: Fluxograma de } \\
\text { Atividades. } \\
\text { Anexo } 9 \text { - Relações das Estações do SGME. }\end{array}$ \\
\hline Dispositivos & LGT, Art. 162 , caput. \\
\hline nenta & $\begin{array}{l}\text { Lei n }{ }^{\circ} 6.442 / 1977 \text { - Dispõe sobre áreas de proteção para o funcionamento das estações } \\
\text { radiogoniométricas de alta frequiência do Ministério da Marinha e de radiomonitoragem } \\
\text { do Ministério das Comunicações. } \\
\text { Lei no } 9.472 / 1997 \text { - Dispõe sobre a organização dos serviços de telecomunicações, a } \\
\text { criação e funcionamento de um órgão regulador e outros aspectos institucionais, nos } \\
\text { termos da Emenda Constitucional no }{ }^{\circ} \text {, de } 1995 \text {. }\end{array}$ \\
\hline
\end{tabular}

Resolução da ANATEL n ${ }^{0}$ 512, de 23 de setembro de 2008 - Aprova a Norma para Certificação e Homologação da Interface Analógica de Adaptadores para Terminal de Assinante. 


\begin{tabular}{|c|c|}
\hline Órgão Emissor & ANATEL - Conselho Diretor. \\
\hline Anexos & $\begin{array}{l}\text { Anexo - Norma para Certificação e Homologação da Interface Analógica de } \\
\text { Adaptadores para Terminal de Assinante. }\end{array}$ \\
\hline Dispositivos & LGT, Art. 19, inciso XIII; LGT, Art. 64, Parágrafo Único. \\
\hline \multirow[t]{7}{*}{ Correlata } & Processo da Anatel $n^{\circ}$ 53500.027443/2007 \\
\hline & $\begin{array}{l}\text { Resolução da ANATEL n }{ }^{\circ} \text { 238/2000 - Aprova o Regulamento para a Certificação de } \\
\text { Equipamentos de Telecomunicações quanto aos Aspectos de Segurança Elétrica. }\end{array}$ \\
\hline & $\begin{array}{l}\text { Resolução da ANATEL n }{ }^{\circ} \text { 242/2000 - Aprova o Regulamento para Certificação e } \\
\text { Homologação de Produtos para Telecomunicações. }\end{array}$ \\
\hline & $\begin{array}{l}\text { Resolução da ANATEL no 390/2004 - Aprova o Regulamento para Certificação e } \\
\text { Homologação de Centrais Privadas de Comutação Telefônica - CPCT. }\end{array}$ \\
\hline & $\begin{array}{l}\text { Resolução da ANATEL no 392/2005 - Aprova o Regulamento da Interface Usuário- } \\
\text { Rede e de Terminais do Serviço Telefônico Fixo Comutado. }\end{array}$ \\
\hline & $\begin{array}{l}\text { Resolução da ANATEL no }{ }^{\circ} \text { 426/2005 - Aprova o Regulamento do Serviço Telefônico } \\
\text { Fixo Comutado - STFC. }\end{array}$ \\
\hline & $\begin{array}{l}\text { Resolução da ANATEL no 442/2006 - Aprova Regulamento para a Certificação de } \\
\text { Equipamentos de Telecomunicações quanto aos Aspectos de Compatibilidade } \\
\text { Eletromagnética. }\end{array}$ \\
\hline Regulamenta & $\begin{array}{l}\text { Lei no } 9.472 / 1997 \text { - Dispõe sobre a organização dos serviços de telecomunicações, a } \\
\text { criação e funcionamento de um órgão regulador e outros aspectos institucionais, nos } \\
\text { termos da Emenda Constitucional n }{ }^{\circ} 8 \text {, de } 1995 \text {. }\end{array}$ \\
\hline
\end{tabular}

Resolução da ANATEL no 513, de 29 de setembro de 2008 - Prorroga o prazo de suspensão da eficácia dos arts. 29, 30 e 32 do Regulamento de Proteção e Defesa dos Direitos dos Assinantes dos Serviços de Televisão por Assinatura, aprovado pela Resolução no 488, de 3 de dezembro de 2007.

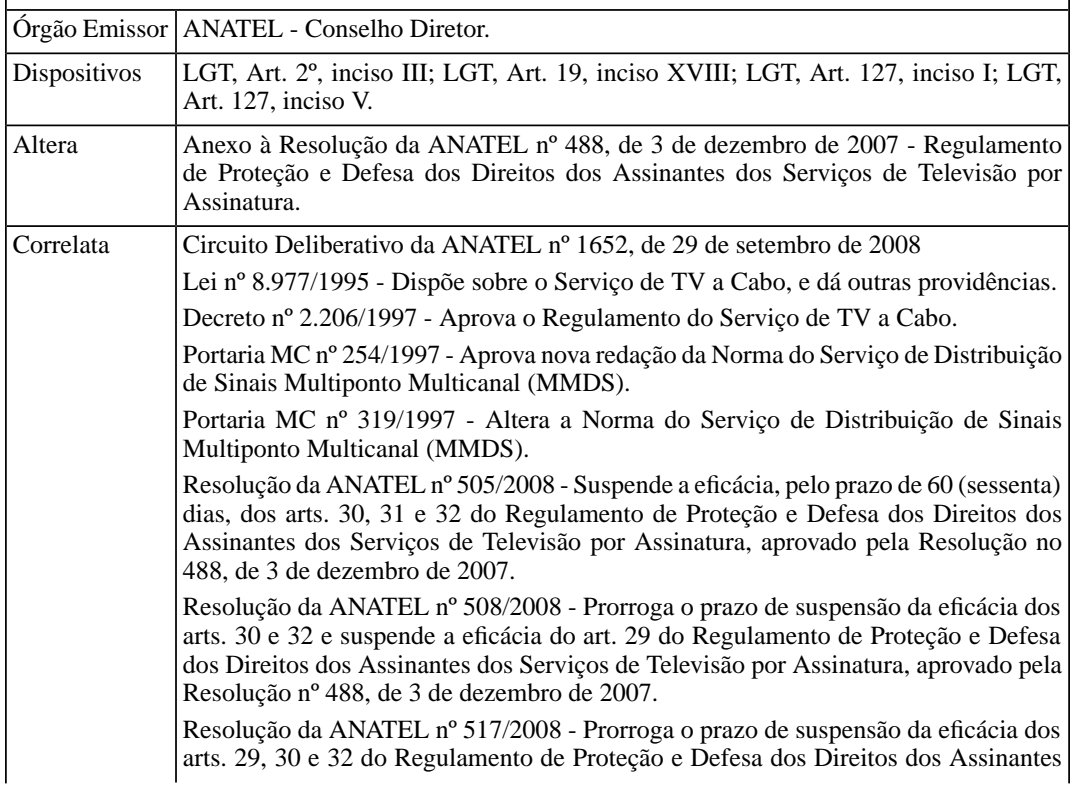




\begin{tabular}{|l|l|}
\hline & $\begin{array}{l}\text { dos Serviços de Televisão por Assinatura, aprovado pela Resolução no } 488, \text { de } 3 \text { de } \\
\text { dezembro de 2007. } \\
\text { Resolução da ANATEL n }{ }^{\circ} \text { 520/2008 - Prorroga o prazo de suspensão da eficácia dos } \\
\text { arts. 29, 30 e 32 do Regulamento de Proteção e Defesa dos Direitos dos Assinantes } \\
\text { dos Serviços de Televisão por Assinatura, aprovado pela Resolução n }{ }^{\circ} 488, \text { de } 3 \text { de } \\
\text { dezembro de 2007. }\end{array}$ \\
\hline Regulamenta & $\begin{array}{l}\text { Lei no 9.472/1997 - Dispõe sobre a organização dos serviços de telecomunicações, a } \\
\text { criação e funcionamento de um órgão regulador e outros aspectos institucionais, nos } \\
\text { termos da Emenda Constitucional no } 8 \text {, de } 1995 .\end{array}$ \\
\hline
\end{tabular}

Resolução da ANATEL $\mathbf{n}^{\circ}$ 514, de 7 de outubro de 2008 - Aprova a alteração do Regulamento Técnico para Prestação do Serviço de Radiodifusão Sonora em Onda Média e em Onda Tropical (faixa de $120 \mathrm{~m})$.

\begin{tabular}{|c|c|}
\hline Órgão Emissor & ANATEL - Conselho Diretor. \\
\hline Anexos & $\begin{array}{l}\text { Anexo - Alteração do Regulamento Técnico para Prestação do Serviço de Radiodifusão } \\
\text { Sonora em Onda Média e em Onda Tropical (faixa de } 120 \text { m), aprovado pela Resolução } \\
\text { no } 116 \text {, de } 25 \text { de março de } 1999 \text {. }\end{array}$ \\
\hline Dispositivos & LGT, Art. 19, inciso VIII; LGT, Art. 211, caput. \\
\hline Altera & $\begin{array}{l}\text { Anexo à Resolução da ANATEL n }{ }^{\circ} 116 \text {, de } 25 \text { de março de } 1999 \text { - Regulamento } \\
\text { Técnico para a Prestação do Serviço de Radiodifusão Sonora em Onda Média e em } \\
\text { Onda Tropical (faixa de } 120 \text { metros). }\end{array}$ \\
\hline Correlata & Processo da ANATEL n5350000012164/2007 \\
\hline Regulamenta & $\begin{array}{l}\text { Lei no 9.472/1997 - Dispõe sobre a organização dos serviços de telecomunicações, a } \\
\text { criação e funcionamento de um órgão regulador e outros aspectos institucionais, nos } \\
\text { termos da Emenda Constitucional n } n^{\circ} 8 \text {, de } 1995 \text {. }\end{array}$ \\
\hline
\end{tabular}

Resolução da ANATEL n$^{0}$ 515, de 10 de outubro de 2008 - Destina a faixa de radiofreqüências de 143,60 MHz a 143,65 MHz ao Serviço Limitado Privado, para uso em aplicações de Pesquisa Espacial, sentido espaço para Terra.

\begin{tabular}{|l|l|}
\hline Órgão Emissor & ANATEL - Conselho Diretor. \\
\hline Dispositivos & LGT, Art. 19, inciso VIII; LGT, Art. 159, caput; LGT, Art. 161, caput. \\
\hline Correlata & Processo da Anatel n ${ }^{\circ}$ 53500.014886/2007 \\
\hline Regulamenta & $\begin{array}{l}\text { Lei no 9.472/1997 - Dispõe sobre a organização dos serviços de telecomunicações, a } \\
\text { criação e funcionamento de um órgão regulador e outros aspectos institucionais, nos } \\
\text { termos da Emenda Constitucional nº 8, de 1995. }\end{array}$ \\
\hline
\end{tabular}

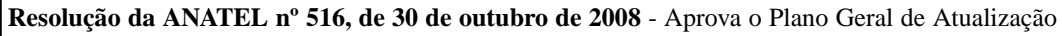
da Regulamentação das Telecomunicações no Brasil (PGR).

\begin{tabular}{|l|l|}
\hline Órgão Emissor & ANATEL - Conselho Diretor. \\
\hline Anexos & $\begin{array}{l}\text { Anexo - Plano Geral de Atualização da Regulamentação das Telecomunicações no } \\
\text { Brasil (PGR). }\end{array}$ \\
\hline Dispositivos & $\begin{array}{l}\text { LGT, Art. } 2^{\circ} \text {, caput; LGT, Art. 2 }{ }^{\circ} \text {, inciso V; LGT, Art. 2 }{ }^{\circ} \text {, inciso VI; LGT, Art. } 3^{\circ}, \\
\text { inciso I; LGT, Art. } 3^{\circ} \text {, inciso II; LGT, Art. 19, caput; LGT, Art. 76, caput; LGT, Art. } \\
77, \text { caput; LGT, Art. 127, inciso IX. }\end{array}$ \\
\hline
\end{tabular}




\begin{tabular}{|l|l|}
\hline Regulamenta & $\begin{array}{l}\text { Lei } \mathrm{n}^{\circ} \text { 9.472/1997 - Dispõe sobre a organização dos serviços de telecomunicações, a } \\
\text { criação e funcionamento de um órgão regulador e outros aspectos institucionais, nos } \\
\text { termos da Emenda Constitucional } \mathrm{n}^{\circ} 8, \text { de } 1995 .\end{array}$
\end{tabular}

Resolução da ANATEL n ${ }^{0}$ 517, de 31 de outubro de 2008 - Prorroga o prazo de suspensão da eficácia dos arts. 29, 30 e 32 do Regulamento de Proteção e Defesa dos Direitos dos Assinantes dos Serviços de Televisão por Assinatura, aprovado pela Resolução nº 488, de 3 de dezembro de 2007.

\begin{tabular}{|c|c|}
\hline Órgão Emissor & ANATEL - Conselho Diretor. \\
\hline Dispositivos & $\begin{array}{l}\text { LGT, Art. } 2^{\circ} \text {, inciso III; LGT, Art. 19, inciso XVIII; LGT, Art. 127, inciso I; LGT, } \\
\text { Art. } 127 \text {, inciso V. }\end{array}$ \\
\hline Altera & $\begin{array}{l}\text { Anexo à Resolução da ANATEL n }{ }^{\circ} 488 \text {, de } 3 \text { de dezembro de } 2007 \text { - Regulamento } \\
\text { de Proteção e Defesa dos Direitos dos Assinantes dos Serviços de Televisão por } \\
\text { Assinatura. }\end{array}$ \\
\hline Correlata & 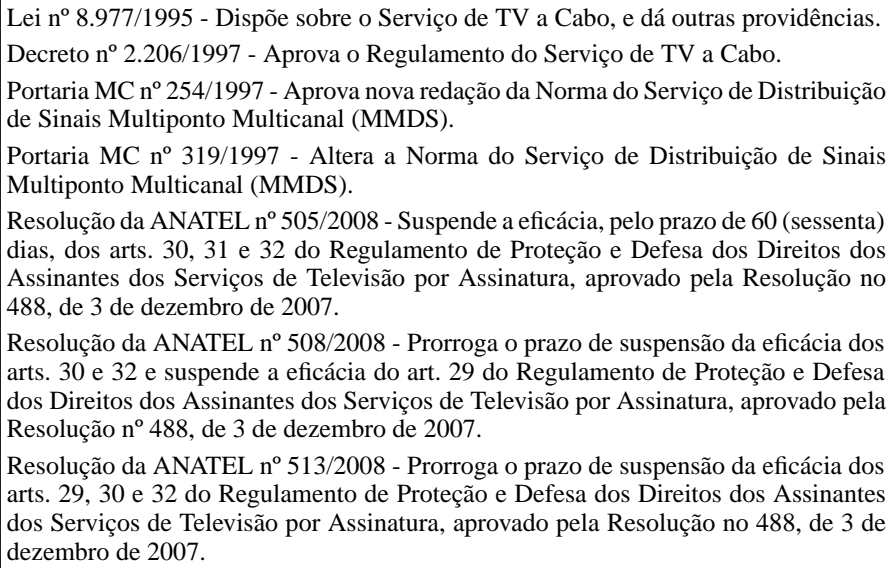 \\
\hline Regulamenta & $\begin{array}{l}\text { Lei } \mathrm{n}^{\circ} 9.472 / 1997 \text { - Dispõe sobre a organização dos serviços de telecomunicações, a } \\
\text { criação e funcionamento de um órgão regulador e outros aspectos institucionais, nos } \\
\text { termos da Emenda Constitucional n }{ }^{\circ} 8 \text {, de } 1995 \text {. }\end{array}$ \\
\hline Publicação & ág. 61 \\
\hline
\end{tabular}

Resolução da ANATEL no 518, de 21 de novembro de 2008 - Aprova alteração no Regulamento do Serviço Móvel Especializado -SME.

\begin{tabular}{|l|l|}
\hline Órgão Emissor & ANATEL - Conselho Diretor. \\
\hline Anexos & Anexo - Alteração do Regulamento do Serviço Móvel Especializado -SME. \\
\hline Dispositivos & $\begin{array}{l}\text { LGT, Art. 20, inciso V; LGT, Art. 6 }{ }^{\circ} \text {, caput; LGT, Art. 127, caput; LGT, Art. 161, } \\
\text { Parágrafo Único; LGT, Art. 164, inciso I; LGT, Art. 167, caput. }\end{array}$ \\
\hline Altera & $\begin{array}{l}\text { Anexo à Resolução da ANATEL n }{ }^{\circ} 404, \text { de } 5 \text { de maio de 2005 - Regulamento do } \\
\text { Serviço Móvel Especializado. }\end{array}$ \\
\hline Regulamenta & $\begin{array}{l}\text { Lei no 9.472/1997 - Dispõe sobre a organização dos serviços de telecomunicações, a } \\
\text { criação e funcionamento de um órgão regulador e outros aspectos institucionais, nos } \\
\text { termos da Emenda Constitucional n }{ }^{\circ} \text { 8, de 1995. }\end{array}$ \\
\hline
\end{tabular}


\begin{tabular}{|l|l}
\hline Publicação & Diário Oficial da União, Seção 1, 24/11/2008, pág. 65 \\
\hline
\end{tabular}

\begin{tabular}{|l|l|}
\hline \multicolumn{2}{|l|}{$\begin{array}{l}\text { Resolução da ANATEL no 519, de } 21 \text { de novembro de 2008 - Aprova alteração no Plano Geral de } \\
\text { Autorizações do Serviço Móvel Especializado - SME. }\end{array}$} \\
\hline Órgão Emissor & ANATEL - Conselho Diretor. \\
\hline Anexos & $\begin{array}{l}\text { Anexo - Alteração do Plano Geral de Autorizações do Serviço Móvel Especializado } \\
\text { - SME. }\end{array}$ \\
\hline Dispositivos & $\begin{array}{l}\text { LGT, Art. 6 } \\
\text { caput. }\end{array}$ \\
\hline Altera & $\begin{array}{l}\text { Anexo à Resolução da ANT, Art. 22, inciso VI; LGT, Art. 127, caput; LGT, Art. 131, } \\
\text { Autorizações do Serviço Móvel Especializado - SME. }\end{array}$ \\
\hline Regulamenta & $\begin{array}{l}\text { Lei no 9.472/1997 - Dispõe sobre a organização dos serviços de telecomunicações, a } \\
\text { criação e funcionamento de um órgão regulador e outros aspectos institucionais, nos } \\
\text { termos da Emenda Constitucional no 8, de 1995. }\end{array}$ \\
\hline Publicação & Diário Oficial da União, Seção 1, 24/11/2008, pág. 65 \\
\hline
\end{tabular}

Resolução da ANATEL no 520, de 27 de novembro de 2008 - Prorroga o prazo de suspensão da eficácia dos arts. 29, 30 e 32 do Regulamento de Proteção e Defesa dos Direitos dos Assinantes dos Serviços de Televisão por Assinatura, aprovado pela Resolução nº 488, de 3 de dezembro de 2007.

\begin{tabular}{|c|c|}
\hline Órgão Emissor & ANATEL - Conselho Diretor. \\
\hline Dispositivos & $\begin{array}{l}\text { LGT, Art. } 2^{\circ} \text {, inciso III; LGT, Art. 19, inciso XVIII; LGT, Art. 127, inciso I; LGT, } \\
\text { Art. } 127 \text {, inciso V. }\end{array}$ \\
\hline Altera & $\begin{array}{l}\text { Anexo à Resolução da ANATEL n }{ }^{\circ} 488 \text {, de } 3 \text { de dezembro de } 2007 \text { - Regulamento } \\
\text { de Proteção e Defesa dos Direitos dos Assinantes dos Serviços de Televisão por } \\
\text { Assinatura. }\end{array}$ \\
\hline Correlata & 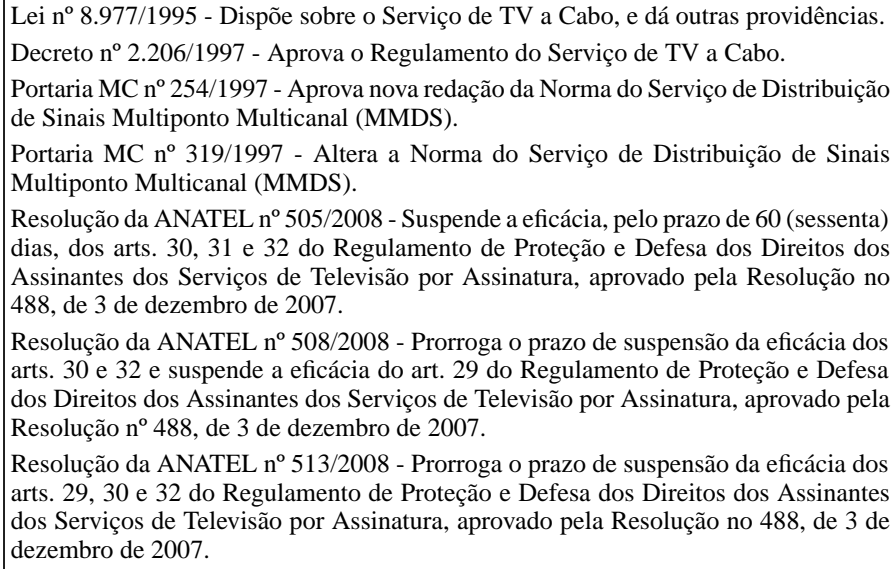 \\
\hline Regulamenta & $\begin{array}{l}\text { Lei n }{ }^{\circ} \text { 9.472/1997 - Dispõe sobre a organização dos serviços de telecomunicações, a } \\
\text { criação e funcionamento de um órgão regulador e outros aspectos institucionais, nos } \\
\text { termos da Emenda Constitucional n }{ }^{\circ} 8 \text {, de } 1995 \text {. }\end{array}$ \\
\hline
\end{tabular}


\begin{tabular}{|l|l}
\hline Publicação & Diário Oficial da União, Seção 1, 28/11/2008, pág. 210
\end{tabular}

\begin{tabular}{|c|c|}
\hline Órgão Emissor & ANATEL - Conselho Diretor. \\
\hline Dispositivos & LGT, Art. 39 , caput; LGT, Art. $158, \S 1^{\circ}$, inciso I. \\
\hline Regulamenta & $\begin{array}{l}\text { Lei } \mathrm{n}^{\circ} 9.472 / 1997 \text { - Dispõe sobre a organização dos serviços de telecomunicações, a } \\
\text { criação e funcionamento de um órgão regulador e outros aspectos institucionais, nos } \\
\text { termos da Emenda Constitucional } \mathrm{n}^{\circ} 8 \text {, de } 1995 \text {. }\end{array}$ \\
\hline Publicação & Diário Oficial da União, Seção 1, 08/12/2008, pág. 44 \\
\hline
\end{tabular}

Resolução da ANATEL $\mathbf{n}^{\circ}$ 523, de 15 de dezembro de 2008 - Aprova o Regulamento sobre Canalização e Condições de Uso de Radiofreqüências na Faixa de $148 \mathrm{MHz}$ a $174 \mathrm{MHz}$.

\begin{tabular}{|l|l|}
\hline Órgão Emissor & ANATEL - Conselho Diretor. \\
\hline Anexos & Anexo \\
\hline Dispositivos & LGT, Art. 19, inciso VIII; LGT, Art. 214, inciso I. \\
\hline Revoga & Portaria MC n ${ }^{\circ} 989 / 1974$ \\
\hline Correlata & $\begin{array}{l}\text { Resolução da ANATEL }{ }^{\circ} \text { 239/2000 - Aprova o Regulamento sobre Canalização e } \\
\text { Condições de Uso de Radiofreqüências por Sistemas do Serviço Móvel nas Faixas de } \\
\text { 33 MHz, 34 MHz, 38 MHz, 39 MHz, 152 MHz, 159 MHz, 160 MHz, 164 MHz, 169 } \\
\text { MHz e de 173 MHz. } \\
\text { Resolução da ANATEL no 303/2002 - Aprova o Regulamento sobre Limitação da } \\
\text { Exposição a Campos Elétricos, Magnéticos e Eletromagnéticos na Faixa de } \\
\text { Radiofrequiências entre 9 kHz e 300 GHz. }\end{array}$ \\
\hline Regulamenta & $\begin{array}{l}\text { Lei no 9.472/1997 - Dispõe sobre a organização dos serviços de telecomunicações, a } \\
\text { criação e funcionamento de um órgão regulor e outros aspectos institucionais, nos } \\
\text { termos da Emenda Constitucional nº 8, de 1995. }\end{array}$ \\
\hline Publicação & Diário Oficial da União, Seção 1, 24/12/2008, págs. 149-154 \\
\hline
\end{tabular}

Resolução da ANATEL no ${ }^{0}$ 524, de 23 de dezembro de 2008 - Aprova a alteração dos Contratos de Concessão para a prestação do Serviço Telefônico Fixo Comutado - STFC, nas modalidades de serviço Local, Longa Distância Nacional - LDN e Longa Distância Internacional - LDI.

\begin{tabular}{|l|l|}
\hline Órgão Emissor & ANATEL - Conselho Diretor. \\
\hline Regulamenta & $\begin{array}{l}\text { Lei no } 9.472 / 1997 \text { - Dispõe sobre a organização dos serviços de telecomunicações, a } \\
\text { criação e funcionamento de um órgão regulador e outros aspectos institucionais, nos } \\
\text { termos da Emenda Constitucional no 8, de 1995. }\end{array}$ \\
\hline Publicação & Diário Oficial da União, Seção 1, 24/12/2008, pág. 154 \\
\hline
\end{tabular}

\section{Resolução emitida por outros órgãos}

Resolução da ANTT n $^{0}$ 2.552, de 14 de fevereiro de 2008 - Dispõe sobre a captação de receitas extraordinárias nas rodovias federais reguladas pela ANTT.

Órgão Emissor Agência Nacional de Transportes Terrestres - ANTT.

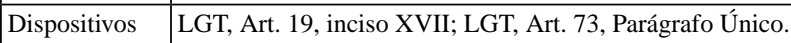




\begin{tabular}{|l|l|}
\hline Regulamenta & $\begin{array}{l}\text { Lei no } 8.987 / 1995 \text { - Dispõe sobre o regime de concessão e permissão da prestação de } \\
\text { serviços públicos previsto no artigo 175 da Constituição Federal, e dá outras } \\
\text { providências. } \\
\text { Lei n }{ }^{\circ} 10.233 / 2001\end{array}$ \\
\hline
\end{tabular}

\section{Julgados Referenciados}

\section{Súmulas}

\section{Superior Tribunal de Justiça (STJ)}

\begin{tabular}{|l|l|}
\hline \multicolumn{2}{|l|}{ Súmula do STJ no 350} \\
\hline Órgão Julgador & Primeira Seção do STJ \\
\hline Julgamento & $11 / 06 / 2008$ \\
\hline Comentário & O ICMS não incide sobre o serviço de habilitação de telefone celular. \\
\hline Dispositivos & LGT, Art. 60, caput. \\
\hline Ref. Leg. & Anexo à Lei Complementar n ${ }^{\circ} 87$, de 13 de setembro de 1996 - art. $2^{\circ}$, III \\
\hline Publicação & Diário Oficial da União, Seção 1, 19/06/2008, pág. 1 \\
\hline
\end{tabular}

\begin{tabular}{|l|l|}
\hline \multicolumn{2}{|l|}{ Súmula do STJ $\mathbf{n}^{\mathbf{0}} \mathbf{3 5 6}$} \\
\hline Órgão Julgador & Primeira Seção do STJ \\
\hline Julgamento & $25 / 06 / 2008$ \\
\hline Comentário & É legítima a cobrança da tarifa básica pelo uso dos serviços de telefonia fixa. \\
\hline Dispositivos & LGT, Art. 64, Parágrafo Único; LGT, Art. 103, caput. \\
\hline Ref. Leg. & $\begin{array}{l}\text { Lei } \mathrm{n}^{\circ} 8.078, \text { de } 11 \text { de setembro de } 1990 \\
\text { Lei } \mathrm{n}^{\circ} 8.987, \text { de } 13 \text { de fevereiro de } 1995 \\
\text { Lei } \mathrm{n}^{\circ} \text { 9.472, de } 16 \text { de julho de } 1997 \\
\text { Lei }{ }^{\circ} \text { 10.406, de 10 de janeiro de } 2002\end{array}$ \\
\hline Publicação & Diário da Justiça, 08/09/2008 \\
\hline
\end{tabular}

\begin{tabular}{|c|c|}
\hline \multicolumn{2}{|c|}{ Súmula do STJ no 357} \\
\hline Órgão Julgador & Primeira Seção do STJ \\
\hline Julgamento & $25 / 06 / 2008$ \\
\hline Comentário & $\begin{array}{l}\text { A pedido do assinante, que responderá pelos custos, é obrigatória, a partir de } 1^{\circ} \text { de } \\
\text { janeiro de 2006, a discriminação de pulsos excedentes e ligações de telefone fixo para } \\
\text { celular. }\end{array}$ \\
\hline Dispositivos & LGT, Art. $3^{\circ}$, inciso IV; LGT, Art. 64, Parágrafo Único; LGT, Art. 109, inciso I. \\
\hline Ref. Leg. & $\begin{array}{l}\text { Lei } \mathrm{n}^{\circ} 9.472, \text { de } 16 \text { de julho de } 1997 \\
\text { Decreto } \mathrm{n}^{\circ} 4.733 \text {, de } 10 \text { de junho de } 2003\end{array}$ \\
\hline Publicação & Diário da Justiça, 08/09/2008 \\
\hline
\end{tabular}




\section{Acórdãos}

\section{Supremo Tribunal Federal (STF)}

\begin{tabular}{|c|c|}
\hline \multicolumn{2}{|c|}{ Recurso Extraordinário no 571572-8 (STF - RE 571572-8 / BA - Bahia) } \\
\hline Relator & Min. Gilmar Mendes \\
\hline Órgão Julgador & Tribunal Pleno do STF \\
\hline Votação & Unânime \\
\hline Julgamento & $08 / 10 / 2008$ \\
\hline Comentário & $\begin{array}{l}\text { Discussão acerca da competência judicial - estadual ou federal - para julgamento de } \\
\text { controvérsia entre consumidor e concessionária de STFC sobre cobrança de pulsos } \\
\text { telefônicos além da franquia mensal. Decisão unânime do Pleno do STF no sentido } \\
\text { de que é competente o juizado especial da justiça estadual, uma vez que não houve } \\
\text { manifestação da Anatel no sentido de ter interesse na lide. Além do mais, a demanda } \\
\text { não se caracteriza por complexa, bastando a análise de documentos e sua confrontação } \\
\text { com as normas jurídicas aplicáveis. Quanto ao mérito do recurso em si, considerou- } \\
\text { se que a matéria é eminentemente infraconstitucional, vez que as normas legais de } \\
\text { direito do consumidor é que orientam o resultado da demanda e estas não tiveram sua } \\
\text { constitucionalidade impugnada no curso da controvérsia. }\end{array}$ \\
\hline Dispositivos & LGT, Art. 64, Parágrafo Único; LGT, Art. 103, caput. \\
\hline Correlata & $\begin{array}{l}\text { Agravo Regimental no Agravo de Instrumento n } 109483 \text { (STF - AI } 109483 \text { - AgR / } \\
\text { PR- Paraná) } \\
\text { Agravo Regimental no Agravo de Instrumento nº } 388982 \text { (STF - AI } 388982 \text { - AgR / } \\
\text { ES - Espírito Santo) } \\
\text { Agravo Regimental no Agravo de Instrumento nº } 607035 \text { (STF - AI } 607035 \text { - AgR / } \\
\text { PB - Paraíba) } \\
\text { Agravo Regimental no Agravo de Instrumento nº } 650085 \text { (STF - AI } 650085 \text { - AgR / } \\
\text { RJ - Rio de Janeiro) }\end{array}$ \\
\hline Ref. Leg. & $\begin{array}{l}\text { Lei } n^{\circ} 5.869, \text { de } 11 \text { de janeiro de } 1973 \\
\text { Lei } n^{\circ} 8.070, \text { de } 11 \text { de setembro de } 1990 \\
\text { Lei } n^{\circ} 9.469, \text { de } 10 \text { de julho de } 1997\end{array}$ \\
\hline Publicação & Diário da Justiça, Seção 1, 21/10/2008 \\
\hline $\begin{array}{l}\text { Descrição do C } \\
\text { A concessionári } \\
\text { Federal pelo qu } \\
\text { Bahia, que conf } \\
\text { ação ajuizada } \\
\text { cobrança de pul } \\
\text { Federal entende } \\
\text { ser que a Anate } \\
\text { espécie. O coleg } \\
\text { especiais são o } \\
\text { matéria, em reg } \\
\text { com relação à } 1 \\
\text { violado o art. } 3 \\
\text { bases do contra } \\
\text {-, a egrégia Cor } \\
\text { decisão recorric }\end{array}$ & $\begin{array}{l}\text { aso } \\
\text { ia Telemar Norte Leste S/A interpôs recurso extraordinário perante o Supremo Tribunal } \\
\text { lal impugna decisão de Turma Recursal Cível e Criminal do Tribunal de Justiça da } \\
\text { irmou sentença de Juizado Especial Cível, a qual havia julgado procedente pedido em } \\
\text { oor consumidor pessoa física em face da concessionária consistente em impedir a } \\
\text { lsos além da franquia. Ao apreciar o recurso, o Tribunal Pleno do Supremo Tribunal } \\
\text { u que a matéria é, a princípio, da competência da justiça estadual e não federal, a não } \\
\text { l manifestasse expressamente o seu interesse na lide - o que não havia acontecido na } \\
\text { tiado afirmou também o entendimento de que, no âmbito da justiça estadual, os juizados } \\
\text { s juízos competentes para processar e decidir controvérsias deste jaez, visto que a } \\
\text { ra, não é complexa, prescindindo de perícia ou maior dilação probatória. Por último, } \\
\text { natéria de fundo articulada no recurso - qual seja, a de que a decisão recorrida teria } \\
\text { 7, XXI da Constituição Federal, extrapolando a função jurisdicional ao intervir nas } \\
\text { to administrativo de concessão celebrado entre a concessionária recorrente e a União } \\
\text { te entendeu que o recurso extraordinário não deveria ser sequer conhecido, vez que a } \\
\text { ta se arvorou exclusivamente no direito do consumidor, revestindo-se a controvérsia }\end{array}$ \\
\hline
\end{tabular}


de caráter estritamente infraconstitucional. Quis a Corte dizer que, ainda que se vislumbre um resvalo tangencial na questão da violação ou não do art. 37, XXI da Constituição Federal, o é em dimensão insuficiente para que a lide seja qualificada como veículo de questão constitucional.

\begin{tabular}{|l|l|}
\hline Catalogador & Patrick Faria \\
\hline
\end{tabular}

Referendo de Medida Cautelar no Mandado de Segurança n 27483 (STF MS no 27483 REF-MC / DF - Distrito Federal)

\begin{tabular}{|c|c|}
\hline Relator & Min. Cezar Peluso \\
\hline Órgão Julgador & Tribunal Pleno do STF \\
\hline Votação & Maioria \\
\hline Julgamento & $14 / 08 / 2008$ \\
\hline Comentário & $\begin{array}{l}\text { Reconhecimento, por parte do Plenário do Supremo Tribunal Federal, da } \\
\text { constitucionalidade de poderes de Comissão Parlamentar de Inquérito (CPI) em } \\
\text { requisitar de operadoras de telecomunicações dados consolidados de juízos, mandados, } \\
\text { órgãos policiais, localização e duração de interceptações telefônicas em determinado } \\
\text { período para fins investigativos, vedada a entrega de quaisquer outras informações, } \\
\text { em especial, números de processos, nomes das partes, titulares dos terminais } \\
\text { interceptados, números telefônicos interceptados e cópias dos mandados ou de decisões } \\
\text { que os ensejaram. Mantida a posição jurisprudencial do tribunal em vedar a decretação, } \\
\text { por CPI, de interceptação telefônica, por tratar-se de matéria de reserva de jurisdição. } \\
\text { Declarada a aplicação do princípio da separação dos poderes como limite a pretensões } \\
\text { de CPI em obter informações sigilosas de processos em segredo de justiça. }\end{array}$ \\
\hline Dispositivos & LGT, Art. $3^{\circ}$, inciso V; LGT, Art. $3^{\circ}$, inciso IX; LGT, Art. $72, \S 1^{\circ}$. \\
\hline Leading Case & $\begin{array}{l}\text { Referendo de Medida Cautelar no Mandado de Segurança n }{ }^{\circ} 27483 \text { (STF MS n }{ }^{\circ} 27483 \\
\text { REF-MC / DF - Distrito Federal) }\end{array}$ \\
\hline Ref. Leg. & Lei $\mathrm{n}^{\circ} 9.296$, de 24 de julho de 1996 \\
\hline Publicação & Diário da Justiça, 10/10/2008 \\
\hline \multicolumn{2}{|c|}{ Descrição do Caso } \\
\hline \multicolumn{2}{|c|}{$\begin{array}{l}\text { Trata-se de referendo do plenário do Supremo Tribunal Federal sobre decisão liminar concedida pelo } \\
\text { Min. Cezar Peluso, em mandado de segurança impetrado por TIM Celular S/A e por outras operadoras } \\
\text { de telefonia fixa e móvel contra ato do Presidente da CPI das Escutas Telefônicas Clandestinas (CPI } \\
\text { dos Grampos) que lhes determinara a remessa de informações protegidas por sigilo judicial, mais } \\
\text { especificamente, a transferência à CPI do conteúdo de todos os mandados judiciais de interceptação } \\
\text { telefônica cumpridos no ano de } 2007 \text {. A liminar concedida autorizou as impetrantes a não encaminharem } \\
\text { à Comissão Parlamentar de Inquérito o conteúdo dos mandados judiciais de interceptação telefônica } \\
\text { cumpridos no ano de } 2007 \text { e protegidos por segredo de justiça, exceto se os correspondentes sigilos } \\
\text { fossem quebrados prévia e legalmente. Em face da colisão entre o interesse público de apuração de } \\
\text { irregularidades, de um lado, e do de preservação do segredo de justiça incidente sobre o conteúdo dos } \\
\text { mandados judiciais de interceptação telefônica e da defesa da garantia constitucional da intimidade } \\
\text { dos envolvidos, de outro, as impetrantes requereram a liminar para legitimar a recusa à prestação de } \\
\text { tais informações sem que o ato configurasse crime de desobediência ou violação dos segredos de } \\
\text { justiça. }\end{array}$} \\
\hline \multicolumn{2}{|c|}{$\begin{array}{l}\text { A concessão da liminar foi fundamentada no reconhecimento de que as Comissões Parlamentares de } \\
\text { Inquérito, nos termos do art. } 58, \$ 3^{\circ} \text {, da Constituição da República, têm todos os "poderes de } \\
\text { investigação próprios das autoridades judiciais", mas dentro de limites formais e materiais oponíveis } \\
\text { aos juízes de qualquer grau no desempenho de idênticas funções. Assim, a CPI, nos limites da qualidade } \\
\text { e extensão dos seus poderes instrutórios, não detém poderes de intervir no exercício jurisdicional do } \\
\text { Poder Judiciário por respeito ao princípio da separação de poderes, como também por decorrência da } \\
\text { proteção especial de que se revestem as decisões jurisdicionais que decretam o "segredo de justiça". }\end{array}$} \\
\hline
\end{tabular}


As Comissões Parlamentares de Inquérito "carecem, ex autoritate propria, de poder jurídico para revogar, cassar, compartilhar, ou de qualquer outro modo quebrar sigilo legal e constitucionalmente imposto a processo judiciário" (Voto do relator, p. 4), por se tratar de competência privativa do Poder Judiciário, ou seja, de "reserva jurisdicional".

Em reavaliação de aspectos do caso após a concessão da liminar descrita, o relator da matéria submeteu à consideração da Corte a discussão sobre a extensão das informações que o Judiciário poderia fornecer à CPI para o cumprimento de suas funções investigativas, propondo-se a aditar seu voto.

As informações passíveis de transferência pelas operadoras de telecomunicações a Comissões Parlamentares de Inquérito são: [1] relação dos juízos que expediram os mandados de interceptação (somente a relação dos juízos); [2] quantidade de mandados emitidos por cada juízo; [3] relação dos órgãos policiais específicos destinatários das ordens judiciais, tendo em vista a alegação de que até a Polícia Rodoviária teria sido destinatária de ordens de interceptação quando não detém, via de regra, competência de polícia judiciária; [4] se houver elementos que justifiquem, a relação dos órgãos que requereram as interceptações para informação de quem teve interesse nas interceptações; [5] relação da cidade ou das cidades em que se situam os terminais telefônicos objeto das ordens de interceptação para detecção de eventuais ordens de interceptação de terminais situados fora da jurisdição dos juízos emitentes; [6] duração total de cada interceptação autorizada. Em consequência, fica vedado às operadoras de telecomunicações fornecerem: [1] os números dos processos em que as ordens de interceptação foram expedidas, pois o conteúdo das ordens encontra-se fora do alcance legítimo da CPI; [2] o nome de qualquer das partes do processo ou dos titulares dos terminais interceptados; [3] os números dos terminais interceptados, pois a sua divulgação quebra indiretamente o sigilo judicial; [4] as cópias dos mandados ou das decisões que os acompanharam, ou mesmo das decisões que, embora não tenham acompanhado os mandados, sejam as ordens judiciais de que resultaram os mandados.

Quanto ao reconhecimento das informações passíveis de serem exigidas por CPI e acima descritas, houve unanimidade no Plenário do STF, restando o voto divergente do Min. Marco Aurélio contrário ao instituto do referendo de cautelar em mandado de segurança, bem como contrário às limitações aos poderes investigativos da CPI. Assim, no que diz respeito ao fornecimento de dados consolidados de juízos, mandados, órgãos policiais, localização e duração das interceptações telefônicas em determinado período, o Supremo Tribunal Federal, por unanimidade, reconheceu o poder da CPI de legitimamente obrigar as operadoras de telecomunicações a fornecerem tais informações, e somente tais informações não-identificadas.

\begin{tabular}{l|l}
\hline Catalogador & Márcio Iório Aranha \\
\hline
\end{tabular}

\section{Superior Tribunal de Justiça (STJ)}

\begin{tabular}{|c|c|}
\hline \multicolumn{2}{|c|}{ Habeas Corpus n 76686 (STJ - HC 76686 / PR - Paraná) } \\
\hline Relator & Min. Nilson Naves \\
\hline Órgão Julgador & Sexta Turma do STJ \\
\hline Votação & Unânime \\
\hline Julgamento & $09 / 09 / 2008$ \\
\hline Comentário & $\begin{array}{l}\text { Discussão sobre a legalidade da renovação sucessiva de autorização judicial de } \\
\text { interceptação telefônica. Decisão unânime da } 6^{\text {a }} \text { Turma do STJ no sentido de que } \\
\text { inexiste, na Lei n }{ }^{\circ} 9.296 / 96 \text {, previsão de renovação sucessiva de interceptação e de } \\
\text { que, havendo conflito entre normas, decide-se a favor da liberdade, sendo que a } \\
\text { prorrogação de quebra de sigilo por prazo distinto ao da Lei de Interceptação deve ser } \\
\text { exaustivamente fundamentada. }\end{array}$ \\
\hline Dispositivos & LGT, Art. $3^{\circ}$, inciso V. \\
\hline Correlata & $\begin{array}{l}\text { Habeas Corpus no } 15820 \text { (STJ - HC } 15820 \text { / DF - Distrito Federal) } \\
\text { Habeas Corpus no } 43234 \text { (STJ - HC } 43234 \text { / SP - São de Paulo) }\end{array}$ \\
\hline
\end{tabular}

Revista de Direito, Estado e Telecomunicações, v. 1, n. 1, p. 313-523 (2009) 


\begin{tabular}{|c|c|}
\hline & $\begin{array}{l}\text { Habeas Corpus no } 43958 \text { (STJ - HC } 43958 \text { / SP - São de Paulo) } \\
\text { Habeas Corpus no } 44165 \text { (STJ - HC } 44165 \text { / RS - Rio Grande do Sul) } \\
\text { Habeas Corpus no } 95838 \text { (STJ - HC } 95838 \text { / RJ - Rio de Janeiro) } \\
\text { Habeas Corpus no } 96521 \text { (STJ - HC } 96521 \text { / SP - São de Paulo) } \\
\text { Habeas Corpus no } 34701 \text { (STJ - HC } 34701 \text { / SP - São Paulo) }\end{array}$ \\
\hline Ref. Leg. & Les n 9.296, de 24 de julho de 1996 \\
\hline dot & 8 \\
\hline \multicolumn{2}{|c|}{ Descrição do Caso } \\
\hline \multicolumn{2}{|c|}{$\begin{array}{l}\text { Os advogados dos uruguaios IRT e RRE impetraram "habeas corpus" perante o Superior Tribunal de } \\
\text { Justiça contra decisão da } 7^{\mathrm{a}} \text { Turma do Tribunal Regional Federal da } 4^{\mathrm{a}} \text { Região que considerou legais } \\
\text { decisões judiciais que renovaram por sucessivas vezes a ordem de quebra de sigilo telefônico dos } \\
\text { pacientes, entendendo que referidas decisões se fundamentaram em relevantes indícios de práticas } \\
\text { delituosas. O relator do HC, Ministro Nilson Naves, assinalando, preambularmente, estar-se diante de } \\
\text { um aparente conflito de princípios (a inviolabilidade das comunicações e o interesse do Estado na } \\
\text { repressão criminal), entendeu que tal conflito há de ser resolvido a favor da liberdade da pessoa. } \\
\text { Compreende o Ministro que a relatividade do direito ao sigilo das comunicações, consubstanciada nas } \\
\text { diretivas da Lei no } 9.296 / 96 \text {, possui ao menos duas balizas bem definidas, quais sejam, o prazo de } \\
\text { quinze dias e a possibilidade de renovação por mais quinze dias. Giza que esta possibilidade de } \\
\text { renovação, segundo compreende, é de apenas uma vez, não sendo razoável interpretar a Lei no }{ }^{\circ} 9.296 / 96 \\
\text { no sentido de que a mesma admite sucessivas renovações da quebra de sigilo. Admite o Ministro, no } \\
\text { entanto, que até se poderia ultrapassar este prazo de trinta dias, porém dentro de limites razoáveis, } \\
\text { como seria exemplo o prazo de sessenta dias correspondente ao estado de defesa (art. } 136, \S 2^{\circ} \text { da } \\
\text { Constituição Federal), sempre mediante decisão judicial exaustivamente fundamentada. Contudo, o } \\
\text { período de quase dois anos em que se prolongou a quebra de sigilo no caso sob julgamento desborda } \\
\text { de qualquer juízo de razoabilidade, pelo o quê a ordem foi concedida, havendo-se como ilegal a prova } \\
\text { produzida, e todas as demais derivadas, por meio da mencionada quebra de sigilo. }\end{array}$} \\
\hline & \\
\hline
\end{tabular}

\begin{tabular}{|l|l|}
\hline \multicolumn{2}{|l|}{ Medida Cautelar no 13406 (STJ - MC 13406 / SP - São Paulo) } \\
\hline Relator & Min. Eliana Calmon \\
\hline Órgão Julgador & Segunda Turma do STJ \\
\hline Votação & Unânime \\
\hline Julgamento & $16 / 10 / 2008$ \\
\hline Comentário & $\begin{array}{l}\text { Discussão sobre a legalidade de taxa instituída pelo município de São Paulo pela } \\
\text { instalação de fios e cabos usados por empresas de telecomunicações no perímetro do } \\
\text { sistema viário de sua área. Decisão unânime da 2a Turma do STJ no sentido de, } \\
\text { primeiro, admitir a medida cautelar para conferir efeito suspensivo ao recurso especial } \\
\text { pendente de admissibilidade na origem; posteriormente, julgar procedente o pedido } \\
\text { cautelar, uma vez que configurado o fumus bonis iuris e o periculum in mora. O fumus } \\
\text { bonis iuris, em razão do próprio dissídio jurisprudencial em que se assenta a } \\
\text { admissibilidade do recurso, havendo precedentes no STJ no sentido da ilegalidade da } \\
\text { cobrança por não deter esta natureza de preço público tampouco de taxa. O periculum } \\
\text { in mora, tendo em vista que, caso a taxa seja considerada legal, acarretará o pagamento } \\
\text { de vultosas quantias, fato que resultará em danos de difícil reparação. }\end{array}$ \\
\hline Dispositivos & LGT, Art. 1 ${ }^{\circ}$, caput. \\
\hline Correlata & $\begin{array}{l}\text { Agravo Regimental em Medida Cautelar no 10517 (STJ - MC 10517 AgR / SP - São } \\
\text { Paulo) }\end{array}$ \\
\hline
\end{tabular}




\begin{tabular}{|c|c|}
\hline & $\begin{array}{l}\text { Embargos Declaratónios no Agravo Regımental em Medida Cautelar n } 1178 \\
\text { - MC } 11785 \text { AgR - ED / RS - Rio Grande do Sul) } \\
\text { Recurso Especial no } 694684 \text { (STJ - RESP } 694684 \text { / RS - Rio Grande do Sul) } \\
\text { Recurso Especial no } 802428 \text { (STJ - RESP } 802428 \text { / SP - São Paulo) } \\
\text { Recurso Especial no } 881937 \text { (STJ - RESP } 881937 \text { / RS - Rio Grande do Sul) }\end{array}$ \\
\hline & \\
\hline Public & \\
\hline \multicolumn{2}{|c|}{$\begin{array}{l}\text { Descrição do Caso } \\
\text { A Associação Brasileira das Prestadoras de Serviços de Telecomunicação Competitivas (Telcomp) } \\
\text { ajuizou ação cautelar perante o Superior Tribunal de Justiça requerendo, em sede liminar, a atribuição } \\
\text { de efeito suspensivo para estancar os efeitos de acórdão proferido pelo Tribunal de Justiça de São } \\
\text { Paulo. Referido acórdão entendeu pela legalidade da taxa instituída pelo município de São Paulo } \\
\text { incidente sobre a instalação de fios e cabos usados por empresas de telecomunicações no perímetro } \\
\text { do sistema viário de sua área. A relatora, Ministra Eliana Calmon, concedeu o efeito suspensivo } \\
\text { desejado, asseverando que o Superior Tribunal de Justiça tem admitido, em circunstâncias excepcionais, } \\
\text { medida cautelar para dar efeito suspensivo a recurso especial pendente de admissibilidade, quando, } \\
\text { além de a parte já ter esgotado todas as possibilidades de conseguir mencionado efeito junto ao tribunal } \\
\text { de origem, a urgência for evidente. No que pertine ao mérito, a relatora vislumbrou a presença de } \\
\text { ambos os requisitos, quais sejam, o "fumus boni iuris" e o "periculum in mora", concedendo a medida. } \\
\text { Fundamentou encontrar o "fumus boni iuris" no fato de haver precedentes daquela Corte de Justiça } \\
\text { nos quais se considerou ilegais contraprestações semelhantes à imposta pelo município de São Paulo } \\
\text { por não deterem natureza de preço público nem de taxa. Quanto ao "periculum in mora", assinalou a } \\
\text { requerida que o cumprimento do decidido pelo Tribunal de Justiça implicará no pagamento de enormes } \\
\text { somas de dinheiro, o que acarretará dano de difícil reparação às empresas envolvidas. Por último, } \\
\text { gizou ainda não encontrar na espécie o "periculum in mora" inverso, assinalado pelo município } \\
\text { recorrido, vez que as funções constitucionais deste devem ser cumpridas com recursos financeiros } \\
\text { legalmente arrecadados, não podendo o ente público fazer frente a tais mediante instituições de } \\
\text { contraprestações ilegais. }\end{array}$} \\
\hline & \\
\hline
\end{tabular}

\begin{tabular}{|l|l|}
\hline \multicolumn{2}{|l|}{ Recurso Especial no 1053778 (STJ - RESP 1053778 / RS - Rio Grande do Sul) } \\
\hline Relator & Min. Herman Benjamin \\
\hline Órgão Julgador & Segunda Turma do STJ \\
\hline Votação & Unânime \\
\hline Julgamento & $09 / 09 / 2008$ \\
\hline Comentário & $\begin{array}{l}\text { É ilegal a prática de repercussão do PIS e da COFINS na tarifa cobrada do usuário de } \\
\text { serviços de telefonia fixa prestado por concessionária, tanto de forma expressa, quanto } \\
\text { de forma não destacada na conta telefônica. Consideração da composição de tarifa de } \\
\text { telefonia como líquida de tributos não autoriza a empresa a acrescer à tarifa o PIS e } \\
\text { a COFINS. Incidentalmente, reafirmou-se a competência da Justiça Estadual para } \\
\text { julgar causas envolvendo composição da fatura de telefonia. A prática comercial de } \\
\text { englobar no valor da tarifa o repasse do PIS e da COFINS viola o disposto no art. } 3^{\circ}, \\
\text { IV, da LGT, de direito à informação adequada, bem como se caracteriza como prática } \\
\text { abusiva, conforme o art. 39, caput, do Código de Defesa do Consumidor. }\end{array}$ \\
\hline
\end{tabular}




\begin{tabular}{|c|c|}
\hline Dispositivos & \\
\hline Leading Case & pecial no 1053778 (STJ - RESP 1053778 / RS - Rio Grande do Sul) \\
\hline Leg. & $\begin{array}{l}472 \text {, de } 16 \text { de julho de } 1997 \\
637 \text {, de } 30 \text { de dezembro de } 2002\end{array}$ \\
\hline ublicação & Diário da Justiça, 10/10/2008 \\
\hline \multicolumn{2}{|c|}{ Descrição do Caso } \\
\hline \multicolumn{2}{|c|}{$\begin{array}{l}\text { Trata-se de recurso especial interposto contra decisão relativa a demanda, de origem no Tribunal de } \\
\text { Justiça do Estado do Rio Grande do Sul, em que consumidores de telefonia fixa se insurgem contra } \\
\text { prática da empresa de telecomunicações Brasil Telecom de repasse direto e mensal ao consumidor- } \\
\text { assinante do ônus do PIS e da COFINS. }\end{array}$} \\
\hline \multicolumn{2}{|c|}{$\begin{array}{l}\text { O tribunal entendeu por bem aplicar a mesma solução dada aos casos de cobrança de assinatura básica } \\
\text { no que se refere à participação da ANATEL na lide. Assim, firmou-se o entendimento de que a discussão } \\
\text { sobre a cobrança do PIS e da COFINS na fatura de telefonia não enseja o interesse processual da } \\
\text { ANATEL, pois eventual ilegalidade da repercussão daqueles tributos na fatura não afeta diretamente } \\
\text { a esfera jurídica da agência, mantendo-se a lide na esfera de competência da Justiça Estadual. }\end{array}$} \\
\hline \multicolumn{2}{|c|}{$\begin{array}{l}\text { Como tópico central do processo, encontra-se a discussão sobre a legalidade de prática adotada pelas } \\
\text { concessionárias de serviço público de telefonia fixa de repasse ao consumidor do ônus referente ao } \\
\text { PIS e à COFINS, que vinham incluídos e englobados no preço do serviço anunciado e cobrados de } \\
\text { forma não destacada na nota fiscal, fatura ou conta telefônica dos autores. Considerando como fato } \\
\text { gerador do PIS e da COFINS o faturamento ou a receita bruta mensal da pessoa jurídica, a incidência } \\
\text { dos percentuais do PIS e da COFINS sobre cada operação ou prestação isolada foi reputada indevida } \\
\text { por incorrer em duplo equívoco: [1] o fato gerador passaria a ser a prestação do serviço, e não o } \\
\text { faturamento ou receita bruta da concessionária; [2] a base de cálculo passaria a ser o valor do serviço, } \\
\text { ao invés do valor do faturamento ou receita bruta mensal da concessionária, que não se compõe } \\
\text { exclusivamente de receitas operacionais, mas também das receitas não-operacionais, excluídas as } \\
\text { previsões do art. } 1^{\circ}, \S 3^{\circ} \text {, da Lei } 10.637 / 02 \text { (PIS) e do art. } 1^{\circ}, \S 3^{\circ} \text {, da Lei } 10.833 / 03 \text { (COFINS). }\end{array}$} \\
\hline \multicolumn{2}{|c|}{$\begin{array}{l}\text { A concessionária de STFC alegou que não estaria efetuando o repasse direto das contribuições aos } \\
\text { consumidores finais, ou seja, que não estaria praticando a repercussão jurídica das contribuições sobre } \\
\text { os consumidores, como ocorre com o ICMS, mas somente repercussão econômica autorizada pelo } \\
\text { ordenamento jurídico brasileiro, pois inerente à atividade empresarial de fazer repercutir } \\
\text { economicamente os tributos incidentes sobre a cadeia produtiva. Em resposta a esse argumento, o } \\
\text { julgado firmou o entendimento de que o PIS e a COFINS embutidos nos valores do serviço prestado } \\
\text { pela concessionária estavam sendo suportados pelos usuários e que o ônus daí decorrente seria } \\
\text { relacionado, de forma apenas mediata, à prestação do serviço. Embora todos os tributos constituam } \\
\text { custos levados em consideração na composição do preço final, à exceção do ICMS e do IPI, que são } \\
\text { suportados diretamente pelo consumidor final, isso não leva à consequência de que qualquer tributo } \\
\text { possa ser embutido no preço pago pelo usuário, como não se pode embutir o IPTU pago pela } \\
\text { concessionária a título de propriedade de seus imóveis no valor da tarifa. Os tributos arcados pela } \\
\text { empresa somente geram repercussão econômica para composição da tarifa e não para sua cobrança } \\
\text { como acréscimos. Para os julgadores, não existe norma jurídica de natureza legal ou infralegal que } \\
\text { autorize, "expressa e inequivocamente", a cobrança adicional do PIS/COFINS no valor do serviço. } \\
\text { Argumenta-se, no voto do relator, que mesmo que houvesse reconhecimento da ANATEL de que o } \\
\text { cálculo das tarifas seria líquido de impostos e contribuições incidentes na operação, o PIS/COFINS } \\
\text { não pode incidir sobre cada operação individualizada. Assim, o Tribunal firmou o entendimento da } \\
\text { impossibilidade de alteração da base de cálculo do PIS/COFINS por ato da ANATEL, já que disciplina } \\
\text { reservada à lei em sentido formal. A prática comercial de englobar no valor da tarifa o repasse do PIS } \\
\text { e da COFINS viola o disposto no art. }{ }^{\circ} \text {, IV, da LGT, de direito à informação adequada, bem como se } \\
\text { caracteriza como prática abusiva, conforme o art. } 39 \text {, caput, do Código de Defesa do Consumidor. }\end{array}$} \\
\hline
\end{tabular}


O pedido dos autores de devolução do pagamento a maior (repetição do indébito) em dobro foi negado pelo Tribunal por considerar a cobrança um engano justificável, nos termos do art. 42, do Código de Defesa do Consumidor.

Com tais considerações, a $2^{\text {a }}$ Turma do STJ, por unanimidade, negou provimento ao recurso especial interposto pela Brasil Telecom S/A.

\begin{tabular}{l|l}
\hline Catalogador & Márcio Iório Aranha \\
\hline
\end{tabular}

\begin{tabular}{|c|c|}
\hline \multicolumn{2}{|c|}{ Recurso Especial no 938827 (STJ - RESP 938827 / DF - Distrito Federal) } \\
\hline Relator & Min. Denise Arruda \\
\hline Órgão Julgador & Primeira Turma do STJ \\
\hline Votação & Unânime \\
\hline Julgamento & $18 / 09 / 2008$ \\
\hline Comentário & $\begin{array}{l}\text { Discussão acerca da legitimidade passiva ad causam da concessionária do serviço } \\
\text { público de telecomunicações para responder pela devolução de valores de ICMS. } \\
\text { Pronunciamento pela ilegitimidade da prestadora para figurar no pólo passivo dessas } \\
\text { demandas, por ser a Fazenda Pública o sujeito ativo da relação tributária, e não a } \\
\text { concessionária de telefonia, simples responsável pelo repasse dos tributos ao ente } \\
\text { federativo. }\end{array}$ \\
\hline Dispositivos & LGT, Art. 83, Parágrafo Único. \\
\hline Correlata & $\begin{array}{l}\text { Agravo Regimental no Recurso Especial no } 797826 \text { (STJ - RESP } 797826 \text { AgR / MT } \\
\text { - Mato Grosso) } \\
\text { Recurso Especial no } 838542 \text { (STJ - RESP } 838542 \text { / MT - Mato Grosso) } \\
\text { Recurso Especial no } 1036589 \text { (STJ - RESP } 1036589 \text { / MG - Minas Gerais) }\end{array}$ \\
\hline Ref. Leg. & Lei Complementar $\mathrm{n}^{\circ}$ 87, de 13 de setembro de 1996 \\
\hline Publicação & Diário da Justiça, 29/09/2008 \\
\hline \multicolumn{2}{|c|}{ Descrição do Caso } \\
\hline \multicolumn{2}{|c|}{$\begin{array}{l}\text { Trata-se de Recurso Especial interposto pela Companhia Brasileira de Distribuição em face de acórdão } \\
\text { do Tribunal de Justiça do Distrito Federal e Territórios que, em sede de ação ordinária de repetição } \\
\text { de indébito proposta em desfavor da BRASIL TELECOM S/A, julgou improcedente o pleito de } \\
\text { ressarcimento de valores indevidos, cobrados a título de ICMS, por entender que a empresa prestadora } \\
\text { do serviço não teria responsabilidade pela repetição do indébito, enquanto mera arrecadadora do tributo, } \\
\text { repassado posteriormente ao ente federado que o instituiu. }\end{array}$} \\
\hline \multicolumn{2}{|c|}{$\begin{array}{l}\text { A recorrente, em suas razões, sustentou a legitimidade da concessionária de serviço público de } \\
\text { telecomunicações para responder pela cobrança indevida do ICMS, sob o escólio de que não haveria } \\
\text { qualquer relação tributária entre o consumidor e o Estado. Diante da suposta violação de direito do } \\
\text { consumidor, alegou, ademais, ofensa aos arts. } 4^{\circ}, 6^{\circ}, 39 \text {, parágrafo único, e } 42 \text { do Código de Proteção } \\
\text { e Defesa do Consumidor. }\end{array}$} \\
\hline \multicolumn{2}{|c|}{$\begin{array}{l}\text { Não obstante as teses deduzidas pela recorrente, a relatora entendeu não assistir-lhe razão, em primeiro } \\
\text { momento, face à ausência do indispensável prequestionamento, na instância recorrida, das questões } \\
\text { consumeristas suscitadas no Recurso Especial, pelo que, com fulcro na Súmula } 211 / \text { STJ, propôs, } \\
\text { quanto a esta parte, o não conhecimento do Recurso. Quanto à alegação de legitimidade passiva ad } \\
\text { causam da concessionária para responder pela devolução de valores de ICMS, a relatora remeteu-se } \\
\text { à orientação do Superior Tribunal de Justiça acerca da impossibilidade da cobrança pleiteada, por } \\
\text { entender serem, as concessionárias de telefonia, simples responsáveis pelo recolhimento e repasse dos } \\
\text { valores de ICMS ao ente federativo, e não contribuintes deste, pelo que não podem, a seu próprio } \\
\text { talante, atender demanda de exclusão de montante cobrado indevidamente, pretensão de que é titular } \\
\text { somente a Fazenda Pública. }\end{array}$} \\
\hline
\end{tabular}


Pelo exposto e, colacionando julgados de hipóteses assemelhadas, a relatora sustentou que, nas ações versando sobre o ICMS devido em virtude da prestação de serviços de telecomunicações, somente ser parte legítima para figurar no pólo passivo da demanda de devolução o Estado ou o Distrito Federal, sujeitos ativos da relação tributária em tela, nos termos do art. 119 do Código Tributário Nacional mormente tendo em consideração que é o próprio consumidor final do serviço de telefonia, enquanto contribuinte, o sujeito passivo da obrigação tributária. Negou, assim, provimento ao recurso, prestigiando a decisão de primeira instância.

A $1^{\text {a }}$ Turma acompanhou o voto da relatora e, por unanimidade, conheceu parcialmente do Recurso Especial e, nessa parte, negou-lhe provimento.

\begin{tabular}{|l|l|}
\hline Catalogador & Rosa Amaral \\
\hline
\end{tabular}

\begin{tabular}{|c|c|}
\hline \multicolumn{2}{|c|}{ 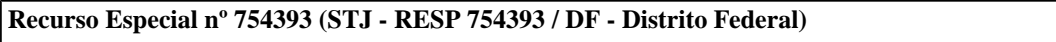 } \\
\hline Relator & Min. Francisco Falcão \\
\hline Órgão Julgador & Primeira Turma do STJ \\
\hline Votação & Maioria \\
\hline Julgamento & $02 / 12 / 2008$ \\
\hline Comentário & $\begin{array}{l}\text { Não-incidência do ICMS sobre a assinatura mensal de telefonia, quando esta não } \\
\text { comporta franquia de utilização. }\end{array}$ \\
\hline Dispositivos & LGT, Art. 129, caput. \\
\hline Correlata & $\begin{array}{l}\text { Recurso Especial no } 402047 \text { (STJ - RESP } 402047 \text { / MG - Minas Gerais) } \\
\text { Recurso Especial nº } 418594 \text { (STJ - RESP } 418594 \text { / PR - Paraná) } \\
\text { Recurso Especial nº } 601056 \text { (STJ - RESP 601056 / BA - Bahia) }\end{array}$ \\
\hline Ref. Leg. & 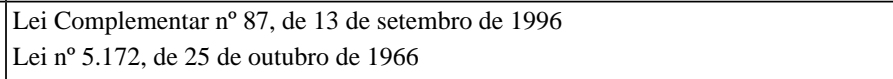 \\
\hline Publicação & Diário da Justiça, 16/02/2009 \\
\hline \multicolumn{2}{|c|}{ Descrição do Caso } \\
\hline \multicolumn{2}{|c|}{$\begin{array}{l}\text { Trata-se de recurso especial interposto por Global Village Telecom Ltda (GVT) decorrente de mandado } \\
\text { de segurança inicialmente impetrado para suspender a exigibilidade do ICMS incidente sobre as receitas } \\
\text { de assinaturas básicas mensais dos serviços de telefonia fixa da empresa, alegando-se a violação ao } \\
\text { art. } 2^{\circ} \text {, III, da Lei Complementar } 87 / 96 \text { (Lei Kandir), e ao art. 97, do Código Tributário Nacional } \\
\text { (CTN). } \\
\text { A questão em causa foi, portanto, a de se "saber se a assinatura telefônica constitui serviço de } \\
\text { comunicação apto a ensejar a incidência do ICMS", ou, em outras palavras, "se a denominada assinatura } \\
\text { mensal pode ser incluída no conceito de serviço de comunicação". }\end{array}$} \\
\hline \multicolumn{2}{|c|}{$\begin{array}{l}\text { O Convênio ICMS } 69 / 98 \text { prevê, em sua Cláusula Primeira, que se incluem na base de cálculo do ICMS } \\
\text { incidente sobre prestações de serviços de comunicação "os valores cobrados a título de acesso, adesão, } \\
\text { ativação, habilitação, disponibilidade, assinatura e utilização dos serviços, bem assim aqueles relativos } \\
\text { a serviços suplementares e facilidades adicionais que otimizem ou agilizem o processo de comunicação, } \\
\text { independentemente da denominação que lhes seja dada". Seguindo-se o precedente do REsp } \\
601.056 / B A, \text { a } 1^{a} \text { Turma do STJ afirmou, por maioria, a ilegalidade do Convênio ICMS no } 69 / 98 \text { em } \\
\text { sua pretensão de ampliação do campo de incidência do ICMS para além da atividade-fim do serviço } \\
\text { de comunicação, atingindo atividades-meio ou intermediárias, tais como a "habilitação, a instalação, } \\
\text { a disponibilidade, a assinatura, o cadastro de usuário e de equipamento, entre outros serviços". O } \\
\text { posicionamento esposado pelo voto vencido do Min. Teori Albino Zavascki partiu da leitura da Lei } \\
\text { Complementar } 87 / 96 \text {, que, ao definir o ICMS sobre os serviços de comunicações, acrescenta a ocorrência } \\
\text { do fato gerador do tributo como sendo "no momento (...) das prestações onerosas" (art. 12, VII), } \\
\text { considerando a base de cálculo do tributo como sendo "o preço do serviço" (art. 13, III). Com base } \\
\text { nisso, o voto vencido argumenta que a assinatura básica de telefonia, ao remunerar o serviço público }\end{array}$} \\
\hline
\end{tabular}


prestado ao consumidor, como contraprestação legítima ao serviço de comunicação,integraria a base de cálculo do ICMS-comunicação por constituir-se em contraprestação ao fornecimento do "ambiente de comunicação", pois remunera "tanto a franquia mensal em chamadas locais quanto a manutenção do acesso telefônico privativo do usuário à rede de telefonia de forma ininterrupta, ou seja, a manutenção da infraestrutura necessária à disponibilização do STFC" (p. 20). O voto vencido, portanto, alega incoerência da jurisprudência do STJ em relação à assinatura básica, cuja cobrança fora considerada legítima com base na afirmação de se configurar em contraprestação "pela efetiva prestação de serviços de telecomunicações consistente em assegurar aos usuários a fruição contínua de serviços", mas estaria sendo tratada diversamente para fins de incidência do ICMS, sob o argumento de que a assinatura básica não constituiria remuneração pelo serviço de telecomunicações prestado. Em contraste às ponderações do voto vencido, o voto-vista do Min. José Delgado afirma a consagração doutrinária de que o "ICMS não incide sobre a comunicação propriamente dita, mas sobre a relação comunicativa" (p. 26) e conclui que o serviço realizado para que a relação comunicativa se concretize não seria, em sua essência, a comunicação propriamente dita, mesmo porque aparatos físicos e lógicos necessários à comunicação, mesmo quando remunerados, não são considerados como fatos geradores do ICMS. Afirma, enfim, que a assinatura básica reflete serviço de telefonia fixa que possibilita originar e receber chamadas e que se refere ao serviço de comunicação, mas não se confunde com ele, divisando-se as atividades de manutenção da infraestrutura e de viabilidade da comunicação, do serviço propriamente dito. Em seu voto, o Min. Luiz Fux acrescenta detalhamento inexistente nos demais votos de que a assinatura básica de telefonia "admite dicotomização" (p. 39). De um lado, encontra-se a assinatura básica como simples atividade-meio sem disponibilização de franquia de minutos para ligações locais; de outro, a assinatura básica que, além de viabilizar a comunicação, disponibiliza franquia de minutos para ligações locais "prestando, nessa hipótese, efetivo serviço de comunicação" (p. 39). Com base nesse argumento, a existência de franquia de utilização nos contratos de concessão de STFC leva à consideração da assinatura básica, em tais casos, como legítima base de cálculo para o ICMS. Como o recorrente em pauta se trata de autorizada de serviços de telefonia, a inexistência de franquia de utilização na assinatura básica do serviço permite concluir-se pela não-incidência do ICMS sobre o correspondente valor. Conclui, o Min. Luiz Fux, que a não-incidência do ICMS sobre assinatura básica somente se justifica no caso de autorizadas à prestação de serviços de telecomunicações que não incluam "qualquer minuto no preço cobrado a título de assinatura mensal em seus planos, o que torna a sua assinatura a típica remuneração pela mera disponibilidade do meio" (p.41).

\begin{tabular}{|l|l}
\hline Catalogador & Márcio Iório Aranha
\end{tabular}

\section{Tribunal Superior do Trabalho (TST)}

\begin{tabular}{|l|l|}
\hline $\begin{array}{l}\text { Agravo de Instrumento no Recurso de Revista no 1542/2005-055-02-40 (TST - RR 1542/2005- } \\
\text { 055-02-40 - AI) }\end{array}$ \\
\hline Relator & Min. Ives Gandra Martins Filho \\
\hline Órgão Julgador & Sétima Turma do TST \\
\hline Votação & Unânime \\
\hline Julgamento & $04 / 06 / 2008$ \\
\hline Comentário & $\begin{array}{l}\text { É lícito o acesso, por empregador, à caixa de e-mail corporativo de seu empregado, } \\
\text { não configurando violação de sigilo de comunicações de dados. }\end{array}$ \\
\hline Dispositivos & LGT, Art. 61, § $1^{\circ}$. \\
\hline Correlata & Recurso de Revista n ${ }^{\circ} 613 / 2000-013-10-00$ (TST - RR 613/2000-013-10-00) \\
\hline Ref. Leg. & Constituição da República Federativa do Brasil de 1988 \\
\hline Publicação & Diário da Justiça, 06/06/2008 \\
\hline Descrição do Caso
\end{tabular}


Trata-se de Agravo de Instrumento em Recurso de Revista pleiteado por empregado contra decisão pautada em prova acostada aos autos oriunda de acesso à conta de e-mail corporativo oferecido pela Reclamada ao Reclamante para o exercício de suas atividades funcionais.

O conteúdo de dito e-mail corporativo averiguado pelo empregador, constatando-se tráfego inapropriado de conteúdos que estimulavam comportamentos preconceituosos, bem como outros índices reveladores de desperdício de tempo ao trabalho, fora utilizado como prova lícita para demissão por justa causa.

O entendimento da $7^{\mathrm{a}}$ turma do TST, seguindo precedente da $1^{\mathrm{a}}$ Turma do TST (TST-RR-613/2000013-10-00, Rel. Min. João Oreste Dalazen, $1^{\text {a }}$ Turma, DJ de 10/06/05), sustentou que, embora o art. $5^{\circ}$, X e XII, da Constituição Federal de 1988, garanta a inviolabilidade à intimidade, vida privada, honra e imagem, bem como o sigilo de suas correspondências, dados e comunicações telegráficas e telefônicas, caixa de e-mail corporativo não se enquadra nas hipóteses protegidas pelos dispositivos constitucionais citados contra o acesso do empregador. Tratando-se de ferramenta de trabalho para fins de potencializar a agilização e eficiência das funções do empregado para alcance do objeto social da empresa, não constitui ambiente de assuntos particulares, mesmo porque "como assinante do provedor de acesso à Internet, a empresa é responsável pela sua utilização com observância da lei" (voto do relator). Em resultado, negou-se provimento ao agravo.

\begin{tabular}{|l|l|}
\hline Catalogador & Márcio Iório Aranha \\
\hline
\end{tabular}

\section{Tribunal de Contas da União (TCU)}

\begin{tabular}{|c|c|}
\hline \multicolumn{2}{|c|}{ Processo Público no TC-002.660/2007-8 - Auditoria de Natureza Operacional } \\
\hline Relator & Min. Raimundo Carreiro \\
\hline Órgão Julgador & Plenário do TCU \\
\hline Votação & Unânime \\
\hline Julgamento & $02 / 04 / 2008$ \\
\hline Comentário & $\begin{array}{l}\text { Decisão em que o TCU verificou a existência de baixo grau de consistência na } \\
\text { elaboração de políticas públicas para o setor de telecomunicações; a ausência de metas } \\
\text { para a utilização dos recursos do Fundo para o Desenvolvimento Tecnológico das } \\
\text { Telecomunicações - Funttel; a carência de controles de arrecadação, bem como a } \\
\text { ocorrência de irregularidades na elaboração e execução de convênios, contratos de } \\
\text { repasses e outros instrumentos congêneres. }\end{array}$ \\
\hline Dispositivos & LGT, Art. $1^{\circ}$, caput; LGT, Art. 77, caput. \\
\hline Ref. Leg. & Lei $\mathrm{n}^{\circ} 10.052$, de 28 de novembro de 2000 \\
\hline Publicação & Diário Oficial da União, Seção 1, 04/04/2008 \\
\hline \multicolumn{2}{|c|}{ Descrição do Caso } \\
\hline \multicolumn{2}{|c|}{$\begin{array}{l}\text { Trata-se de Auditoria de Natureza Operacional feita no Fundo para o Desenvolvimento Tecnológico } \\
\text { das Telecomunicações - Funttel, com o objetivo de avaliar aspectos de legalidade e legitimidade da } \\
\text { gestão dos responsáveis, bem como de aferir os resultados alcançados pelos convênios e contratos } \\
\text { firmados para aplicação dos recursos envolvidos. }\end{array}$} \\
\hline \multicolumn{2}{|c|}{$\begin{array}{l}\text { Verificou-se que a grande maioria dos projetos custeados pelo Fundo para o Desenvolvimento } \\
\text { Tecnológico das Telecomunicações - Funttel tem como origem demandas espontâneas de interessados, } \\
\text { o que demonstra a falta de metas e de ações que antecipem a previsão de necessidades da área. }\end{array}$} \\
\hline \multicolumn{2}{|c|}{$\begin{array}{l}\text { Identificou-se que o Funttel não dispõe de estrutura administrativa, operacional e de processos para } \\
\text { garantir que os valores devidos sejam integralmente recolhidos ou que os contribuintes inadimplentes } \\
\text { sejam compelidos a fazê-lo por meio da aplicação de sanções. }\end{array}$} \\
\hline \multicolumn{2}{|c|}{$\begin{array}{l}\text { Dentre as irregularidades encontradas podem ser citadas a descrição e o detalhamento incompletos de } \\
\text { objeto, pagamentos indevidos de despesas, inconsistências entre a execução e as relações de dispêndios, } \\
\text { pagamentos sem contraprestação efetiva, etc. }\end{array}$} \\
\hline
\end{tabular}


Concluiu-se que a celebração de convênios, contratos de repasses e outros instrumentos congêneres, com a utilização de recursos do Funttel, não vinham respeitando a legislação aplicável nem as normas regulamentares específicas.

Além da realização de audiências, o TCU determinou a adoção das seguintes medidas:

"9.2. determinar à Secretaria de Telecomunicações do Ministério das Comunicações que:

9.2.1. com base no art. 11, incisos I e IV, do Decreto n ${ }^{\circ} 5.220$, de 30/09/2004:

9.2.1.1. estabeleça processo de formulação de políticas públicas consistente e sistematizado, em que a atuação de seu corpo técnico seja efetiva, e que, caso entenda necessário contar com serviços de terceiros para subsidiar suas decisões, tenha o cuidado de prevenir a ocorrência de conflitos de interesse e de garantir a prevalência dos princípios constitucionais da impessoalidade e da isonomia, encaminhando a este Tribunal e à Controladoria-Geral da União, no prazo de 90 (noventa) dias, um plano de ação com a indicação das medidas a serem implementadas com este objetivo;

9.2.1.2. estabeleça normas e critérios para a alocação de recursos para os projetos e programas financiados pelo Funttel;

9.2.2. por ocasião da celebração de convênios com o $\mathrm{CPqD}$ :

9.2.2.1. observe os requisitos previstos no capítulo II - Dos Requisitos para Celebração - da IN STN $\mathrm{n}^{\circ} 01 / 97$;

9.2.2.2. em cumprimento do disposto no art. $2^{\circ}, \S 1^{\circ}$, da IN STN n $01 / 97 \mathrm{c} / \mathrm{c}$ os arts. $7^{\circ}, 14$ e 55 , inciso I, da Lei $n^{\circ} 8.666 / 93$, exija que o Plano de Trabalho dos convênios a serem celebrados contenha a especificação completa do bem a ser produzido ou adquirido e, no caso de obras, instalações ou serviços, o projeto básico, entendido como tal o conjunto de elementos necessários e suficientes para caracterizar, de modo preciso, a obra, instalação ou serviço objeto do convênio, sua viabilidade técnica, custos, fases, ou etapas, e prazos de execução, devendo conter os elementos discriminados no inciso IX do art. $6^{\circ}$ da Lei $n^{\circ} 8.666 / 93$;

9.2.2.3. abstenha-se de firmar convênios com objetos incompatíveis com os objetivos do Funttel legalmente estabelecidos;

9.2.2.4. em cumprimento do art. $8^{\circ}$, incisos V e VI, da IN STN 01/97, não inclua, tolere ou admita cláusulas ou condições que prevejam ou permitam a realização de despesas em data anterior ou posterior à sua vigência e a atribuição de vigência ou de efeitos financeiros retroativos;

9.2.2.5. observe os dispositivos das Leis $n^{\circ}$ 8.958/94 e $n^{\circ} 10.973 / 04$ referentes à remuneração de servidores públicos ou empregados públicos e à compatibilização de jornadas de trabalho, bem como o art. $8^{\circ}$, II da IN STN n ${ }^{\circ}$ 01/97, para autorizar concessão de bolsas, despesas com pessoal e contratação de serviços de consultoria ou assistência técnica;

9.2.2.6. no caso de solicitação de remanejamento de verbas pelo órgão/entidade convenente, exija, além de justificativas adequadas e completas, o mesmo detalhamento exigido nos planos de trabalho dos convênios aprovados;

9.2.3. por ocasião da celebração de contratos com recursos do Funttel observe as orientações previstas nos arts. $1^{\circ}$, inciso IV, e $4^{\circ}$, incisos I e II, do Anexo à Resolução $n^{\circ} 3$ do Conselho Gestor do Funttel ao decidir sobre a aplicação dos recursos do Fundo para promover o acesso de empresas a recursos de capital;

9.2.4. informe ao TCU e à CGU, no prazo de 90 dias, as medidas adotadas referentes a estas determinações;

9.3. determinar à $1^{\text {a }}$ Secex que monitore o cumprimento das determinações constantes no subitem anterior;

9.4. determinar ao Conselho Gestor do Funttel que:

9.4.1. no cumprimento do art. $3^{\circ}$, inciso I, da Lei $n^{\circ} 10.052 / 2000$, oriente-se pelas políticas públicas estabelecidas para o setor de telecomunicações ao aprovar as normas de aplicação de recursos do Fundo em programas, projetos e atividades prioritárias na área de telecomunicações;

9.4.2. defina metas e seus respectivos indicadores para o setor de telecomunicações, em consonância com o art. 13 do Decreto $\mathrm{n}^{\circ} 3.737$, de 30/01/2001, bem como monitore e divulgue os resultados alcançados pelo Fundo; 
9.4.3. providencie a efetiva implantação e funcionamento do Sistema de Arrecadação do Funttel SAF, de sorte a possibilitar o controle de gestão da arrecadação dos recursos do Fundo, e avalie a possibilidade de integrá-lo com os sistemas da Anatel para aumentar a confiabilidade dos dados de arrecadação;

9.4.4. defina processos consistentes para garantir o recolhimento dos valores devidos por seus contribuintes na sua integralidade;

9.4.5. altere o parágrafo único do art. 10 da Resolução $\mathrm{n}^{\circ} 3$, por ser ele incompatível com os termos do art. $8^{\circ}$, incisos V e VI, da IN STN 01/97;

9.4.6. por ocasião da celebração de convênios com o CPqD:

9.4.6.1. observe os requisitos previstos no capítulo II - Dos Requisitos para Celebração - da IN STN $\mathrm{n}^{\circ} 01 / 97$

9.4.6.2. nos termos do art. $2^{\circ}, \S 1^{\circ}$, da IN STN $n^{\circ} 01 / 97 \mathrm{c} / \mathrm{c}$ os arts. $7^{\circ}, 14$ e 55 , inciso I, da Lei $\mathrm{n}^{\circ}$ 8.666/93, exija que o Plano de Trabalho dos convênios a serem celebrados contenha a especificação completa do bem a ser produzido ou adquirido e, no caso de obras, instalações ou serviços, o projeto básico, entendido como tal o conjunto de elementos necessários e suficientes para caracterizar, de modo preciso, a obra, instalação ou serviço objeto do convênio, sua viabilidade técnica, custos, fases, ou etapas, e prazos de execução, devendo conter os elementos discriminados no inciso IX do art. $6^{\circ}$ da Lei $n^{\circ}$ 8.666/93;

9.4.6.3. abstenha-se de firmar convênios com objetos incompatíveis com os objetivos do Funttel legalmente estabelecidos;

9.4.6.4. em cumprimento do art. $8^{\circ}$, incisos V e VI, da IN STN n ${ }^{\circ} 01 / 97$, não inclua, tolere ou admita cláusulas ou condições que prevejam ou permitam a realização de despesas em data anterior ou posterior à sua vigência e a atribuição de vigência ou de efeitos financeiros retroativos;

9.4.6.5. observe os dispositivos das Leis $n^{\circ} 8.958 / 94$ e $n^{\circ} 10.973 / 04$ referentes à remuneração de servidores públicos ou empregados públicos e à compatibilização de jornadas de trabalho, bem como o art. $8^{\circ}$, II da IN STN n ${ }^{\circ} 01 / 97$, para autorizar concessão de bolsas, despesas com pessoal e contratação de serviços de consultoria ou assistência técnica;

9.4.6.6. no caso de solicitação de remanejamento de verbas pelo órgão/entidade convenente, exija, além de justificativas adequadas e completas, o mesmo detalhamento exigido nos planos de trabalho dos convênios aprovados;

9.4.7. por ocasião da celebração de contratos com recursos do Funttel observe as orientações previstas nos arts. $1^{\circ}$, IV e $4^{\circ}$, I e II, do Anexo à Resolução $n^{\circ} 3$ do Conselho Gestor do Funttel ao decidir sobre a aplicação dos recursos do Fundo para promover o acesso de empresas a recursos de capital;

9.4.8. em todos os convênios e contratos, a fim de assegurar a observância dos princípios constitucionais e legais da moralidade, da impessoalidade, da isonomia e da legalidade, bem como dar cumprimento ao art. $3^{\circ}$, incisos I, V e VII da Lei $\mathrm{n}^{\circ} 10.052 / 2000 \mathrm{c} / \mathrm{c}$ o art. $5^{\circ}$, incisos II, VII e VIII, do Decreto $\mathrm{n}^{\circ}$ 3.737/01, tome as seguintes providências:

9.4.8.1. estabeleça critérios e valores para a concessão de diárias e passagens e para o pagamento de bolsas, aplicáveis a todos os convênios firmados, bem como vede a prática de ressarcimento de despesas de viagens;

9.4.8.2. defina os itens financiáveis, necessários ao cumprimento dos objetivos avençados, e não financiáveis, observando as vedações e limites para pagamentos de despesas contidas na IN STN $\mathrm{n}^{\circ}$ 01/97 e na Lei $\mathrm{n}^{\circ}$ 10.973/2004, notadamente aquelas referentes aos pagamentos de despesas administrativas e operacionais;

9.4.8.3. oriente os agentes financeiros (Finep, BNDES, entre outros) a utilizarem os critérios estabelecidos;

9.4.8.4. torne mais adequados os convênios vigentes, inclusive aqueles firmados pelos agentes financeiros, aos critérios estabelecidos;

9.4.8.5. abstenha-se de celebrar convênios que não detalhem, em suas cláusulas ou em seu plano de trabalho, as despesas com bolsas, diárias, hospedagens, alimentação e transporte necessários ao 
cumprimento dos objetivos avençados, se for o caso, de forma a assegurar o cumprimento dos art. $7^{\circ}$ incisos I e XII, "c" da IN STN n 01/97;

9.4.9. estabeleça mecanismos de controle de bens patrimoniais adquiridos com recursos do Fundo, bem como regulamente o direito de propriedade dos bens materiais remanescentes na data de conclusão ou extinção dos convênios, no sentido de dar a máxima aplicação possível aos equipamentos comprados com recursos do Fundo e evitar investimentos em duplicidade;

9.4.10. em cumprimento ao art. $3^{\circ}$, inciso II, da Lei $\mathrm{n}^{\circ} 10.052 / 2000$, regulamente e implemente mecanismos de controle necessários à demonstração da regularidade da execução do Plano de Aplicação de Recursos submetido pelos agentes financeiros e pela Fundação CPqD, bem como elabore um plano de fiscalização regular dos projetos executados com recursos do Fundo;

9.4.11. em todos os convênios celebrados com recursos do Funttel, notadamente aqueles firmados com a Fundação CPqD, exija que os convenentes:

9.4.11.1. mantenham os recursos federais repassados em conta bancária específica, somente sendo permitidos saques para o pagamento de despesas previstas no Plano de Trabalho, mediante cheque nominativo ao credor ou ordem bancária, ou para aplicação no mercado financeiro, consoante art. 20 da IN/STN no 01/97;

9.4.11.2. observem fielmente o disposto no art. 30 da IN STN $n^{\circ} 01 / 97$, no sentido de comprovar as despesas realizadas com recursos oriundos de convênios federais, mediante documentos originais fiscais ou equivalentes, devendo as faturas, recibos, notas fiscais e quaisquer outros documentos comprobatórios serem emitidos em nome do convenente ou do executor, devidamente identificados com referência ao título e número do convênio;

9.4.11.3. façam constar dos planos de trabalho estimativa dos valores a serem pagos a título de eventuais tributos, na hipótese de não se caracterizar imunidade tributária, isenção ou não incidência, para atendimento do inciso $\mathrm{V}$ e $\S 1^{\circ}$ do art. $2^{\circ}$ da IN/STN n. ${ }^{\circ} 01 / 97$;

9.4.12. em todos os convênios celebrados com recursos do Funttel, com fundamento nos artigos $2^{\circ}, \S$ $1^{\circ}$ e inciso XII.c, 15 e 22 da IN STN n ${ }^{\circ} 01 / 97$ :

- exija planilha contendo relação completa da equipe executora (registrando, no mínimo, a titulação obtida, instituição, ano de formação e função no projeto) e especificando, para cada mês de execução do projeto, para cada membro da equipe, a quantidade de horas alocadas para cada meta em que atuar e a remuneração correspondente acrescida dos encargos legais e trabalhistas incidentes;

- quaisquer alterações na composição e na quantidade de horas trabalhadas das equipes executoras sejam previamente formalizadas e justificadas, com a apresentação de planilha contendo as especificações previstas no item anterior, pelos convenentes e aprovadas pelo concedente;

- identifique, nos convênios vigentes, desde o seu início, pagamento de pessoal não previsto nos planos de trabalho, bem como o pagamento a maior de pessoal previsto inicialmente nos planos de trabalho e que não foi efetivamente disponibilizado para as atividades do convênio, e promova a glosa dos valores pagos impropriamente, devidamente atualizados;

9.4.13. com fundamento nos arts. $2^{\circ}, \S 1^{\circ}$ e inciso XII.c, 15 e 22 da IN STN n ${ }^{\circ} 01 / 97$, reduza, nos convênios vigentes, as despesas administrativas e operacionais ao máximo de $5 \%$ do valor total dos recursos financeiros destinados à execução do projeto, a fim de dar cumprimento ao art. 11 da Lei $\mathrm{n}^{\circ}$ $10.973 / 04$, para que seu total se amolde ao percentual previsto em lei;

9.4.14. em cumprimento ao art. 10 da Lei $\mathrm{n}^{\circ} 10.973 / 04 \mathrm{c} / \mathrm{c}$ o art. 11 do Decreto $\mathrm{n}^{\circ} 5.563 / 05$, ao aprovar convênios a serem financiados com recursos do Fundo, observem o limite de 5\% para despesas administrativas e operacionais apresentadas no plano de trabalho;

9.4.15. informe a este Tribunal e à CGU, no prazo de 90 dias, a situação de cada convênio vigente com relação às despesas administrativas e operacionais;

9.4.16. consoante o art. 21 da IN STN nº 01/97, observe a comprovação da boa e regular aplicação das parcelas já recebidas pelo convenente, conforme estabelecido em plano de trabalho previamente aprovado, para fins de liberação das parcelas seguintes do convênio;

9.4.17. em todos os convênios celebrados com recursos do Funttel, com fundamento nos arts. $2^{\circ}, \S 1^{\circ}$ e inciso XII.c, 15 e 22 da IN STN no 01/97, desenvolva e adote critérios e procedimentos com a 
finalidade de exigir e comprovar a observância, pelos convenentes, das disposições da Lei n ${ }^{\circ} 8.666 / 93$, no que couber, a fim de dar cumprimento ao art. 27 da IN STN n ${ }^{\circ}$ 01/97;

9.4.18. oriente os convenentes e os agentes financeiros, para contratações de serviços técnicos especializados e consultorias realizados no âmbito dos convênios firmados com recursos do Fundo, no sentido de:

9.4.18.1. definirem os serviços a serem contratados com objetividade e clareza (arts. $7^{\circ}, 14$ e 55 , inciso I, da Lei $\mathrm{n}^{\circ} 8.666 / 93 \mathrm{c} / \mathrm{co}$ art. $2^{\circ}$ da IN STN $n^{\circ} 01 / 97$ ), apresentando seu detalhamento e os respectivos custos, de modo a viabilizar a aferição da necessidade da contratação, bem como a razoabilidade e exeqüibilidade dos preços acordados (art. $6^{\circ}$, inciso IX, "f" da Lei $n^{\circ} 8.666 / 93 \mathrm{c} / \mathrm{c}$ o art. $2^{\circ}, \S 1^{\circ}$, da IN $\mathrm{STN} \mathrm{n}^{\circ}$ 01/97), informando ao TCU e à CGU, no prazo de 90 dias, as medidas adotadas referentes a esta determinação;

9.4.18.2. instruírem os contratos ou instrumentos congêneres com, entre outras informações, o objeto da contratação, o valor do contrato, a identificação dos signatários, preços e condições de pagamento, os direitos e as responsabilidades das partes, com a identificação precisa das contrapartidas acordadas, a fim de permitir o controle da execução da avença (arts. $54, \S 1^{\circ}$ e 55 da Lei ${ }^{\circ} 8.666 / 93 \mathrm{c} / \mathrm{c}$ o art. $7^{\circ}$ da IN STN n ${ }^{\circ}$ 01/97);

9.4.18.3. garantirem que os contratados apresentem situação fiscal regular (arts. 27, inciso IV, e 29 da Lei $\mathrm{n}^{\circ} 8.666 / 93 \mathrm{c} / \mathrm{c}$ o art. $3^{\circ}$ da IN STN n ${ }^{\circ} 01 / 97$ );

9.4.19. realize a glosa da importância de $\mathrm{R} \$ 9.188 .630,96$ (nove milhões cento e oitenta e oito mil seiscentos e trinta reais e noventa e seis centavos), referente a despesas pagas indevidamente até dezembro de 2006 no âmbito dos convênios firmados com o CPqD, que superam o limite máximo de $5 \%$ para despesas administrativas e operacionais previsto no art. 11 da Lei $\mathrm{n}^{\circ} 10.973 / 2004$, calculada conforme planilha do Apêndice B da instrução de fls. 27/138, bem como realize a glosa para os períodos subseqüentes;

9.4.20. realize a glosa dos valores a serem pagos ao CPqD, a importância de $\mathrm{R} \$ 192.960,00$ (cento e noventa e dois mil novecentos e sessenta reais), referentes a contratação, no âmbito do convênio Cenários Tecnológicos de Telecomunicações, de Manesco Ramires P. Azevedo Marques, para a prestação de consultoria para finalidades diversas daquelas para as quais os recursos foram transferidos, caracterizando desvio de finalidade, em consonância com o art. $7^{\circ}$, inciso XII, c da IN STN n ${ }^{\circ} 01 / 97$;

9.4.21. realize a glosa dos valores a serem pagos ao CPqD, a importância de $\mathrm{R} \$ 920.134,00$ (novecentos e vinte mil cento e trinta e quatro reais), referentes ao serviços de consultoria relacionados no quadro a seguir, por restar caracterizado pagamento sem contraprestação, informando ao TCU e à CGU, no prazo de 90 dias, as medidas adotadas;

Convênio Contrato Objeto Contratado Valor (R\$)

SIGPPT Não disponível serviços de pesquisa e desenvolvimento de um simulador de pontos de disponibilização de rádio comunitária, conforme o Formulário de Apontamento 19884 Funcamp $15.000,00$

Cenários 1549 Every Consultoria e Desenvolvimento de Negócios Ltda. 64.000,00

SIC 1509 Funcamp 103.700,00

SBTVD 1195 Funcamp 282.039,00

Cenários 2236 Tosi Assessoria em Telecomunicações 144.001,00

Cenários 2132 Lima Verde Consultoria em Engenharia Ltda. 100.400,00

Cenários 2370 F\&R Engenheiros Consultores Associados Ltda. 52.000,00

1558 Funcamp 158.994,00

Total (R\$) 920.134,00

9.4.22. exija que o CPqD:

9.4.22.1. em cumprimento ao art. $2^{\circ}$, inciso V, da Resolução $\mathrm{n}^{\circ} 3$ do Conselho Gestor do Funttel, no sentido de privilegiar a manutenção de sua capacidade de realização de pesquisa e desenvolvimento tecnológico em telecomunicações, evite a contratação de serviços técnicos especializados e consultorias para realizar atividades que possam ser desempenhadas por seus empregados; 
9.4.22.2. observe os princípios constitucionais da impessoalidade, da moralidade e da publicidade, estabelecidos no art. 37, caput, da Constituição Federal, e do devido processo licitatório para selecionar a proposta mais vantajosa, conforme prevê o art. $3^{\circ}$ da Lei $n^{\circ} 8.666 / 93$, bem como demonstre a necessidade da contratação;

9.4.23. no cumprimento de suas competências estabelecidas no art. $3^{\circ}$, I e II, da Lei $n^{\circ} 10.052 / 00$, observe, além dos normativos aplicáveis, os princípios da isonomia e da impessoalidade na análise de projetos submetidos à sua aprovação, abstendo-se de privilegiar interesses particulares em suas decisões de alocação de recursos do Fundo;

9.4.24. identifique os produtos passíveis de registro de patente e/ou proteção da criação intelectual para firmar os acordos cabíveis referentes aos direitos de propriedade intelectual, licenciamento, comercialização e pagamentos de royalties, segundo as normas vigentes e as cláusulas dos convênios e contratos celebrados;

9.4.25. ultime as providências no sentido de dotar-se de mecanismos que garantam que os royalties a que tem direito sejam devidamente recolhidos, bem como proceda a transferência aos cofres do Fundo dos recursos devidos a título de royalties pelo CPqD no Convênio 01.03.0349.00;

9.4.26. informar ao TCU e à CGU, no prazo de 90 dias, as medidas adotadas a respeito destas determinações;

9.5. determinar à $1^{\mathrm{a}}$ Secex que monitore o cumprimento das determinações constantes no subitem anterior;

9.6. determinar ao Ministério das Comunicações que, em vista das disposições constantes do art. $4^{\circ}$, do Decreto $\mathrm{n}^{\circ} 3.737 / 01$, torne a estrutura administrativa e operacional de suporte mais adequada a gestão do Fundo às necessidades de gestão da arrecadação dos recursos estabelecidas pelo Conselho Gestor do Funttel, bem como institua procedimentos formais de notificação e responsabilização pelo recolhimento de tributos em desacordo com as exigências legais, informando ao TCU e à CGU, no prazo de 90 dias, as medidas adotadas referentes a esta determinação;

9.7. determinar à $1^{\text {a }}$ Secex que monitore o cumprimento da determinação constante no subitem anterior 9.8. recomendar ao Conselho Gestor do Funttel que:

9.8.1. divulgue relação de bens patrimoniais do Fundo com o intuito de permitir que as instituições de pesquisa possam contemplar a utilização desses equipamentos em planos de trabalho submetidos à aprovação do Funttel, otimizando-se assim os gastos do Fundo com despesas de capital;

9.8.2. implemente ações com o objetivo de aumentar a transparência e divulgar os resultados obtidos com recursos do Fundo, inspiradas no art. 18 do Decreto 5.563/2005;

9.8.3. normatize a questão de direitos de propriedade intelectual, licenciamento, comercialização e pagamento de royalties associados a produtos desenvolvidos com recursos do Funttel;

9.8.4. estabeleça mecanismos que possibilitem a monitoração da destinação, produção, licenciamento e comercialização de bens desenvolvidos com recursos do Funttel após a conclusão dos projetos.

9.9. determinar à Finep que:

9.9.1. por ocasião da celebração de convênios com recursos do Funttel:

9.9.1.1. observe os requisitos previstos no Capítulo II da IN STN nº 01/97;

9.9.1.2. abstenha-se de firmar convênios com objetos incompatíveis com os objetivos do Funttel legalmente estabelecidos;

9.9.1.3. em cumprimento do disposto no art. $2^{\circ}, \S 1^{\circ}$, da IN STN $n^{\circ} 01 / 97 \mathrm{c} / \mathrm{c}$ os arts. $7^{\circ}, 14$ e 55 , inciso I, da Lei $n^{\circ} 8.666 / 93$, exija que o Plano de Trabalho dos convênios a serem celebrados contenha a especificação completa do bem a ser produzido ou adquirido e, no caso de obras, instalações ou serviços, o projeto básico, entendido como tal o conjunto de elementos necessários e suficientes para caracterizar, de modo preciso, a obra, instalação ou serviço objeto do convênio, sua viabilidade técnica, custos, fases, ou etapas, e prazos de execução, devendo conter os elementos discriminados no inciso IX do art. $6^{\circ}$ da Lei $n^{\circ} 8.666 / 93$;

9.9.1.4. em cumprimento ao art. $8^{\circ}$, incisos V e VI, da IN STN n ${ }^{\circ} 01 / 97$, não inclua, tolere ou admita cláusulas ou condições que prevejam ou permitam a realização de despesas em data anterior ou posterior à sua vigência e a atribuição de vigência ou de efeitos financeiros retroativos; 
9.9.1.5. observe os dispositivos das Leis $\mathrm{n}^{\circ}$ 8.958/94 e $\mathrm{n}^{\circ}$ 10.973/04 referentes à remuneração de servidores públicos ou empregados públicos e à compatibilização de jornadas de trabalho, bem como o art. $8^{\circ}$, II da IN STN n ${ }^{\circ}$ 01/97, para autorizar concessão de bolsas, despesas com pessoal e contratação de serviços de consultoria ou assistência técnica, adotando as medidas corretivas cabíveis nos convênios em andamento, a exemplo do Convênio 01.07.0022.00;

9.9.1.6. no caso de solicitação de remanejamento de verbas pelo órgão/entidade convenente, exija, além de justificativas adequadas e completas, o mesmo detalhamento exigido nos planos de trabalho dos convênios aprovados;

9.9.2. por ocasião da celebração de contratos com recursos do Funttel observe as orientações previstas nos arts. $1^{\circ}$, IV e $4^{\circ}$, I e II, do Anexo à Resolução $n^{\circ} 3$ do Conselho Gestor do Funttel ao decidir sobre a aplicação dos recursos do Fundo para promover o acesso de empresas a recursos de capital;

9.9.3. em todos os convênios celebrados com recursos do Funttel, notadamente aqueles firmados com a Fundação CPqD, exija que os convenentes:

9.9.3.1. mantenham os recursos federais repassados mediante convênio em conta bancária específica, somente sendo permitidos saques para o pagamento de despesas previstas no Plano de Trabalho, mediante cheque nominativo ao credor ou ordem bancária, ou para aplicação no mercado financeiro, consoante art. 20 da IN/STN n ${ }^{\circ} 01 / 97$, atualmente em vigor;

9.9.3.2. observem fielmente o disposto no art. 30 da IN STN $n^{\circ} 01 / 97$, no sentido de comprovar as despesas realizadas com recursos oriundos de convênios federais, mediante documentos originais fiscais ou equivalentes, devendo as faturas, recibos, notas fiscais e quaisquer outros documentos comprobatórios serem emitidos em nome do convenente ou do executor, devidamente identificados com referência ao título e número do convênio;

9.9.3.3. façam constar dos planos de trabalho estimativa dos valores a serem pagos a título de CPMF e eventuais tributos em que não se caracterizar hipóteses de imunidade, isenção ou não incidência, para atendimento do inciso $\mathrm{V}$ e $\S 1^{\circ}$ do art. $2^{\circ}$ da IN/STN n. ${ }^{\circ} 01 / 97$;

9.9.4. com fundamento nos artigos $2^{\circ}, \S 1^{\circ}$, e inciso XII.c, 15 e 22 da IN STN n ${ }^{\circ} 01 / 97$, reduza, nos convênios vigentes, as despesas administrativas e operacionais ao máximo de $5 \%$ do valor total dos recursos financeiros destinados à execução do projeto, a fim de dar cumprimento ao art. 11 da Lei $\mathrm{n}^{\circ}$ $10.973 / 04$, para que seu total se amolde ao percentual previsto em lei;

9.9.5. em cumprimento ao art. $10 \mathrm{da}$ Lei $\mathrm{n}^{\circ} 10.973 / 04 \mathrm{c} / \mathrm{c}$ o art. 11 do Decreto $\mathrm{n}^{\circ}$ 5.5.63/05, ao aprovarem convênios a serem financiados com recursos do Fundo, observem o limite de 5\% para despesas administrativas e operacionais apresentadas no plano de trabalho;

9.9.6. informe a este Tribunal e à CGU, no prazo de 90 dias, a situação de cada convênio vigente com relação às despesas administrativas e operacionais;

9.9.7. consoante o art. 21 da IN STN n ${ }^{\circ} 01 / 97$, observe a comprovação da boa e regular aplicação das parcelas já recebidas pelo convenente, conforme estabelecido em plano de trabalho previamente aprovado, para fins de liberação das parcelas seguintes do convênio;

9.9.8. em todos os convênios celebrados com recursos do Funttel, com fundamento nos artigos $2^{\circ}, \S$ $1^{\circ}$ e inciso XII.c, 15 e 22 da IN STN n ${ }^{\circ}$ 01/97:

9.9.8.1. exija planilha contendo relação completa da equipe executora (registrando, no mínimo, a titulação obtida, instituição, ano de formação e função no projeto) e especificando, para cada mês de execução do projeto, para cada membro da equipe, a quantidade de horas alocadas para cada meta em que atuar e a remuneração correspondente acrescida dos encargos legais e trabalhistas incidentes;

9.9.8.2. quaisquer alterações na composição e na quantidade de horas trabalhadas das equipes executoras sejam previamente formalizadas e justificadas, com a apresentação de planilha contendo as especificações previstas no item anterior, pelos convenentes e aprovadas pelo concedente;

9.9.8.3. identifique, nos convênios vigentes, desde o seu início, pagamento de pessoal não previsto nos planos de trabalho, bem como o pagamento a maior de pessoal previsto inicialmente nos planos de trabalho e que não foi efetivamente disponibilizado para as atividades do convênio, e promova a glosa dos valores pagos impropriamente, devidamente atualizados;

9.9.9. em todos os convênios celebrados com recursos do Funttel, com fundamento nos artigos $2^{\circ}, \S$ $1^{\circ}$ e XII.c, 15 e 22 da IN STN no 01/97, desenvolva e adote critérios e procedimentos com a finalidade 
de exigir e comprovar a observância, pelos convenentes, das disposições da Lei $n^{\circ} 8.666 / 93$, no que couber, a fim de dar cumprimento ao art. 27 da IN STN n ${ }^{\circ} 01 / 97$;

9.9.10. com supedâneo no art. $8^{\circ}, \S 1^{\circ}$, da Lei $\mathrm{n}^{\circ} 8.443 / 92 \mathrm{c} / \mathrm{c}$ o art. $197, \S 1^{\circ}$, do Regimento Interno do TCU e no art. 38 da IN STN $n^{\circ} 01 / 97$, instaure tomada de contas especial para apuração dos fatos, identificação dos responsáveis e quantificação do dano referente às despesas de serviços e consultorias firmadas nos Convênios 22.02.0303.00 e 01.05.0154.00, apresentando ao Tribunal, no prazo de 90 dias, o resultado da apuração;

9.9.11. identifique os produtos passíveis de registro de patente e/ou proteção da criação intelectual para firmar os acordos cabíveis referentes aos direitos de propriedade intelectual, licenciamento, comercialização e pagamentos de royalties, segundo as normas vigentes e as cláusulas dos convênios e contratos celebrados;

9.10. determinar à $1^{\text {a }}$ Secex que monitore o cumprimento das determinações constantes no subitem anterior;

9.11. com fundamento no art. $5^{\circ}$, inciso LV, da Constituição Federal c/c art. 31 da Lei n ${ }^{\circ} 8.443 / 92$, para que seja assegurado a ampla defesa e o contraditório de todas as partes envolvidas, promover a oitiva da Fundação CPqD para que se manifeste, no prazo de 15 (quinze) dias, acerca de:

9.11.1. serviços de consultoria relacionados no quadro a seguir, por restar caracterizado pagamento sem contraprestação, e da glosa determinada no subitem 9.4.19 deste acórdão;

Convênio Contrato Objeto Contratado Valor (R\$)

SIGPPT Não disponível serviços de pesquisa e desenvolvimento de um simulador de pontos de disponibilização de rádio comunitária, conforme o Formulário de Apontamento 19884 Funcamp $15.000,00$

Cenários 1549 Every Consultoria e Desenvolvimento de Negócios Ltda. 64.000,00

SIC 1509 Funcamp 103.700,00

SBTVD 1195 Funcamp 282.039,00

Cenários 2236 Tosi Assessoria em Telecomunicações 144.001,00

Cenários 2132 Lima Verde Consultoria em Engenharia Ltda. 100.400,00

Cenários 2370 F\&R Engenheiros Consultores Associados Ltda. 52.000,00

1558 Funcamp 158.994,00

Total (R\$) 920.134,00

9.11.2. contratação, no âmbito do convênio Cenários Tecnológicos de Telecomunicações, de Manesco Ramires P. Azevedo Marques, para a prestação de consultoria para finalidades diversas daquelas para as quais os recursos foram transferidos, caracterizando desvio de finalidade, em consonância com o art. $7^{\circ}$, XII, c da IN STN n ${ }^{\circ}$ 01/97, e da glosa determinada no subitem 9.4.20 deste acórdão;

9.11.3. despesas indevidas no âmbito dos convênios firmados com o Funttel, que superam o limite máximo de 5\% para despesas administrativas e operacionais previsto no art. 11 da Lei $n^{\circ} 10.973 / 04$, e da glosa determinada no subitem 9.4.21 deste acórdão;

9.12. encaminhar cópia das fls. 103/106 dos presentes autos à Delegacia Regional do Trabalho e a Superintendência Regional da Receita Federal do Brasil em Campinas, informando os indícios de burla à legislação trabalhista e tributária identificados, para que tomem as providências que julgarem necessárias;

9.13. remeter cópia do presente acórdão, bem como do Relatório e do Voto que o fundamentam, ao Ministério Público Federal, ao Ministério Público do Estado de São Paulo, a quem incumbe velar pelas Fundações CPqD e Casimiro Montenegro Filho, e ao Ministério Público do Estado do Rio de Janeiro, responsável pela Fundação Padre Leonel Franca, para conhecimento das irregularidades envolvendo as respectivas fundações nos convênios celebrados com recursos do Funttel e adoção das providências que julgar necessárias.

9.14. remeter cópia do presente acórdão, bem como do Relatório e do Voto que o fundamentam, ao Ministério das Comunicações para que a determinação alvitrada no subitem 9.6 seja melhor entendida e implementada; 
9.15. encaminhar cópia da instrução de fls. 27/138 e do presente acórdão, bem como do Relatório e do Voto que o fundamentam, à Presidência da CPI das Organizações Não-Governamentais do Senado Federal".

\begin{tabular}{l|l}
\hline Catalogador & Rodrigo Fernandes \\
\hline
\end{tabular}

\begin{tabular}{|c|c|}
\hline \multicolumn{2}{|c|}{ Processo Público no TC-023.855/2007-0 - Acompanhamento } \\
\hline Relator & Min. Raimundo Carreiro \\
\hline Órgão Julgador & Plenário do \\
\hline Votação & ช \\
\hline Julgamento & $23 / 04 / 2008$ \\
\hline Come & $\begin{array}{l}\text { ecisão em que o TCU verificou o processo de outorga de autorização para exploração } \\
\text { Serviço Móvel Pessoal e de autorização de uso de radiofrequências nas subfaixas } \\
\text { IMT-2000 (J, F, G e I). O TCU entendeu regulares os compromissos de abrangência } \\
\text { tipulados que se destinavam a assegurar o acesso ao serviço móvel pessoal em } \\
\text { unicípios com população inferior a } 30.000 \text { mil habitantes. }\end{array}$ \\
\hline Dispo & LGT, Art. 127, inciso I; LGT, A \\
\hline Publicação & Diário Oficial da União, Seção 1, 25/04/2008 \\
\hline \multicolumn{2}{|c|}{$\begin{array}{l}\text { Ao aprovar os estágios do processo de outorga de SMP, o TCU acolheu a manifestação do Relator, } \\
\text { que assim se pronunciou; }\end{array}$} \\
\hline \multicolumn{2}{|c|}{$\begin{array}{l}\text { "Ressalto tema de notória importância. O edital (fls. } 04 / 30 \text { e segs. do Anexo } 4 \text { ) estabelece critérios } \\
\text { que visam operacionalizar a universalização de acesso ao serviço móvel pessoal a municípios com } \\
\text { população inferior a } 30.000 \text { mil habitantes. Impugnações ao edital vieram, no sentido de alegar que } \\
\text { diversos desses itens, por razões diversas, implicariam em cláusulas abusivas, pois não encontrariam } \\
\text { respaldo no arcabouço regulatório e extrapolariam as competências da Anatel (fls. } 121 \text { do Anexo } 4 \text { ). } \\
\text { Como se sabe, o edital (e seus anexos) é uma norma. Norma apenas de abrangência reduzida (lei entre } \\
\text { as partes). Portanto, nele cabe operacionalizar (nas situações que aparecem no caso concreto) os } \\
\text { mandamentos que se vão especializando conforme vamos descendo na pirâmide da hierarquia das } \\
\text { normas. Portanto, acerta a Anatel quando afirma que as normas do edital referentes à unificação dos } \\
\text { termos de autorização que visa repassar ganhos do mercado ao consumidor - (fls. 132-v e } 133 \text { do } \\
\text { Anexo 4), ao compartilhamento de rede (que visa permitir a implementação do serviço em áreas de } \\
\text { baixa atratividade econômica - fls. 133 e seu verso do Anexo 4) e ao atendimento obrigatório a usuários } \\
\text { visitantes (que permite, em municípios com menos de 30.000 habitantes, a possibilidade de receber } \\
\text { interessados na competição - fls. 133-v e } 134 \text { do Anexo 4) estão conforme o espírito, os princípios e } \\
\text { as normas gerais de telecomunicações. Aliás, e não preciso estender-me no tema, princípios têm força } \\
\text { de norma e normas gerais são apenas molduras, sendo o momento máximo de concretização as normas } \\
\text { do edital. Guardando estas conformidade com as normas de hierarquia superior, têm plena validade } \\
\text { jurídica. Portanto, a Anatel agiu conforme, em especial, os fundamentos e os objetivos fundamentais } \\
\text { elencados na Constituição, os princípios estampados no art. } 20 \text { e a norma do art. } 155 \text { da Lei } 9.472 / 97 \text {, } \\
\text { as suas Resoluções, sendo lícito fixar regras operacionais no edital (conforme art. } 199 \text { c/c o art. } 80 \text { da } \\
\text { Lei 9.472/97), em especial quando estas regras convergem com as demais do sistema." }\end{array}$} \\
\hline & \\
\hline
\end{tabular}

\begin{tabular}{|l|l|}
\hline \multicolumn{2}{|l|}{ Processo Público $\mathbf{n}^{\mathbf{0}}$ TC-010.978/2008-1- Monitoramento } \\
\hline Relator & Min. Augusto Sherman Cavalcanti \\
\hline Órgão Julgador & Plenário do TCU \\
\hline Votação & Unânime \\
\hline
\end{tabular}




\begin{tabular}{|c|c|}
\hline Julgamento & $23 / 07 / 2008$ \\
\hline Comentário & $\begin{array}{l}\text { cisão em que o TCU, ao monitorar o cumprimento do Acórdão 532/2005-TCU- } \\
\text { nário, atinente a irregularidades no recolhimento de taxas de fiscalização dos } \\
\text { viços de telecomunicações, entendeu indevido o procedimento adotado pela } \\
\text { JATEL de cancelar os créditos decorrentes do não pagamento da taxa de fiscalização } \\
\text { s serviços de telecomunicações - TFF. }\end{array}$ \\
\hline spositivos & . \\
\hline Ref. Leg. & $\begin{array}{l}\text { Lei no } 5.070, \text { de } 7 \text { de julho de } 1966 \\
\text { Resolução da ANATEL n } 255 \text {, de } 29 \text { de março de } 2001\end{array}$ \\
\hline Publicação & 8 \\
\hline \multicolumn{2}{|c|}{ Descrição do Caso } \\
\hline \multicolumn{2}{|c|}{$\begin{array}{l}\text { A divergência na interpretação da legislação aplicável ao caso foi assim retratada pelo relator do } \\
\text { processo: }\end{array}$} \\
\hline \multirow{3}{*}{\multicolumn{2}{|c|}{$\begin{array}{l}\text { "2. Por ocasião da prolação do decisum monitorado, ressaltei, como fundamento à expedição das duas } \\
\text { referidas determinações, o seguinte: } \\
\text { "III } \\
\text { 15. A segunda irregularidade refere-se ao cancelamento indevido dos créditos decorrentes da taxa de } \\
\text { fiscalização dos serviços de telecomunicações - TFF. A falha teria sido constatada em decorrência do } \\
\text { disposto no Parecer } 752 / 2000 \text { da Procuradoria Jurídica da Anatel (fls. } 95 \text { ), o qual assim dispôs: }\end{array}$}} \\
\hline & \\
\hline & \\
\hline \multirow{2}{*}{\multicolumn{2}{|c|}{$\begin{array}{l}\text { 'Em vistoria realizada por esta Agência, constatou-se que o } \mathrm{Sr} . . . \text { estava operando o serviço sem a } \\
\text { comprovação do pagamento das taxas do Fistel. } \\
\text { (...) }\end{array}$}} \\
\hline & \\
\hline \multicolumn{2}{|c|}{$\begin{array}{l}\text { A Instrução } 03 / 88 \text {-Dentel, de } 30 / 06 / 88 \text {, aos itens } 6.1 \text { e } 6.2 \text {, determina que: " } 6.1 \text { A Licença de Estação } \\
\text { será expedida com validade até } 31 \text { de março do ano seguinte ao da sua expedição. } 6.2 \text { O prazo de } \\
\text { validade da Licença estará prorrogado a cada ano, desde que ela esteja acompanhada da guia DARF } \\
\text { emitida pelo Dentel, comprovando o recolhimento da Taxa de Fiscalização do Funcionamento do } \\
\text { exercício.' }\end{array}$} \\
\hline \multicolumn{2}{|c|}{$\begin{array}{l}\text { Desta forma, o autorizado deverá ter seus débitos relativos ao não pagamento das TFFs cancelados, } \\
\text { haja vista que a legislação que norteia a matéria aduz que o não pagamento do tributo é uma confissão } \\
\text { clara de que o usuário não tem mais interesse na exploração do serviço. }\end{array}$} \\
\hline \multicolumn{2}{|c|}{$\begin{array}{l}\text { A regularização da situação instalada é inviável, não havendo a possibilidade de ser expedida licença } \\
\text { de funcionamento com data retrógrada.' (grifos meus). }\end{array}$} \\
\hline \multicolumn{2}{|c|}{$\begin{array}{l}\text { 16. Tal parecer foi efetuado em processo de apuração de infração. A sua fundamentação decorre do } \\
\text { raciocínio que o não pagamento da taxa de fiscalização implica a caducidade da licença e, caso houvesse } \\
\text { a prestação do serviço sem a respectiva licença, estar-se-ia diante de operações clandestinas dos serviços } \\
\text { de telecomunicações, sujeitando-se os infratores às penalidades cabíveis e não ao pagamento da taxa. }\end{array}$} \\
\hline \multicolumn{2}{|c|}{$\begin{array}{l}\text { 17. Quanto a essas considerações, observo que o fato gerador do pagamento da taxa é o exercício do } \\
\text { poder de polícia referente à fiscalização dos serviços. O fato de os serviços estarem sendo prestados } \\
\text { sem amparo nas normas não os exime de serem fiscalizados e, em assim sendo, deve haver a cobrança } \\
\text { da taxa respectiva, cujos objetivos são exatamente custear esse serviços de fiscalização. O Código } \\
\text { Tributário Nacional - CTN, em seu art. } 118 \text {, caput e inciso I, bem dispõe que 'a definição legal de fato } \\
\text { gerador é interpretada abstraindo-se da validade jurídica dos atos efetivamente praticados pelos } \\
\text { contribuintes, responsáveis, ou terceiros, bem como da natureza do seu objeto ou dos seus efeitos.' } \\
\text { (grifos meus). }\end{array}$} \\
\hline \multicolumn{2}{|c|}{$\begin{array}{l}\text { 18. Consoante Luiz Emygdio da Rosa Júnior (Manual de Direito Financeiro e Tributário, } 11^{\text {a ed., }} \text { 1997, } \\
\text { p. 469) ‘não interessa para a autoridade tributária se o ato é lícito ou ilícito, criminoso ou imoral, pois } \\
\text { o que importa é que ocorreu o fato gerador do tributo.' Observa ainda o autor que feriria a regra da } \\
\text { igualdade tributária se o Estado tributasse apenas as atividades lícitas, e que a cobrança de tributos } \\
\text { não possui o condão de legitimar aquelas ilícitas. }\end{array}$} \\
\hline
\end{tabular}


19. Deveras, seria um verdadeiro contra-senso que os prestadores ilegais de serviços não estivessem sujeitos às taxas de fiscalização, e aqueles em situação regular, sim. Tratar-se-ia de um flagrante estímulo à clandestinidade. A tributação, deve-se bem destacar, não constitui sanção por ato ilícito $\left(\right.$ art. $3^{\circ}$ do CTN), de forma que não há óbices para que o infrator sofra as penalidades expressas na norma, sem a ocorrência de bis in idem. Não se trata, igualmente, da expedição de licenças retroativas, pois a cobrança de tributos não implica que as atividades devam ser regularizadas.

20. Observa-se ainda, ao contrário do contido no referido parecer jurídico, que a manifestação de desinteresse na continuidade de execução do serviço não exonera o outorgado de pagar a taxa referente ao exercício em que houve tal manifestação, a teor do disposto no art. 14 da Resolução Anatel 255/2001: 'A TFF somente deixará de incidir sobre a estação licenciada, a partir do exercício subseqüente àquele em que a Prestadora venha a protocolizar, na sede da Anatel, ER ou UO, pedido de cancelamento da licença.'

21. Isso posto, manifesto-me de acordo com a unidade técnica no sentido de que a ausência de licença de operação não exime o prestador dos serviços do pagamento das taxas de fiscalização, devendo a exclusão dessas obrigações somente ocorrer mediante lei específica ( $\$ 6^{\circ}$ do art. 150 da CF).

22. Por outro lado, é de se considerar as autorizações aqui tratadas não extintas em razão de não ter sido seguido o rito tratado no tópico anterior deste voto.

24. Cabe, portanto, a realização de determinação à Anatel para que adote providências no sentido de rever as declarações de caducidade de outorgas feitas em desacordo com o disposto no art. $8^{\circ}$, $\S 2^{\circ}$, da Lei 5.070/66, limitado ao período de vigência da Resolução Anatel 255/2001, bem como rever dispensas de pagamento de tributo, nesse período, ainda não alcançadas pela prescrição e decadência.

25. Não cabe, contudo, a determinação de antemão para que os nomes dos inadimplentes sejam inscritos na Dívida Ativa da União ou no cadastro de inadimplentes de que trata a Lei 10.522/2000, pelo fato de que os procedimentos a serem adotados dependem da análise de cada caso concreto. (...).”

3. Em razão do claro posicionamento desta Corte de Contas sobre referidos assuntos, não poderia a Agência agir em descumprimento das determinações de que tomou ciência. Acaso houvesse discordado desse posicionamento, haveria de ser interposto recurso contra a deliberação. Não havendo justo motivo, surge a possibilidade de sanção por descumprimento de determinação deste Tribunal.

4. Entretanto, em que pese o não cumprimento das referidas determinações, entendo, como sugerido pela Semag, que este Tribunal deva reiterar as determinações e alertar a unidade jurisdicionada acerca das conseqüências de eventual descumprimento ou de reincidência no descumprimento, diante da reiteração e da nova determinação sugerida, a qual entendo deva comportar prazo de sessenta e não de trinta dias para cumprimento."

\begin{tabular}{|l|l} 
Catalogador & Rodrigo Fernandes
\end{tabular}

\begin{tabular}{|c|c|}
\hline \multicolumn{2}{|c|}{ Processo Público no TC-027.077/2006-4- Representação } \\
\hline Relator & Min. Ubiratan Aguiar \\
\hline Órgão Julgador & Plenário do TCU \\
\hline Votação & Unânime \\
\hline Julgamento & $03 / 09 / 2008$ \\
\hline Comentário & $\begin{array}{l}\text { Decisão em que o TCU entendeu que o art. } 223, \S 4^{\circ} \text {, da Constituição Federal não se } \\
\text { aplica nos casos em que se verifica ocorrência de nulidade. A consultoria jurídica do } \\
\text { Ministério das Comunicações, apesar de reconhecer o vício existente no processo de } \\
\text { concessão de radiodifusão, entendia que somente seria possível a anulação da concessão } \\
\text { por meio de ação judicial. }\end{array}$ \\
\hline Dispositivos & LGT, Art. 211, caput. \\
\hline Leading Case & Mandado de Segurança nº 8937 (STJ - MS 8937 / DF - Distrito Federal) \\
\hline Ref. Leg. & Constituição da República Federativa do Brasil de 1988 - art. 223, § $4^{\circ}$ \\
\hline
\end{tabular}

Revista de Direito, Estado e Telecomunicações, v. 1, n. 1, p. 313-523 (2009) 


\begin{tabular}{|c|c|}
\hline dblicação & tário Oficial da União Secão 1 . 05/ \\
\hline \multicolumn{2}{|c|}{ Descrição do Caso } \\
\hline \multicolumn{2}{|c|}{$\begin{array}{l}\text { Neste processo o TCU determinou ao Ministério das Comunicações a anulação da Portaria que outorgou } \\
\text { à empresa Rádio Novo Horizonte FM Ltda. permissão para explorar o serviço de radiodifusão sonora } \\
\text { em frequiência modulada, na cidade de Unaí - MG, independentemente de decisão judicial. O relator } \\
\text { assim fundamentou seu voto: }\end{array}$} \\
\hline \multicolumn{2}{|c|}{$\begin{array}{l}\text { 23. Não há dúvidas, nem mesmo no âmbito da Consultoria Jurídica do Ministério das Comunicações, } \\
\text { acerca da ocorrência de vícios nas Concorrências } 73 / 2000 \text { e } 13 / 1998 \text { para outorga de serviços de } \\
\text { radiodifusão sonora. Como se vê do trecho a seguir, constante do PARECER/MC/CONJUR/MBH/n } \\
\text { 0113-2.15/2007, de 19/1/2007, emitido em relação aos fatos objeto desta Representação, o Consultor } \\
\text { Jurídico reconheceu que a exclusão da empresa Rádio e TV Sucesso Ltda. da Concorrência 13/1998 } \\
\text { foi ilegal, constituindo vício no procedimento: }\end{array}$} \\
\hline \multicolumn{2}{|c|}{$\begin{array}{l}\text { "Ora, conforme pode ser facilmente verificado na tabela acima [quantidade de outorgas de radiodifusão } \\
\text { da empresa Rádio e TV Sucesso Ltda., em 30/10/2002, data em que foi excluída da Concorrência } \\
\text { 13/1998-SSR/MC por atingir os limites do art. 12, inciso I, "a", do Decreto-Lei n } 236 / 67 \text {, os resultados } \\
\text { referentes às localidades de Vargem Grande, Várzea da Palma e Varzelândia, todas de Minas Gerais, } \\
\text { da Concorrência de } n^{\circ} 073 / 2000-S S R / M C \text {, somente foram homologados em 06.12.2002, tal qual } \\
\text { afirmado pela licitante Rádio e TV Sucesso Ltda. em sua reclamação ao TCU, de sorte que, realmente, } \\
\text { em 30.10.2002, não poderia ter sido excluída da Concorrência de n }{ }^{\circ} 013 / 1998 \text {-SSR/MC. A Constituição } \\
\text { da República é clara em dispor, em seu art. } 223, \S 3^{\circ} \text {, que o ato de outorga para o serviço de radiodifusão } \\
\text { sonora e de sons e imagens somente produzirá efeitos legais após deliberação do Congresso Nacional. }\end{array}$} \\
\hline \multicolumn{2}{|c|}{$\begin{array}{l}\text { Não se pretende no presente momento, mesmo porque irrelevante para a solução da controvérsia, } \\
\text { enfrentar o tópico relativo ao momento em que, para fins do art. } 12 \text { do Decreto-Lei de no } 236 / 67 \text {, devem } \\
\text { ser considerados ultrapassados os limites quantitativos de outorgas (homologação, publicação do } \\
\text { decreto legislativo ou assinatura do contrato). A verdade é que, não havendo na data da exclusão da } \\
\text { licitante do certame ao menos } 06 \text { (seis) permissões homologadas para a exploração de serviço de } \\
\text { radiodifusão sonora em freqüência modulada, a Comissão Especial de Licitaça não poderia ter } \\
\text { considerado tais limites como malferidos, nos precisos termos do item } 2.6 \text { do Edital." }\end{array}$} \\
\hline \multicolumn{2}{|c|}{$\begin{array}{l}\text { 24. Após afirmar que o vício é procedente, representando mácula ao interesse público, o Consultor } \\
\text { Jurídico conclui que é necessário o ajuizamento de ação judicial para cancelar a permissão, em face } \\
\text { de já ter havido a homologação do certame e adjudicação de seu objeto à empresa Rádio Novo Horizonte } \\
\text { FM Ltda., e a publicação do Decreto Legislativo } 340 / 2006 \text {, e em face, também, do que dispõe o art. } \\
223, \S 4^{\circ} \text {, da Constituição Federal. Portanto, a Advocacia Geral da União deveria ser acionada para } \\
\text { adotar as providências pertinentes. Essa é também a posição final do Ministério das Comunicações. }\end{array}$} \\
\hline \multicolumn{2}{|c|}{$\begin{array}{l}\text { 25. Na verdade, verifica-se que houve um vício no desenvolvimento da Concorrência } 13 / 1998 \text { que, } \\
\text { por si só, seria motivo suficiente para a anulação da inabilitação da empresa Rádio e TV Sucesso Ltda. } \\
\text { Na data de sua exclusão do certame, essa empresa não havia atingido o limite quantitativo de outorgas } \\
\text { definido no art. } 12 \text { do Decreto-lei } 236 / 67 \text {, pois, em } 30 / 10 / 2002 \text {, ainda não havia sido, sequer, } \\
\text { homologado o resultado da Concorrência } 73 / 2000 \text {. Portanto, não existia causa que determinasse a sua } \\
\text { inabilitação. }\end{array}$} \\
\hline \multicolumn{2}{|c|}{$\begin{array}{l}\text { 26. Esse fato mostra que não seria necessária a anulação do resultado da Concorrência } 73 / 2000 \text { para } \\
\text { que fosse anulada a inabilitação da empresa Rádio e TV Sucesso Ltda. indevidamente feita na } \\
\text { Concorrência 13/1998. Nesse sentido, são independentes os fatos irregulares identificados nos dois } \\
\text { certames. Portanto, como reconhecido pelo Consultor Jurídico do Ministério das Comunicações, a } \\
\text { exclusão dessa empresa da Concorrência } 13 / 1998 \text { foi irregular. Destaque-se que sua proposta seria a } \\
\text { vencedora, caso tivesse permanecido na disputa. Verifica-se, dessa forma, que o resultado dessa } \\
\text { concorrência está contaminado por ilegalidade praticada na fase de habilitação dos interessados. }\end{array}$} \\
\hline \multicolumn{2}{|c|}{$\begin{array}{l}\text { 27. Constada a ilegalidade, cabe verificar se é necessária a decisão judicial referida no art. } 223, \S 4^{\circ} \text {, } \\
\text { da Constituição Federal para que seja anulado o resultado da Concorrência } 13 / 1998 \text {. }\end{array}$} \\
\hline & \\
\hline
\end{tabular}


29. O art. 223, $\S 4^{\circ}$, da Constituição Federal dispõe que "§ $4^{\circ} \mathrm{O}$ cancelamento da concessão ou permissão, antes de vencido o prazo, depende de decisão judicial.”. Assim, para o deslinde do caso, deve ser averiguado se a anulação por ilegalidade é forma de extinção unilateral da outorga que se enquadra no "cancelamento" a que se refere o mencionado dispositivo, demandando ação judicial.

30. No presente caso, cabe avaliar se a outorga viciada na origem por ilegalidade é válida e produz efeitos legais. Para tanto, deve ser avaliado o ato administrativo que deu origem a essa outorga e que apresenta vício insanável decorrente de ilegalidade. Aplicam-se, nesse sentido, a doutrina administrativista no tocante às definições de ato administrativo nulo e ato administrativo anulável, e à possibilidade de sua anulação ou convalidação.

31. Como bem destacado na instrução, a doutrina é convergente no sentido de que o ato administrativo dotado de vício insanável não pode ser convalidado, impondo-se à Administração o dever de invalidálo, por nulidade absoluta. Nesse sentido está vazada a Súmula 473 do Supremo Tribunal Federal que, ao reconhecer o poder de autotutela da Administração, dispõe:

"A Administração pode anular seus próprios atos, quando eivados de vícios que os tornam ilegais, porque deles não se originam direitos; ou revogá-los, por motivo de conveniência ou oportunidade, respeitados os direitos adquiridos, e ressalvada, em todos os casos, a apreciação judicial."

32. Na mesma linha estabelece a Lei 9.784/99, em seu art. 53: "A Administração deve anular seus próprios atos, quando eivados de vício de legalidade, e pode revogá-los por motivo de conveniência ou oportunidade, respeitados os direitos adquiridos.” .

33. A doutrina também converge no sentido de que ato ilegal não produz efeitos válidos, não gerando direitos. Sendo insanáveis não podem ser convalidados, cabendo, portanto, a sua anulação que produzirá efeitos desde a sua origem, alcançando todos os atos dele decorrentes. Assim, ato que contenha o vício da ilegalidade deve ser anulado pela Administração ou pelo Poder Judiciário.

34. Por essa razão, o ato em exame - portaria que outorgou permissão de serviço de radiodifusão comporta vício insanável, decorrente de ilegalidade ocorrida no procedimento licitatório (inabilitação ilegal de concorrente). Nesse sentido, a sua anulação não é forma de extinção unilateral da outorga, mas significa o reconhecimento de que se trata de outorga sem validade, pois concedida sob fundamento ilegal, representando ato que não existe no mundo jurídico como válido. Portanto, a anulação da outorga em foco não pode ser reconhecida como cancelamento que se subordine à prescrição do art. $223, \S 4^{\circ}$, da Constituição Federal.

35. O precedente do Superior Tribunal de Justiça trazido pela Sefid acerca da possibilidade de anulação, pelo Ministro das Comunicações, de contrato de concessão de serviço de radiodifusão viciado por ilegalidade, sem prévia decisão judicial, aplica-se integralmente ao presente caso. No Mandado de Segurança $\mathrm{n}^{\circ}$ 8.937/DF, julgado em 8/10/2003, aquele Tribunal firmou entendimento de que o Ministro de Estado das Comunicações é competente para anular contrato de concessão de serviço de radiodifusão eivado de nulidade, sem que haja necessidade de apreciação pelo Poder Judiciário.

36. Naquele caso, a nulidade do ato de outorga foi provocada pela empresa outorgada que, descumprindo as normas, transferiu ilegalmente cotas de capital para outra empresa. Por essa razão, o Ministro das Comunicações, sem prévia decisão judicial, anulou o respectivo contrato de concessão, por nulidade da outorga que havia sido concedida por decreto presidencial, vigente o decreto legislativo que a havia aprovado.

37. O entendimento do STJ foi no sentido de que a previsão constitucional do art. $223, \S 4^{\circ}$ é para o cancelamento de outorgas válidas e não para o reconhecimento de nulidade, e que a autoridade que celebrou o contrato administrativo pode declarar sua nulidade sem desconstituir seus atos preparatórios.

38. Naquele caso, o Ministro das Comunicações anulou o contrato de concessão e não o ato de outorga, da competência do Presidente da República, nem o decreto legislativo, de competência do Congresso Nacional.

39. Da ementa do acórdão que julgou o MS 8.937-DF, destaca-se:

“CONTRATO ADMINISTRATIVO - DESCONSTITUIÇÃO - ATO COMPLEXO - CÓDIGO NACIONAL DE TELECOMUNICAÇÕES (ART. 38) - RECEPÇÃO CONSTITUCIONAL VIGÊNCIA - CONCESSIONÁRIAS DE RADIODIFUSÃO - COMPOSIÇÃO ACIONÁRIA CONSENTIMENTO DA UNIÃO (L. 4.117/62 - ART. 38). 
1 - É lícito à autoridade que celebra contrato administrativo, declarar-lhe a nulidade, sem desconstituir os respectivos atos preparatórios.

(...)"

40. O que fica é o entendimento de que o art. $223, \S 4^{\circ}$, da Constituição Federal busca resguardar concessões e permissões regularmente outorgadas de eventual arbítrio da Administração no sentido de, antes do prazo definido, extingui-las.

41. Portanto, contrariamente à conclusão do Consultor Jurídico do Ministério das Comunicações, o ato ilegal aqui identificado não só pode, como deve, ser anulado pela autoridade administrativa por ele responsável, em decorrência do poder de autotutela, não sendo necessária a prévia apreciação pelo Poder Judiciário. Nesse sentido, compete ao Ministro das Comunicações anular a portaria que outorgou permissão à empresa Rádio Novo Horizonte FM Ltda. para explorar o serviço de radiodifusão sonora em frequiência modulada, na cidade de Unaí - MG, independentemente de decisão judicial.

\begin{tabular}{|l|l|}
\hline Catalogador & Rodrigo Fernandes \\
\hline
\end{tabular}

\begin{tabular}{|c|c|}
\hline \multicolumn{2}{|c|}{ Processo Público no TC-010.385/2006-7 - Denúncia } \\
\hline Relator & Min. Ubiratan Aguiar \\
\hline Órgão Julgador & Plenário do TCU \\
\hline Votação & Unânime \\
\hline Julgamento & $24 / 09 / 2008$ \\
\hline Comentário & $\begin{array}{l}\text { Decisão em que o TCU verificou que o Ministério das Comunicações não observou } \\
\text { o critério da representatividade, definido no art. } 9^{\circ}, \S 5^{\circ} \text {, da Lei } 9.612 / 98 \text {, na seleção } \\
\text { de prestador do serviço de radiodifusão comunitária. Apurou-se ainda, a existência } \\
\text { de fragilidade na instrução e análise dos processos naquele órgão. }\end{array}$ \\
\hline Dispositivos & LGT, Art. 211, caput. \\
\hline Ref. Leg. & $\begin{array}{l}\text { Lei } \mathrm{n}^{\circ} 9.612, \text { de } 19 \text { de fevereiro de } 1998 \\
\text { Lei } \mathrm{n}^{\circ} 10.597 \text {, de } 11 \text { de dezembro de } 2002\end{array}$ \\
\hline Publicação & Diário Oficial da União, Seção 1, 26/09/2008 \\
\hline \multicolumn{2}{|c|}{$\begin{array}{l}\text { 3. Saliento, de início, que, nos termos da Lei } 10.597 / 2002 \text {, o prazo de outorga dos Serviços de } \\
\text { Radiodifusão Comunitária foi aumentado de três para dez anos. A Associação Comunitária Amigos } \\
\text { do Brigadeiro (ACAB) foi autorizada pelo Poder Concedente a explorar o referido serviço na cidade } \\
\text { de Ervália/MG, por meio da Portaria/MC } 97 \text {, de } 29 / 1 / 2002 \text {, possuindo Licença para Funcionamento } \\
\text { de Estação de Radiodifusão Comunitária desde } 28 / 10 / 2003 \text {, inicialmente provisória e posteriormente } \\
\text { definitiva, desde } 29 / 6 / 2004 \text {. }\end{array}$} \\
\hline \multicolumn{2}{|c|}{$\begin{array}{l}\text { 4. Conforme registrado pela Sefid, o serviço vem sendo prestado sem que haja notícia de que tenha } \\
\text { sido imputado à autorizatária o cometimento de qualquer das infrações previstas no art. } 21 \text { da Lei } \\
9.612 / 1998 \text {. }\end{array}$} \\
\hline \multicolumn{2}{|c|}{$\begin{array}{l}\text { 5. Passando aos fatos denunciados, verificou-se a partir de resposta à diligência ao Ministério das } \\
\text { Comunicações e das razões de justificativa apresentadas pelo Sr. Antônio Carlos Tardeli, Diretor, à } \\
\text { época, do Departamento de Outorga de Serviços de Radiodifusão da então Secretaria de Serviços de } \\
\text { Radiodifusão do Ministério das Comunicações, que um dos passos definidos na legislação para a } \\
\text { seleção do prestador do serviço em questão não foi observado. Trata-se da apuração do critério da } \\
\text { representatividade, definido no art. } 9^{\circ}, \S 5^{\circ} \text {, da Lei } 9.612 / 98 \text {, por meio do qual o Poder Concedente } \\
\text { estabelece que, caso não alcance êxito a iniciativa de entendimento entre os diversos interessados, } \\
\text { procederá à escolha da entidade levando em consideração o critério da representatividade, evidenciada } \\
\text { por meio de manifestações de apoio encaminhadas por membros da comunidade a ser atendida e/ou } \\
\text { por associações que a representem. }\end{array}$} \\
\hline
\end{tabular}


(...)

7. Como mencionado anteriormente, um dos passos definidos acima para a seleção do prestador do serviço em questão - o do critério da representatividade - não foi observado. Conforme informações prestadas pelo Ministério das Comunicações, apesar de a Associação Comunitária Amigos de Ervália (ACAE) ter apresentado maior número de manifestações de apoio (28 consideradas válidas pelo Ministério), a autorização do serviço foi outorgada, ao arrepio da lei, à Associação Comunitária Amigos do Brigadeiro (ACAB), que apresentou 21 manifestações de apoio consideradas válidas.

(...)

10. Na verdade, verificou-se que foi tomada uma decisão contrária aos critérios estabelecidos na legislação pertinente, com a seleção de prestador de serviço que deixou de preencher um desses critérios. Cabe averiguar, portanto, quem é o responsável por esse ato.

(...)

15. Quero com isso ressaltar que, no presente caso, houve erro sim, conforme se verifica das informações prestadas pelo Ministério das Comunicações quando informa o número de manifestações válidas de cada associação interessada na prestação do serviço. Todavia, parece-me ser de extremo rigor apenar o mencionado senhor, uma vez que a falha, ainda que involuntária, aconteceu em etapa anterior à sua manifestação, dada na presunção de que as esferas técnica e jurídica competentes haviam procedido aos exames necessários, nos termos definidos na legislação. De outra forma, somente teria sido possível ao Sr. Antonio Carlos Tardeli verificar o erro se tivesse recontado as manifestações de apoio, verificando as válidas e as não-válidas, de modo a confrontar com o resultado apontado ao final da seleção.

16. Assim, apesar de discordar da Sefid no tocante à aplicação de multa ao Sr. Antonio Carlos Tardeli, considero que, em face do erro apontado, deve ser determinado ao Ministério das Comunicações que não prorrogue a autorização concedida à $\mathrm{ACAB}$.

(...)

21. A ausência de análise das questões materiais e jurídicas argüidas pela recorrente no julgamento de recurso administrativo e julgamento intempestivo de recurso administrativo foi comprovada, após a realização de diligência ao Ministério das Comunicações. Portanto, com relação a esses fatos, a Denúncia deve ser considerada procedente.

22. Apesar de o recurso da ACAE ter sido apresentado fora do prazo previsto pela Lei 9.784/99 (art. 59, caput), não há justificativa para o atraso do pronunciamento do Ministério das Comunicações que se deu um ano e quatro meses após recebido. Segundo o $\S 1^{\circ}$ do art. 59 da referida Lei, o prazo para a deliberação do órgão sobre o recurso é de trinta dias.

23. A ausência de análise das questões materiais e jurídicas argüidas pela ACAE no julgamento de recurso administrativo não foi devidamente justificada pelo Ministério das Comunicações. Da leitura da Informação 534/REC/2005-RADCOM/DOS/SSCE/MC-NGF (Anexo 3, fls. 206/208), que tratou do pedido de reconsideração apresentado pela ACAE e fundamentou a negativa de provimento do recurso, reafirma-se que a ACAE apresentou menor número de manifestações de apoio que sua concorrente, fato que, a propósito, o próprio Ministério reconhece como inverídico. Ademais, não há menção à intempestividade da apresentação do recurso.

24. Esses dois últimos aspectos também demonstram a fragilidade da instrução e análise dos processos que trataram do interesse da ACAB e da ACAE na prestação do serviço de Radiodifusão Comunitária, ensejando a formulação de determinação ao Ministério das Comunicações para que adote providências no sentido de analisar e instruir os processos administrativos que tratem da outorga de serviços de Radiodifusão Comunitária - RadCom com maior consistência fática, técnica e jurídica, observando as disposições legais e regulamentares pertinentes, especialmente as Leis 9.612/1998, e suas alterações, e 9.784/1999, e o Decreto 2.615/1998.

25. Por fim, em razão de orientação que fiz constar em despacho, a Sefid examinou as conseqüências dos atos aqui examinados, tidos como irregulares, com o objetivo de verificar se as irregularidades perpetradas poderiam conduzir à anulação da concessão em exame, com a necessária oitiva prévia dos interessados (Ministério das Comunicações e ACAB), ou que fosse considerada a hipótese de apenas ser determinada ao Ministério das Comunicações a não-prorrogação da outorga em análise. 
26. No entendimento da Sefid, atende melhor o interesse público a hipótese de determinação ao Ministério das Comunicações para que se abstenha de prorrogar a outorga do Serviço de Radiodifusão Comunitária à Associação Cultural Amigos do Brigadeiro (ACAB) no Município de Ervália/MG, efetuada por meio da Portaria/MC 97, de 29/01/2002.

27. Destaca a Sefid que o Serviço de Radiodifusão Comunitária difere profundamente dos serviços de radiodifusão comercial (radiodifusão sonora - rádios AM, FM e OM e radiodifusão de sons e imagens - Televisão), sendo outorgado a fundações e associações comunitárias sem fins lucrativos. Esse fato, aliado à finalidade do Serviço de RadCom, estatuído no art. $3^{\circ}$ da Lei 9.612/1998, faz, na visão da unidade técnica, concluir que a eventual anulação da outorga sob exame traria prejuízos exclusivamente à comunidade beneficiada.

28. Ademais, o tempo estimado para que fosse levada a efeito nova outorga seria de dois anos e meio. Nesse período, na hipótese de se anular a outorga em andamento, a comunidade, que hoje desfruta dos benefícios da prestação do serviço, seria deles privada.

29. Outro aspecto ponderado pela Sefid refere-se ao período em que a ACAB vem prestando o serviço, cerca de cinco anos, sem que haja notícia de que tenha sido imputada à autorizatária o cometimento de qualquer das infrações previstas no art. 21 da Lei 9.612/98.

30. Pondera, ainda, a Sefid que, como o Congresso Nacional, por meio do Decreto Legislativo 900, de 19/11/2003, aprovou o ato de outorga em questão, ainda que se procedesse a anulação da Portaria de outorga, seria necessário a adoção de medidas para a anulação do Decreto Legislativo que aprovou aquele ato. Nesse sentido, salienta o disposto no art. $223, \S 4^{\circ}$, da Constituição Federal, que estabelece que o cancelamento da concessão ou permissão de serviço de radiodifusão sonora e de sons e imagens, antes de vencido o prazo, depende de decisão judicial.

31. Quanto a esse aspecto, saliento que examinei essa questão no TC 027.077/2006-4, relatado na Sessão Plenária de 3/9/2008 (Acórdão 1.900/2008-Plenário). Na oportunidade, consignei meu entendimento, acolhido por este Colegiado, no sentido de que o cancelamento da outorga de que trata o art. 223, $\S 4^{\circ}$, da Constituição Federal busca resguardar concessões e permissões regularmente outorgadas de eventual arbítrio da Administração no sentido de, antes do prazo definido, extingui-las, e de que o ato de outorga concedida com vício de ilegalidade deve, em decorrência do poder de autotutela, ser anulado pela autoridade administrativa que celebra o ato, não sendo necessária a decisão judicial referida no citado art. 223, $\S 4^{\circ}$, da CF. Portanto, nesta situação, se fosse o caso, não haveria necessidade de decisão judicial, em face de ilegalidade verificada na fase de avaliação das propostas.

32. Por essas razões, ainda que, de fato, tenha sido verificada irregularidade no procedimento de seleção de entidade para a prestação do Serviço de Radiodifusão Comunitária no Município de Ervália/MG, entendo que a opção que melhor atende o interesse público e a manutenção dos benefícios auferidos pela comunidade é a realização de determinação ao Ministério das Comunicações para que se abstenha de prorrogar a presente outorga".

\begin{tabular}{|l|l|}
\hline Catalogador & Rodrigo Fernandes \\
\hline
\end{tabular}

\begin{tabular}{|l|l|}
\hline Processo Público no TC-019.677/2006-2 - Monitoramento \\
\hline Relator & Min. Ubiratan Aguiar \\
\hline Órgão Julgador & Plenário do TCU \\
\hline Votação & Unânime \\
\hline Julgamento & $26 / 11 / 2008$ \\
\hline Comentário & $\begin{array}{l}\text { Decisão em que o TCU verificou que o estudo realizado acerca da situação econômico- } \\
\text { financeira dos contratos de concessão de telefonia fixa, apresentava inconsistências } \\
\text { na segregação dos dados e padecia de circularidades nos procedimentos de cálculo, } \\
\text { bem como fazia conclusões com base em metodologia não confiável, não permitindo, } \\
\text { portanto, aferir se foi mantido o equilíbrio econômico-financeiro dos contratos de } \\
\text { concessão, no período de 1999-2004. }\end{array}$ \\
\hline Dispositivos & LGT, Art. 64, Parágrafo Único; LGT, Art. 99, caput; LGT, Art. 202, § $1^{\circ}$. \\
\hline
\end{tabular}




\begin{tabular}{|c|c|}
\hline Publicação & al da União, Seção 1, 01 \\
\hline \multicolumn{2}{|c|}{ Descrição do Caso } \\
\hline \multicolumn{2}{|c|}{ O TCU acolheu a análise do relator, que assim apresentou a questão: } \\
\hline \multicolumn{2}{|c|}{$\begin{array}{l}\text { "Trago à apreciação dos nobres pares relatório de monitoramento realizado pela Sefid para verificar } \\
\text { o cumprimento das determinações constantes dos subitens 9.1.1. e 9.1.2 do Acórdão 1.196/2005- } \\
\text { Plenário, com o seguinte teor: }\end{array}$} \\
\hline \multicolumn{2}{|c|}{ "9.1. determinar à Agência Nacional de Telecomunicações - Anatel que: } \\
\hline \multicolumn{2}{|c|}{$\begin{array}{l}\text { 9.1.1. apresente ao Tribunal, no prazo de } 6 \text { (seis) meses, a contar da ciência desta deliberação, estudo } \\
\text { que demonstre a preservação do equilíbrio econômico-financeiro por modalidade de STFC, a cada } \\
\text { ano, desde o início da vigência dos atuais contratos de concessão, de forma a dar fiel cumprimento ao } \\
\text { art. } 108 \text { da Lei Geral de Telecomunicações - LGT; }\end{array}$} \\
\hline \multicolumn{2}{|c|}{$\begin{array}{l}\text { 9.1.2. adote ações imediatas com vistas ao restabelecimento do equilíbrio contratual, caso o estudo } \\
\text { indicado no subitem anterior evidencie a não preservação do equilíbrio econômico-financeiro dos } \\
\text { contratos de concessão, nos termos do art. } 108 \text { e seus parágrafos da LGT (...)" }\end{array}$} \\
\hline \multicolumn{2}{|c|}{$\begin{array}{l}\text { 2. Assinale-se de início que a Anatel atendeu à determinação contida no subitem 9.1.1. acima, no } \\
\text { sentido de encaminhar ao TCU estudo sobre o equilíbrio econômico-financeiro das concessionárias } \\
\text { de telefonia fixa no período de } 1990-2004 \text {. }\end{array}$} \\
\hline \multicolumn{2}{|c|}{$\begin{array}{l}\text { 3. A Anatel concluiu que, realizando uma apreciação comparativa dos resultados agregados das seis } \\
\text { concessionárias, com base nos dados apresentados no referido estudo, o segmento de telefonia evoluiu } \\
\text { de uma posição francamente deficitária nos primeiros anos de exploração do serviço para uma situação } \\
\text { mais favorável no penúltimo ano do período contratual analisado. }\end{array}$} \\
\hline \multicolumn{2}{|c|}{$\begin{array}{l}\text { 4. Afirmou o Órgão Regulador que, conforme os relatórios de acompanhamento econômico-financeiro } \\
\text { encaminhados ao Tribunal, não se verificou a existência de desequilíbrio econômico-financeiro das } \\
\text { concessões, manifesto sob a forma de anomalia na evolução do Valor Econômico Adicionado (EVA) } \\
\text { ou da Taxa Interna de Retorno (TIR), observado o Custo Médio Ponderado de Capital estimado para } \\
\text { o período em questão. }\end{array}$} \\
\hline \multicolumn{2}{|c|}{$\begin{array}{l}\text { 5. No estudo apresentado pela Anatel, para as três principais concessionárias (Telesp, Brasil Telecom } \\
\text { e Telemar), o Custo Médio Ponderado de Capital deu resultado acima dos valores da TIR, bem como } \\
\text { o valor acumulado do EVA deu negativo para o período de 1999-2004. }\end{array}$} \\
\hline \multicolumn{2}{|c|}{$\begin{array}{l}\text { 6. Alertou a Anatel que uma análise restrita a poucos anos não expressa a resposta econômica das } \\
\text { concessões do STFC e sua avaliação precisa ser elaborada levando-se em conta um período de maturação } \\
\text { consistente com a especificidade setorial e as regras e condições estabelecidas. }\end{array}$} \\
\hline \multicolumn{2}{|c|}{$\begin{array}{l}\text { 7. Conforme ressaltado no relatório, o estudo apresentado pela Anatel foi analisado pela equipe de } \\
\text { fiscalização quanto aos seus resultados e conclusões, tendo sido avaliados também, sob o ponto de } \\
\text { vista regulatório, os dados de receitas, despesas e investimentos das empresas concessionários de } \\
\text { Serviço Telefônico Fixo Comutado (STFC), mais especificamente da Telemar, Telesp (do Grupo } \\
\text { Telefônica) e Brasil Telecom, no período de } 1999 \text { a 2004. Analisou-se ainda a metodologia apresentada } \\
\text { pela Anatel para apurar o equilíbrio econômico-financeiro das concessionárias de telefonia. }\end{array}$} \\
\hline \multicolumn{2}{|c|}{$\begin{array}{l}\text { 8. Assinala a equipe, no item } 2 \text { do relatório, que as conclusões do estudo apresentado pela Anatel sobre } \\
\text { o equilíbrio econômico-financeiro das concessões de STFC são baseadas em dados operacionais e } \\
\text { patrimoniais das concessionárias. }\end{array}$} \\
\hline \multicolumn{2}{|c|}{$\begin{array}{l}\text { 9. Ressalta a também que a Agência } \\
\text { receitas, custos, despesas e inves } \\
\text { importantes do ponto de vista regul } \\
\text { a separação dos registros contábeis } \\
\text { de dados), conforme previsto no art. }\end{array}$} \\
\hline \multicolumn{2}{|l|}{ "Ar } \\
\hline \multicolumn{2}{|c|}{$\begin{array}{l}\text { I - prestar informações de natureza técnica, operacional, econômico-financeira e contábil, ou outras } \\
\text { pertinentes que a Agência solicitar; }\end{array}$} \\
\hline & \\
\hline
\end{tabular}


10. Transcrevo a seguir, por pertinente, as conclusões expostas pela equipe de auditoria no item 4 do relatório, quanto à análise do estudo encaminhado pela Anatel:

147. O primeiro e principal desafio da Anatel, com vistas à elaboração de um estudo para avaliar a evolução das concessionárias, foi obter junto às empresas tais dados e informações. As fontes de informação foram os relatórios contábeis publicados pelas empresas. Sabendo que as informações contábeis estão disponíveis apenas em nível agregado para cada empresa do setor de telefonia, especial atenção foi dada pela análise da equipe do TCU para os procedimentos de desagregação da informação por segmento de atuação e para a verificação da consistência dos resultados obtidos.

148. Da análise do estudo encaminhado pela Anatel, observou-se que havia nos documentos contábeis informações que permitiram a desagregação das receitas por segmento de atuação (serviço local, de longa distância e transporte de dados). Já no caso das despesas de operação e dos investimentos, a Anatel precisou acordar uma metodologia para cada concessionária desagregar as informações por segmento. No entanto, como apresentado neste relatório, a Anatel não conseguiu obter as informações necessárias, nem aplicar procedimentos que possibilitassem chegar a resultados confiáveis.

149. A análise do equilíbrio econômico-financeiro realizado pela Anatel, ademais, padece de circularidades nos procedimentos de cálculo que debilitam completamente os resultados em termos de aferição deste equilíbrio. Sendo assim, é necessário aprimorar os procedimentos para estimar as despesas, os investimentos e a base de remuneração para cada segmento de atuação das empresas de telefonia fixa. Feito isso, será possível realizar inferências mais acuradas sobre o equilíbrio econômicofinanceiro das concessões, pois a qualidade e confiabilidade dos dados utilizados no estudo são condições imprescindíveis para que a metodologia aplicada possa dar resultados confiáveis e conclusivos.

150. Nesse sentido, a Agência deveria solicitar novamente esses dados às concessionárias, apesar de que, conforme relatado no estudo da Anatel, as próprias empresas alegaram dificuldades em segregar os custos e investimentos por modalidade de serviço, principalmente para os anos de 1999 a 2004. Isso representa um grande desafio, que deve ser superado em um curto espaço de tempo. É importante observar, no entanto, que a realização do trabalho ora em análise já representa um avanço em termos de informações sobre o setor.

151. Contudo, a Anatel, ao receber os dados das empresas solicitados via Documento de Separação e Alocação de Contas - DSAC, passou a dispor de um conjunto de informações econômico-financeiras que lhe permite atuar de forma mais efetiva na regulação econômica dos contratos de concessão. Nesse sentido, cabe avaliar se as informações encaminhadas pelas concessionárias atendem a segregação de dados preconizada no DSAC.

152. A equipe de auditoria analisou também a metodologia utilizada pela Anatel para verificar a condição de equilíbrio econômico-financeiro das concessões. Foi verificada que a metodologia utilizada foi elaborada exclusivamente para o atendimento à determinação do TCU, não havendo uma definição prévia pela Agência de uma forma de acompanhamento do equilíbrio econômico-financeiro dos contratos de concessão. Ademais, observou-se que a Agência não fez nenhuma crítica em relação à prudência dos investimentos realizados pelas empresas ou à eficiência das despesas e custos realizados.

153. O fato de a TIR ter apresentado resultado superior ou inferior ao esperado, ou de o EVA ser negativo, não enseja de forma direta uma revisão tarifária extraordinária, vez que é necessário inicialmente verificar as causas que levaram a esses resultados, identificando se essas causas não caracterizam áleas ordinárias ou extraordinárias, ou mesmo uma ineficiência na atividade empresarial ou na realização de investimentos não prudentes.

154. De se ressaltar que, para a modalidade local, o valor da TIR com ajustes para a Telemar deu superior ao seu custo de capital. Também deve se destacar os valores muito baixos da TIR para a TELESP, que supostamente se encontra na região mais rentável do país.

155. Adicionalmente, o fato de não haver uma metodologia definida para revisão tarifária (extraordinária ou periódica), sem a submissão das regras à consulta pública, torna o estudo apresentado pela Anatel sem respaldo junto à sociedade, pois a metodologia utilizada para definição do equilíbrio econômicofinanceiro foi desenvolvida somente para o atendimento à solicitação do TCU.

156. Ademais, a equipe de auditoria concorda que a análise restrita a poucos anos pode não ser conclusiva em termos de resposta econômica, mas tal afirmação representa confirmação da necessidade 
de aperfeiçoamento por parte da Anatel nos procedimentos de controle e aferição de equilíbrio econômico-financeiro dos contratos. Pois, ainda que a determinação do TCU tenha especificado os anos iniciais de vigência dos contratos de telefonia fixa pública como parâmetro para realização do estudo, a Agência, como órgão regulador do setor, deveria ter elementos para realizar uma projeção da viabilidade econômica dos contratos de telefonia por um período maior, já que esses têm um horizonte de duração de 27 anos, e destes já se passaram 10. Portanto, já se tem um panorama bem consolidado do setor.

157. Isso demonstra que ainda é incipiente no órgão regulador uma cultura de acompanhamento econômico-financeiro - que é requerimento constante em vários aspectos estratégicos da atividade regulatória - na medida em que carece de agentes com formação e experiência em procedimentos de regulação econômica. Ainda, a Anatel não dispõe de uma estrutura interna específica para realização de procedimentos dessa natureza, a exemplo de outras agências reguladoras como a Aneel e a ANTT. 158. Isso posto, conclui-se, da avaliação dos parâmetros e da metodologia utilizados pela Agência, que o estudo enviado ao TCU não permite obter um resultado conclusivo sobre a situação de equilíbrio econômico-financeiro dos contratos de concessão de telefonia fixa, em virtude da falta de consistência dos dados apresentados, principalmente no que se refere à segregação de valores por modalidade de serviço e aos problemas verificados na metodologia utilizada."

11. Na linha exposta pela equipe, entendo não ser razoável que a Anatel não possua os dados para a realização da regulação econômica de uma concessão de serviço público que traz inúmeras responsabilidades à concessionária e ao concedente, no caso representado pela Agência, com previsões legais e constitucionais relacionadas ao acompanhamento da concessão de serviço público.

12. Conclui-se assim que a má qualidade dos dados apresentados é consequiência da uma não-atuação mais efetiva da Agência no cumprimento das obrigações legais de acompanhamento do equilíbrio econômico-financeiro das concessões.

13. Verifica-se que o acompanhamento é fundamental não somente para verificação de eficiência dos custos e investimentos das empresas, mas também para observar a própria situação financeira da concessionária, que, por administrar a prestação de serviço público, possui a obrigação de dar continuidade ao serviço, entre outras obrigações.

14. Assim, entendo ser necessário que o Tribunal continue a monitorar a atividade de regulação econômica da Anatel, a fim de verificar se a Agência está adotando as medidas necessárias para atender, de forma tempestiva, os dispositivos legais previstos na Lei Geral de Telecomunicações e no Decreto 4.733/2003, no que se refere ao modelo para estabelecer as tarifas de público e de interconexão na telefonia fixa, bem como à metodologia a ser utilizada no processo de revisão tarifária e de transferência de possíveis ganhos econômicos aos usuários".

\begin{tabular}{l|l}
\hline Catalogador & Rodrigo Fernandes \\
\hline
\end{tabular}

\begin{tabular}{|l|l|}
\hline \multicolumn{2}{|l|}{ Processo $\mathbf{n}^{\mathbf{0}}$ TC-010.681/2008-0- Representação } \\
\hline Relator & Min. Marcos Vinicios Vilaça \\
\hline Órgão Julgador & Plenário do TCU \\
\hline Votação & Unânime \\
\hline Julgamento & $03 / 12 / 2008$ \\
\hline Comentário & $\begin{array}{l}\text { Decisão em que o TCU verificou ser improcedente representação efetuada contra a } \\
\text { aquisição do controle acionário da Brasil Telecom, pela Oi/Telemar, com recursos do } \\
\text { Banco Nacional de Desenvolvimento Econômico e Social. }\end{array}$ \\
\hline Dispositivos & LGT, Art. 64, Parágrafo Único; LGT, Art. 201, caput; LGT, Art. 202, § 1 $1^{\circ}$. \\
\hline Ref. Leg. & Decreto ${ }^{\circ}$ 6.654, de 20 de novembro de 2008 \\
\hline Publicação & Diário Oficial da União, Seção $1,09 / 12 / 2008$ \\
\hline Descrição do Caso
\end{tabular}

Revista de Direito, Estado e Telecomunicações, v. 1, n. 1, p. 313-523 (2009) 
Foram examinadas as operações efetuadas pelo BNDES envolvendo a operadora Telemar. O relator assim fundamentou o voto, acolhido pelo Plenário do TCU, que considerou improcedente a representação:

"Este processo refere-se a representação sobre notícia veiculada no jornal Folha de São Paulo, em 26/04/2008, acerca da aquisição do controle acionário da Brasil Telecom, pela Oi/Telemar, com recursos do Banco Nacional de Desenvolvimento Econômico e Social.

2. 2. Após a realização de diligência, a $5^{\mathrm{a}}$ Secex verificou que ocorreram duas operações distintas e independentes: a reestruturação da Telemar Participações S.A. e a aquisição da Brasil Telecom pela Oi/Telemar.

3. 3. Primeiro, a reestruturação da Telemar Participações S.A. foi realizada com o aporte de R $\$ 2,569$ bilhões do BNDES e teve como motivação econômica a criação, por meio da readequação da governança corporativa, de valor e liquidez para a participação da BNDES Participações S/A no capital da empresa. Com base nas informações contidas na Nota Técnica AMC/DEPAC 19/2008, pode-se constatar que essa operação foi devidamente fundamentada pela BNDESPAR.

4. 4. Registro que os elementos constantes dos autos não permitem afirmar que os recursos utilizados pelo BNDES para reestruturar a Telemar decorreram do crédito extraordinário aberto pela Medida Provisória no 420/2008. Acrescento que, mesmo que os valores tivessem essa origem, não caberia ao Tribunal declarar a inconstitucionalidade da mencionada medida provisória.

5. 5. Segundo, a aquisição da Brasil Telecom pela Oi/Telemar foi realizada com a participação do banco de investimentos Credit Suisse e não contou com o repasse de recursos do BNDES. Como a operação era vedada pelo art. 14 do Decreto $n^{\circ}$ 2.534/98 (Plano Geral de Outorgas), a Oi/Telemar celebrou um contrato de comissão com o Credit Suisse, que efetivou a aquisição, em seu próprio nome, mas por conta e ordem da empresa, do controle acionário da Brasil Telecom. Esse contrato determina que, uma vez superada a proibição contida no Plano Geral de Outorgas, o banco deve ceder sua posição no contrato de compra e venda para a Oi/Telemar, que assumirá a condição de compradora.

6. 6. No tocante a essa transação, concordo com a unidade técnica e o Ministério Público que a proibição de transferência de controle acionário estabelecida no art. 201 da Lei no 9.472/97 está adstrita a um critério temporal que já ocorreu e, portanto, não mais persiste na atualidade.

7. 7. Quanto à restrição legal mencionada no item 5, acima, ressalto que o Presidente da República aprovou o novo Plano Geral de Outorgas em 20/11/2008, por meio do Decreto no 6.654/2008, com a revogação expressa do Decreto no $2.534 / 98$ e, em conseqüência, a eliminação do impedimento para a Oi/Telemar assumir o controle acionário da Brasil Telecom.

8. 9. Observo que a operação ainda deverá ser submetida pela Agência Nacional de Telecomunicações à apreciação do Conselho Administrativo de Defesa Econômica, nos termos do art. $7^{\circ}, \S 2^{\circ}$, da Lei $n^{\circ}$ 9.472/97, e que a Sefid acompanhará, em processo específico, a atuação daquela agência em controle concomitante da fusão das empresas Oi/Telemar e Brasil Telecom.

9. 8. Também destaco as prerrogativas da BNDESPAR que podem contribuir para a correção do procedimento, indicadas no seguinte trecho da instrução:

“56 Em relação à segurança da operação, a BNDESPAR garantiu uma série de salvaguardas, caso a aquisição da Brasil Telecom pela TmarPart seja concretizada. $\mathrm{O}$ acordo de acionistas assegurou à BNDESPAR, por exemplo, veto qualificado sobre matérias relevantes, como fusões, cisões e reestruturações societárias. Essa medida confere maior segurança à operação e impede a venda, sem anuência da BNDESPAR, da companhia a um terceiro grupo. Esse acordo também determina que a TmarPart não poderá realizar, sem o voto da BNDESPAR, operações que ponham em risco a estabilidade do controle da companhia."”"

\begin{tabular}{|l|l|}
\hline Catalogador & Rodrigo Fernandes \\
\hline
\end{tabular} 


\section{Atos Referenciados}

\section{Ato Administrativo}

Ato

\begin{tabular}{|c|c|}
\hline 0 & Piretor da ANATEL n ${ }^{\circ} 1.805$, de $1^{\circ}$ de abril de 2008 \\
\hline Ementa & $\begin{array}{l}\text { Aprova a Edição } 2008 \text { do Plano de Atribuição, Destinação e Distribuição de Faixas } \\
\text { de Freqüências no Brasil. }\end{array}$ \\
\hline Órgão Emissor & ANATEL - Cons \\
\hline Anex & $\begin{array}{l}\text { Anexo - Plano de Atribuição, Destinação e Distribuição de Faixas de Frequiências no } \\
\text { Brasil. }\end{array}$ \\
\hline Dispositivos & $\begin{array}{l}\text { LGT, Art. 19, inciso VIII; LGT, Art. 22, inciso VIII; LGT, Art. 158, caput; LGT, Art. } \\
158, \S 1^{\circ} \text {, inciso III. }\end{array}$ \\
\hline Regulamenta & $\begin{array}{l}\text { Lei no } 9.472 / 1997 \text { - Dispõe sobre a organização dos serviços de telecomunicações, a } \\
\text { criação e funcionamento de um órgão regulador e outros aspectos institucionais, nos } \\
\text { termos da Emenda Constitucional } n^{\circ} 8 \text {, de } 1995 \text {. }\end{array}$ \\
\hline
\end{tabular}

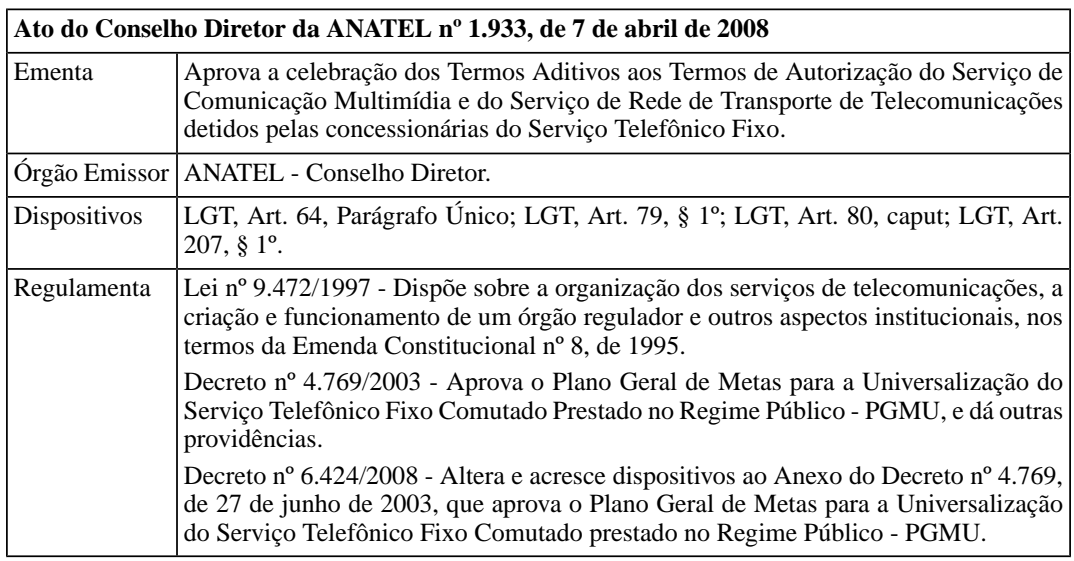

\begin{tabular}{|l|l|}
\hline \multicolumn{2}{|l|}{ Ato do Conselho Diretor da ANATEL no 4.197, de 16 de julho de 2008} \\
\hline Ementa & Fixa os valores dos fatores de transferência X e DEA. \\
\hline Órgão Emissor & ANATEL - Conselho Diretor. \\
\hline Dispositivos & $\begin{array}{l}\text { LGT, Art. 64, Parágrafo Único; LGT, Art. 93, inciso VII; LGT, Art. 103, § 1% LGT, } \\
\text { Art. 108, caput. }\end{array}$ \\
\hline Correlata & $\begin{array}{l}\text { Resolução da ANATEL n }{ }^{\circ} \text { 507/2008 - Aprova a Norma da Metodologia para Cálculo } \\
\text { do Fator de Transferência "X", aplicado nos Reajustes de Tarifas do Serviço Telefônico } \\
\text { Fixo Comutado, destinado ao uso do público em geral - STFC. }\end{array}$ \\
\hline
\end{tabular}




\begin{tabular}{|l|l|}
\hline Regulamenta & $\begin{array}{l}\text { Lei no 9.472/1997 - Dispõe sobre a organização dos serviços de telecomunicações, a } \\
\text { criação e funcionamento de um órgão regulador e outros aspectos institucionais, nos } \\
\text { termos da Emenda Constitucional no } 8 \text {, de 1995. }\end{array}$ \\
\hline Publicação & Diário Oficial da União, Seção 1, 18/07/2008, pág. 57 \\
\hline
\end{tabular}

\begin{tabular}{|l|l|}
\hline \multicolumn{2}{|l|}{ Ato do Conselho Diretor da ANATEL no 7.828, de 19 de dezembro de 2008 } \\
\hline Ementa & $\begin{array}{l}\text { Anuência prévia à aquisição por parte da TELEMAR NORTE LESTE S.A. de ações } \\
\text { representativas do controle societário da Invitel S.A., controladora direta da Solpart } \\
\text { Participações S.A. e controladora indireta da Brasil Telecom Participações S.A., da } \\
\text { Brasil Telecom S.A., da Brasil Telecom Celular S.A., da Brasil Telecom Comunicação } \\
\text { Multimídia S.A., da Brasil Telecom Cabos Submarinos LTDA., e da Vant } \\
\text { Telecomunicações S.A. }\end{array}$ \\
\hline Órgão Emissor & ANATEL - Conselho Diretor. \\
\hline Anexos & Anexo - Condicionamentos para o Ato de Anuência. \\
\hline Dispositivos & LGT, Art. $7^{\circ}, \S 1^{\circ}$; LGT, Art. 19, inciso XIX; LGT, Art. 64, Parágrafo Único. \\
\hline Regulamenta & $\begin{array}{l}\text { Lei no } \text { }^{\circ} .472 / 1997 \text { - Dispõe sobre a organização dos serviços de telecomunicações, a } \\
\text { criação e funcionamento de um órgão regulador e outros aspectos institucionais, nos } \\
\text { termos da Emenda Constitucional no 8, de 1995. }\end{array}$ \\
\hline Publicação & Diário Oficial da União, Seção 1, 22/12/2008, págs. 301-303 \\
\hline
\end{tabular}

\section{Análise da ANATEL}

\begin{tabular}{|l|l|}
\hline \multicolumn{2}{|l|}{ Análise ANATEL/GCPJ n $\mathbf{0}^{\mathbf{3}} \mathbf{3 6 8}, \mathbf{d e} \mathbf{7}$ de outubro de 2008} \\
\hline Ementa & $\begin{array}{l}\text { Submete à aprovação a proposta de revisão do Plano Geral de Outorgas (PGO), } \\
\text { aprovado pelo Decreto n }{ }^{\circ} 2.534, \text { de 2 de abril de 1998. }\end{array}$ \\
\hline Órgão Emissor & ANATEL - Gabinete do Conselheiro Pedro Jaime Ziller de Araújo. \\
\hline Dispositivos & LGT, Art. 19, inciso XXX; LGT, Art. 207, $\S 3^{\circ}$. \\
\hline
\end{tabular}

\begin{tabular}{|l|l|}
\hline \multicolumn{2}{|l|}{ Análise ANATEL/GCAB no $\mathbf{4 5 5}$, de 9 de outubro de 2008} \\
\hline Ementa & $\begin{array}{l}\text { Submete à aprovação a proposta de Plano Geral para Atualização da Regulamentação } \\
\text { das Telecomunicaçes no Brasil (PGR). }\end{array}$ \\
\hline Órgão Emissor & ANATEL - Gabinete do Conselheiro Antonio Domingos Teixeira Bedran. \\
\hline Dispositivos & LGT, Art. 22, inciso III. \\
\hline
\end{tabular}

\section{Termo de Autorização}

\begin{tabular}{|l|l|}
\hline \multicolumn{2}{|l|}{ Termo Aditivo $\mathbf{n}^{\mathbf{0}} \mathbf{0 0 1 / 2 0 0 8 / S P V}$ - BRASIL TELECOM, de 8 de abril de 2008} \\
\hline Ementa & $\begin{array}{l}\text { Termo Aditivo ao Termo de Autorização para Exploração do SCM celebrado entre a } \\
\text { ANATEL e a BRASIL TELECOM S.A. para implementação do compromisso de } \\
\text { instalação e manutenção de provimento de serviço de acesso banda larga a escolas } \\
\text { públicas até } 31 \text { de dezembro de 2025. }\end{array}$ \\
\hline Órgão Emissor & ANATEL - Conselho Diretor. \\
\hline Anexos & $\begin{array}{l}\text { Anexo - Prazos, condições e critérios de qualidade para prestação de serviço de acesso } \\
\text { banda larga. }\end{array}$ \\
\hline
\end{tabular}




\begin{tabular}{|c|c|}
\hline Dispositivos & $\begin{array}{l}\text { LGT, Art. 64, Parágrafo Único; LGT, Art. 79, } \S 1^{\circ} \text {; LGT, Art. 80, caput; LGT, Art. } \\
207, \S 1^{\circ} .\end{array}$ \\
\hline \multirow[t]{3}{*}{ Regulamenta } & $\begin{array}{l}\text { Lei no } 9.472 / 1997 \text { - Dispõe sobre a organização dos serviços de telecomunicações, a } \\
\text { criação e funcionamento de um órgão regulador e outros aspectos institucionais, nos } \\
\text { termos da Emenda Constitucional no } 8 \text {, de } 1995 \text {. }\end{array}$ \\
\hline & $\begin{array}{l}\text { Decreto } \mathrm{n}^{\circ} 4.769 / 2003 \text { - Aprova o Plano Geral de Metas para a Universalização do } \\
\text { Serviço Telefônico Fixo Comutado Prestado no Regime Público - PGMU, e dá outras } \\
\text { providências. }\end{array}$ \\
\hline & $\begin{array}{l}\text { Decreto } n^{\circ} 6.424 / 2008 \text { - Altera e acresce dispositivos ao Anexo do Decreto } n^{\circ} 4.769 \text {, } \\
\text { de } 27 \text { de junho de } 2003 \text {, que aprova o Plano Geral de Metas para a Universalização } \\
\text { do Serviço Telefônico Fixo Comutado prestado no Regime Público - PGMU. }\end{array}$ \\
\hline
\end{tabular}

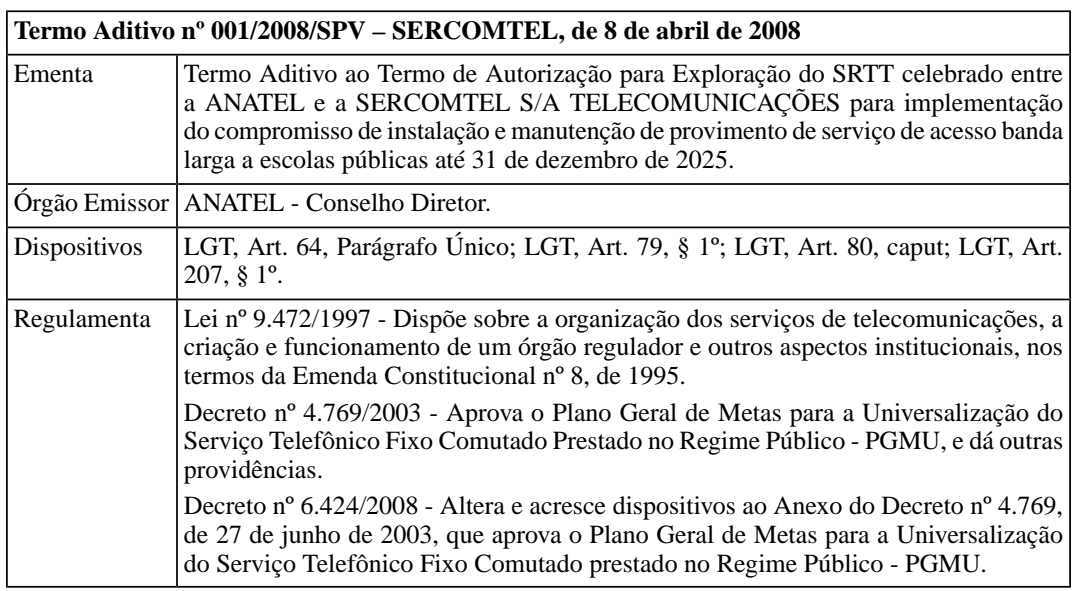

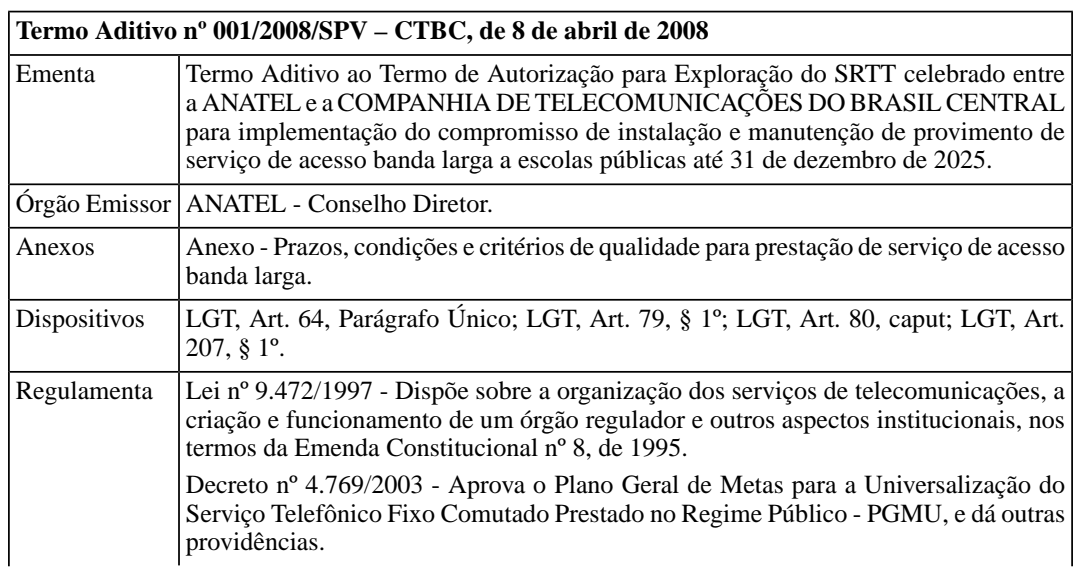




\begin{tabular}{|l|l|}
\hline & $\begin{array}{l}\text { Decreto } \mathrm{n}^{\circ} \text { 6.424/2008 - Altera e acresce dispositivos ao Anexo do Decreto } \mathrm{n}^{\circ} 4.769, \\
\text { de } 27 \text { de junho de 2003, que aprova o Plano Geral de Metas para a Universalização } \\
\text { do Serviço Telefônico Fixo Comutado prestado no Regime Público - PGMU. }\end{array}$ \\
\hline
\end{tabular}

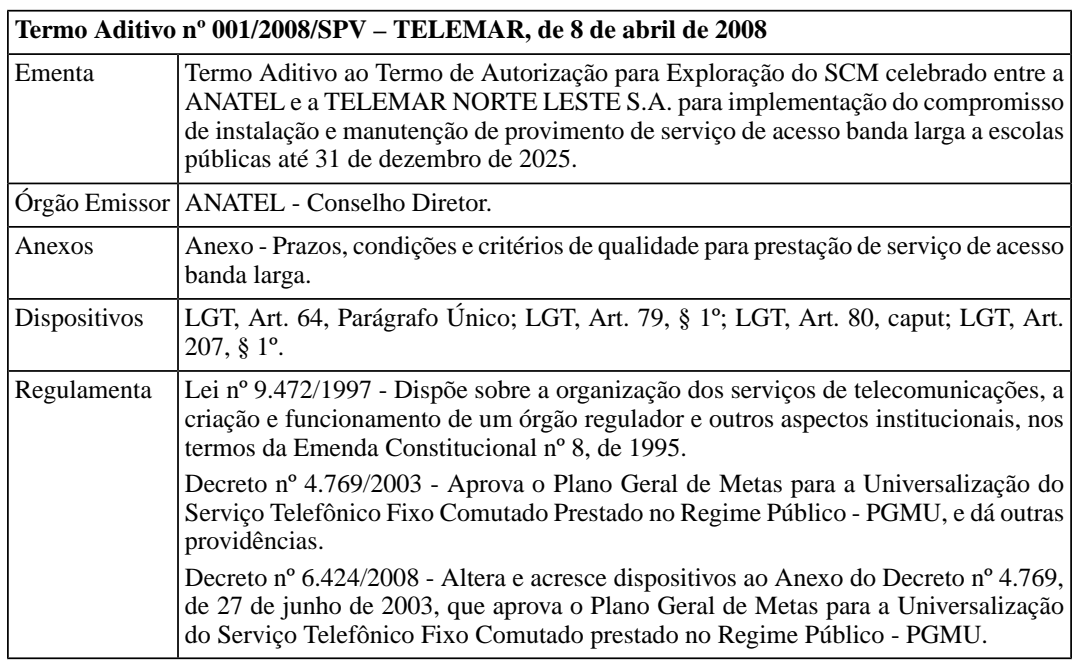




\section{Índice Alfabético e Remissivo}

A

Ação de Curto Prazo

listagem de ações de curto prazo a serem tomadas a partir de 2008, 436

[Resolução da ANATEL n ${ }^{\circ}$ 516/2008]

\section{Ação de Longo Prazo}

listagem de ações de longo prazo a serem tomadas a partir de 2008, 436

[Resolução da ANATEL no 516/2008]

\section{Ação de Médio Prazo}

listagem de ações de médio prazo a serem tomadas a partir de 2008, 436

[Resolução da ANATEL n ${ }^{\circ}$ 516/2008]

Acessibilidade, 400

(ver Deficiente Físico)

\section{Acessibilidade}

Central de Intermediação de

Comunicação Telefônica

Procedimentos e critérios para atendimento de usuários com deficiência auditiva ou da fala no âmbito do STFC e SMP., 433

[Resolução da ANATEL no 509/2008]

Acesso a Serviços de Interesse Público e Uso de Radiofrequência por tais Serviços, 401

\section{Acesso às Telecomunicações, 362}

Acesso Comutado

compromisso de disponibilização pela

TELEMAR/Oi de acesso comutado à INTERNET, 471

[Ato do Conselho Diretor da ANATEL $\mathrm{n}^{\circ} 7.828$, de 19 de dezembro de 2008]

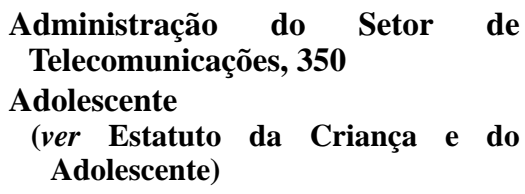

AEB

(ver Agência Espacial Brasileira)

Aeromodelismo, 401

Agência Espacial Brasileira

compromisso da TELEMAR/Oi em propor memorando de entendimento à $\mathrm{AEB}$ sobre seu papel no projeto Sistema Geoestacionário Brasileiro, 471

[Ato do Conselho Diretor da ANATEL $\mathrm{n}^{\circ} 7.828$, de 19 de dezembro de 2008]

\section{Agência Nacional de}

\section{Telecomunicações}

Arbitragem de conflitos entre agentes econômicos e usuários de serviços de telecomunicações, $\mathbf{4 2 7}$

[Resolução da ANATEL no 496/2008]

Comitê de Defesa dos Usuários de Serviços de Telecomunicações criação e aprovação do Regimento Interno do, $\mathbf{4 2 7}$

[Resolução da ANATEL n 496/2008]

Função Comissionada Técnica remanejamento de FCTs da, 421

[Decreto $n^{\circ}$ 6.602/2008]

Mediação

de conflitos entre agentes econômicos e usuários de serviços de telecomunicações, $\mathbf{4 2 7}$

[Resolução da ANATEL no 496/2008]

Princípio Regulatório

relação de princípios regulatórios de orientação da atuação da Anatel, 436

[Resolução da ANATEL no 516/2008] procedimentos para autorização do início de obras em áreas contíguas às estações fixas de radiogoniometria e de radiomonitoragem de responsabilidade da ANATEL, 434

[Resolução da ANATEL nº 511/2008]

Progressão Funcional

regulamentação da promoção e progressão funcional para servidores do quadro efetivo das agências reguladoras, $\mathbf{4 2 1}$ 
[Decreto ${ }^{\circ}$ 6.530/2008]

\section{Agência Nacional de Transportes Terrestres, 439}

[Resolução da ANTT nº 2.552/2008]

Concessionária de Rodovia

cálculo do valor a ser cobrado pela ocupação de uso da faixa de domínio de, 439

[Resolução da ANTT nº 2.552/2008]

\section{AGUIAR, Ubiratan}

relator (julgado), 460, 463, 465

ANATEL, 403

(ver Agência Nacional de Telecomunicações)

\section{Antena}

(ver também Equipamentos de Telecomunicações)

vedação de uso de antenas alternativas às fornecidas com o equipamento de radiação restrita, $\mathbf{4 3 1}$

[Resolução da ANATEL n ${ }^{\circ}$ 506/2008]

\section{Antenas, 344}

\section{ANTT}

(ver Agência Nacional de Transportes Terrestres)

Aparelho Telefônico

(ver Telefone Fixo)

Aplicações de Segurança, 399

Aplicações de Telecomunicações, 399

Aplicações de Telecomunicações

Dispositivo de Auxílio Auditivo sua qualificação como equipamento de radiação restrita, $\mathbf{4 3 1}$

[Resolução da ANATEL nº 506/2008]

Dispositivo de Telemedição Biomédica sua qualificação como equipamento de radiação restrita, $\mathbf{4 3 1}$

[Resolução da ANATEL n ${ }^{\circ}$ 506/2008]

Aplicações Médicas, 399

Aquisição, 468

(ver também BRASIL TELECOM

S.A)

[TC-010.681/2008-0]

\section{Arbitragem}

de conflitos entre agentes econômicos

e usuários de serviços de telecomunicações, $\mathbf{4 2 7}$

[Resolução da ANATEL nº 496/2008]

Área de Proteção

Radiogoniometria

definição da área de proteção de estações de, 434

[Resolução da ANATEL nº 511/2008]

Radiomonitoragem

definição da área de proteção de estações de, $\mathbf{4 3 4}$

[Resolução da ANATEL n ${ }^{\circ}$ 511/2008]

Área Local

(ver Área Local (Serviço Telefônico Público))

Área Local (Serviço Telefônico Público)

Regulamento sobre Áreas Locais para

o STFC alteração do, $\mathbf{4 2 8}$

[Resolução da ANATEL nº 499/2008]

\section{Área Rural}

(ver Zona Rural)

Assentimento Prévio

para instalação de meios de transmissão, edificação de prédios ou estruturas metálicas nas áreas de proteção das estações radiogoniométricas e de radiomonitoragem, 434

[Resolução da ANATEL n 511/2008]

\section{Assinante}

(ver também Usuário)

Ponto-Extra (Serviços de Televisão por Assinatura)

suspensão da eficácia dos dispositivos pertinentes do regulamento de proteção dos direitos dos assinantes de Televisão por Assinatura, 431, 437-438 
[Resolução da ANATEL n 505/2008]

[Resolução da ANATEL n ${ }^{\circ}$ 517/2008]

[Resolução da ANATEL n ${ }^{\circ}$ 520/2008]

Suspensão da eficácia dos dispositivos pertinentes do regulamento de proteção dos direitos dos assinantes de Televisão por Assinatura, 432

[Resolução da ANATEL n ${ }^{\circ}$ 508/2008]

Suspensão da eficácia dos dispositivos pertinentes do regulamento de proteção dos direitos dos assinantes de Televisão por Assinatura., 435

[Resolução da ANATEL no 513/2008]

\section{Assinatura, 448}

\section{(ver também Assinatura Básica)}

[STJ - RESP 754393 / DF]

ICMS

não-incidência sobre a assinatura despida de franquia de utilização, $\mathbf{4 4 8}$

[STJ - RESP 754393 / DF]

\section{Assinatura Básica, 441 \\ (ver também Assinatura) \\ (ver também Pagamento de Serviços \\ de Telecomunicações) \\ (ver também Pulso Telefônico) \\ (ver também Tarifa) \\ (ver também Tarifa Básica)}

[STF - RE 571572-8 / BA - Bahia]

competência do Juizado Especial Cível estadual para julgamento de matéria de cobrança de pulsos para além da franquia, 441

$$
\text { [STF - RE 571572-8 / BA - Bahia] }
$$

Franquia de Utilização

não-incidência do ICMS sobre assinatura básica condicionada à inexistência de franquia de utilização, 448

[STJ - RESP 754393 / DF]

ICMS

não-incidência sobre assinatura básica se esta não comportar franquia de utilização, 448

[STJ - RESP 754393 / DF] legitimidade de cobrança da assinatura básica nos serviços de telefonia fixa, 440

[Súmula do STJ no 356]

Pulso Excedente

obrigatoriedade, a partir de $1^{\circ}$ de janeiro de 2006, de discriminação de pulsos excedentes e ligações de telefone fixo para celular a pedido e às custas do assinante, $\mathbf{4 4 0}$

[Súmula do $\mathrm{STJ}^{\circ}{ }^{\circ}$ 357]

Ato de Concentração Econômica

(ver Competição)

Atores no Setor de Telecomunicações, 403

Atualização da Regulamentação

princípios, objetivos, propósitos e ações de curto, médio e longo prazos contados a partir de 2008 para, 436

[Resolução da ANATEL nº 516/2008]

Augusto Sherman Cavalcanti

(ver CAVALCANTI, Augusto Sherman)

Autorização (regras aplicáveis), 357

Autorização

Compromisso de Abrangência

regularidade de compromisso de abrangência para garantia de acesso em municípios com até 30mil habitantes, $\mathbf{4 5 8}$

[TC-023.855/2007-0]

Plano Geral de Autorizações do Serviço Móvel Especializado alteração do, $\mathbf{4 3 8}$

[Resolução da ANATEL n ${ }^{\circ}$ 519/2008]

Serviço Telefônico Fixo Comutado

não-incidência de ICMS sobre assinatura básica despida de franquia de utilização, 448

[STJ - RESP 754393 / DF]

\section{Autorizatária}

Serviço Telefônico Fixo Comutado

não-incidência de ICMS sobre assinatura básica despida de franquia de utilização, 448 
[STJ - RESP 754393 / DF]

\author{
Auxílio Auditivo, 401 \\ Auxílio Auditivo \\ Dispositivo de Auxílio Auditivo \\ sua qualificação como equipamento de \\ radiação restrita, 431 \\ [Resolução da ANATEL n 506/2008]
}

\section{Avaliação de Conformidade (ver Certificação)}

B

\section{Backhaul, 436}

(ver também Banda Larga)

[Resolução da ANATEL no 516/2008]

Serviço Telefônico Fixo Comutado aprovação de celebração de termos aditivos aos termos de autorização de SCM e SRTT das concessionárias de STFC para instalação de banda larga em escolas públicas em troca de metas de universalização de PSTs, 470

[Ato do Conselho Diretor da ANATEL

$\mathrm{n}^{\circ} 1.933$, de 7 de abril de 2008]

termo aditivo a termo de autorização de SCM para implementação de banda larga nas escolas públicas em substituição a metas de universalização celebrado com a BRASIL TELECOM, 471

[Termo Aditivo n ${ }^{\circ}$ 001/2008/SPV -

BRASIL TELECOM, de 8 de abril de 2008]

termo aditivo a termo de autorização de SCM para implementação de banda larga nas escolas públicas em substituição a metas de universalização celebrado com a TELEMAR, 473

[Termo Aditivo ${ }^{\circ}$ 001/2008/SPV -

TELEMAR, de 8 de abril de 2008]

termo aditivo a termo de autorização de SRTT para implementação de banda larga nas escolas públicas em substituição a metas de universalização celebrado com a CTBC, 472

[Termo Aditivo no 001/2008/SPV -

CTBC, de 8 de abril de 2008]

termo aditivo a termo de autorização de SRTT para implementação de banda larga nas escolas públicas em substituição a metas de universalização celebrado com a SERCOMTEL, 472

[Termo Aditivo $\mathrm{n}^{\circ}$ 001/2008/SPV SERCOMTEL, de 8 de abril de 2008] troca de metas de universalização no, 419

[Decreto ${ }^{\circ}$ 6.424/2008]

TELEMAR NORTE LESTE S.A.

compromisso de lançamento comercial de oferta de banda larga nas sedes de municípios das Regiões I e II do PGO que passarem a contar com a facilidade de backhaul, 471

[Ato do Conselho Diretor da ANATEL $\mathrm{n}^{\circ} 7.828$, de 19 de dezembro de 2008]

Banco Nacional de Desenvolvimento Econômico e Social

BRASIL TELECOM S.A

anuência prévia e condicionamentos para aquisição da BRASIL TELECOM pela TELEMAR/Oi, 471

[Ato do Conselho Diretor da ANATEL

$\mathrm{n}^{\circ} 7.828$, de 19 de dezembro de 2008] improcedência de representação efetuada contra a aquisição do controle acionário da Brasil Telecom pela Telemar/Oi com recursos do BNDES, 468

$$
\text { [TC-010.681/2008-0] }
$$

\section{Banda Larga, 402 \\ Banda Larga}

(ver também Backhaul)

freqüências para implantação de rotas de entroncamento em distâncias superiores a $20 \mathrm{~km}, \mathbf{4 3 0}$

[Resolução da ANATEL n ${ }^{\circ}$ 504/2008] Grupo 
previsão de equilíbrio entre grupos para ampliação da competição em STFC, SMP, TV por Assinatura e Banda Larga, 436

[Resolução da ANATEL nº 516/2008] inscrição da massificação do acesso à banda larga como objetivo de atualização da regulamentação a partir de 2008, 436

[Resolução da ANATEL no 516/2008]

Radiação Restrita

casos de liberação de licença e cadastramento de estações, $\mathbf{4 3 1}$

[Resolução da ANATEL no 506/2008]

Bem Público (utilização e restrição), 343

\section{BENJAMIN, Herman}

relator (julgado), 445

Bloqueador de Sinais de
Radiocomunicações (ver também Equipamentos de Telecomunicações)

sua qualificação como equipamento de radiocomunicação de radiação restrita, 431

[Resolução da ANATEL n ${ }^{\circ}$ 506/2008]

BNDES

\section{(ver Banco Nacional de Desenvolvimento Econômico e Social)}

Boa Vista

compromisso de interligação de Boa Vista à infraestrutura de telecomunicações por meio de fibra ótica, 471

[Ato do Conselho Diretor da ANATEL

$\mathrm{n}^{\circ}$ 7.828, de 19 de dezembro de 2008]

BRASIL TELECOM S.A, 422

(ver também Aquisição)

(ver também Grupo BRASIL

TELECOM)

[Decreto $n^{\circ} 6.654 / 2008$ ]

improcedência de representação efetuada contra a aquisição do controle acionário da Brasil Telecom pela Telemar/Oi com recursos do BNDES, 468

[TC-010.681/2008-0]

Plano Geral de Outorgas

novo PGO que eliminou obstáculo jurídico à aquisição da Brasil Telecom pela TELEMAR/Oi, 422

[Decreto $n^{\circ}$ 6.654/2008]

BSR

(ver Bloqueador de Sinais de Radiocomunicações)

Busca e Salvamento

(ver Operação de Busca e Salvamento)

\section{Calamidade Pública}

Regulamento sobre Canalização e Condições de Uso de Radiofrequiências na Faixa de 4,9 GHz destinação de frequiência para proteção pública e situações de calamidade, $\mathbf{4 2 7}$

[Resolução da ANATEL nº 494/2008]

\section{CALMON, Eliana}

relator (julgado), 444

\section{Câmara dos Deputados}

Distribuição obrigatória de canal de programação do Poder Executivo por prestadoras de serviços de TV por assinatura., 417

[Lei ${ }^{\circ} 11.652 / 2008$ ]

\section{Campo}

(ver Zona Rural)

\section{Canal de}

Sua previsão como dever de prestadoras de serviços de TV por assinatura., 417

[Lei ${ }^{\circ}$ 11.652/2008]

Canal de Programação de Distribuição Obrigatória (ver Distribuição Obrigatória)

Canalização

(ver Distribuição de Canais)

Capacidade de Transmissão

Backhaul 
metas de capacidade mínima de transmissão para $0, \mathbf{4 1 9}$

[Decreto ${ }^{\circ} 6.424 / 2008$ ]

\section{Caráter Secundário}

operação em caráter secundário dos equipamentos de radiocomunicação de radiação restrita, $\mathbf{4 3 1}$

[Resolução da ANATEL n 506/2008]

\section{Carreira}

regulamentação da promoção e progressão funcional para servidores do quadro efetivo das agências reguladoras, 421

[Decreto $\left.n^{\circ} 6.530 / 2008\right]$

\section{Cartografia}

Dado Espacial

instituição da Infra-Estrutura Nacional de Dados Espaciais, 422

[Decreto ${ }^{\circ}$ 6.666/2008]

\section{CAVAlCANTI, Augusto Sherman}

relator (julgado), 458

CBC 1

(ver Comissão Brasileira de Comunicações $n^{0} 1$ - Governança e Regimes Internacionais)

\section{CBC 2}

(ver Comissão Brasileira de Comunicações $n^{0} 2$ Radiocomunicações)

CBC 3

(ver Comissão Brasileira de Comunicações no 3 - Normalização de Telecomunicações)

CBC 4

(ver Comissão Brasileira de Comunicações $n^{0} 4$ Desenvolvimento das Telecomunicações)

CDC

(ver Código de Defesa do Consumidor)

\section{CEITEC}

(ver Centro Nacional de Tecnologia Eletrônica Avançada S.A)
Celular

(ver Telefone Celular)

(ver Telefone Fixo)

Central de Intermediação de Comunicação Telefônica, 433

[Resolução da ANATEL n ${ }^{\circ}$ 509/2008]

Procedimentos e critérios para atendimento de usuários com deficiência auditiva ou da fala no âmbito do STFC e SMP., 433

[Resolução da ANATEL nº 509/2008]

Centro Nacional de Tecnologia Eletrônica Avançada S.A, 418 (ver também Empresa Estatal)

[Lei ${ }^{\circ}$ 11.759/2008]

autorização para criação da empresa pública, 418

[Lei ${ }^{\circ} 11.759 / 2008$ ]

criação do, $\mathbf{4 2 2}$

[Decreto $n^{\circ}$ 6.638/2008]

\section{Certificação}

(ver também Homologação)

Equipamento de Radiocomunicação de Radiação Restrita

dever de possuir certificação emitida pela ANATEL por parte do, $\mathbf{4 3 1}$

[Resolução da ANATEL n ${ }^{\circ}$ 506/2008]

Norma para Certificação e Homologação da Interface Analógica de Adaptadores para Terminal de Assinante aprovação da, 434

[Resolução da ANATEL nº 512/2008]

Norma para Certificação e Homologação de Transmissores e Retransmissores para o Sistema Brasileiro de Televisão Digital Terrestre, 428

[Resolução da ANATEL nº 498/2008] Worldwide Interoperability for Microwave Access, 426

[Resolução da ANATEL nº 492/2008]

Certificação / Homologação, 348

Cezar Peluso 
(ver PELUSO, Cezar)

CIC

(ver Central de Intermediação de Comunicação Telefônica)

Ciência e Tecnologia (ver Ministério da Ciência e Tecnologia)

Circuito Integrado

(ver também Semicondutor)

Centro Nacional de Tecnologia Eletrônica Avançada S.A atribuição de produção e comercialização de semicondutores pelo, 418

[Lei $\mathrm{n}^{\circ}$ 11.759/2008]

\section{Classificação Indicativa}

extensão do prazo para cumprimento da classificação indicativa nos fusos horários do país para 7 de abril de 2008, 423

[Portaria MJ nº 36/2008]

Classificações de Serviços no Setor de Telecomunicações, 369

\section{CMR}

(ver Conferência Mundial de Radiocomunicações)

\section{Código de Acesso}

Intermediação da Comunicação para Portadores de Necessidades Especiais, 433

[Resolução da ANATEL nº 509/2008]

Portador de Deficiência

Confirmação do número 142 para a intermediação da comunicação para, 433

[Resolução da ANATEL nº 509/2008]

\section{Código de Barras}

Radio Frequency Identification Device

(Sistema de Identificação por Radiofrequiência)

sua qualificação como equipamento de radiação restrita, $\mathbf{4 3 1}$

[Resolução da ANATEL n ${ }^{\circ}$ 506/2008]

Código de Defesa do Consumidor

Serviço de Atendimento ao Consumidor normas gerais aplicáveis ao SAC por telefone no âmbito dos fornecedores de serviços regulados pelo Poder Público federal, $\mathbf{4 2 1}$

[Decreto $\mathrm{n}^{\circ}$ 6.523/2008]

Vedação de publicidade por fornecedor a consumidor que aguarda atendimento em ligação telefônica para ele onerosa., 418

[Lei n ${ }^{\circ} 11.800 / 2008$ ]

\section{Código de Seleção de Prestadora}

prazo de 18 meses para devolução de um dos códigos de seleção de prestadora da Brasil Telecom e da Telemar/Oi após aquisição da Brasil Telecom pela Oi, 471

[Ato do Conselho Diretor da ANATEL

$\mathrm{n}^{\circ} 7.828$, de 19 de dezembro de 2008]

\section{COFINS}

(ver Contribuição para Financiamento da Seguridade Social)

Comissão Brasileira de Comunicações $n^{0} 1$ - Governança e Regimes Internacionais criação da, $\mathbf{4 2 9}$

[Resolução da ANATEL n 502/2008]

Comissão Brasileira de Comunicações $\mathrm{n}^{0} 2$ - Radiocomunicações criação da, $\mathbf{4 2 9}$

[Resolução da ANATEL n ${ }^{\circ}$ 502/2008]

Comissão Brasileira de Comunicações $n^{0} 3$ - Normalização de Telecomunicações criação da, $\mathbf{4 2 9}$

[Resolução da ANATEL nº 502/2008]

Comissão Brasileira de Comunicações $\mathrm{n}^{\circ} 4$ - Desenvolvimento das Telecomunicações criação da, $\mathbf{4 2 9}$

[Resolução da ANATEL nº 502/2008]

Comissão Parlamentar de Inquérito (ver também CPI das Escutas Telefônicas Clandestinas) 
(ver também CPI dos Grampos)

CPI das Escutas Telefônicas Clandestinas

possibilidade de requisição por CPI de dados consolidados de juízos, mandados, órgãos policiais, localização e duração de interceptações telefônicas em determinado período para fins investigativos, $\mathbf{4 4 2}$

[STF MS n $27483 \mathrm{RE}-\mathrm{MC} / \mathrm{DF}$ ]

Comissões Brasileiras de

Comunicações, 402

Comitê de Defesa dos Usuários de Serviços de Telecomunicações

criação e aprovação do Regimento Interno do, $\mathbf{4 2 7}$

[Resolução da ANATEL n ${ }^{\circ}$ 496/2008]

\section{Companhia de Telecomunicações do Brasil Central, 472}

[Termo Aditivo $n^{\circ}$ 001/2008/SPV - CTBC, de 8 de abril de 2008]

Backhaul

termo aditivo a termo de autorização de SRTT para implementação de banda larga nas escolas públicas em substituição a metas de universalização celebrado com a CTBC, 472

[Termo Aditivo ${ }^{\circ}$ 001/2008/SPV CTBC, de 8 de abril de 2008]

\section{Compartilhamento de Infra-estrutura} (ver também Mediação)

Contrato de Receita Extraordinária

(Concessionária de Rodovia)

cálculo do valor a ser cobrado pela ocupação de uso da faixa de domínio de concessionária de rodovia, 439

[Resolução da ANTT n ${ }^{\circ}$ 2.552/2008]

Compartilhamento de Infraestrutura, 343

\section{Competência}

Assinatura Básica

competência do Juizado Especial Cível estadual para julgamento de matéria de cobrança de pulsos para além da franquia, 441

[STF - RE 571572-8 / BA - Bahia]

\section{Competição}

Princípio Regulatório

previsão da competição como, 436

[Resolução da ANATEL n 516/2008]

Serviço Móvel Especializado

limites à outorga de uso de radiofreqüências em uma mesma área geográfica para autorizadas do SME, suas coligadas, controladas ou controladoras, 437-438

[Resolução da ANATEL n ${ }^{\circ}$ 518/2008]

[Resolução da ANATEL nº 519/2008]

\section{Compromisso de Abrangência}

regularidade de compromisso de abrangência para garantia de acesso em municípios com até 30mil habitantes, $\mathbf{4 5 8}$

[TC-023.855/2007-0]

\section{Concessão}

(ver Concessão (Radiodifusão))

Concessão (Radiodifusão)

(ver também Concessão)

Globo

renovação de concessão em Belo Horizonte em 2008, 419

[Decreto/2008]

renovação de concessão em Brasília em 2008, 419

[Decreto/2008]

renovação de concessão em Recife em 2008, 420

[Decreto/2008]

renovação de concessão em São Paulo em 2008, 420

[Decreto/2008]

renovação de concessão no Rio de Janeiro em 2008, 420

[Decreto/2008]

Record

renovação de concessão no Rio de Janeiro em 2008, 421

[Decreto/2008] 


\section{Concessão (regras aplicáveis), 355 Concessão}

(ver também Concessão

(Radiodifusão))

adiamento da alteração qüinqüenal de 2009, 439

[Resolução da ANATEL no 524/2008]

Plano Geral de Metas de Universalização do STFC no Regime Público

alteração do, 419

[Decreto $n^{\circ}$ 6.424/2008]

aprovação de celebração de termos aditivos aos termos de autorização de SCM e SRTT das concessionárias de STFC para instalação de banda larga em escolas públicas em troca de metas de universalização de PSTs, 470

[Ato do Conselho Diretor da ANATEL $\mathrm{n}^{\circ} 1.933$, de 7 de abril de 2008]

termo aditivo a termo de autorização de SCM para implementação de banda larga nas escolas públicas em substituição a metas de universalização celebrado com a BRASIL TELECOM, 471

[Termo Aditivo ${ }^{\circ}$ 001/2008/SPV BRASIL TELECOM, de 8 de abril de 2008]

termo aditivo a termo de autorização de SCM para implementação de banda larga nas escolas públicas em substituição a metas de universalização celebrado com a TELEMAR, 473

[Termo Aditivo ${ }^{\circ}$ 001/2008/SPV TELEMAR, de 8 de abril de 2008] termo aditivo a termo de autorização de SRTT para implementação de banda larga nas escolas públicas em substituição a metas de universalização celebrado com a CTBC, 472

[Termo Aditivo n ${ }^{\circ}$ 001/2008/SPV CTBC, de 8 de abril de 2008] termo aditivo a termo de autorização de SRTT para implementação de banda larga nas escolas públicas em substituição a metas de universalização celebrado com a SERCOMTEL, 472

[Termo Aditivo $n^{\circ}$ 001/2008/SPV SERCOMTEL, de 8 de abril de 2008] Plano Geral de Outorgas, 422

[Decreto $\mathrm{n}^{\circ}$ 6.654/2008]

Radiodifusão

inexigibilidade de decisão judicial para anulação de concessão de radiodifusão, inaplicável o art. 223, $\$ 4^{\circ}$ da Constituição Federal, 460

[TC-027.077/2006-4]

renovação de concessão em Belo Horizonte em 2008, 419

[Decreto/2008]

renovação de concessão em Brasília em 2008, 419

[Decreto/2008]

renovação de concessão em Recife em 2008, 420

[Decreto/2008]

renovação de concessão em São Paulo em 2008, 420

[Decreto/2008]

renovação de concessão no Rio de Janeiro em 2008, 420-421

[Decreto/2008]

Renovação dos Contratos de Concessão do STFC

inconsistência no estudo de situação econômico-financeira dos contratos de concessão de STFC no período de 1999 a 2004, $\mathbf{4 6 5}$

[TC-019.677/2006-2]

Serviço Telefônico Fixo Comutado improcedência de representação efetuada contra a aquisição do controle acionário da Brasil Telecom pela Telemar/Oi com recursos do BNDES, 468

[TC-010.681/2008-0]

\section{Concessionária}


Backhaul

aprovação de celebração de termos aditivos aos termos de autorização de SCM e SRTT das concessionárias de STFC para instalação de banda larga em escolas públicas em troca de metas de universalização de PSTs, 470

[Ato do Conselho Diretor da ANATEL $\mathrm{n}^{\circ} 1.933$, de 7 de abril de 2008]

termo aditivo a termo de autorização de SCM para implementação de banda larga nas escolas públicas em substituição a metas de universalização celebrado com a BRASIL TELECOM, 471

[Termo Aditivo ${ }^{\circ}$ 001/2008/SPV -

BRASIL TELECOM, de 8 de abril de 2008]

termo aditivo a termo de autorização de SCM para implementação de banda larga nas escolas públicas em substituição a metas de universalização celebrado com a TELEMAR, 473

[Termo Aditivo ${ }^{\circ}$ 001/2008/SPV TELEMAR, de 8 de abril de 2008] termo aditivo a termo de autorização de SRTT para implementação de banda larga nas escolas públicas em substituição a metas de universalização celebrado com a CTBC, 472

[Termo Aditivo ${ }^{\circ}$ 001/2008/SPV CTBC, de 8 de abril de 2008]

termo aditivo a termo de autorização de SRTT para implementação de banda larga nas escolas públicas em substituição a metas de universalização celebrado com a SERCOMTEL, 472

[Termo Aditivo ${ }^{\circ}$ 001/2008/SPV SERCOMTEL, de 8 de abril de 2008] troca de metas de universalização dos PSTs por instalação de, 419

[Decreto no 6.424/2008]

Diretor Estatutário exigência de cadastro do diretor estatutário responsável pelas informações para cálculo do Fator de Transferência X, 432

[Resolução da ANATEL nº 507/2008] ICMS

ilegitimidade passiva ad causam de concessionária de serviço público de telecomunicações para responder pela devolução de valores de, 447

[STJ - RESP 938827 / DF]

Plano Geral de Metas de Universalização do STFC no Regime Público

a partir de $1^{\circ}$ de janeiro de 2006, 419

[Decreto $\mathrm{n}^{\circ}$ 6.424/2008]

aprovação de celebração de termos aditivos aos termos de autorização de SCM e SRTT das concessionárias de STFC para instalação de banda larga em escolas públicas em troca de metas de universalização de PSTs, 470

[Ato do Conselho Diretor da ANATEL $n^{\circ} 1.933$, de 7 de abril de 2008]

termo aditivo a termo de autorização de SCM para implementação de banda larga nas escolas públicas em substituição a metas de universalização celebrado com a BRASIL TELECOM, 471

[Termo Aditivo $\mathrm{n}^{\mathrm{o}}$ 001/2008/SPV BRASIL TELECOM, de 8 de abril de 2008]

termo aditivo a termo de autorização de SCM para implementação de banda larga nas escolas públicas em substituição a metas de universalização celebrado com a TELEMAR, 473

[Termo Aditivo $\mathrm{n}^{\circ}$ 001/2008/SPV -

TELEMAR, de 8 de abril de 2008] termo aditivo a termo de autorização de SRTT para implementação de banda larga nas escolas públicas em substituição a metas de universalização celebrado com a CTBC, 472 
[Termo Aditivo ${ }^{\circ}$ 001/2008/SPV CTBC, de 8 de abril de 2008] termo aditivo a termo de autorização de SRTT para implementação de banda larga nas escolas públicas em substituição a metas de universalização celebrado com a SERCOMTEL, 472

[Termo Aditivo ${ }^{\circ}$ 001/2008/SPV SERCOMTEL, de 8 de abril de 2008] Plano Geral de Outorgas, 422

[Decreto $n^{\circ} 6.654 / 2008$ ]

\section{Concessionária de Rodovia}

captação de receitas extraordinárias por parte de, 439

[Resolução da ANTT nº 2.552/2008]

\section{Concorrência} (ver Competição)

\section{Concorrência no Setor de Telecomunicações, 361 \\ Condições de Uso de Radiofreqüência \\ e Canalização (Distribuição de Canais), 350}

\section{Conferência \\ Mundial \\ de}

\section{Radiocomunicações}

Regulamento sobre Canalização e Condições de Uso de Radiofreqüências na Faixa de 4,9 GHz destinação de freqüência para proteção pública e situações de calamidade, $\mathbf{4 2 7}$

[Resolução da ANATEL no 494/2008]

\section{Congresso Nacional, 404}

\section{Congresso Nacional}

Comissão Parlamentar de Inquérito poderes de requisição de dados consolidados de juízos, mandados, órgãos policiais, localização e duração de interceptações telefônicas em determinado período para fins investigativos, $\mathbf{4 4 2}$

[STF MS n $27483 \mathrm{RE}-\mathrm{MC} / \mathrm{DF}$ ]

Radiodifusão

inexigibilidade de decisão judicial para anulação de concessão de radiodifusão, inaplicável o art. 223, $\S 4^{\circ}$ da Constituição Federal, 460

[TC-027.077/2006-4]

\section{Conselho de Usuários}

Plano anual de atividades exigência e requisitos, $\mathbf{4 2 6}$

[Resolução da ANATEL n 490/2008]

Regulamento de Conselho de Usuários do STFC aprovação do, $\mathbf{4 2 6}$

[Resolução da ANATEL nº 490/2008]

\section{Consumidor}

(ver também Usuário)

Assinatura Básica

não-incidência de ICMS sobre assinatura básica despida de franquia de utilização, 448

[STJ - RESP 754393 / DF]

Código de Defesa do Consumidor normas gerais aplicáveis ao SAC por telefone no âmbito dos fornecedores de serviços regulados pelo Poder Público federal, 421

[Decreto $n^{\circ}$ 6.523/2008]

Vedação de publicidade por fornecedor a consumidor que aguarda atendimento em ligação telefônica para ele onerosa., 418

[Lei ${ }^{\circ} 11.800 / 2008$ ]

Ponto-Extra (Serviços de Televisão por Assinatura)

suspensão da eficácia dos dispositivos pertinentes do regulamento de proteção dos direitos dos assinantes de Televisão por Assinatura, 431, 437-438

[Resolução da ANATEL n ${ }^{\circ}$ 505/2008] [Resolução da ANATEL n ${ }^{\circ}$ 517/2008]

[Resolução da ANATEL n ${ }^{\circ}$ 520/2008]

Suspensão da eficácia dos dispositivos pertinentes do regulamento de proteção dos direitos dos assinantes de Televisão por Assinatura, 432

[Resolução da ANATEL nº 508/2008]

Suspensão da eficácia dos dispositivos pertinentes do regulamento de 
proteção dos direitos dos assinantes de Televisão por Assinatura., 435

[Resolução da ANATEL nº 513/2008]

Portador de deficiência auditiva ou da fala

Dever de atendimento qualificado do SMP para intermediação de comunicação telefônica entre pessoas com deficiência auditiva ou da fala., 433

[Resolução da ANATEL no 509/2008]

Serviço de Atendimento ao Consumidor normas gerais aplicáveis ao SAC por telefone no âmbito dos fornecedores de serviços regulados pelo Poder Público federal, 421

[Decreto ${ }^{\circ} 6.523 / 2008$ ]

\section{Conteúdo Nacional}

Produção Independente

compromisso da TELEMAR/Oi de ofertar até 31 de março de 2010 no DTH e TV a Cabo um canal de conteúdo nacional de produção independente, $\mathbf{4 7 1}$

[Ato do Conselho Diretor da ANATEL

$n^{\circ} 7.828$, de 19 de dezembro de 2008]

Contrato de Receita Extraordinária

(Concessionária de Rodovia), 439

[Resolução da ANTT no 2.552/2008]

Concessionária de Rodovia

captação de receitas extraordinárias por parte de, 439

[Resolução da ANTT n ${ }^{\circ}$ 2.552/2008]

Contribuição para Financiamento da Seguridade Social

vedação de seu cômputo como acréscimo tarifário arcado pelo usuário, seja expressa ou implicitamente, $\mathbf{4 4 5}$

[STJ - RESP 1053778 / RS]

Contribuição para o Fomento da Radiodifusão Pública

instituição da, $\mathbf{4 1 7}$

[Lei $\mathrm{n}^{\circ}$ 11.652/2008]
Controle Social, Hierárquico e Interorgânico (Accountability), 367

Convergência, 368

Convergência

inscrição da ampliação da oferta convergente de serviços como objetivo da atualização da regulamentação a partir de 2008, 436

[Resolução da ANATEL nº 516/2008]

CPI

(ver Comissão Parlamentar de Inquérito)

CPI das Escutas Telefônicas Clandestinas, 442

(ver também Comissão Parlamentar de Inquérito)

[STF MS n 27483 RE - MC / DF]

CPI dos Grampos, 442

(ver também Comissão Parlamentar de Inquérito)

[STF MS n² $27483 \mathrm{RE}-\mathrm{MC} / \mathrm{DF}$ ]

CRE

(ver Contrato de Receita Extraordinária (Concessionária de Rodovia))

Criança

(ver Estatuto da Criança e do Adolescente)

Crime

HC76686/PR

inadmissibilidade de provas derivadas de interceptação telefônica por prazo superior ao permitido em lei e ausente exaustiva fundamentação judicial das sucessivas renovações, $\mathbf{4 4 3}$

[STJ - HC 76686 / PR - Paraná]

CSP

(ver Código de Seleção de Prestadora)

CTBC

(ver Companhia de Telecomunicações do Brasil Central)

\section{Controle de Conteúdo, 367}


D

Dado Espacial, 422

[Decreto $n^{\circ}$ 6.666/2008]

instituição da Infra-Estrutura Nacional de Dados Espaciais, 422

[Decreto $n^{\circ} 6.666 / 2008$ ]

de Intermediação de Comunicação Telefônica a ser Utilizada por Pessoas com Deficiência Auditiva ou da Fala

Aprovação do, 433

[Resolução da ANATEL no 509/2008]

Defesa Civil, 402

Defesa Civil

Regulamento sobre Canalização e Condições de Uso de Radiofreqüências na Faixa de 4,9 GHz destinação de freqüência para proteção pública e situações de calamidade, $\mathbf{4 2 7}$

[Resolução da ANATEL no 494/2008]

Deficiência Auditiva

(ver também Deficiência Auditiva Parcial)

(ver também Portador de Deficiência)

Central de Intermediação de

Comunicação Telefônica

exigência de regulamentação específica, 426

[Resolução da ANATEL no 491/ 2008]

Procedimentos e critérios para atendimento de usuários com deficiência auditiva ou da fala no âmbito do STFC e SMP., 433

[Resolução da ANATEL n ${ }^{\circ}$ 509/2008]

Deficiência Auditiva Parcial, 433 (ver também Deficiência Auditiva) (ver também Deficiente Físico)

[Resolução da ANATEL no 509/2008]

Deficiência Auditiva Total, 433 (ver também Deficiente Físico)

[Resolução da ANATEL no 509/2008]

Deficiência da fala

(ver também Portador de Deficiência)
Central de Intermediação de Comunicação Telefônica

exigência de regulamentação específica, 426

[Resolução da ANATEL nº 491/ 2008]

\section{Deficiente Físico}

(ver também Deficiência Auditiva Parcial)

(ver também Deficiência Auditiva

Total)

(ver também Portador de Deficiência)

Central de Intermediação de Comunicação Telefônica

Procedimentos e critérios para atendimento de usuários com deficiência auditiva ou da fala no âmbito do STFC e SMP., 433

[Resolução da ANATEL nº 509/2008]

Demanda

(ver Projeção de Demanda)

Denise Arruda

relator (julgado), 447

Desenvolvimento Econômico e Social

Princípio Regulatório

inscrição da aceleração do desenvolvimento econômico e social como, 436

[Resolução da ANATEL n ${ }^{\circ}$ 516/2008]

Desenvolvimento Tecnológico

(ver Pesquisa e Desenvolvimento)

Desigualdade Regional

Princípio Regulatório

inscrição da aceleração da redução de desigualdades regionais como, $\mathbf{4 3 6}$

[Resolução da ANATEL n ${ }^{\circ}$ 516/2008]

Destinação das faixas de 143,60 a 143,65 MHz ao Serviço Limitado Privado para uso em aplicações de pesquisa espacial no sentido espaço para Terra., 436

[Resolução da ANATEL no 515/2008]

Destinação, Atribuição e Designação de Radiofrequência, 349

Direct-to-Home 
(ver Serviço de Distribuição de Sinais de Televisão e de Áudio por Assinatura Via Satélite)

\section{Direito à Informação}

Fatura Telefônica

obrigatoriedade, a partir de $1^{\circ}$ de janeiro de 2006, de discriminação de pulsos excedentes e ligações de telefone fixo para celular a pedido e às custas do assinante, 440

[Súmula do $\mathrm{STJ}^{\circ}{ }^{\circ}$ 357]

Direito Administrativo, 398

Direito da Concorrência, 396

Direito do Consumidor, 394

Direito do Trabalho, 399

Direito Penal, 397

Direito Processual, 397

Direito Tributário, 398

Diretor Estatutário

exigência de cadastro do diretor estatutário responsável pelas informações para cálculo do Fator de Transferência X, 432

[Resolução da ANATEL n ${ }^{\circ}$ 507/2008]

\section{Disponibilidade de Comunicação}

ICMS

não-incidência sobre atividade de disponibilidade de serviço de comunicação, 448

[STJ - RESP 754393 / DF]

Dispositivo de Auxílio Auditivo

sua qualificação como equipamento de radiação restrita, 431

[Resolução da ANATEL no 506/2008]

\section{Dispositivo de Telemedição} Biomédica

sua qualificação como equipamento de radiação restrita, 431

[Resolução da ANATEL nº 506/2008]

Dispositivo Semicondutor (ver Semicondutor)

Distribuição de Canais, 417 (ver também Distribuição Obrigatória) (ver também Espectro de Radiofreqüências)

[Lei $\mathrm{n}^{\circ}$ 11.652/2008]

Regulamento sobre Canalização e Condições de Uso da Faixa de $5 \mathrm{GHz}$, 427

[Resolução da ANATEL nº 495/2008]

Regulamento sobre Canalização e Condições de Uso da Faixa de Radiofreqüências de $6.430 \mathrm{MHz}$ a 7.110MHz, 430

[Resolução da ANATEL no 504/2008]

Regulamento sobre Canalização e

Condições de Uso de

Radiofreqüências na Faixa de $4,9 \mathrm{GHz}$ destinação de freqüência para proteção pública e situações de calamidade, $\mathbf{4 2 7}$

[Resolução da ANATEL no 494/2008]

Regulamento sobre Canalização e Condições de Uso na faixa de Radiofreqüências de $217 \mathrm{MHz}$ a 218 $\mathrm{MHz}$ aprovação do, 434

[Resolução da ANATEL nº 510/2008]

Distribuição Obrigatória, 417

(ver também Distribuição de Canais)

[Lei $\mathrm{n}^{\circ}$ 11.652/2008]

DISTV (Serviço de Distribuição de Sinais de TV por Meios Físicos), 383

Documento de Separação e Alocação de Contas

prazo para sua apresentação por operadora de SMP com PMS, 430

[Resolução da ANATEL n ${ }^{\circ}$ 503/2008]

DSAC

(ver Documento de Separação e Alocação de Contas)

\section{DTH}

(ver Serviço de Distribuição de Sinais de Televisão e de Áudio por Assinatura Via Satélite)

DTH (Direct to Home - Serviço de Distribuição de Sinais de Televisão 
e de Áudio por Assinatura Via Satélite), 381

E

\section{E-mail Corporativo}

licitude de provas oriundas de acesso não-autorizado a e-mail corporativo de empregado por seu empregador, 449

[TST - RR 1542/2005-055-02-40 - AI]

\section{EBC}

(ver Empresa Brasil de Comunicação)

ECA

(ver Estatuto da Criança e do Adolescente)

Educação, 363

Eliana Calmon

(ver CALMON, Eliana)

Empregado

E-mail Corporativo

licitude de provas oriundas de acesso não-autorizado a e-mail corporativo de empregado por seu empregador, 449

\section{Empregador}

[TST - RR 1542/2005-055-02-40 - AI]

E-mail Corporativo

licitude de provas oriundas de acesso não-autorizado a e-mail corporativo de empregado por seu empregador, 449

[TST - RR 1542/2005-055-02-40 - AI]

\section{Empresa Brasil de Comunicação}

(ver também Empresa Estatal)

autorização da criação da, $\mathbf{4 1 7}$

[Lei ${ }^{\circ} 11.652 / 2008$ ]

estatuto social da, $\mathbf{4 2 3}$

[Decreto $n^{\circ}$ 6.689/2008]

regulamento simplificado para contratação de serviços e aquisição de bens pela, 420

[Decreto $n^{\circ} 6.505 / 2008$ ]
Empresa Brasileira de Comunicação S.A. (ver RADIOBRÁS)

Empresa Estatal, 417-418

(ver também Centro Nacional de Tecnologia Eletrônica Avançada S.A)

(ver também Empresa Brasil de Comunicação) (ver também RADIOBRÁS)

[Lei no 11.652/2008] [Lei no 11.759/2008]

Empresa Pública

Centro Nacional de Tecnologia Eletrônica Avançada S.A

autorização para criação da empresa pública, 418

[Lei $\mathrm{n}^{\circ} 11.759 / 2008$ ]

criação do, $\mathbf{4 2 2}$

[Decreto ${ }^{\circ}$ 6.638/2008]

Empresa Brasil de Comunicação

regulamento simplificado para contratação de serviços e aquisição de bens pela, 420

[Decreto $\mathrm{n}^{\circ}$ 6.505/2008]

\section{Entrante, 436}

[Resolução da ANATEL nº 516/2008]

Competição

criação de ambiente favorável a novos prestadores de pequeno e médio porte em nichos específicos de mercado como propósito estratégico da atualização da regulamentação a partir de 2008, 436

[Resolução da ANATEL nº 516/2008]

Equipamento Bloqueador de Sinais de Radiocomunicações

sua qualificação como equipamento de radiocomunicação de radiação restrita, 431

[Resolução da ANATEL nº 506/2008]

Equipamento de Radiação Restrita (ver Equipamento de Radiocomunicação de Radiação Restrita) 
Equipamento de Radiocomunicação de Radiação Restrita

(ver também Equipamentos de Telecomunicações)

Regulamento sobre Equipamentos de Radiocomunicação de Radiação Restrita, 431

[Resolução da ANATEL nº 506/2008]

Equipamentos de Telecomunicações, 344

Equipamentos de Telecomunicações (ver também Antena)

(ver também Bloqueador de Sinais de Radiocomunicações)

(ver também Equipamento de

Radiocomunicação de Radiação

Restrita)

(ver também Telefone Fixo)

Central de Intermediação de Comunicação Telefônica

Garantia de fidelidade, sigilo, confidencialidade e integralidade das mensagens., 433

[Resolução da ANATEL nº 509/2008]

Centro Nacional de Tecnologia

Eletrônica Avançada S.A

atribuição de produção e comercialização de semicondutores pelo, $\mathbf{4 1 8}$

[Lei $\left.{ }^{\circ} 11.759 / 2008\right]$

Certificação, de transmissores e transceptores digitais para o serviço fixo em aplicações ponto-multiponto nas faixas de freqüência acima de $1 \mathrm{GHz}, \mathbf{4 2 6}$

[Resolução da ANATEL n ${ }^{\circ}$ 492/2008]

Espalhamento Espectral utilização de tecnologia de espalhamento espectral para o SCM, 428

[Resolução da ANATEL no 497/2008]

Norma para Certificação e Homologação de Transmissores e Retransmissores para o Sistema Brasileiro de Televisão Digital Terrestre, $\mathbf{4 2 8}$
[Resolução da ANATEL nº 498/2008]

Orthogonal Frequency Division Multiplexing (Multiplexação Ortogonal por Divisão de Freqüência) utilização de tecnologia de multiplexação para o SCM, 428

[Resolução da ANATEL nº 497/2008]

Telefone Fixo

processo produtivo básico, $\mathbf{4 2 4 - 4 2 5}$

[Portaria Interministerial $n^{\circ}$ 23/2008]

[Portaria Interministerial no 236/2008]

[Portaria Interministerial $n^{\circ}$ 237/2008]

[Portaria Interministerial n ${ }^{\circ} 29 / 2008$ ]

\section{Espalhamento Espectral}

Serviço de Comunicação Multimídia utilização da faixa de $2.400 \mathrm{MHz}$ a $2.483,5 \mathrm{MHz}$ por tecnologia de espalhamento espectral para o, $\mathbf{4 2 8}$

[Resolução da ANATEL nº 497/2008]

\section{Espécies de Outorga, 355}

Espectro de Radiofrequencia, 348

Espectro de Radiofrequiências

(ver também Distribuição de Canais)

Plano de Atribuição, Destinação e

Distribuição de Faixas de Frequêencias no Brasil

Edição 2008 do, 470

[Ato do Conselho Diretor da ANATEL

$\mathrm{n}^{\circ} 1.805$, de $1^{\circ}$ de abril de 2008]

Regulamento sobre Canalização e Condições de Uso da Faixa de $5 \mathrm{GHz}$, 427

[Resolução da ANATEL nº 495/2008]

Regulamento sobre Canalização e Condições de Uso de Radiofrequiências na Faixa de 4,9 GHz destinação de freqüência para proteção pública e situações de calamidade, $\mathbf{4 2 7}$

[Resolução da ANATEL nº 494/2008]

Regulamento sobre Canalização e Condições de Uso na faixa de Radiofreqüências de $217 \mathrm{MHz}$ a 218

$\mathrm{MHz}$ aprovação do, 434 
[Resolução da ANATEL n ${ }^{\circ}$ 510/2008]

Serviço Móvel Pessoal

destinação de faixas de radiofreqüência ao, 429

[Resolução da ANATEL n 501/2008]

Estações de Telecomunicações, 345

Estado-Membro

Assinatura Básica

competência do Juizado Especial Cível estadual para julgamento de matéria de cobrança de pulsos para além da franquia, 441

[STF - RE 571572-8 / BA - Bahia]

ICMS

não-incidência sobre habilitação de aparelho móvel celular, 440

[Súmula do $\mathrm{STJ}^{\circ}{ }^{\circ}$ 350]

Estatuto da Criança e do Adolescente

Pornografia Infantil

crimes referentes à, $\mathbf{4 1 8}$

[Lei $\mathrm{n}^{\circ}$ 11.829/2008]

Experimento em Telecomunicação (ver Serviço Especial para Fins Científicos ou Experimentais)

$\mathbf{F}$

Fabricantes de Produtos de Telecomunicações

Telefone Celular

dever de encaminhamento à SEPIN e à SDP de relatório de cumprimento de percentuais de produtos incentivados até 31 de março de cada ano, $\mathbf{4 2 5}$

[Portaria Interministerial no 237/2008] dever de encaminhamento à SUFRAMA de relatório de cumprimento de percentuais de produtos incentivados até 31 de março de cada ano, $\mathbf{4 2 5}$

[Portaria Interministerial no 236/2008]

Faixa de Domínio, 439

[Resolução da ANTT nº 2.552/2008]

Concessionária de Rodovia

cálculo do valor a ser cobrado pela ocupação de uso da faixa de domínio de, 439
[Resolução da ANTT nº 2.552/2008]

Faixa de Radiofrequiência

(ver Espectro de Radiofreqüências)

FALCÃO, Francisco

relator (julgado), 448

Fator de Transferência DEA

sua fixação em 0,00899 para os anos de 2008, 2009 e 2010, 470

[Ato do Conselho Diretor da ANATEL

$\mathrm{n}^{\circ} 4.197$, de 16 de julho de 2008]

Fator de Transferência $X$

Norma para Estabelecimento da Metodologia Simplificada para Cálculo do Fator de Transferência X, 432

[Resolução da ANATEL nº 507/2008] utilização das informações fornecidas com base na Res.418/2005 para o cálculo do Fator X no período de 2008 a 2010, 432

[Resolução da ANATEL n ${ }^{\circ}$ 507/2008] sua fixação em 0,02920 para o ano de 2008, 470

[Ato do Conselho Diretor da ANATEL $\mathrm{n}^{\circ} 4.197$, de 16 de julho de 2008]

\section{Fator X}

(ver Fator de Transferência $X$ )

FCT

(ver Função Comissionada Técnica)

Fibra Óptica

metas de interligação por fibra ótica de sedes municipais à infraestrutura de telecomunicações impostas à aquisição da BRASIL TELECOM pela TELEMAR/Oi, 471

[Ato do Conselho Diretor da ANATEL $\mathrm{n}^{\circ}$ 7.828, de 19 de dezembro de 2008]

Fiscalização das Telecomunicações, 350

FISTEL, 365

Forças Armadas 
destinação de faixas de radiofreqüências para fins exclusivamente militares, 439

[Resolução da ANATEL nº 522/2008]

Fórum Internacional

(ver Relações Internacionais)

Francisco Falcão

(ver FALCÃO, Francisco)

Franquia

(ver Assinatura Básica)

Função Comissionada Técnica

Agência Nacional de Telecomunicações remanejamento de FCTs da, $\mathbf{4 2 1}$

[Decreto $n^{\circ}$ 6.602/2008]

Fundo para o Desenvolvimento Tecnológico das Telecomunicações decisão do TCU sobre irregularidades na aplicação do, $\mathbf{4 5 0}$

[TC-002.660/2007-8]

Tribunal de Contas da União ausência de metas para utilização dos recursos do FUNTTEL, 450

[TC-002.660/2007-8]

Fundos Setoriais

Telecomunicações, 365

FUNTTEL, 365

(ver Fundo para o Desenvolvimento Tecnológico das Telecomunicações)

\section{Fuso Horário}

Classificação Indicativa

extensão do prazo para cumprimento da classificação indicativa nos fusos horários do país para 7 de abril de 2008, 423

[Portaria MJ nº 36/2008]

G

Gilmar Mendes

relator (julgado), 441

GINGA

(ver também TV Digital)

TV Móvel

meta de compatibilidade $5 \%$ de aparelhos celulares incentivados a partir de $1^{\circ}$ de janeiro de 2010 com o SBTVD e o GINGA, 425

[Portaria Interministerial no 236/2008]

[Portaria Interministerial $n^{\circ} 237 / 2008$ ]

Globo, 419-420

[Decreto/2008]

Concessão (Radiodifusão)

renovação de concessão em Belo Horizonte em 2008, 419

[Decreto/2008]

renovação de concessão em Brasília em 2008, 419

[Decreto/2008]

renovação de concessão em Recife em 2008, 420

[Decreto/2008]

renovação de concessão em São Paulo em 2008, 420

[Decreto/2008]

renovação de concessão no Rio de Janeiro em 2008, 420

[Decreto/2008]

\section{Grampo Telefônico}

(ver Interceptação de Telecomunicação)

\section{Grupo}

de equilíbrio entre grupos para ampliação da competição em STFC, SMP, TV por Assinatura e Banda Larga, 436

[Resolução da ANATEL nº 516/2008]

\section{Grupo BRASIL TELECOM}

(ver também BRASIL TELECOM

S.A)

Backhaul

termo aditivo a termo de autorização de SCM para implementação de banda larga nas escolas públicas em substituição a metas de universalização celebrado com a BRASIL TELECOM, 471

[Termo Aditivo $\mathrm{n}^{\circ}$ 001/2008/SPV BRASIL TELECOM, de 8 de abril de 2008] 


\section{Grupo TELEMAR (ver também TELEMAR NORTE LESTE S.A.) \\ Backhaul \\ termo aditivo a termo de autorização de SCM para implementação de banda larga nas escolas públicas em substituição a metas de universalização celebrado com a TELEMAR, 473}

[Termo Aditivo ${ }^{\circ}$ 001/2008/SPV TELEMAR, de 8 de abril de 2008]

H

\section{Habeas Corpus}

HC76686/PR

inadmissibilidade de provas derivadas de interceptação telefônica por prazo superior ao permitido em lei e ausente exaustiva fundamentação judicial das sucessivas renovações, $\mathbf{4 4 3}$

[STJ - HC 76686 / PR - Paraná]

\section{Habilitação}

ICMS

não-incidência sobre atividade de habilitação, 448

[STJ - RESP 754393 / DF]

Habilitação de Aparelho Móvel Celular

ICMS

não-incidência sobre a habilitação de aparelho móvel celular, 440

[Súmula do $\mathrm{STJ}^{\circ}$ 350]

\section{HC76686/PR}

inadmissibilidade de provas derivadas de interceptação telefônica por prazo superior ao permitido em lei e ausente exaustiva fundamentação judicial das sucessivas renovações, 443

[STJ - HC 76686 / PR - Paraná]

Herman Benjamin (ver BENJAMIN, Herman)

Homologação (ver também Certificação)
Norma para Certificação e Homologação de Transmissores e Retransmissores para o Sistema Brasileiro de Televisão Digital Terrestre, $\mathbf{4 2 8}$

[Resolução da ANATEL n 498/2008]

Worldwide Interoperability for Microwave Access, 426

[Resolução da ANATEL nº 492/2008]

\section{I}

\section{IBGE}

(ver Instituto Brasileiro de Geografia e Estatística)

\section{ICMS}

Assinatura Básica

não-incidência do ICMS sobre assinatura básica se esta não comportar franquia de utilização, $\mathbf{4 4 8}$

[STJ - RESP 754393 / DF]

Atividade-meio

reafirmação da não-incidência do ICMS sobre atividades-meio ou intermediárias, tais como habilitação, instalação, disponibilidade, assinatura, cadastro de usuário e de equipamento, 448

[STJ - RESP 754393 / DF]

ilegitimidade passiva ad causam de concessionária de serviço público de telecomunicações para responder pela devolução de valores de, $\mathbf{4 4 7}$

[STJ - RESP 938827 / DF]

não-incidência sobre a habilitação de aparelho móvel celular, 440

[Súmula do $\mathrm{STJ}^{\circ}{ }^{\circ}$ 350]

Imposto sobre Circulação de Mercadorias e Serviços (ver ICMS)

Imposto sobre Operações Relativas à Circulação de Mercadorias e sobre Prestações de Serviços de Transporte Interestadual, Intermunicipal e de Comunicações 
(ver ICMS)

IMT-2000

(ver International Mobile

Telecommunications-2000)

Infraestrutura de Telecomunicações, 343

Infraestrutura e Recursos do Setor de Telecomunicações, 343

Instalação

ICMS

não-incidência sobre atividade de instalação, 448

[STJ - RESP 754393 / DF]

Instituto Brasileiro de Geografia e Estatística

Setor Especial Aglomerado Subnormal sua utilização na definição de área de prestação da televisão por assinatura com infra-estrutura urbana deficiente, 427

[Resolução da ANATEL no 493/2008]

Interceptação de Telecomunicação, 442-443 (ver também Sigilo)

[STF MS no 27483 RE - MC / DF] [STJ -

HC 76686 / PR - Paraná]

Comissão Parlamentar de Inquérito poderes de requisição de dados consolidados de juízos, mandados, órgãos policiais, localização e duração de interceptações telefônicas em determinado período para fins investigativos, $\mathbf{4 4 2}$

[STF MS no $27483 \mathrm{RE}-\mathrm{MC} / \mathrm{DF}$ ]

inadmissibilidade de provas derivadas de interceptação telefônica por prazo superior ao permitido em lei e ausente exaustiva fundamentação judicial das sucessivas renovações, $\mathbf{4 4 3}$

[STJ - HC 76686 / PR - Paraná]

Interceptação Telefônica

(ver Interceptação

Telecomunicação)

Interconexão
Documento de Separação e Alocação de Contas

prazo para sua apresentação por operadora de SMP com PMS, 430

[Resolução da ANATEL n 503/2008]

Interface Analógica

Norma para Certificação e Homologação da Interface Analógica de Adaptadores para Terminal de Assinante

aprovação da, $\mathbf{4 3 4}$

[Resolução da ANATEL no 512/2008]

\section{International}

Mobile

Telecommunications-2000

destinação de faixas de radiofreqüência para serviços móveis que sigam as especificações, $\mathbf{4 2 9}$

[Resolução da ANATEL n 501/2008] regularidade de compromisso de abrangência para garantia de acesso em municípios com até 30mil habitantes, $\mathbf{4 5 8}$

[TC-023.855/2007-0]

International Telecommunications Union

(ver União Internacional de Telecomunicações

Internationale

Télécommunications

Internacionald e

Telecommunicaciones))

Internet, 379, 400

\section{INTERNET}

(ver também Serviço de Valor Adicionado)

Acesso Comutado

compromisso de disponibilização pela

TELEMAR/Oi de acesso comutado à INTERNET, 471

[Ato do Conselho Diretor da ANATEL $n^{\circ} 7.828$, de 19 de dezembro de 2008]

de E-mail Corporativo 
licitude de provas oriundas de acesso não-autorizado a e-mail corporativo de empregado por seu empregador, 449

[TST - RR 1542/2005-055-02-40 - AI]

Neutralidade de Rede

compromisso da TELEMAR/Oi de neutralidade de rede quanto a serviços baseados na INTERNET, 471

[Ato do Conselho Diretor da ANATEL $\mathrm{n}^{\circ} 7.828$, de 19 de dezembro de 2008] Sigilo

inaplicabilidade da proteção ao sigilo na relação empregado-empregador tratando-se de e-mail corporativo, 449

[TST - RR 1542/2005-055-02-40 - AI]

\section{ISDB-TB}

(ver Sistema Brasileiro de Televisão

Digital Terrestre)

\section{ITU}

(ver União Internacional de

Telecomunicações

Internation a le

(Union

Télécommunications / Unión

In t e r n a c i o n a l d e

Telecommunicaciones))

Ives Gandra Martins Filho

relator (julgado), 449

\section{Juridicamente Pobre, 436}

[Resolução da ANATEL nº 516/2008]

inscrição do atendimento à população menos favorecida como propósito estratégico da atualização da regulamentação a partir de 2008, 436

[Resolução da ANATEL no 516/2008]

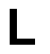

\section{Lei de Interceptação Telecomunicação)} (ver Interceptação de Lei $\mathbf{n}^{\circ}$ 8.078/90 (ver Código de Defesa do Consumidor)

M

\section{Macapá}

compromisso de interligação de Macapá à infraestrutura de telecomunicações por meio de fibra ótica, 471

[Ato do Conselho Diretor da ANATEL $\mathrm{n}^{\circ}$ 7.828, de 19 de dezembro de 2008]

\section{Manaus}

compromisso de interligação de Manaus à infraestrutura de telecomunicações por meio de fibra ótica, 471

[Ato do Conselho Diretor da ANATEL $\mathrm{n}^{\circ} 7.828$, de 19 de dezembro de 2008]

\section{Mandado de Segurança}

REF-MS-MC27483/DF

possibilidade de requisição por CPI de dados consolidados de juízos, mandados, órgãos policiais, localização e duração de interceptações telefônicas em determinado período para fins investigativos, $\mathbf{4 4 2}$

[STF MS n ${ }^{\circ} 27483 \mathrm{RE}-\mathrm{MC} / \mathrm{DF}$ ]

Marcos Vinicios Vilaça

relator (julgado), 468

Massificação

Banda Larga

inscrição da massificação do acesso à banda larga como objetivo de atualização da regulamentação a partir de 2008, 436

[Resolução da ANATEL nº 516/2008]

Material com Condutividade Elétrica (ver Semicondutor)

\section{Mediação}

(ver também Compartilhamento de Infra-estrutura)

de conflitos a concessionária da rodovia e terceiros visando a celebração de contrato de receita extraordinária, 439

[Resolução da ANTT nº 2.552/2008] 
de conflitos entre agentes econômicos

e usuários de serviços de telecomunicações, $\mathbf{4 2 7}$

[Resolução da ANATEL n ${ }^{\circ}$ 496/2008]

\section{Meio Ambiente}

compromissos de promoção de ações de preservação do meio ambiente por parte da TELEMAR/Oi no tocante ao recolhimento e destinação de baterias e distribuição de aparelhos para reutilização, 471

[Ato do Conselho Diretor da ANATEL $\mathrm{n}^{\circ} 7.828$, de 19 de dezembro de 2008]

\section{Metas de Qualidade}

(ver Plano Geral de Metas de Qualidade)

Metas de Universalização, 363

\section{Metodologia}

Reajuste Tarifário

cálculo do Fator de Transferência X, 432

[Resolução da ANATEL nº 507/2008]

\section{Microeletrônica}

Centro Nacional de Tecnologia

Eletrônica Avançada S.A

atribuição de exploração de atividade econômica no âmbito das tecnologias de microeletrônica, 418

[Lei n ${ }^{\circ} 11.759 / 2008$ ]

\section{Microtelco}

Entrante

criação de ambiente favorável a novos prestadores de pequeno e médio porte em nichos específicos de mercado como propósito estratégico da atualização da regulamentação a partir de 2008, 436

[Resolução da ANATEL n ${ }^{\circ}$ 516/2008]

\section{Militar}

compromissos da TELEMAR/Oi em pontos de presença de organizações militares, 471

[Ato do Conselho Diretor da ANATEL

$\mathrm{n}^{\circ} 7.828$, de 19 de dezembro de 2008]

\section{Militares}

destinação de faixas de radiofrequiências para fins exclusivamente militares, 439

[Resolução da ANATEL nº 522/2008]

\section{Ministério da Ciência e Tecnologia, 418}

[Lei $\mathrm{n}^{\circ} 11.759 / 2008$ ]

Centro Nacional de Tecnologia Eletrônica Avançada S.A criação do, $\mathbf{4 2 2}$

[Decreto $\mathrm{n}^{\circ} 6.638 / 2008$ ]

sua vinculação ao Ministério da Ciência e Tecnologia, 418

[Lei no 11.759/2008]

Ministério das Comunicações, 406

Ministério das Comunicações

Fundo para o Desenvolvimento

Tecnológico das Telecomunicações deficiências na consistência de políticas públicas, metas e mecanismos de controle pertinentes ao, $\mathbf{4 5 0}$

[TC-002.660/2007-8]

Política Pública

objetivos e diretrizes das políticas públicas de telecomunicações, $\mathbf{4 2 3}$

[Portaria MC no 178/2008]

Radiodifusão

, inexigibilidade de decisão judicial para anulação de concessão de radiodifusão, inaplicável o art. 223, $\S 4^{\circ}$ da Constituição Federal, 460

[TC-027.077/2006-4]

Serviço de Radiodifusão Comunitária inobservância do critério da representatividade previsto na Lei 9612 para seleção de prestador do serviço de radiodifusão comunitária, 463

[TC-010.385/2006-7]

Ministro das Comunicações

(ver Ministério das Comunicações)

MMDS (Multichannel Multipoint

Distribution Service - Serviço de 


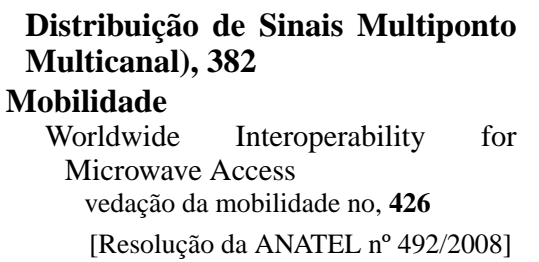

Modelo de Negócio

Princípio Regulatório

previsão de incentivo de modelos de negócios sustentáveis para o setor de telecomunicações como seu, $\mathbf{4 3 6}$

[Resolução da ANATEL n ${ }^{\circ}$ 516/2008]

Município, 417

(ver Prefeitura)

N

NAVES, Nilson

relator (julgado), 443

Negociação Internacional

(ver Relações Internacionais)

Neutralidade de Rede

compromisso da TELEMAR/Oi de neutralidade de rede quanto a serviços baseados na INTERNET, 471

[Ato do Conselho Diretor da ANATEL $\mathrm{n}^{\circ} 7.828$, de 19 de dezembro de 2008]

Nilson Naves (ver NAVES, Nilson)

Norma para Certificação e Homologação da Interface Analógica de Adaptadores para Terminal de Assinante aprovação da, 434

[Resolução da ANATEL n ${ }^{\circ}$ 512/2008]

Norma para Certificação e Homologação de Transmissores e Retransmissores para o Sistema Brasileiro de Televisão Digital Terrestre, 428

[Resolução da ANATEL no 498/2008]
Norma para Certificação e Homologação de Transmissores e Transceptores Digitais para o Serviço Fixo em Aplicações PontoMultiponto nas Faixas de Frequências acima de $1 \mathrm{GHz}, 426$

[Resolução da ANATEL n ${ }^{\circ}$ 492/2008]

Norma para Estabelecimento da Metodologia Simplificada para Cálculo do Fator de Transferência $\mathrm{X}, 432$

[Resolução da ANATEL n ${ }^{\circ}$ 507/2008]

\section{Nova Prestadora \\ (ver Entrante)}

Nulidade

inexigibilidade de decisão judicial para anulação de concessão de radiodifusão, inaplicável o art. 223, $\S 4^{\circ}$ da Constituição Federal, 460

$$
\text { [TC-027.077/2006-4] }
$$

\section{O}

Obra

procedimentos para autorização do início de obras em áreas contíguas às estações fixas de radiogoniometria e de radiomonitoragem de responsabilidade da ANATEL, 434

[Resolução da ANATEL n ${ }^{\circ}$ 511/2008]

Obrigações de Universalização (ver Universalização)

Ocupação do uso da faixa de domínio (ver Faixa de Domínio)

OFDM

(ver Orthogonal Frequency Division Multiplexing (Multiplexação Ortogonal por Divisão de Frequiência))

Oferta por telefone

Código de Defesa do Consumidor Vedação de publicidade por fornecedor a consumidor que aguarda atendimento em ligação telefônica para ele onerosa., 418 
[Lei $\left.{ }^{\circ} 11.800 / 2008\right]$

Oi

(ver TELEMAR NORTE LESTE S.A.)

Operação de Busca e Salvamento, 439

[Resolução da ANATEL n ${ }^{\circ}$ 523/2008]

destinação da radiofrequência 156,80

MHz para, 439

[Resolução da ANATEL n ${ }^{\circ}$ 523/2008]

\section{Operação Tipo Despacho}

Regulamento do Serviço Móvel

Especializado

alteração do, $\mathbf{4 3 7}$

[Resolução da ANATEL nº 518/2008]

Operadora de Telecomunicações (ver também Prestadora)

Assinatura Básica

competência do Juizado Especial Cível estadual para julgamento de matéria de cobrança de pulsos para além da franquia, 441

[STF - RE 571572-8 / BA - Bahia]

legitimidade de cobrança da assinatura básica nos serviços de telefonia fixa, 440

[Súmula do $\mathrm{STJ}^{\circ}{ }^{\circ}$ 356]

não-incidência de ICMS sobre assinatura básica despida de franquia de utilização, 448

[STJ - RESP 754393 / DF]

Contribuição para Financiamento da Seguridade Social

vedação de seu cômputo como acréscimo tarifário arcado pelo usuário, seja expressa ou implicitamente, $\mathbf{4 4 5}$

[STJ - RESP 1053778 / RS]

Deveres

normas gerais aplicáveis ao SAC por telefone no âmbito dos fornecedores de serviços regulados pelo Poder Público federal, 421

[Decreto ${ }^{\circ} 6.523 / 2008$ ]

obrigatoriedade, a partir de $1^{\circ}$ de janeiro de 2006, de discriminação de pulsos excedentes e ligações de telefone fixo para celular a pedido e às custas do assinante, $\mathbf{4 4 0}$

[Súmula do $\mathrm{STJ}^{\circ}{ }^{\circ}$ 357]

Vedação de publicidade por fornecedor a consumidor que aguarda atendimento em ligação telefônica para ele onerosa., 418

[Lei $n^{\circ} 11.800 / 2008$ ]

Programa de Integração Social

vedação de seu cômputo como acréscimo tarifário arcado pelo usuário, seja expressa ou implicitamente, 445

[STJ - RESP 1053778 / RS]

Órbita, 350

(ver também Satélite)

Órbita e Satélite, 350

Organismo Intergovernamental

(ver Relações Internacionais)

Orthogonal Frequency Division

Multiplexing (Multiplexação

Ortogonal por Divisão de

Freqüiência)

Serviço de Comunicação Multimídia utilização da faixa de $2.400 \mathrm{MHz}$ a $2.483,5 \mathrm{MHz}$ por tecnologia de multiplexação ortogonal para o, 428

[Resolução da ANATEL no 497/2008]

Outorgas, 355

$\mathbf{P}$

\section{P\&D}

(ver Pesquisa e Desenvolvimento)

Pagamento de Serviços de Telecomunicações, 448 (ver também Assinatura Básica)

[STJ - RESP 754393 / DF]

\section{Papel Regulador do Estado}

Princípio Regulatório inscrição da otimização e fortalecimento do papel regulador do Estado como, 436

[Resolução da ANATEL nº 516/2008]

PELUSO, Cezar 
relator (julgado), 442

Pesquisa \& Desenvolvimento, 365

Pesquisa e Desenvolvimento

Centro Nacional de Tecnologia

Eletrônica Avançada S.A autorização para criação da empresa pública, 418

[Lei $\mathrm{n}^{\circ} 11.759 / 2008$ ]

Destinação das faixas de 143,60 a $143,65 \mathrm{MHz}$ ao Serviço Limitado Privado para uso em aplicações de pesquisa espacial no sentido espaço para Terra., 436

[Resolução da ANATEL n 515/2008]

Semicondutor autorização para criação da CEITEC para desenvolvimento e produção nacional de, 418

[Lei ${ }^{\circ} 11.759 / 2008$ ]

Telefone Celular isenção ou redução do IPI de terminais portáteis de telefonia celular devido a investimento em atividades de pesquisa e desenvolvimento, $\mathbf{4 1 8}$

[Decreto $\mathrm{n}^{\circ}$ 6.405/2008]

TELEMAR NORTE LESTE S.A. compromisso da TELEMAR/Oi com investimentos mínimos em pesquisa e desenvolvimento, 471

[Ato do Conselho Diretor da ANATEL

$\mathrm{n}^{\circ} 7.828$, de 19 de dezembro de 2008]

Pesquisa Espacial, 402

PGA-SME

(ver Plano Geral de Autorizações do Serviço Móvel Especializado)

PGMQ

(ver Plano Geral de Metas de Qualidade)

PGMQ - televisão por assinatura

(ver Plano Geral de Metas de Qualidade)

PGMQ-SMP

(ver Plano Geral de Metas de Qualidade)

PGMU-2006 (ver Plano Geral de Metas para Universalização do STFC no Regime Público para a Renovação dos Contratos de Concessão)

PGO

(ver Plano Geral de Outorgas)

PGR

(ver Plano Geral de Atualização da

Regulamentação das

Telecomunicações no Brasil)

PIS

(ver Programa de Integração Social)

Planejamento Estratégico, 436

[Resolução da ANATEL n ${ }^{\circ}$ 516/2008]

Atualização da Regulamentação

princípios, objetivos, propósitos e ações de curto, médio e longo prazos contados a partir de 2008 para, 436

[Resolução da ANATEL n ${ }^{\circ}$ 516/2008]

Plano anual de atividades

Conselho de Usuários, $\mathbf{4 2 6}$

[Resolução da ANATEL nº 490/2008]

Plano de Atribuição de Espectro de Radiofreqüiências

Serviço Móvel Pessoal destinação de faixas de radiofreqüência ao, 429

[Resolução da ANATEL n 501/2008]

Plano de Atribuição, Destinação e

Distribuição de Faixas de Freqüências no Brasil

Edição 2008 do, 470

[Ato do Conselho Diretor da ANATEL $\mathrm{n}^{\circ} 1.805$, de $1^{\circ}$ de abril de 2008]

Plano Geral de Atualização da Regulamentação das Telecomunicações no Brasil, 436

[Resolução da ANATEL n ${ }^{\circ}$ 516/2008] aprovação do, 436

[Resolução da ANATEL nº 516/2008] submissão à aprovação, 471

[Análise ANATEL/GCAB n ${ }^{\circ}$ 455/2008] 
Plano Geral de Autorizações do Serviço Móvel Especializado

alteração do, $\mathbf{4 3 8}$

[Resolução da ANATEL n ${ }^{\circ}$ 519/2008]

Plano Geral de Metas de Qualidade

Serviços de Televisão por Assinatura

alteração do PGMQ, 427

[Resolução da ANATEL nº 493/2008]

Plano Geral de Metas de Universalização do STFC no Regime Público (ver também Universalização)

Backhaul

termo aditivo a termo de autorização de SCM para implementação de banda larga nas escolas públicas em substituição a metas de universalização celebrado com a BRASIL TELECOM, 471

[Termo Aditivo no 001/2008/SPV -

BRASIL TELECOM, de 8 de abril de 2008]

termo aditivo a termo de autorização de SCM para implementação de banda larga nas escolas públicas em substituição a metas de universalização celebrado com a TELEMAR, 473

[Termo Aditivo n ${ }^{\circ}$ 001/2008/SPV TELEMAR, de 8 de abril de 2008] termo aditivo a termo de autorização de SRTT para implementação de banda larga nas escolas públicas em substituição a metas de universalização celebrado com a CTBC, 472

[Termo Aditivo $n^{\circ}$ 001/2008/SPV CTBC, de 8 de abril de 2008]

termo aditivo a termo de autorização de SRTT para implementação de banda larga nas escolas públicas em substituição a metas de universalização celebrado com a SERCOMTEL, 472
[Termo Aditivo $\mathrm{n}^{\circ}$ 001/2008/SPV SERCOMTEL, de 8 de abril de 2008] troca de metas de universalização dos PSTs por instalação de, 419

[Decreto $n^{\circ}$ 6.424/2008]

Plano Geral de Metas para Universalização do STFC no Regime Público para a Renovação dos Contratos de Concessão

Backhaul aprovação de celebração de termos aditivos aos termos de autorização de SCM e SRTT das concessionárias de STFC para instalação de banda larga em escolas públicas em troca de metas de universalização de PSTs, 470

[Ato do Conselho Diretor da ANATEL $\mathrm{n}^{\circ} 1.933$, de 7 de abril de 2008]

Plano Geral de Outorgas, 422

[Decreto ${ }^{\circ} 6.654 / 2008$ ]

proposta de revisão do, 471

[Análise ANATEL/GCPJ nº 368/2008]

PMS

(ver Poder de Mercado Significativo)

Pobre

(ver Juridicamente Pobre)

Poder de Mercado Significativo

atribuição de PMS a concessionárias de STFC enquanto não houver ato especifico da ANATEL definindo-as, 426

[Resolução da ANATEL no 490/2008]

Regulamento de Conselho de Usuários do STFC

aprovação do, $\mathbf{4 2 6}$

[Resolução da ANATEL n 490/2008]

Poder Executivo, 406

Poder Executivo, 421

[Decreto ${ }^{\circ} 6.523 / 2008$ ]

Distribuição obrigatória de canal de programação do Poder Executivo por prestadoras de serviços de TV por assinatura., 417 
[Lei $\mathrm{n}^{\circ} 11.652 / 2008$ ]

Poder Judiciário, 406

Poder Legislativo, 404

\section{Poder Público}

Serviço de Atendimento ao Consumidor normas gerais aplicáveis ao SAC por telefone no âmbito dos fornecedores de serviços regulados pelo Poder Público federal, 421

[Decreto $n^{\circ} 6.523 / 2008$ ]

\section{Política Industrial, 360}

\section{Política Pública}

Fundo para o Desenvolvimento

Tecnológico das Telecomunicações baixo grau de consistência na elaboração de políticas públicas para o, 450

[TC-002.660/2007-8]

objetivos e diretrizes das políticas

públicas de telecomunicações, $\mathbf{4 2 3}$

[Portaria $\mathrm{MC} \mathrm{n}^{\circ}$ 178/2008]

Pesquisa e Desenvolvimento

ausência de metas para utilização dos recursos do FUNTTEL, 450

[TC-002.660/2007-8]

incentivo à produção nacional de semicondutores e circuitos integrados, 418

[Lei ${ }^{\circ}$ 11.759/2008]

Tribunal de Contas da União

verificação de existência de baixo grau de consistência na elaboração de políticas públicas para o setor de telecomunicações, $\mathbf{4 5 0}$

[TC-002.660/2007-8]

\section{Política Tarifária, 359}

Políticas de Telecomunicações, 359

Políticas de Telecomunicações

Plano Geral de Atualização da Regulamentação das Telecomunicações no Brasil submissão à aprovação, 471

[Análise ANATEL/GCAB n ${ }^{\circ}$ 455/2008]

\section{Políticas Públicas de} Telecomunicações (ver Políticas de Telecomunicações)

Políticas Setoriais

(ver Políticas de Telecomunicações)

Ponto-Extra

(ver Ponto-Extra (Serviços de Televisão por Assinatura))

Ponto-Extra (Serviços de Televisão por Assinatura)

Cobrança

suspensão da eficácia dos dispositivos pertinentes do regulamento de proteção dos direitos dos assinantes de Televisão por Assinatura, 431, 437-438

[Resolução da ANATEL n ${ }^{\circ}$ 505/2008]

[Resolução da ANATEL no 517/2008]

[Resolução da ANATEL n ${ }^{\circ}$ 520/2008]

Suspensão da eficácia dos dispositivos pertinentes do regulamento de proteção dos direitos dos assinantes de Televisão por Assinatura, 432

[Resolução da ANATEL n ${ }^{\circ}$ 508/2008]

Suspensão da eficácia dos dispositivos pertinentes do regulamento de proteção dos direitos dos assinantes de Televisão por Assinatura., 435

[Resolução da ANATEL n ${ }^{\circ}$ 513/2008]

\section{Ponto-Multiponto}

(ver Sistema Ponto-Multiponto)

Pornografia Infantil

crimes referentes à, $\mathbf{4 1 8}$

[Lei $n^{\circ} 11.829 / 2008$ ]

Portador de Deficiência, 362

Portador de Deficiência

(ver também Deficiência Auditiva)

(ver também Deficiência da fala)

(ver também Deficiente Físico)

Central de Intermediação de

Comunicação Telefônica

Procedimentos e critérios para atendimento de usuários com deficiência auditiva ou da fala no âmbito do STFC e SMP, 433

[Resolução da ANATEL n 509/2008]

Dispositivo de Auxílio Auditivo 
sua qualificação como equipamento de radiação restrita, $\mathbf{4 3 1}$

[Resolução da ANATEL n ${ }^{\circ}$ 506/2008]

Portador de deficiência auditiva ou da fala

Dever de atendimento qualificado do STFC e do SMP para intermediação de comunicação telefônica entre pessoas com deficiência auditiva ou da fala., 433

[Resolução da ANATEL no 509/2008]

Portador de Necessidades Especiais (ver Deficiente Físico)

\section{Posto de Serviço de Telecomunicações}

Backhaul

aprovação de celebração de termos aditivos aos termos de autorização de SCM e SRTT das concessionárias de STFC para instalação de banda larga em escolas públicas em troca de metas de universalização de PSTs, 470

[Ato do Conselho Diretor da ANATEL

$\mathrm{n}^{\circ} 1.933$, de 7 de abril de 2008]

termo aditivo a termo de autorização de SCM para implementação de banda larga nas escolas públicas em substituição a metas de universalização celebrado com a BRASIL TELECOM, 471

[Termo Aditivo n ${ }^{\circ}$ 001/2008/SPV -

BRASIL TELECOM, de 8 de abril de 2008]

termo aditivo a termo de autorização de SCM para implementação de banda larga nas escolas públicas em substituição a metas de universalização celebrado com a TELEMAR, 473

[Termo Aditivo ${ }^{\circ}$ 001/2008/SPV -

TELEMAR, de 8 de abril de 2008]

termo aditivo a termo de autorização de SRTT para implementação de banda larga nas escolas públicas em substituição a metas de universalização celebrado com a CTBC, 472
[Termo Aditivo $\mathrm{n}^{\circ}$ 001/2008/SPV CTBC, de 8 de abril de 2008] termo aditivo a termo de autorização de SRTT para implementação de banda larga nas escolas públicas em substituição a metas de universalização celebrado com a SERCOMTEL, 472

[Termo Aditivo $\mathrm{n}^{\circ}$ 001/2008/SPV SERCOMTEL, de 8 de abril de 2008] troca de metas de universalização dos PSTs por instalação de, 419

[Decreto $n^{\circ}$ 6.424/2008]

\section{Posto de Trabalho}

TELEMAR NORTE LESTE S.A.

compromisso de manutenção de postos de trabalho após aquisição da BRASIL TELECOM, 471

[Ato do Conselho Diretor da ANATEL $n^{\circ} 7.828$, de 19 de dezembro de 2008]

\section{PPB}

(ver Processo Produtivo Básico)

\section{Prazo}

Classificação Indicativa

extensão do prazo para cumprimento da classificação indicativa nos fusos horários do país para 7 de abril de 2008, 423

[Portaria MJ n 36/2008]

\section{Preço Privado}

Assinatura Básica

não-incidência do ICMS sobre assinatura básica despida de franquia de utilização, 448

[STJ - RESP 754393 / DF]

\section{Preço Público e Preço Privado, 358 \\ Prefeitura}

(ver também Prefeitura)

Banda Larga

casos de liberação de licença e cadastramento de estações, 431

[Resolução da ANATEL nº 506/2008]

ilegalidade de lei municipal que institui taxa pela instalação de fios e cabos 
usados para serviços de telecomunicações, 444

[STJ - MC 13406 / SP - São Paulo]

\section{Presidência da República, 406}

Presidência da República

Empresa Brasil de Comunicação estatuto social da, $\mathbf{4 2 3}$

[Decreto ${ }^{\circ}$ 6.689/2008]

Prestador de Serviço de
Telecomunicações
(ver Operadora de Telecomunicações)
Prestadora, 441 (ver também Operadora de Telecomunicações)

[STF - RE 571572-8 / BA - Bahia]

Prestadora / Operadora (direitos e deveres), 410

Princípio da Generalidade (ver Universalização)

Princípio Regulatório

relação de princípios regulatórios de orientação da atuação da Anatel, 436

[Resolução da ANATEL nº 516/2008]

\section{Princípios Constitucionais}

Separação de Poderes

sua utilização na definição dos limites das CPIs quanto ao acesso a dados sigilosos de processo judiciais em que fora decretada interceptação telefônica, $\mathbf{4 4 2}$

[STF MS n $27483 \mathrm{RE}-\mathrm{MC} / \mathrm{DF}$ ]

\section{Procedimento de Coordenação}

exigência entre os serviços fixos e serviço fixo por satélite na faixa de $6.430 \mathrm{MHz}$ a $7.110 \mathrm{MHz}, \mathbf{4 3 0}$

[Resolução da ANATEL nº 504/2008]

\section{Processo Produtivo Básico}

(ver também Telefone Celular)

do telefone celular em tecnologia digital combinada ou não com outras tecnologias, 424-425

[Portaria Interministerial $n^{\circ} 237 / 2008$ ]

[Portaria Interministerial no $29 / 2008$ ] do telefone celular industrializado na Zona Franca de Manaus em tecnologia digital combinada ou não com outras tecnologias, 424-425

[Portaria Interministerial $n^{\circ} 23 / 2008$ ]

[Portaria Interministerial $n^{\circ} 236 / 2008$ ]

Telefone Celular, 424-425

[Portaria Interministerial $n^{\circ} 23 / 2008$ ]

[Portaria Interministerial no 236/2008]

[Portaria Interministerial $n^{\circ} 237 / 2008$ ]

[Portaria Interministerial no 29/2008]

\section{Produção Independente}

compromisso da TELEMAR/Oi de ofertar até 31 de março de 2010 no DTH e TV a Cabo um canal de conteúdo nacional de produção independente, 471

[Ato do Conselho Diretor da ANATEL

$\mathrm{n}^{\circ} 7.828$, de 19 de dezembro de 2008]

\section{Produção Nacional}

Centro Nacional de Tecnologia Eletrônica Avançada S.A atribuição de produção e comercialização de semicondutores e circuitos integrados pelo, $\mathbf{4 1 8}$

[Lei $n^{\circ} 11.759 / 2008$ ]

\section{Produto de Telecomunicação}

(ver Equipamentos de Telecomunicações)

Produtor Industrial, 413

Programa de Integração Social

vedação de seu cômputo como acréscimo tarifário arcado pelo usuário, seja expressa ou implicitamente, $\mathbf{4 4 5}$

[STJ - RESP 1053778 / RS]

\section{Progressão Funcional}

sua regulamentação para servidores do quadro efetivo das agências reguladoras, $\mathbf{4 2 1}$

[Decreto ${ }^{\circ} 6.530 / 2008$ ]

Projeção de Demanda, 436 
[Resolução da ANATEL no 516/2008] de 2008 a 2018 no STFC, SMP, TVA,

SCM e Banda Larga, 436

[Resolução da ANATEL nº 516/2008]

\section{Promoção Funcional}

sua regulamentação para servidores do quadro efetivo das agências reguladoras, $\mathbf{4 2 1}$

[Decreto $n^{\circ} 6.530 / 2008$ ]

\section{Propósito Estratégico}

(ver Planejamento Estratégico)

\section{Proselitismo}

Radiodifusão Pública vedação de proselitismo na, $\mathbf{4 1 7}$

[Lei $\mathrm{n}^{\circ} 11.652 / 2008$ ]

\section{Proteção Pública}

Regulamento sobre Canalização e Condições de Uso de Radiofrequiências na Faixa de 4,9 GHz destinação de freqüência para proteção pública e situações de calamidade, $\mathbf{4 2 7}$

[Resolução da ANATEL nº 494/2008]

PST

(ver Posto de Serviço de Telecomunicações)

Publicidade de Bens e Serviços por Telefone

Código de Defesa do Consumidor

Vedação de publicidade por fornecedor a consumidor que aguarda atendimento em ligação telefônica para ele onerosa., 418

[Lei $\mathrm{n}^{\circ}$ 11.800/2008]

\section{Pulso Telefônico, 440}

\section{(ver também Assinatura Básica)}

[Súmula do STJ n ${ }^{\circ} 356$ ]

Serviço Telefônico Fixo Comutado competência do Juizado Especial Cível estadual para julgamento de matéria de cobrança de pulsos para além da franquia, 441

[STF - RE 571572-8 / BA - Bahia] obrigatoriedade, a partir de $1^{\circ}$ de janeiro de 2006, de discriminação de pulsos excedentes e ligações de telefone fixo para celular a pedido e às custas do assinante, $\mathbf{4 4 0}$

[Súmula do STJ n ${ }^{\circ}$ 357]

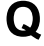

QoS

(ver Qualidade do Serviço)

Qualidade do Serviço, 366

Qualidade do Serviço

inscrição da melhoria dos níveis de qualidade percebida pelos usuários como objetivo da atualização da regulamentação a partir de 2008, 436

[Resolução da ANATEL n ${ }^{\circ}$ 516/2008]

Quanto ao Gênero, 369

Quanto ao Regime Jurídico de Prestação, 369

$\mathbf{R}$

\section{RadCom}

(ver Serviço de Radiodifusão Comunitária)

Radiação Restrita

Regulamento sobre Equipamentos de Radiocomunicação de Radiação Restrita, 431

[Resolução da ANATEL nº 506/2008]

Radio Frequency Identification Device (Sistema de Identificação por Radiofreqüiência)

condições de uso de subfaixas de radiofrequiência pelo, $\mathbf{4 3 1}$

[Resolução da ANATEL n 506/2008] sua qualificação como equipamento de radiação restrita, $\mathbf{4 3 1}$

[Resolução da ANATEL n 506/2008]

Rádio-taxi, 387

Rádio-Táxi, 439

(ver também Serviço de Radiotáxi Especializado)

(ver também Serviço de Radiotáxi Privado) 
[Resolução da ANATEL no 523/2008]

revogação da destinação das radiofreqüências de $158,71 \mathrm{MHz}$, $163,31 \mathrm{MHz}, 163,95 \mathrm{MHz}$ e 163,97 $\mathrm{MHz}$ ao serviço de, 439

[Resolução da ANATEL n 523/2008]

\section{Radioamador, 384}

\section{RADIOBRÁS}

\section{(ver também Empresa Estatal)}

Empresa Brasil de Comunicação estatuto social da, $\mathbf{4 2 3}$

[Decreto $n^{\circ}$ 6.689/2008]

Previsão de incorporação do patrimônio da RADIOBRÁS para integralização do capital da EBC., 417

[Lei $\mathrm{n}^{\circ} 11.652 / 2008$ ]

\section{Radiodifusão, 384}

\section{Radiodifusão, 425}

(ver também Radiodifusão Pública)

(ver também Sistema Brasileiro de Televisão Digital Terrestre)

[Portaria Interministerial no 236/2008]

Concessão

renovação de concessão em Brasília em 2008, 419

[Decreto/2008]

renovação de concessão em Recife em 2008, $\mathbf{4 2 0}$

[Decreto/2008]

renovação de concessão em São Paulo em 2008, 420

[Decreto/2008]

renovação de concessão no Rio de Janeiro em 2008, 420

[Decreto/2008]

Contribuição para o Fomento da

Radiodifusão Pública

instituição da, $\mathbf{4 1 7}$

[Lei n ${ }^{\circ} 11.652 / 2008$ ]

Empresa Brasil de Comunicação estatuto social da, $\mathbf{4 2 3}$

[Decreto $n^{\circ}$ 6.689/2008]

regulamento simplificado para contratação de serviços e aquisição de bens pela, $\mathbf{4 2 0}$
[Decreto $\mathrm{n}^{\circ}$ 6.505/2008]

Globo

renovação de concessão em Belo Horizonte em 2008, 419

[Decreto/2008]

Nulidade

inexigibilidade de decisão judicial para anulação de concessão de radiodifusão, inaplicável o art. 223, $\S 4^{\circ}$ da Constituição Federal, 460

[TC-027.077/2006-4]

Record

renovação de concessão no Rio de Janeiro em 2008, 421

[Decreto/2008]

Regulamento Técnico para a Prestação do Serviço de Radiodifusão Sonora em Onda Média e em Onda Tropical (faixa de 120 metros) alteração do, $\mathbf{4 3 6}$

[Resolução da ANATEL no 514/2008]

\section{Radiodifusão Comunitária, 386}

(ver Serviço de Radiodifusão

Comunitária)

Radiodifusão Pública

(ver também Radiodifusão)

Empresa Brasil de Comunicação

autorização da criação da, $\mathbf{4 1 7}$

[Lei $n^{\circ} 11.652 / 2008$ ]

estatuto social da, $\mathbf{4 2 3}$

[Decreto ${ }^{\circ}$ 6.689/2008]

regulamento simplificado para contratação de serviços e aquisição de bens pela, $\mathbf{4 2 0}$

[Decreto $n^{\circ}$ 6.505/2008]

Radiofreqüência

(ver Espectro de Radiofreqüências)

Radiogoniometria

Agência Nacional de Telecomunicações procedimentos para autorização do início de obras em áreas contíguas às estações fixas de radiogoniometria e de radiomonitoragem de responsabilidade da ANATEL, $\mathbf{4 3 4}$

[Resolução da ANATEL nº 511/2008] 


\section{Radiomonitoragem}

Agência Nacional de Telecomunicações procedimentos para autorização do início de obras em áreas contíguas às estações fixas de radiogoniometria e de radiomonitoragem de responsabilidade da ANATEL, 434

[Resolução da ANATEL n ${ }^{\circ}$ 511/2008]

\section{Raimundo Carreiro}

relator (julgado), 450, 458

Ramos Jurídicos Afins, 394

\section{Reajuste Tarifário}

(ver também Tarifa)

Norma para Estabelecimento da Metodologia Simplificada para Cálculo do Fator de Transferência X, 432

[Resolução da ANATEL n ${ }^{\circ}$ 507/2008]

\section{Receita Extraordinária (ANTT)}

Concessionária de Rodovia

captação de receitas extraordinárias por parte de, 439

[Resolução da ANTT nº 2.552/2008]

\section{Record, 421}

[Decreto/2008]

Concessão (Radiodifusão)

renovação de concessão no Rio de Janeiro em 2008, 421

[Decreto/2008]

Rede de Suporte à Banda Larga

Concessionária obrigação de universalização da rede de suporte à banda larga, $\mathbf{4 2 2}$

[Decreto $n^{\circ}$ 6.654/2008]

Rede Nacional de Pesquisa

TELEMAR NORTE LESTE S.A.

compromisso de cessão de capacidade de transmissão em fibras óticas para uso não comercial pela RNP, 471

[Ato do Conselho Diretor da ANATEL

$\mathrm{n}^{\circ} 7.828$, de 19 de dezembro de 2008]

Redes de Telecomunicações, 344

Regime de Prestação de Serviços de Telecomunicações (ver Serviços de Telecomunicações)

\section{Regime Jurídico}

Serviço Telefônico Fixo Comutado, 422

[Decreto $\mathrm{n}^{\circ}$ 6.654/2008]

Serviços de Telecomunicações, 422

[Decreto $n^{\circ}$ 6.654/2008]

\section{Regime Jurídico de Direito Privado}

Autorização

regularidade de compromisso de abrangência para garantia de acesso em municípios com até 30mil habitantes, 458

$$
\text { [TC-023.855/2007-0] }
$$

\section{Regimento Interno}

Comitê de Defesa dos Usuários de

Serviços de Telecomunicações, $\mathbf{4 2 7}$

[Resolução da ANATEL nº 496/2008]

Regulamento de Conselho de Usuários do STFC

aprovação do, $\mathbf{4 2 6}$

[Resolução da ANATEL n ${ }^{\circ}$ 490/2008]

Regulamento de Proteção e Defesa dos Direitos dos Assinantes dos Serviços de Televisão por Assinatura

alteração do, 431, 435, 437-438

[Resolução da ANATEL no 505/2008]

[Resolução da ANATEL no 513/2008]

[Resolução da ANATEL no 517/2008]

[Resolução da ANATEL n ${ }^{\circ}$ 520/2008] aprovação do, 432

[Resolução da ANATEL n ${ }^{\circ}$ 508/2008]

Regulamento de Separação e Alocação de Contas

prazo para sua apresentação por operadora de SMP com PMS, 430

[Resolução da ANATEL nº 503/2008]

Regulamento do Serviço Móvel Especializado

alteração do, $\mathbf{4 3 7}$

[Resolução da ANATEL nº 518/2008] 
Regulamento sobre Áreas Locais para o STFC

alteração do, $\mathbf{4 2 8}$

[Resolução da ANATEL no 499/2008]

Regulamento sobre Canalização e Condições de Uso da Faixa de 5 GHz, 427

[Resolução da ANATEL n ${ }^{\circ}$ 495/2008]

Regulamento sobre Canalização e Condições de Uso da Faixa de Radiofreqüências de $6.430 \mathrm{MHz}$ a 7.110MHz, 430

[Resolução da ANATEL no 504/2008]

Regulamento sobre Canalização e Condições de Uso de Radiofreqüências na Faixa de 4,9 GHz

destinação de frequiência para proteção pública e situações de calamidade, 427

[Resolução da ANATEL n ${ }^{\circ}$ 494/2008]

Regulamento sobre Canalização e Condições de Uso na faixa de Radiofrequiências de 217 MHz a 218 MHz aprovação do, 434

[Resolução da ANATEL n ${ }^{\circ}$ 510/2008]

Regulamento sobre Equipamentos de Radiocomunicação de Radiação Restrita, 431

[Resolução da ANATEL n 506/2008]

Regulamento Técnico para a Prestação do Serviço de Radiodifusão Sonora em Onda Média e em Onda Tropical (faixa de 120 metros)

alteração do, $\mathbf{4 3 6}$

[Resolução da ANATEL n ${ }^{\circ}$ 514/2008]

\section{Relações Internacionais}

Comissão Brasileira de Comunicações $\mathrm{n}^{\mathrm{o}} 1$ - Governança e Regimes Internacionais

criação da, $\mathbf{4 2 9}$
[Resolução da ANATEL no 502/2008]

Comissão Brasileira de Comunicações $\mathrm{n}^{\circ} 2$ - Radiocomunicações

criação da, $\mathbf{4 2 9}$

[Resolução da ANATEL n 502/2008]

Comissão Brasileira de Comunicações $\mathrm{n}^{\mathrm{o}} 4$ - Desenvolvimento das Telecomunicações

criação da, $\mathbf{4 2 9}$

[Resolução da ANATEL nº 502/2008]

Renovação dos Contratos de Concessão do STFC

cálculo do Fator de Transferência X, 432

[Resolução da ANATEL n ${ }^{\circ}$ 507/2008] inconsistência no estudo de situação econômico-financeira dos contratos de concessão de STFC no período de 1999 a 2004, 465

[TC-019.677/2006-2]

Reserva de Jurisdição

Interceptação de Telecomunicação

possibilidade de requisição por CPI de dados consolidados de juízos, mandados, órgãos policiais, localização e duração de interceptações telefônicas em determinado período para fins investigativos, $\mathbf{4 4 2}$

[STF MS n $27483 \mathrm{RE}-\mathrm{MC} / \mathrm{DF}$ ]

\section{RFID}

(ver Radio Frequency Identification Device (Sistema de Identificação por Radiofrequiência))

RNP

(ver Rede Nacional de Pesquisa)

Rodovia, 439

[Resolução da ANTT nº 2.552/2008]

Faixa de Domínio

cálculo do valor a ser cobrado pela ocupação de uso da, 439

[Resolução da ANTT nº 2.552/2008]

\section{Rotas de Entroncamento}

Banda Larga 
frequiências para implantação de rotas de entroncamento em distâncias superiores a $20 \mathrm{~km}, \mathbf{4 3 0}$

[Resolução da ANATEL n ${ }^{\circ}$ 504/2008]

RSAC

(ver Regulamento de Separação e Alocação de Contas)

S

SAC

(ver Serviço de Atendimento ao Consumidor)

Satélite, 350, 430

(ver também Órbita)

exigência de coordenação entre o serviço fixo e serviço fixo por satélite na faixa de $6.430 \mathrm{MHz}$ a $7.110 \mathrm{MHz}$, 430

[Resolução da ANATEL nº 504/2008]

SBTVD-T

(ver Sistema Brasileiro de Televisão Digital Terrestre)

SCM

(ver Serviço de Comunicação

Multimídia)

Secretaria de Comunicação Social

Empresa Brasil de Comunicação sua vinculação à Secretaria de Comunicação Social, $\mathbf{4 2 3}$

[Decreto $n^{\circ} 6.689 / 2008$ ]

Secundário

(ver Caráter Secundário)

Segurança Pública, 401

Semicondutor, 418

(ver também Circuito Integrado)

[Lei n ${ }^{\circ} 11.759 / 2008$ ]

Centro Nacional de Tecnologia

Eletrônica Avançada S.A

atribuição de produção e comercialização de semicondutores pelo, 418

[Lei n ${ }^{\circ} 11.759 / 2008$ ]

Separação de Poderes sua utilização na definição dos limites das CPIs quanto ao acesso a dados sigilosos de processo judiciais em que fora decretada interceptação telefônica, 442

[STF MS no $27483 \mathrm{RE}-\mathrm{MC} / \mathrm{DF}$ ]

\section{Separação Empresarial}

sua previsão como ação de curto prazo no PGR de 2008, 436

[Resolução da ANATEL nº 516/2008]

\section{Separação Estrutural}

sua previsão como ação de curto prazo no PGR de 2008, 436

[Resolução da ANATEL n ${ }^{\circ}$ 516/2008]

\section{Separação Funcional}

sua previsão como ação de curto prazo no PGR de 2008, 436

[Resolução da ANATEL nº 516/2008]

\section{SERCOMTEL}

Backhaul

termo aditivo a termo de autorização de SRTT para implementação de banda larga nas escolas públicas em substituição a metas de universalização celebrado com a SERCOMTEL, 472

[Termo Aditivo $\mathrm{n}^{\circ}$ 001/2008/SPV SERCOMTEL, de 8 de abril de 2008]

Serviço Auxiliar de Radiodifusão e Correlatos (SARC), 386

Serviço Avançado de Mensagens (SAM), 391

Serviço de Atendimento ao Consumidor

normas gerais aplicáveis ao SAC por telefone no âmbito dos fornecedores de serviços regulados pelo Poder Público federal, 421

[Decreto $\mathrm{n}^{\circ}$ 6.523/2008]

Serviço de Comunicação Multimída (SCM), 377

Serviço de Comunicação Multimídia Backhaul 
termo aditivo a termo de autorização de SCM para implementação de banda larga nas escolas públicas em substituição a metas de universalização celebrado com a BRASIL TELECOM, 471

[Termo Aditivo n ${ }^{\circ}$ 001/2008/SPV -

BRASIL TELECOM, de 8 de abril de 2008]

termo aditivo a termo de autorização de SCM para implementação de banda larga nas escolas públicas em substituição a metas de universalização celebrado com a TELEMAR, 473

[Termo Aditivo n ${ }^{\circ}$ 001/2008/SPV TELEMAR, de 8 de abril de 2008]

Espalhamento Espectral

utilização da faixa de $2.400 \mathrm{MHz}$ a $2.483,5 \mathrm{MHz}$ por tecnologia de, 428

[Resolução da ANATEL n 497/2008] Orthogonal Frequency Division Multiplexing (Multiplexação Ortogonal por Divisão de Freqüência) utilização da faixa de $2.400 \mathrm{MHz}$ a 2.483,5MHz por tecnologia de, $\mathbf{4 2 8}$

[Resolução da ANATEL n 497/2008]

Serviço de Despacho

(ver Operação Tipo Despacho)

Serviço de Despacho Internacional (ver Operação Tipo Despacho)

Serviço de Distribuição de Sinais de Televisão e de Áudio por Assinatura Via Satélite

Conteúdo Nacional

compromisso da TELEMAR/Oi de ofertar até 31 de março de 2010 no DTH e TV a Cabo um canal de conteúdo nacional de produção independente, $\mathbf{4 7 1}$

[Ato do Conselho Diretor da ANATEL

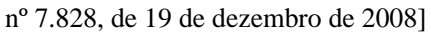

Produção Independente

compromisso da TELEMAR/Oi de ofertar até 31 de março de 2010 no
DTH e TV a Cabo um canal de conteúdo nacional de, 471

[Ato do Conselho Diretor da ANATEL

$n^{\circ} 7.828$, de 19 de dezembro de 2008]

Serviço de Exploração da Terra por Satélite, 393

Serviço de Exploração da Terra por Satélite

instituição da Infra-Estrutura Nacional de Dados Espaciais, 422

[Decreto ${ }^{\circ}$ 6.666/2008]

Serviço de Pesquisa Espacial, 392

Serviço de Radiochamada ou Serviço Limitado Privado de Radiochamada (SLPR), 388

Serviço de Radiocomunicação Aeronáutico Público Restrito (SRA), 392

Serviço de Radiodifusão Comunitária inobservância do critério da representatividade previsto na Lei 9612 para seleção de prestador do serviço de radiodifusão comunitária, 463

$$
\text { [TC-010.385/2006-7] }
$$

Serviço de Radiodifusão de Sons e Imagens

(ver Radiodifusão)

Serviço de Radiodifusão Pública (ver Radiodifusão Pública)

Serviço de Radiodifusão Sonora (ver Radiodifusão)

Serviço de Radiotáxi Especializado, 439

(ver também Rádio-Táxi)

[Resolução da ANATEL n ${ }^{\circ}$ 523/2008]

Serviço de Radiotáxi Privado, 439 (ver também Rádio-Táxi)

[Resolução da ANATEL n ${ }^{\circ}$ 523/2008]

Serviço de Rede de Transporte de Telecomunicações (SRTT), 387

Serviço de Rede de Transporte de Telecomunicações 
Backhaul

termo aditivo a termo de autorização de SRTT para implementação de banda larga nas escolas públicas em substituição a metas de universalização celebrado com a CTBC, 472

[Termo Aditivo ${ }^{\circ}$ 001/2008/SPV -

CTBC, de 8 de abril de 2008]

termo aditivo a termo de autorização de SRTT para implementação de banda larga nas escolas públicas em substituição a metas de universalização celebrado com a SERCOMTEL, 472

[Termo Aditivo ${ }^{\circ}$ 001/2008/SPV -

SERCOMTEL, de 8 de abril de 2008]

Serviço de Telefonia Rural, 394

Serviço de Telefonia Rural

uso das subfaixas de radiofrequências

de $164,60 \mathrm{MHz}$ a $165,60 \mathrm{MHz}$ e de

$169,20 \mathrm{MHz}$ a 170,20 MHz pelo, 439

[Resolução da ANATEL no 523/2008]

Serviço de Televisão por Assinatura (ver Serviços de Televisão por Assinatura)

Serviço de TV a Cabo

Conteúdo Nacional

compromisso da TELEMAR/Oi de ofertar até 31 de março de 2010 no DTH e TV a Cabo um canal de conteúdo nacional de produção independente, 471

[Ato do Conselho Diretor da ANATEL

$\mathrm{n}^{\circ} 7.828$, de 19 de dezembro de 2008]

Produção Independente

compromisso da TELEMAR/Oi de ofertar até 31 de março de 2010 no DTH e TV a Cabo um canal de conteúdo nacional de, $\mathbf{4 7 1}$

[Ato do Conselho Diretor da ANATEL

$n^{\circ} 7.828$, de 19 de dezembro de 2008]

Serviço de Valor Acrescentado

(ver Serviço de Valor Adicionado)

Serviço de Valor Acrescido (ver Serviço de Valor Adicionado)

Serviço de Valor Adicionado

(ver também INTERNET)

INTERNET

inaplicabilidade da proteção ao sigilo na relação empregado-empregador tratando-se de e-mail corporativo, 449

[TST - RR 1542/2005-055-02-40 - AI]

Serviço Especial de Boletins

Metereológicos, 390

Serviço Especial de Circuito Fechado de Televisão com utilização de Radioenlace, 391

Serviço Especial de Fins Científicos ou Experimentais, 390

Serviço Especial de Frequência Padrão, 389

Serviço Especial de Música Funcional, 390

Serviço Especial de Radiochamada (SER) - ou Serviço Móvel Especial de Radiochamada, 388

Serviço Especial de Radiorrecado, 391

Serviço Especial de Repetição de Televisão (RpTV), 387

Serviço Especial de Sinais Horários, 389

Serviço Especial para Fins Científicos ou Experimentais

Serviço de Exploração da Terra por Satélite

instituição da Infra-Estrutura Nacional de Dados Espaciais, 422

[Decreto $n^{\circ} 6.666 / 2008$ ]

Serviço Limitado, 369

Serviço Limitado de Radioestrada, 391

Serviço Limitado Especializado (SLE), 392

Serviço Limitado Especializado

destinação de subfaixas de radiofrequência entre $148 \mathrm{MHz}$ e 174 MHz para o, 439 
[Resolução da ANATEL n ${ }^{\circ}$ 523/2008]

Regulamento sobre Canalização e Condições de Uso na faixa de Radiofreqüências de $217 \mathrm{MHz}$ a 218 $\mathrm{MHz}$ aprovação do, $\mathbf{4 3 4}$

[Resolução da ANATEL n ${ }^{\circ}$ 510/2008]

Serviço Limitado Móvel Privado, 393 Serviço Limitado Privado, 369, 393 Serviço Limitado Privado

Banda Larga

liberação de licença e cadastramento de estações, 431

[Resolução da ANATEL no 506/2008]

Destinação das faixas de 143,60 a $143,65 \mathrm{MHz}$ ao SLP para uso em aplicações de pesquisa espacial no sentido espaço para Terra., 436

[Resolução da ANATEL n ${ }^{\circ}$ 515/2008] mantida a destinação de subfaixas de radiofrequência entre $148 \mathrm{MHz}$ e 174 $\mathrm{MHz}$ para o, 439

[Resolução da ANATEL no 523/2008] Regulamento sobre Canalização e Condições de Uso na faixa de Radiofreqüências de 217 MHz a 218 $\mathrm{MHz}$

aprovação do, 434

[Resolução da ANATEL n ${ }^{\circ}$ 510/2008]

\section{Serviço Móvel Especializado}

, limites à outorga de uso de radiofrequências em uma mesma área geográfica para autorizadas do SME, suas coligadas, controladas ou controladoras, 438

[Resolução da ANATEL no 519/2008]

limites à outorga de uso de radiofrequências em uma mesma área geográfica para autorizadas do SME, suas coligadas, controladas ou controladoras, 437

[Resolução da ANATEL no 518/2008]

Plano Geral de Autorizações do Serviço Móvel Especializado

alteração do, $\mathbf{4 3 8}$
[Resolução da ANATEL n 519/2008]

Regulamento do Serviço Móvel

Especializado

alteração do, $\mathbf{4 3 7}$

[Resolução da ANATEL n ${ }^{\circ}$ 518/2008]

Serviço Móvel Especializado ou Trunking ou Trunk ou Sistema Troncalizado, 388

Serviço Móvel Global por Satélite (SMGS), 389

\section{Serviço Móvel Marítimo, 389}

Serviço Móvel Marítimo

mantida a destinação das subfaixas de radiofrequência de $156,025 \mathrm{MHz}$ a $157,425 \mathrm{MHz}$, de $160,625 \mathrm{MHz}$ a $160,875 \mathrm{MHz}$, de $160,925 \mathrm{MHz}$ a $160,975 \mathrm{MHz}$ e de $161,475 \mathrm{MHz}$ a 162,025 MHz, 439

[Resolução da ANATEL n ${ }^{\circ}$ 523/2008]

\section{Serviço Móvel Pessoal (SMP), 374}

Serviço Móvel Pessoal

Central de Intermediação de Comunicação Telefônica

exigência de regulamentação específica, 426

[Resolução da ANATEL no 491/ 2008]

Procedimentos e critérios para atendimento de usuários com deficiência auditiva ou da fala no âmbito do STFC e SMP., 433

[Resolução da ANATEL nº 509/2008]

Compromisso de Abrangência

regularidade de compromisso de abrangência para garantia de acesso em municípios com até 30mil habitantes, $\mathbf{4 5 8}$

[TC-023.855/2007-0]

destinação de faixas de radiofreqüência ao, 429

[Resolução da ANATEL nº 501/2008]

Documento de Separação e Alocação de Contas

prazo para sua apresentação por operadora de SMP com PMS, 430

[Resolução da ANATEL n ${ }^{\circ}$ 503/2008] 
Grupo

previsão de equilíbrio entre grupos para ampliação da competição, 436

[Resolução da ANATEL nº 516/2008]

ICMS

não-incidência sobre habilitação de aparelho móvel celular, 440

[Súmula do $\left.\mathrm{STJ}^{\circ}{ }^{\circ} 350\right]$

International Mobile

Telecommunications-2000

regularidade de compromisso de abrangência para garantia de acesso em municípios com até 30mil habitantes, $\mathbf{4 5 8}$

[TC-023.855/2007-0]

Regulamento do Serviço Móvel Pessoal alteração do, 426

[Resolução da ANATEL n ${ }^{\circ}$ 491/ 2008]

Telefone Fixo

processo produtivo básico, $\mathbf{4 2 4 - 4 2 5}$

[Portaria Interministerial $n^{\circ} 23 / 2008$ ]

[Portaria Interministerial n ${ }^{\circ}$ 236/2008]

[Portaria Interministerial n ${ }^{\circ} 237 / 2008$ ]

[Portaria Interministerial no 29/2008]

\section{Serviço Rádio do Cidadão, 384}

Serviço Telefônico Fixo Comutado

(STFC), 369

Serviço Telefônico Fixo Comutado, 369

Assinatura Básica

legitimidade de cobrança da assinatura básica nos serviços de telefonia fixa, 440

[Súmula do $\mathrm{STJ}^{\circ}{ }^{\circ} 356$ ]

Central de Intermediação de

Comunicação Telefônica

Procedimentos e critérios para atendimento de usuários com deficiência auditiva ou da fala no âmbito do STFC e SMP., 433

[Resolução da ANATEL nº 509/2008]

Concessão

adiamento da alteração qüinqüenal de 2009, 439

[Resolução da ANATEL no 524/2008] improcedência de representação efetuada contra a aquisição do controle acionário da Brasil Telecom pela Telemar/Oi com recursos do BNDES, 468

[TC-010.681/2008-0]

condições de uso da faixa de $57 \mathrm{GHz}$ a $64 \mathrm{GHz}$ por aplicações do, $\mathbf{4 3 1}$

[Resolução da ANATEL n 506/2008] Grupo

previsão de equilíbrio entre grupos para ampliação da competição, 436

[Resolução da ANATEL n ${ }^{\circ}$ 516/2008] ICMS

não-incidência sobre a assinatura despida de franquia de utilização, $\mathbf{4 4 8}$

[STJ - RESP 754393 / DF]

mantida a destinação das subfaixas de radiofrequência de $164,60 \mathrm{MHz}$ a $165,60 \mathrm{MHz}$ e de $169,20 \mathrm{MHz}$ a $170,20 \mathrm{MHz}$ para o, 439

[Resolução da ANATEL no 523/2008] obrigatoriedade, a partir de $1^{\circ}$ de janeiro de 2006, de discriminação de pulsos excedentes e ligações de telefone fixo para celular a pedido e às custas do assinante, 440

[Súmula do $\mathrm{STJ} \mathrm{n}^{\circ}$ 357]

Plano Geral de Metas de Universalização do STFC no Regime Público

aprovação de celebração de termos aditivos aos termos de autorização de SCM e SRTT das concessionárias de STFC para instalação de banda larga em escolas públicas em troca de metas de universalização de PSTs, 470

[Ato do Conselho Diretor da ANATEL $\mathrm{n}^{\circ} 1.933$, de 7 de abril de 2008]

termo aditivo a termo de autorização de SCM para implementação de banda larga nas escolas públicas em substituição a metas de universalização celebrado com a BRASIL TELECOM, 471 
[Termo Aditivo ${ }^{\circ}$ 001/2008/SPV BRASIL TELECOM, de 8 de abril de 2008]

termo aditivo a termo de autorização de SCM para implementação de banda larga nas escolas públicas em substituição a metas de universalização celebrado com a TELEMAR, 473

[Termo Aditivo ${ }^{\circ}$ 001/2008/SPV -

TELEMAR, de 8 de abril de 2008]

termo aditivo a termo de autorização de SRTT para implementação de banda larga nas escolas públicas em substituição a metas de universalização celebrado com a CTBC, 472

[Termo Aditivo ${ }^{\circ}$ 001/2008/SPV -

CTBC, de 8 de abril de 2008]

termo aditivo a termo de autorização de SRTT para implementação de banda larga nas escolas públicas em substituição a metas de universalização celebrado com a SERCOMTEL, 472

[Termo Aditivo ${ }^{\circ}$ 001/2008/SPV -

SERCOMTEL, de 8 de abril de 2008] troca de metas de universalização dos PSTs por instalação de, 419

[Decreto ${ }^{\circ}$ 6.424/2008]

Plano Geral de Outorgas, 422

[Decreto $n^{\circ} 6.654 / 2008$ ]

Reajuste Tarifário cálculo do Fator de Transferência X, 432

[Resolução da ANATEL nº 507/2008]

Rede de Suporte à Banda Larga

obrigação de universalização da rede de suporte à banda larga, $\mathbf{4 2 2}$

[Decreto ${ }^{\circ} 6.654 / 2008$ ]

Regime Jurídico, 422

[Decreto ${ }^{\circ}$ 6.654/2008]

Renovação dos Contratos de Concessão do STFC inconsistência no estudo de situação econômico-financeira dos contratos de concessão de STFC no período de 1999 a 2004, 465

[TC-019.677/2006-2]

Serviços Científicos, 392

Serviços de Telecomunicações

Plano Geral de Outorgas, 422

[Decreto $\left.{ }^{\circ} 6.654 / 2008\right]$

Regime Jurídico, 422

[Decreto ${ }^{\circ} 6.654 / 2008$ ]

Serviços de Televisão por Assinatura

Plano Geral de Metas de Qualidade

alteração do, $\mathbf{4 2 7}$

[Resolução da ANATEL n ${ }^{\circ}$ 493/2008]

Serviços no Setor de

Telecomunicações, 369

Servidor Público

(Direito

Administrativo), 396

Servidor Público

regulamentação da promoção e progressão funcional para servidores do quadro efetivo das agências reguladoras, $\mathbf{4 2 1}$

[Decreto $\mathrm{n}^{\circ}$ 6.530/2008]

\section{Setor Especial Aglomerado \\ Subnormal}

sua utilização na definição de área de prestação da televisão por assinatura com infra-estrutura urbana deficiente, 427

[Resolução da ANATEL nº 493/2008]

SGB

(ver Sistema Geoestarcionário Brasileiro)

\section{Sigilo}

(ver também Interceptação de Telecomunicação)

Comissão Parlamentar de Inquérito vedação à CPI de obtenção de dados que possibilitem a identificação dos processos, das partes, dos terminais e números telefônicos interceptados e das peças processuais de interceptação telefônica sigilosa Supremo Tribunal 
Federal, poderes das CPIs de requisição de dados consolidados de juízos, mandados, órgãos policiais, localização e duração de interceptações telefônicas em determinado período para fins investigativos, $\mathbf{4 4 2}$

[STF MS no $27483 \mathrm{RE}-\mathrm{MC} / \mathrm{DF}$ ]

E-mail Corporativo

inaplicabilidade da proteção ao sigilo na relação empregado-empregador tratando-se de e-mail corporativo, 449

[TST - RR 1542/2005-055-02-40 - AI]

Interceptação de Telecomunicação

inadmissibilidade de provas derivadas de interceptação telefônica por prazo superior ao permitido em lei e ausente exaustiva fundamentação judicial das sucessivas renovações, $\mathbf{4 4 3}$

[STJ - HC 76686 / PR - Paraná]

Militares

destinação de faixas de radiofreqüências para fins exclusivamente militares, 439

[Resolução da ANATEL nº 522/2008]

Sigilo em Telecomunicações, 367

Sistema Analógico

operação em caráter secundário na faixa de $6.430 \mathrm{MHz}$ a $7.110 \mathrm{MHz}$ até $31 \mathrm{de}$ dezembro de 2014, 430

[Resolução da ANATEL no 504/2008]

\section{Sistema Brasileiro de Televisão \\ Digital Terrestre, 425 \\ (ver também Radiodifusão) \\ (ver também TV Digital)}

[Portaria Interministerial no 236/2008]

Norma para Certificação e

Homologação de Transmissores e

Retransmissores para o Sistema Brasileiro de Televisão Digital Terrestre, 428

[Resolução da ANATEL nº 498/2008]

Sistema Geoestarcionário Brasileiro compromisso da TELEMAR/Oi em propor memorando de entendimento sobre seu papel no, 471
[Ato do Conselho Diretor da ANATEL $n^{\circ} 7.828$, de 19 de dezembro de 2008]

Sistema Ponto-Multiponto

certificação e homologação para serviço fixo em faixas acima de $1 \mathrm{GHz}, \mathbf{4 2 6}$

[Resolução da ANATEL no 492/2008]

\section{Sistema TELEBRÁS}

(ver Telecomunicações Brasileiras S.A.)

SLE

(ver Serviço Limitado Especializado)

SME

(ver Serviço Móvel Especializado)

SMP

(ver Serviço Móvel Pessoal)

Solicitação de Assentimento

Radiogoniometria requisitos da solicitação de assentimento à ANATEL para obras em áreas contíguas às estações de, $\mathbf{4 3 4}$

[Resolução da ANATEL nº 511/2008]

Radiomonitoragem

requisitos da solicitação de assentimento à ANATEL para obras em áreas contíguas às estações de, $\mathbf{4 3 4}$

[Resolução da ANATEL nº 511/2008]

\section{SRTT}

(ver Serviço de Rede de Transporte de Telecomunicações)

STF, 406

(ver Supremo Tribunal Federal)

STFC

(ver Serviço Telefônico Fixo Comutado)

STJ, 407

(ver Superior Tribunal de Justiça)

Súmula (Superior Tribunal de Justiça)

ICMS

não-incidência sobre habilitação de aparelho móvel celular, 440

[Súmula do STJ no 350]

Súmula (Superior Tribunal de Justiça) 
Assinatura Básica

legitimidade de cobrança da assinatura básica nos serviços de telefonia fixa, 440

[Súmula do $\mathrm{STJ}^{\circ}$ 356]

Fatura Telefônica

obrigatoriedade, a partir de $1^{\circ}$ de janeiro de 2006, de discriminação de pulsos excedentes e ligações de telefone fixo para celular a pedido e às custas do assinante, 440

[Súmula do $\mathrm{STJ}^{\circ}$ 357]

\section{Superior Tribunal de Justiça}

HC76686/PR

inadmissibilidade de provas derivadas de interceptação telefônica por prazo superior ao permitido em lei e ausente exaustiva fundamentação judicial das sucessivas renovações, $\mathbf{4 4 3}$

[STJ - HC 76686 / PR - Paraná]

MC13406/SP

ilegalidade de lei municipal que institui taxa pela instalação de fios e cabos usados para serviços de telecomunicações, 444

[STJ - MC 13406 / SP - São Paulo]

REsp754393/DF

não-incidência de ICMS sobre assinatura básica de autorizada de STFC despida de franquia de utilização, 448

[STJ - RESP 754393 / DF]

Súmula 350

não-incidência de ICMS sobre habilitação de aparelho móvel celular, 440

[Súmula do STJ no 350]

Súmula 356

legitimidade de cobrança da assinatura básica nos serviços de telefonia fixa, 440

[Súmula do $\mathrm{STJ}^{\circ}{ }^{\circ}$ 356]

Súmula 357

obrigatoriedade, a partir de $1^{\circ}$ de janeiro de 2006, de discriminação de pulsos excedentes e ligações de telefone fixo para celular a pedido e às custas do assinante, $\mathbf{4 4 0}$
[Súmula do STJ no 357]

\section{Supremo Tribunal Federal}

Distribuição obrigatória de canal de programação do Poder Executivo por prestadoras de serviços de TV por assinatura., 417

[Lei $n^{\circ} 11.652 / 2008$ ]

SVA

(ver Serviço de Valor Adicionado)

T

\section{Tarifa, 440}

(ver também Assinatura Básica) (ver também Reajuste Tarifário)

[Súmula do STJ n ${ }^{\circ}$ 356]

Direito à Informação sua violação quando embutido PIS e COFINS na tarifa de telefonia, $\mathbf{4 4 5}$

ICMS

[STJ - RESP 1053778 / RS]

ilegitimidade passiva ad causam de concessionária de serviço público de telecomunicações para responder pela devolução de valores de, 447

[STJ - RESP 938827 / DF]

Reajuste Tarifário

cálculo do Fator de Transferência X, 432

[Resolução da ANATEL n 507/2008]

\section{Tarifa Básica, 440}

(ver também Assinatura Básica)

[Súmula do STJ no 356]

\section{Taxa de Fiscalização da Instalação}

Banda Larga

casos de isenção, $\mathbf{4 3 1}$

[Resolução da ANATEL n ${ }^{\circ}$ 506/2008]

Taxa de Fiscalização de Funcionamento

(ver Taxa de Fiscalização do Funcionamento)

Taxa de Fiscalização de Instalação

(ver Taxa de Fiscalização da Instalação) 
Taxa de Fiscalização do Funcionamento

cancelamento dos créditos do não pagamento da TFF, $\mathbf{4 5 8}$

[TC-010.978/2008-1]

\section{TCU}

(ver Tribunal de Contas da União)

TELEBRÁS

(ver Telecomunicações Brasileiras

\section{S.A.)}

Telecentro Comunitário, 363

Telecentro Comunitário

Inclusão Digital

capacitação de representantes municipais para uso de telecentros comunitários, $\mathbf{4 2 3}$

[Portaria $\left.\mathrm{MC} \mathrm{n}^{\circ} 711 / 2008\right]$

convergência de ações e produção colaborativa de conteúdo às iniciativas de, 424

[Portaria $\left.\mathrm{MC} \mathrm{n}^{\circ} 825 / 2008\right]$

Telecomando, 400

\section{Telecomunicações Brasileiras S.A.}

Regime Jurídico

dos serviços de telecomunicações pósdesestatização do Sistema TELEBRÁS, 422

[Decreto $n^{\circ} 6.654 / 2008$ ]

\section{Telecomunicações no Cenário \\ Internacional, $\mathbf{4 0 2}$ \\ Telefone Celular, 425 \\ (ver também Processo Produtivo \\ Básico) \\ (ver também Telefone Fixo)}

[Portaria Interministerial $n^{\circ}$ 236/2008]

[Portaria Interministerial no 237/2008]

Imposto sobre Produtos Industrializados isenção ou redução do IPI de terminais portáteis de telefonia celular devido a investimento em atividades de pesquisa e desenvolvimento, $\mathbf{4 1 8}$

[Decreto ${ }^{\circ}$ 6.405/2008]

Processo Produtivo Básico, 424-425
[Portaria Interministerial $n^{\circ}$ 23/2008]

[Portaria Interministerial $n^{\circ}$ 236/2008]

[Portaria Interministerial no 237/2008]

[Portaria Interministerial no 29/2008]

\section{Telefone Fixo, 418}

(ver também Equipamentos de Telecomunicações)

(ver também Telefone Celular)

[Decreto ${ }^{\circ}$ 6.405/2008]

Telefone Celular

não-incidência de ICMS sobre a habilitação de Tributo, 440

[Súmula do $\mathrm{STJ}^{\circ}{ }^{\circ} 350$ ]

processo produtivo básico para o, $\mathbf{4 2 4}$ 425

[Portaria Interministerial $n^{\circ} 23 / 2008$ ]

[Portaria Interministerial no 236/2008]

[Portaria Interministerial n ${ }^{\circ} 237 / 2008$ ]

[Portaria Interministerial no $29 / 2008$ ]

Telefone Fixo

isenção ou redução do IPI de aparelhos telefônicos por fio com unidade auscultador-microfone sem fio que incorporem controle por técnicas digitais, 418

[Decreto $n^{\circ}$ 6.405/2008]

Telefone Sem Cordão

sua qualificação como equipamento de radiocomunicação de radiação restrita, 431

[Resolução da ANATEL n 506/2008]

\section{Telefone Sem Cordão}

sua qualificação como equipamento de radiocomunicação de radiação restrita, 431

[Resolução da ANATEL n ${ }^{\circ}$ 506/2008]

\section{Telefone Sem Fio}

(ver Telefone Sem Cordão)

TELEMAR NORTE LESTE S.A., 422

(ver também Grupo TELEMAR)

[Decreto ${ }^{\circ} 6.654 / 2008$ ] 
anuência prévia e condicionamentos para aquisição da BRASIL TELECOM pela TELEMAR/Oi, 471

[Ato do Conselho Diretor da ANATEL

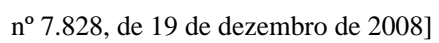
improcedência de representação efetuada contra a aquisição do controle acionário da Brasil Telecom pela Telemar/Oi com recursos do BNDES, 468

[TC-010.681/2008-0]

Plano Geral de Outorgas

novo PGO que eliminou obstáculo jurídico à aquisição da Brasil Telecom pela TELEMAR/Oi, $\mathbf{4 2 2}$

[Decreto no 6.654/2008]

\section{Telemedição Biomédica}

Dispositivo de Telemedição Biomédica sua qualificação como equipamento de radiação restrita, 431

[Resolução da ANATEL n 506/2008]

\section{Telemetria, 400}

Televisão Digital

(ver TV Digital)

\section{Televisão por Assinatura (Gênero)}

Câmara dos Deputados

Distribuição obrigatória de canal de programação do Poder Executivo por prestadoras de serviços de TV por assinatura., 417

[Lei $\mathrm{n}^{\circ} 11.652 / 2008$ ]

Canal de

Sua previsão como dever de prestadoras de serviços de TV por assinatura., $\mathbf{4 1 7}$

[Lei ${ }^{\circ} 11.652 / 2008$ ]

Direito

alteração do regulamento de proteção dos direitos dos assinantes de Televisão por Assinatura, 431, 437438

[Resolução da ANATEL no 505/2008]

[Resolução da ANATEL n ${ }^{\circ}$ 517/2008]

[Resolução da ANATEL no 520/2008]
Alteração do regulamento de proteção dos direitos dos assinantes de Televisão por Assinatura, 432, 435

[Resolução da ANATEL n ${ }^{\circ}$ 508/2008] Grupo

[Resolução da ANATEL n ${ }^{\circ}$ 513/2008]

previsão de equilíbrio entre grupos para ampliação da competição, 436

[Resolução da ANATEL nº 516/2008] inscrição de sua expansão para distribuição de conteúdo como objetivo da atualização da regulamentação a partir de 2008, 436

[Resolução da ANATEL nº 516/2008]

Poder Executivo

Distribuição obrigatória de canal de programação do Poder Executivo por prestadoras de serviços de TV por assinatura., 417

[Lei $\left.n^{\circ} 11.652 / 2008\right]$

Ponto-Extra (Serviços de Televisão por Assinatura)

suspensão da eficácia dos dispositivos pertinentes do regulamento de proteção dos direitos dos assinantes de Televisão por Assinatura, 431, 437-438

[Resolução da ANATEL n ${ }^{\circ}$ 505/2008]

[Resolução da ANATEL no 517/2008]

[Resolução da ANATEL n ${ }^{\circ}$ 520/2008]

Suspensão da eficácia dos dispositivos pertinentes do regulamento de proteção dos direitos dos assinantes de Televisão por Assinatura, 432, 435

[Resolução da ANATEL no 508/2008]

[Resolução da ANATEL nº 513/2008]

Senado Federal

Distribuição obrigatória de canal de programação do Poder Executivo por prestadoras de serviços de TV por assinatura., 417

[Lei ${ }^{\circ}$ 11.652/2008]

Setor Especial Aglomerado Subnormal 
sua utilização na definição de área de prestação da televisão por assinatura com infra-estrutura urbana deficiente, 427

[Resolução da ANATEL no 493/2008]

Supremo Tribunal Federal

Distribuição obrigatória de canal de programação do Poder Executivo por prestadoras de serviços de TV por assinatura., 417

[Lei ${ }^{\circ} 11.652 / 2008$ ]

Terminais, 346

Terminal Portátil de Telefonia

Celular

(ver Telefone Celular)

TFF

(ver Taxa de Fiscalização do

Funcionamento)

TFI

(ver Taxa de Fiscalização da

Instalação)

Tipificação

(ver Crime)

TJs, 409

Transparência

da relação usuário-prestadora como propósito estratégico da atualização da regulamentação a partir de 2008 , 436

[Resolução da ANATEL nº 516/2008]

\section{Tribunal de Contas da União, 404}

Tribunal de Contas da União

Fundo para o Desenvolvimento

Tecnológico das Telecomunicações

ausência de metas para utilização dos recursos do FUNTTEL, 450

[TC-002.660/2007-8]

improcedência de representação efetuada contra a aquisição do controle acionário da Brasil Telecom pela Telemar/Oi com recursos do BNDES, 468

[TC-010.681/2008-0]

Radiodifusão inexigibilidade de decisão judicial para anulação de concessão de radiodifusão, inaplicável o art. 223, $\S 4^{\circ}$ da Constituição Federal, 460

[TC-027.077/2006-4]

Serviço de Radiodifusão Comunitária inobservância do critério da representatividade previsto na Lei 9612 para seleção de prestador do serviço de radiodifusão comunitária, 463

[TC-010.385/2006-7]

Serviço Móvel Pessoal

, regularidade de compromisso de abrangência para garantia de acesso em municípios com até 30mil habitantes, $\mathbf{4 5 8}$

[TC-023.855/2007-0]

Serviço Telefônico Fixo Comutado

inconsistência no estudo de situação econômico-financeira dos contratos de concessão de STFC no período de 1999 a 2004, 465

[TC-019.677/2006-2]

Taxa de Fiscalização do Funcionamento cancelamento dos créditos do não pagamento da TFF, 458

$$
\text { [TC-010.978/2008-1] }
$$

\section{Tribunal Superior do Trabalho}

licitude de provas oriundas de acesso não-autorizado a e-mail corporativo de empregado por seu empregador, 449

[TST - RR 1542/2005-055-02-40 - AI]

Tributação no Setor de Telecomunicações, 353

\section{Tributo}

Contribuição para Financiamento da Seguridade Social

vedação de seu cômputo como acréscimo tarifário arcado pelo usuário, seja expressa ou implicitamente, 445

[STJ - RESP 1053778 / RS]

ICMS

ilegitimidade passiva ad causam de concessionária de serviço público de 
telecomunicações para responder pela devolução de valores de, $\mathbf{4 4 7}$

[STJ - RESP 938827 / DF]

Programa de Integração Social

vedação de seu cômputo como acréscimo tarifário arcado pelo usuário, seja expressa ou implicitamente, 445

[STJ - RESP 1053778 / RS]

\section{Trunking}

(ver Serviço Móvel Especializado)

TST, 409

(ver Tribunal Superior do Trabalho)

TV a Cabo, 379

TV Digital, 425

(ver também GINGA)

(ver também Sistema Brasileiro de Televisão Digital Terrestre)

[Portaria Interministerial no 236/2008]

Middleware

dever de produção de ao menos $5 \%$ do total de aparelhos celulares incentivados com capacidade de recepção da TV digital aberta compatível com o middleware GINGA-NCL a partir de $1^{\circ}$ de janeiro de 2010, 425

[Portaria Interministerial no 236/2008]

[Portaria Interministerial no 237/2008]

Norma para Certificação e

Homologação de Transmissores e

Retransmissores para o Sistema Brasileiro de Televisão Digital Terrestre, 428

[Resolução da ANATEL nº 498/2008]

TV Globo

(ver Globo)

TV Móvel

GINGA

do telefone celular em tecnologia digital combinada ou não com outras tecnologias, $\mathbf{4 2 5}$

[Portaria Interministerial no 237/2008] meta de compatibilidade $5 \%$ de aparelhos celulares incentivados a partir de $1^{\circ}$ de janeiro de 2010 com o SBTVD e o, $\mathbf{4 2 5}$

[Portaria Interministerial n ${ }^{\circ} 236 / 2008$ ]

TV por Assinatura

(ver Televisão por Assinatura (Gênero))

TVA (Serviço Especial de TV por Assinatura), 380

U

UAC

(ver Unidade de Atendimento de Cooperativa)

Ubiratan Aguiar (ver AGUIAR, Ubiratan)

UIT

(ver União Internacional de Telecomunicações (Union Internationaledes Télécommunications / Unión In t e r n a c i o a l d e Telecommunicaciones))

União Internacional de Telecomunicações (Union Internationale des Télécommunications / Unión Int e r n a c i o n a l d e Telecommunicaciones)

International Mobile

Telecommunications-2000

destinação de faixas de radiofrequiência para serviços móveis que sigam as especificações, 429

[Resolução da ANATEL n ${ }^{\circ}$ 501/2008]

Unidade de Atendimento de Cooperativa

Posto de Serviço de Telecomunicações aprovação de celebração de termos aditivos aos termos de autorização de SCM e SRTT das concessionárias de STFC para instalação de banda larga em escolas públicas em troca de metas de universalização de PSTs, 470 
[Ato do Conselho Diretor da ANATEL

$\mathrm{n}^{\mathrm{o}} 1.933$, de 7 de abril de 2008]

metas de instalação de, $\mathbf{4 1 9}$

[Decreto $n^{\circ} 6.424 / 2008$ ]

termo aditivo a termo de autorização de SCM para implementação de banda larga nas escolas públicas em substituição a metas de universalização celebrado com a BRASIL TELECOM, 471

[Termo Aditivo n ${ }^{\circ}$ 001/2008/SPV -

BRASIL TELECOM, de 8 de abril de 2008]

termo aditivo a termo de autorização de SCM para implementação de banda larga nas escolas públicas em substituição a metas de universalização celebrado com a TELEMAR, 473

[Termo Aditivo ${ }^{\circ}$ 001/2008/SPV TELEMAR, de 8 de abril de 2008] termo aditivo a termo de autorização de SRTT para implementação de banda larga nas escolas públicas em substituição a metas de universalização celebrado com a CTBC, 472

[Termo Aditivo n ${ }^{\circ}$ 001/2008/SPV CTBC, de 8 de abril de 2008]

termo aditivo a termo de autorização de SRTT para implementação de banda larga nas escolas públicas em substituição a metas de universalização celebrado com a SERCOMTEL, 472

[Termo Aditivo ${ }^{\circ}$ 001/2008/SPV SERCOMTEL, de 8 de abril de 2008]

\section{Universalização, 362}

\section{Universalização}

(ver também Plano Geral de Metas de Universalização do STFC no Regime Público)

Backhaul

aprovação de celebração de termos aditivos aos termos de autorização de SCM e SRTT das concessionárias de
STFC para instalação de banda larga em escolas públicas em troca de metas de universalização de PSTs, 470

[Ato do Conselho Diretor da ANATEL $\mathrm{n}^{\circ} 1.933$, de 7 de abril de 2008] termo aditivo a termo de autorização de SCM para implementação de banda larga nas escolas públicas em substituição a metas de universalização celebrado com a BRASIL TELECOM, 471

[Termo Aditivo $\mathrm{n}^{\circ}$ 001/2008/SPV BRASIL TELECOM, de 8 de abril de 2008]

termo aditivo a termo de autorização de SCM para implementação de banda larga nas escolas públicas em substituição a metas de universalização celebrado com a TELEMAR, 473

[Termo Aditivo $n^{\circ}$ 001/2008/SPV TELEMAR, de 8 de abril de 2008] termo aditivo a termo de autorização de SRTT para implementação de banda larga nas escolas públicas em substituição a metas de universalização celebrado com a CTBC, 472

[Termo Aditivo $n^{\circ}$ 001/2008/SPV CTBC, de 8 de abril de 2008] termo aditivo a termo de autorização de SRTT para implementação de banda larga nas escolas públicas em substituição a metas de universalização celebrado com a SERCOMTEL, 472

[Termo Aditivo $\mathrm{n}^{\mathrm{o}}$ 001/2008/SPV SERCOMTEL, de 8 de abril de 2008] troca de metas de universalização dos PSTs por instalação de, 419

[Decreto $n^{\circ}$ 6.424/2008]

Inclusão Digital

capacitação de representantes municipais para uso de telecentros comunitários, $\mathbf{4 2 3}$

[Portaria MC n $\left.{ }^{\circ} 711 / 2008\right]$ 
convergência de ações e produção colaborativa de conteúdo às iniciativas de, 424

[Portaria $\mathrm{MC} \mathrm{n}^{\circ} 825 / 2008$ ]

Plano Geral de Metas de Universalização do STFC no Regime

Público

aprovação de celebração de termos aditivos aos termos de autorização de SCM e SRTT das concessionárias de STFC para instalação de banda larga em escolas públicas em troca de metas de universalização de PSTs, 470

[Ato do Conselho Diretor da ANATEL $\mathrm{n}^{\circ} 1.933$, de 7 de abril de 2008]

termo aditivo a termo de autorização de SCM para implementação de banda larga nas escolas públicas em substituição a metas de universalização celebrado com a BRASIL TELECOM, 471

[Termo Aditivo n ${ }^{\circ}$ 001/2008/SPV -

BRASIL TELECOM, de 8 de abril de 2008]

termo aditivo a termo de autorização de SCM para implementação de banda larga nas escolas públicas em substituição a metas de universalização celebrado com a TELEMAR, 473

[Termo Aditivo ${ }^{\circ}$ 001/2008/SPV -

TELEMAR, de 8 de abril de 2008]

termo aditivo a termo de autorização de SRTT para implementação de banda larga nas escolas públicas em substituição a metas de universalização celebrado com a CTBC, 472

[Termo Aditivo ${ }^{\circ}$ 001/2008/SPV CTBC, de 8 de abril de 2008]

termo aditivo a termo de autorização de SRTT para implementação de banda larga nas escolas públicas em substituição a metas de universalização celebrado com a SERCOMTEL, 472
[Termo Aditivo $\mathrm{n}^{\mathrm{o}}$ 001/2008/SPV SERCOMTEL, de 8 de abril de 2008] troca de metas de universalização dos PSTs por instalação de, $\mathbf{4 1 9}$

[Decreto $n^{\circ}$ 6.424/2008]

Usuário (Serviço Telefônico Fixo Comutado)

Conselho de Usuários aprovação do regulamento de, $\mathbf{4 2 6}$

[Resolução da ANATEL nº 490/2008]

Regulamento de Conselho de Usuários do STFC

aprovação do, $\mathbf{4 2 6}$

[Resolução da ANATEL nº 490/2008]

\section{Usuário}

(ver também Assinante)

(ver também Consumidor)

Assinatura Básica

competência do Juizado Especial Cível estadual para julgamento de matéria de cobrança de pulsos para além da franquia, 441

[STF - RE 571572-8 / BA - Bahia]

incidência de ICMS sobre assinatura básica que contenha franquia de utilização, 448

[STJ - RESP 754393 / DF]

legitimidade de cobrança da assinatura básica nos serviços de telefonia fixa, 440

[Súmula do $\mathrm{STJ} \mathrm{n}^{\circ}$ 356]

Código de Defesa do Consumidor normas gerais aplicáveis ao SAC por telefone no âmbito dos fornecedores de serviços regulados pelo Poder Público federal, 421

[Decreto $n^{\circ}$ 6.523/2008]

Vedação de publicidade por fornecedor a consumidor que aguarda atendimento em ligação telefônica para ele onerosa., 418

[Lei ${ }^{\circ}$ 11.800/2008]

Comitê de Defesa dos Usuários de Serviços de Telecomunicações criação e aprovação do Regimento Interno do, $\mathbf{4 2 7}$ 
[Resolução da ANATEL n ${ }^{\circ}$ 496/2008]

Conselho de Usuários

aprovação do regulamento de, $\mathbf{4 2 6}$

[Resolução da ANATEL n 490/2008]

Contribuição para Financiamento da Seguridade Social

, vedação de seu cômputo como acréscimo tarifário arcado pelo usuário, seja expressa ou implicitamente, 445

[STJ - RESP 1053778 / RS]

Direito

ao não pagamento de PIS e COFINS embutidos na tarifa de telefonia, 445

[STJ - RESP 1053778 / RS]

Direito à Informação

obrigatoriedade, a partir de $1^{\circ}$ de janeiro de 2006, de discriminação de pulsos excedentes e ligações de telefone fixo para celular a pedido e às custas do assinante, 440

[Súmula do $\mathrm{STJ}^{\circ}{ }^{\circ}$ 357]

ICMS

ilegitimidade passiva ad causam de concessionária de serviço público de telecomunicações para responder pela devolução de valores de, $\mathbf{4 4 7}$

[STJ - RESP 938827 / DF]

Plano Geral de Metas de Qualidade para os serviços de televisão por assinatura, $\mathbf{4 2 7}$

[Resolução da ANATEL n 493/2008]

Portador de deficiência auditiva ou da fala

Dever de atendimento qualificado do STFC para intermediação de comunicação telefônica entre pessoas com deficiência auditiva ou da fala., 433

[Resolução da ANATEL nº 509/2008]

Programa de Integração Social

vedação de seu cômputo como acréscimo tarifário arcado pelo usuário, seja expressa ou implicitamente, $\mathbf{4 4 5}$

[STJ - RESP 1053778 / RS]

Serviço de Atendimento ao Consumidor normas gerais aplicáveis ao SAC por telefone no âmbito dos fornecedores de serviços regulados pelo Poder Público federal, 421

[Decreto $n^{\circ} 6.523 / 2008$ ]

Serviço Telefônico Fixo Comutado obrigatoriedade, a partir de $1^{\circ}$ de janeiro de 2006, de discriminação de pulsos excedentes e ligações de telefone fixo para celular a pedido e às custas do assinante, 440

[Súmula do $\mathrm{STJ}^{\circ}{ }^{\circ}$ 357]

Usuário / Consumidor (direitos e deveres), 413

V

\section{Valor Adicionado}

(ver Serviço de Valor Adicionado)

Valor de Remuneração de Uso de Rede do SMP

sua fixação a partir de 2010 pela ANATEL para operadoras em Grupo de PMS, 430

[Resolução da ANATEL nº 503/2008]

Venda por Telefone

Código de Defesa do Consumidor

Vedação de publicidade por fornecedor a consumidor que aguarda atendimento em ligação telefônica para ele onerosa., 418

[Lei ${ }^{\circ} 11.800 / 2008$ ]

VU-M

(ver Valor de Remuneração de Uso de Rede do SMP)

W

WIMAX

(ver Worldwide Interoperability for Microwave Access)

Worldwide Interoperability for

Microwave Access

restrição de mobilidade do, $\mathbf{4 2 6}$

[Resolução da ANATEL n ${ }^{\circ}$ 492/2008] 
Z

\section{Zona Franca de Manaus}

Processo Produtivo Básico

do telefone celular industrializado na Zona Franca de Manaus em tecnologia digital combinada ou não com outras tecnologias, 424-425

[Portaria Interministerial $n^{\circ} 23 / 2008$ ]

[Portaria Interministerial no 236/2008]

\section{Zona Rural, 363}

\section{Zona Rural}

inscrição da criação e oferta de serviços a preços módicos em áreas rurais como objetivo da atualização da regulamentação a partir de 2008, 436

[Resolução da ANATEL nº 516/2008] 